\title{
MOTIVATIONS FOR VIRTUAL COMMUNITY PARTICIPATION IN SOCIAL COMMERCE: CUSTOMERS AND SELLERS IN THE MALAY LIFESTYLE BLOGGING COMMUNITY
}

\author{
By \\ SYAHIDA BINTI HASSAN
}

A thesis submitted to the Victoria University of Wellington in fulfilment of the requirements for the degree of Doctor of Philosophy in Information Systems

Victoria University of Wellington 2016 



\begin{abstract}
Although the field of social commerce has gained a lot of attention recently, there are many areas that still remain unexplored. A new phenomenon emerging within virtual communities is a blurring between social and commercial activities. To date, scholars in the social commerce literature have either focused on customers in the community or on medium to large scale businesses. There has been little research on social commerce communities which include micro-businesses despite their rapid growth in South East Asian countries.
\end{abstract}

This study explores a social commerce community of Malay lifestyle bloggers, who are a subset of the Malaysian blogosphere community. Bloggers begin by using the personal genre, some then move on to set up online businesses using their personal blogs as a platform. The characteristic of blogging's ease of use means there are low barriers to starting a small business, merging blogging and commerce. This changes the nature of the community by bringing in a new relationship, as well as relationships between bloggers and readers, there are now also relationships between sellers and customers.

This study aims to understand the motivations for both sellers and customers, and how their relationships as bloggers and readers influence their participation in social commerce within the same community. To address the research objective, 20 sellers and 21 customers who also play a role as bloggers or readers were interviewed. In-depth interviews using laddering and semistructured interview techniques were carried out to explore social commerce behaviour, the perceived consequences, and goals or values of participation. In addition, observation was also conducted on the platform used by the sellers. Data was coded using NVivo whilst the themes arising from the coding process were transformed into an implication matrix and hierarchical value map using Ladderux software.

This study found that strong ties within the community, influenced by homophily and the sense of virtual community, motivated the customers to 
participate in commercial activities in order to obtain their goals which included a sense of obligation, loyalty, satisfaction and self-esteem. The relationships influenced customers to trust each other, provide social support and made purchasing products more convenient. Sellers were influenced by the convenience of using social media and the social support provided by the customers which helped them to achieve their goals which are profit and business sustainability.

This study contributes to social commerce theory by highlighting an underexplored type of social commerce setting and addressing how trust can be transferred from social to commercial activities. The findings provide a useful insight for businesses, regardless of their size, to build an understanding of the need to create a good relationship with their customers. For macrobusinesses, this model can be used to identify what is lacking in their social media marketing strategy. 


\section{ACKNOWLEDGMENTS}

Bismillah ar-rahman ar-rahim. In the name of Allah, the Beneficent, the Merciful. Alhamdulillah. Praise to Allah.

My sincerest thanks to all those people who have made this thesis possible and an unforgettable experience for me. First and foremost, thanks to my supervisors, Dr. Janet Toland and Dr. Mary Tate for their endless guidance, support, patience, motivation, enthusiasm, and immense knowledge. I could not have imagined having better supervisors for my study.

To my examiners, Dr. Hongzhi Guo (Victoria University of Wellington, New Zealand), Prof Bob McQueen (University of Waikato, New Zealand), and Dr. Shan Wang (University of Saskatchewan, Canada), thanks for your constructive feedback.

Thanks to the academic and administrative staff at the School of Information Management, especially to Usha Varatharaju, Associate Prof Val Hooper, Dr. Dan Dorner, Prof Pak Yoong, Associate Prof Lalita Rajasingham, Prof Anne Goulding, Dr. Chern Li Liew, and Prof Sid Huff for their advice and support.

I would like to acknowledge the Ministry of Higher Education Malaysia and Universiti Utara Malaysia for their scholarships. The gratitude also goes to Victoria Business School, Faculty of Humanities and Social Sciences and Postgraduate Students' Association for the data collection and conference funding.

My sincere thanks also goes to Dr. Zixiu Guo and Dr. Xiao Lin from the University of New South Wales, for some guidance on laddering technique, as well as to Dr. Hongzhi Gao from the School of Marketing and International Business for his advice at the early stage of my research. Not forgotten are the participants in my research for their time and insight. Also to Ms. Penelope and Ms. Jackie Bell for their proofreading service. 
Words cannot express how grateful I am to my source of happiness, my parents, Hassan Haji Salleh and Misbah Haji Khalid, for their endless love, support and doa. I also want to thank my family: Syukri, Syafiq, Nadia Syamim, Syazwan, Arif, Alya, Sofia, my late grandparents, my aunts and my uncles, as well as my cousins (especially Aina and Mira) for their love and encouragement.

I would also like to gratefully acknowledge various people who have contributed in many ways throughout the journey: Sanisah, Zana, Idzwan, Siti, Yana, Lia, Tiqa, Naj, Syazwani, Quang, Amitha, Thuan, Geetha, Rhys, Tara, Kak Shida, Kak Sai, Fahimi, Fiza, Daem, Isaac, Lakshila, Alireza, Dr. Huda, Kak Iadah, Kak Nass, CikP, Lynn, Nett, and Rafthah. I wouldn't have made it without the support from them.

Last but not least, my appreciation also goes to the many other helpful people at Victoria University of Wellington and Universiti Utara Malaysia.

Pisang emas bawa belayar,

Masak sebiji di atas peti,

Hutang emas dapat dibayar,

Hutang budi dibawa mati.

Terima kasih. Thank you. 


\section{TABLE OF CONTENTS}

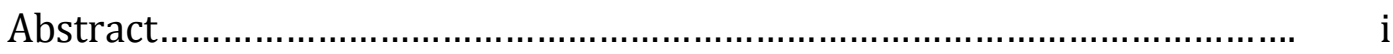

Acknowledgement............................................................................... iii

Table of Content.................................................................................... $\quad \mathrm{V}$

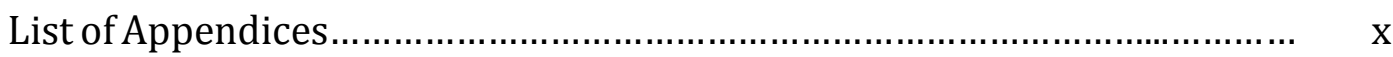

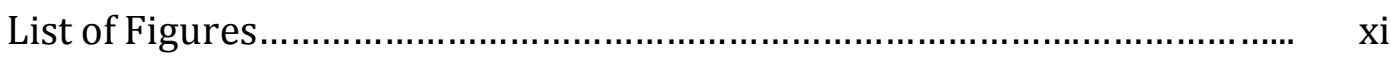

List of Tables...................................................................................... xii

List of Abbreviations............................................................................... xiv

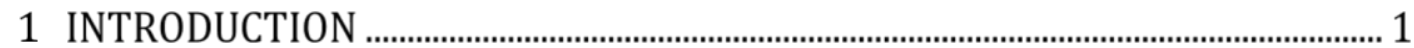

1.1 Motivations for the Research...................................................................... 1

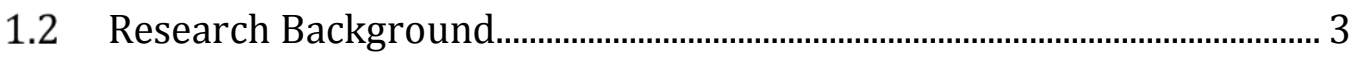

1.3 Social Commerce ………................................................................................... 5

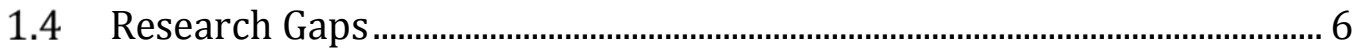

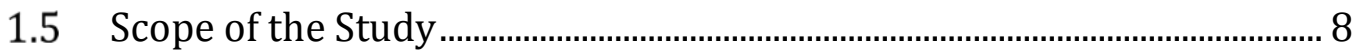

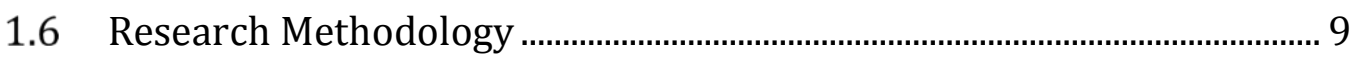

1.7 Significance and Contribution of the Study …............................................11

1.8 Thesis Outline .................................................................................................... 12

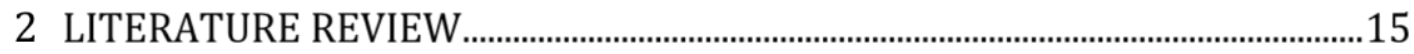

2.1 Means-end Theory ........................................................................................17

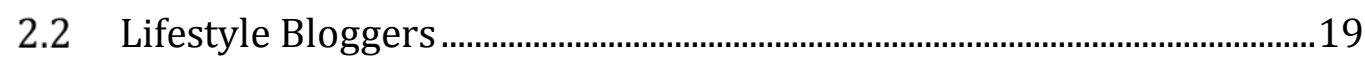

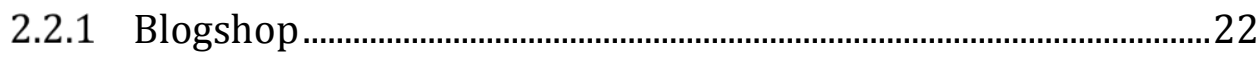

2.2.2 Lifestyle Blogs Community as Virtual Community .......................22

2.2.3 Social Network Theory: Social Ties and Homophily .....................25

2.2.4 Sense of Virtual Community .............................................................28

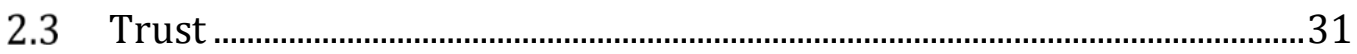

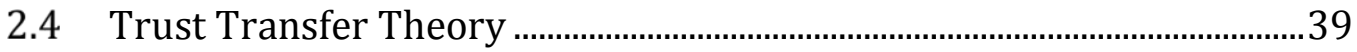

2.5 Social Support in Virtual Community ............................................................ 41

2.6 Defining Social Commerce ......................................................................... 43

2.6.1 Past Studies on Social Commerce .....................................................52

2.6.2 Motivation to Participate in Social Commerce by Microbusinesses. . .55 
2.6.3 Customers' Motivation to Participate in Social Commerce.........58

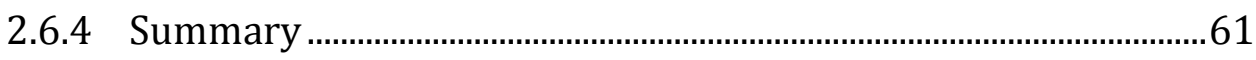

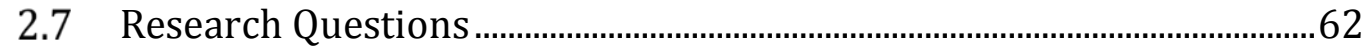

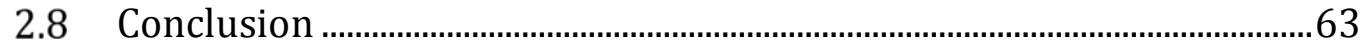

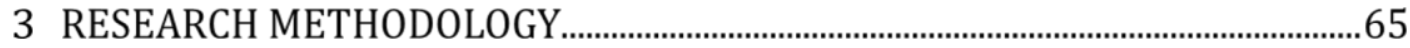

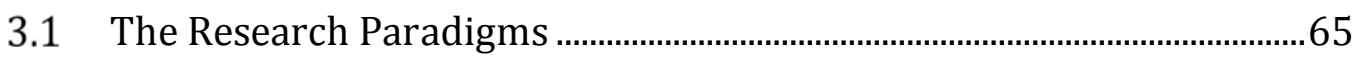

3.1.1 Philosophical Paradigm and IS Research ........................................65

3.1.2 Philosophical Approach for the Study.............................................67

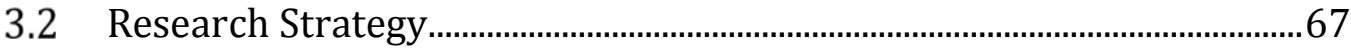

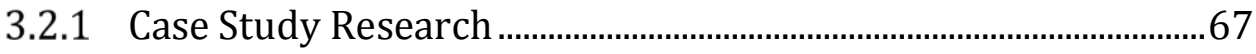

3.2.2 Case Design: Single Case Design .....................................................70

3.2.3 The Unit of Analysis ............................................................................ 71

3.3 Research Design and Data Collection Procedure..........................................72

3.3.1 Phase One....................................................................................... 72

3.3.1.1 Observation ............................................................................ 73

3.3.1.2 Content Analysis (Justifying the Case) .............................75

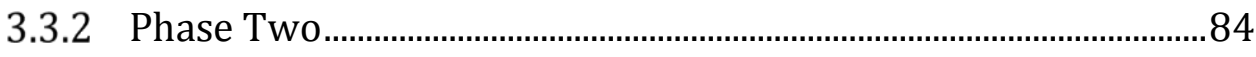

3.3.2.1 Participant Selection ...............................................................85

3.3.2.2 In-Depth Interview ................................................................ 86

3.4 Approaches to Ensuring Quality and Rigour..............................................93

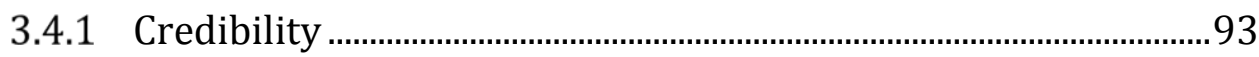

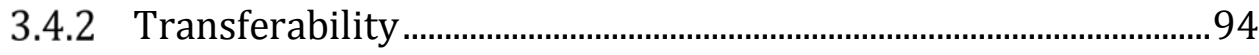

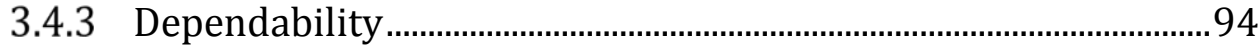

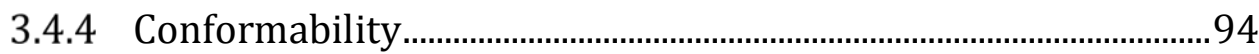

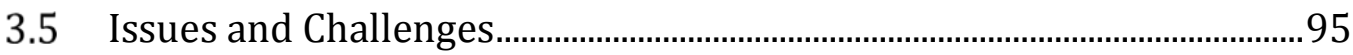

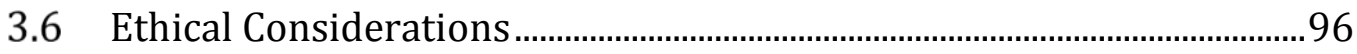

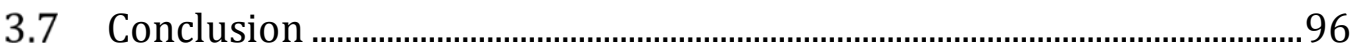

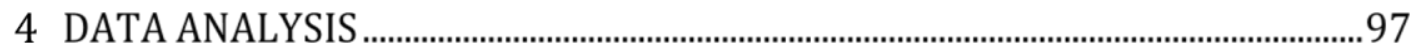

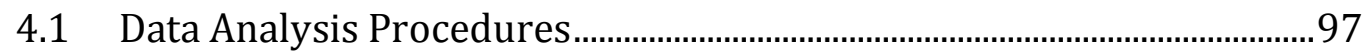

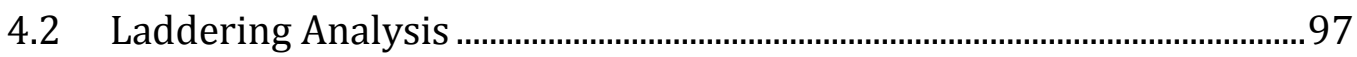

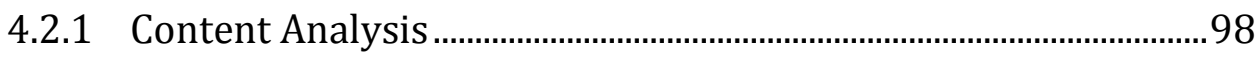

4.2.2 Using Ladderux to Construct the Implication Matrix .................103 
4.2.3 Development of Hierarchical Value Map for Sellers 105

4.3 Semi-structured Interview and Observation Data Analysis 106

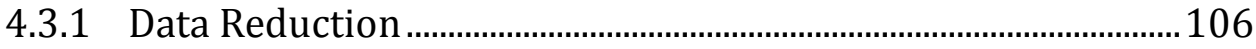

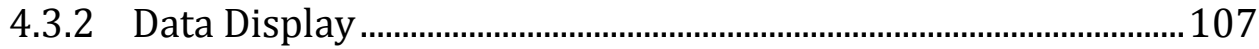

4.3.3 Drawing Conclusions...........................................................................10

4.4 Inter-rater Reliability using Cohen's Kappa .............................................108

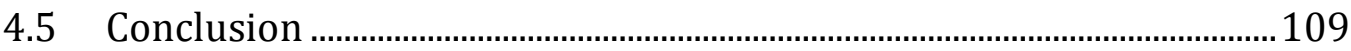

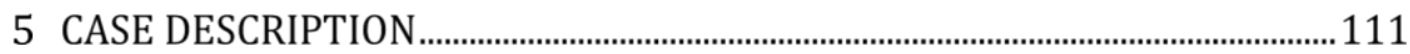

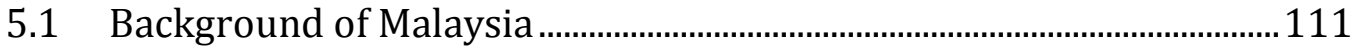

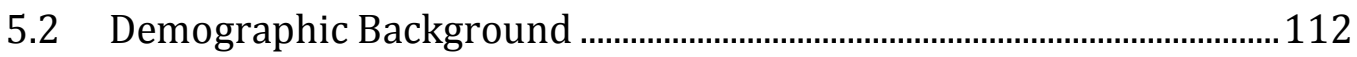

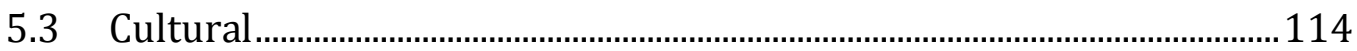

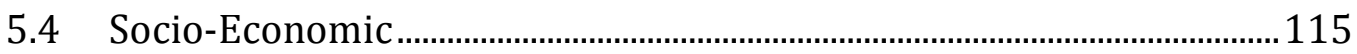

5.5 Internet Penetration in Malaysia ...................................................................117

5.6 Blogging in Malaysia ............................................................................

5.7 Lifestyle Blogging in Malaysia .................................................................118

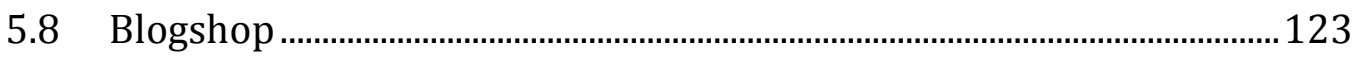

5.9 Boundary and Roles in Malay Blogging Community ………................... 124

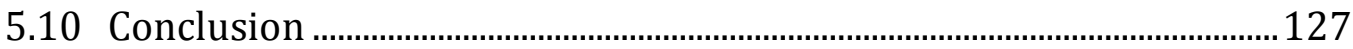

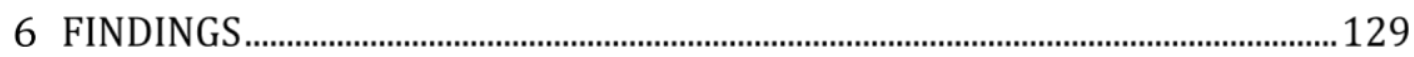

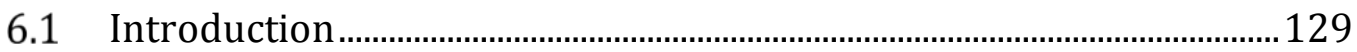

6.2 Sellers' Motivational Factors .................................................................... 131

6.2.1 Sellers' Implication Matrix................................................................. 131

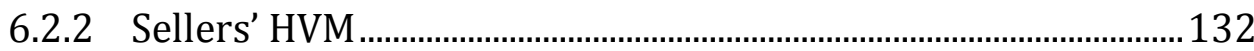

6.2.2.1 Social Support Path .............................................................135

6.2.2.2 Perceived Convenience Path.............................................. 146

6.2.2.3 The Remaining Paths in Sellers' HVM...........................149

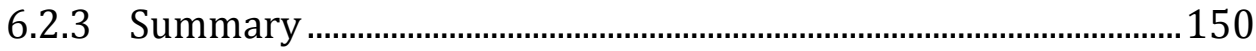

6.3 Customers' Motivational Factors.................................................................. 151

6.3.1 Customers' Implication Matrix ........................................................151

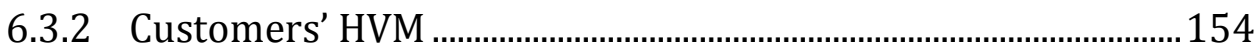

6.3.2.1 VC Relationship - Trust Path ..............................................155

6.3.2.2 Reading Reviews - Trust Path ..........................................160 
6.3.2.4 VC Relationship - Self-Esteem and VC Relationship Perceived Convenience Path...............................................166

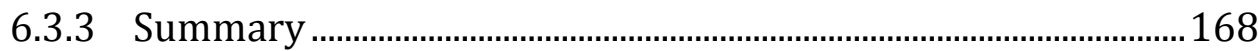

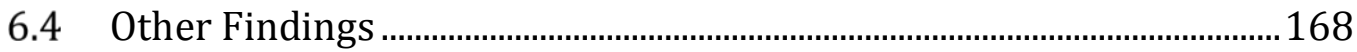

6.4.1 Reasons for Participating in Blogging Community ....................169

6.4.2 Factors Influencing Members' Relationships ...............................172

6.4.3 Factors Influencing Trust...............................................................173

6.4.4 Factors Influencing Social Support Practices ………………........174

6.4.5 Type of Participation in the Malay Lifestyle Blogging Community 176

6.4.6 Level of the Sense of Virtual Community (SOVC) .......................178

6.4.6.1 Membership ....................................................................179

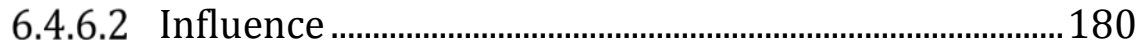

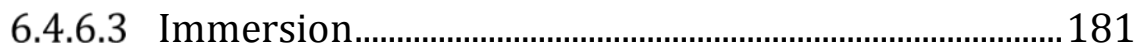

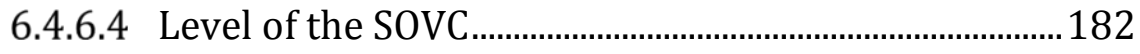

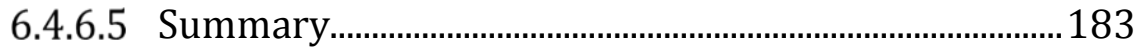

6.5 Eliminated Elements.................................................................................. 183

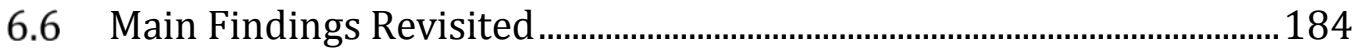

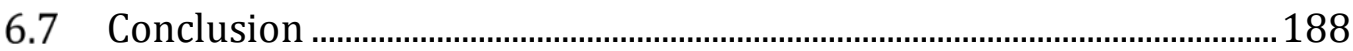

7 DISCUSSION

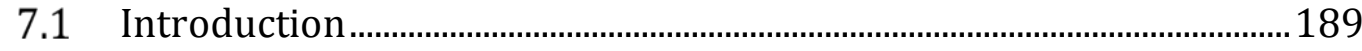

7.2 Research Questions Revisited ...................................................................190

7.3 The Community Characteristics and Practices .........................................192

7.3.1 Social Network Theory: Social Ties and Homophily ..................192

7.3.2 Sense of Virtual Community (SOVC) ..............................................195

7.3.2.1 Membership ........................................................................196

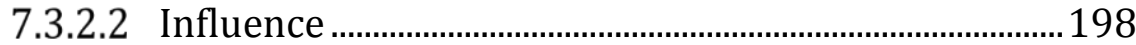

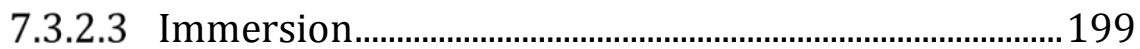

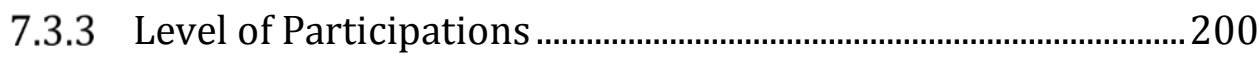

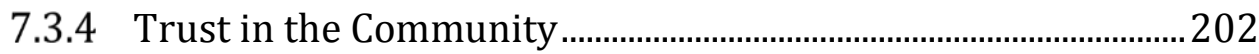

7.3.5 Social Support Practices in the Community ……………….........205 


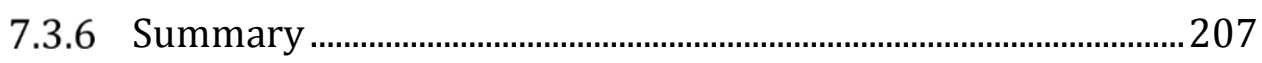

7.4 Motivational Factors for the Sellers in the Community ..........................215

7.4.1 Social Support from the Community Members ............................215

7.4.2 Convenience: As Perceived by Sellers .............................................216

7.4.3 Other Relevant Motivational Factors for Sellers..........................217

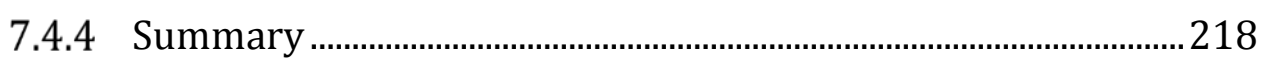

7.5 Motivational Factors for Customers in the Community .........................221

7.5.1 Trust Transfer .................................................................................221

7.5.2 Social Support to Sellers ................................................................222

7.5.3 Perceived Convenience ……………………………………………......226

7.5.4 Other Relevant Motivational Factors for Customers .................228

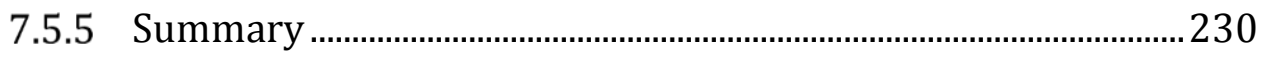

7.6 Lessons Learned ...........................................................................................2234

7.6.1 Lifestyle bloggers ............................................................................234

7.6.2 Beyond Branding ..........................................................................2 237

7.6.3 Social Commerce Implementation.................................................2. 240

7.6.4 Comparison to Traditional E-Commerce Practices .....................243

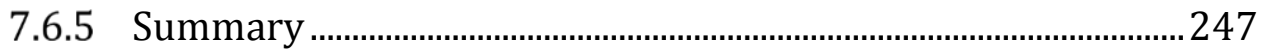

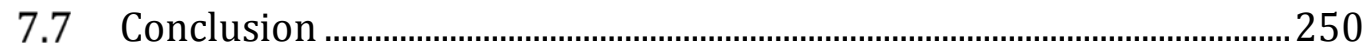

8 CONCLUSION ...............................................................................................................251

8.1 A Synthesis of the Main Findings of this Research.................................251

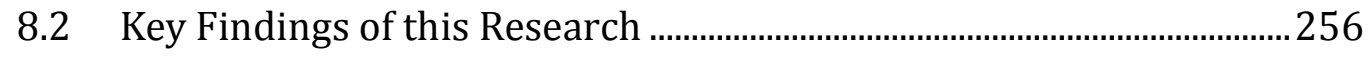

8.3 Theoretical Contributions ...........................................................................259

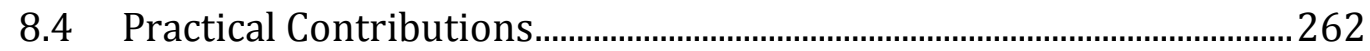

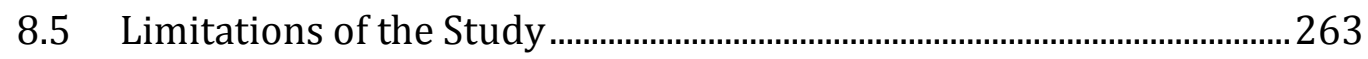

8.6 Future Research ........................................................................................... 265

8.7 Concluding Remarks.................................................................................26

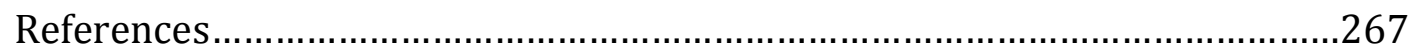

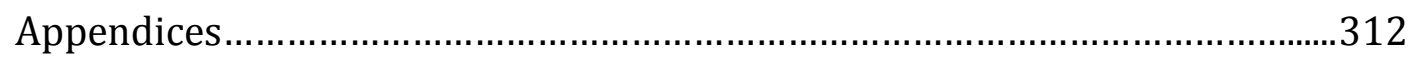




\section{LIST OF APPENDICES}

APPENDIX A: $\quad$ Invitation Email To Participants................................. 312

APPENDIX B: $\quad$ Social Commerce Experience - Sellers........................ 313

APPENDIX C: $\quad$ Social Commerce Experience - Customers.................. 314

APPENDIX D: $\quad$ Interview Protocol ...................................................... 315

APPENDIX E-1: Information Sheet................................................... 320

APPENDIX E-2: Consent Form......................................................... 321

APPENDIX F-1: $\quad$ List of Ladders - Sellers ............................................ 322

APPENDIX F-2: $\quad$ List of Ladders - Customers......................................... 326 


\section{LIST OF FIGURES}

Figure 1.1: Timeline of the development of the Malay lifestyle blogging

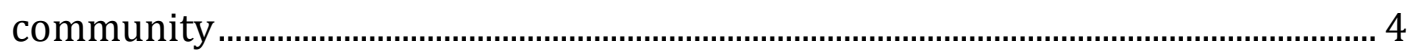

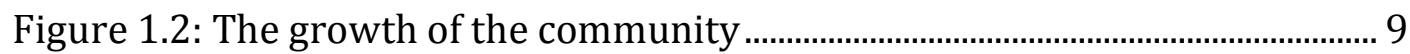

Figure 2.1: The relationship between the topics discussed in this chapter .......16

Figure 3.1: Research design process ........................................................................

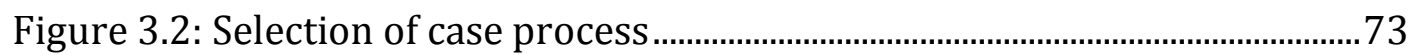

Figure 3.3: Approach to identifying blog communities (adapted from Efimova

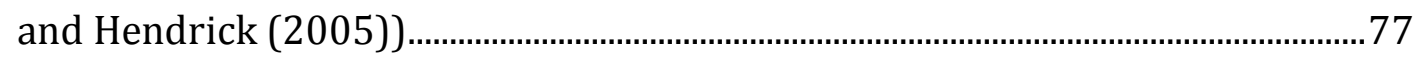

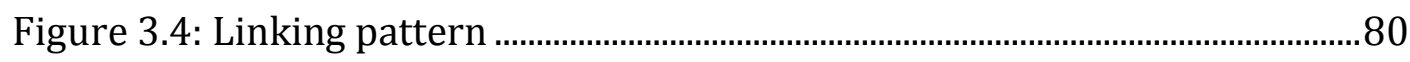

Figure 3.5: Phase two data collection process.........................................................84

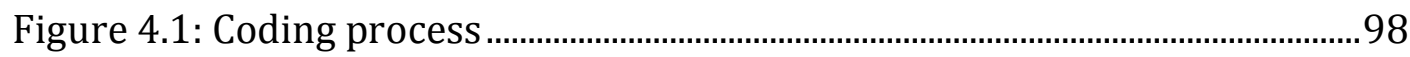

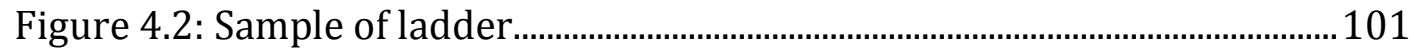

Figure 4.3: Creating ladders using Ladderux software .........................................104

Figure 4.4: Implication matrix in Ladderux software ............................................104

Figure 4.5: Component of data analysis: Interactive model (source: Miles and

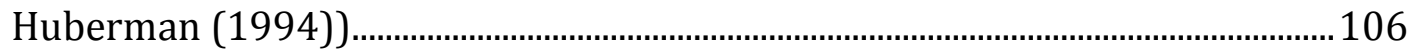

Figure 5.1: Map of Malaysia ......................................................................................111

Figure 5.2: Boundary of the community selected in this study .............................125

Figure 6.1: The flow of findings based on the laddering data.............................130

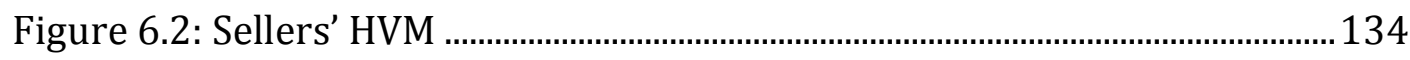

Figure 6.3: Social support path ……………….......................................................136

Figure 6.4: Perceived convenience path..................................................................147

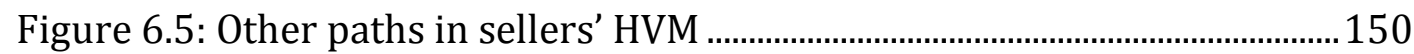

Figure 6.6: Customers' HVM ..................................................................................... 153

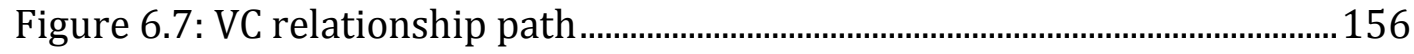

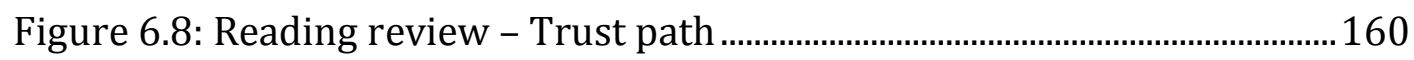

Figure 6.9: VC relationship - Social support path....................................................162

Figure 6.10: VC relationship - Perceived convenience path and VC relationship

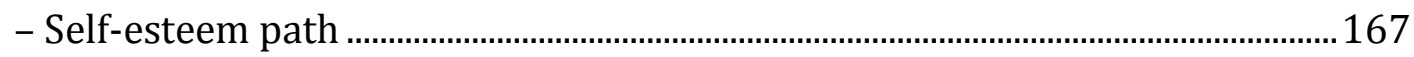

Figure 6.11: The main motivations of both sellers and customers .....................185

Figure 6.12 Key Findings of this research .............................................................187

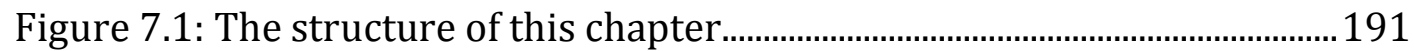

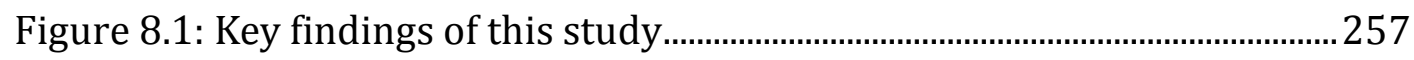




\section{LIST OF TABLES}

Table 2.1: Blog genres in Malaysia (Adapted from Hopkins (2010a)) ..................20

Table 2.2: The indicators of a weblog community existence...................................24

Table 2.3: Trust antecedents based on categories of trust.......................................36

Table 2.4: Past studies on trust transfer theory . .41

Table 2.5: Social commerce definitions (Adapted from Wang and Zhang (2012))

Table 2.6: The advantages of venturing into social commerce for the businesses 58

Table 2.7: The motivations for online participations (social commerce activities, online purchasing, online communities etc.) 61

Table 3.1: Data collection procedures . .72

Table 3.2: Link lists for 20 lifestyle bloggers (Retrieved on 23 September 2013) 80

Table 3.3: Cross analysis of interconnectedness between bloggers ......................81

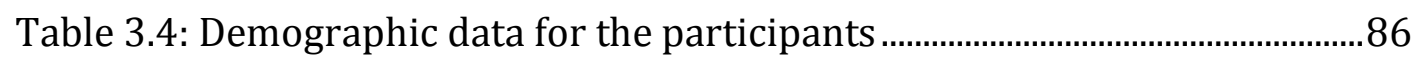

Table 3.5: Laddering questions..............................................................................

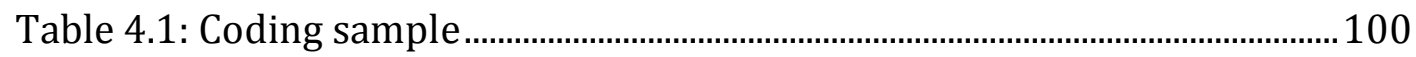

Table 4.2: Coding and categorization process …….................................................... 101

Table 4.3: Summary of the content codes for sellers …….....................................102

Table 4.4: Summary of the content codes for customers .......................................103

Table 4.5: Sample of coding for observation data .................................................107

Table 4.6: Data display to explain each motivation found in this research .....107

Table 4.7: The comparison of Cohen's Kappa value for each coder ....................109

Table 4.8: The Cohen's Kappa value for inter-rater reliability test......................109

Table 5.1: Demographic background of Malaysia (source: Economic Planning

Unit (2015))

Table 5.2: GDP growth, inflation rate and unemployment rate in Malaysia in 2014 (source: Economic Planning Unit (2015)). 116

Table 5.3: Mean monthly gross household income by ethnic group and strata in 2014 (source: Economic Planning Unit (2015)) ...

Table 5.4: Poverty rate in Malaysia in 2014 (source: Economic Planning Unit (2015)).

Table 5.5: The number of followers for a sample of 10 lifestyle bloggers ....... 122

Table 5.6: General descriptions on how the sellers manage their online store

Table 5.7: Classification of members' role in social commerce activities ........125

Table 5.8: Characteristics of the members ............................................................127

Table 6.1: Motivational factors based on benefit and goal layers ......................131

Table 6.2: Sellers' implication matrix .........................................................................133

Table 6.3: Motivational factors based on benefit and goal layers .......................151

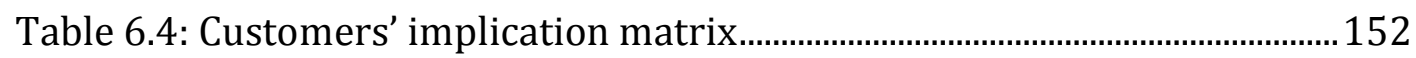


Table 6.5: Reasons to participate in the blogging community

Table 6.6: Why customers trust sellers...................................................................174

Table 6.7: Factors influencing the social support practices..................................176

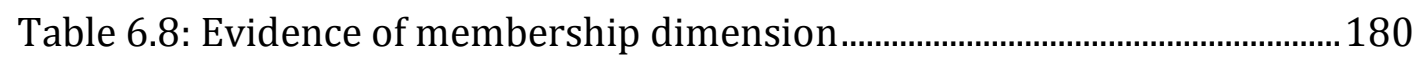

Table 6.9: Evidence of influence dimension ............................................................ 181

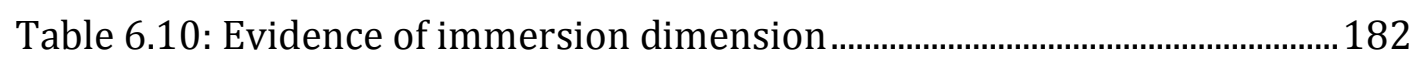

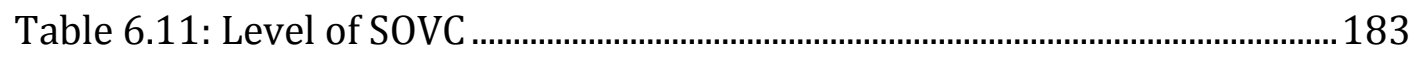

Table 6.12: The benefit and values layers for both sellers and customers...... 184

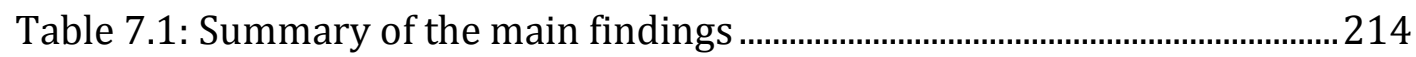

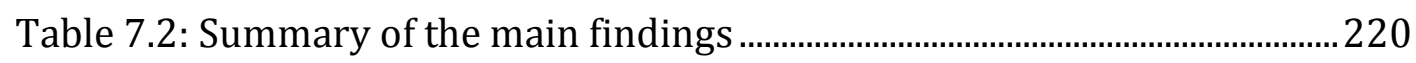

Table 7.3: Comparison between the constructs' criteria......................................225

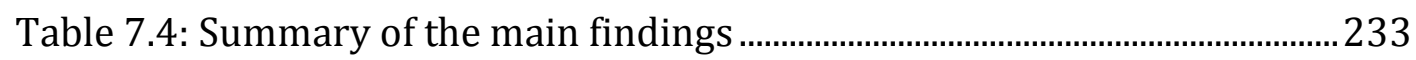

Table 7.5: Descriptions of social commerce implementation in Malay lifestyle

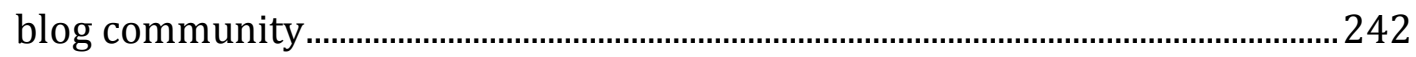

Table 7.6: Comparison between the findings of this study and traditional e-

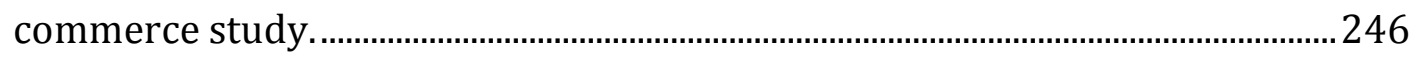

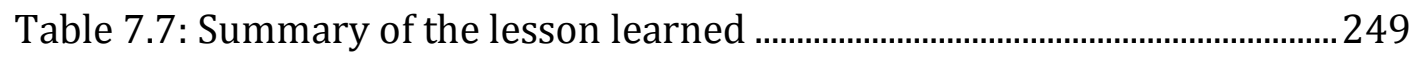




\section{LIST OF ABBREVIATIONS}

$\begin{array}{lll}\text { A } & : \text { Attributes } \\ \text { C } & : \text { Consequences } \\ \text { HVM } & : \text { Hierarchical Value Map } \\ \text { PEOU } & : \text { Perceived Ease of Use } \\ \text { PU } & : \text { Perceived Usefulness } \\ \text { SMS } & : \text { Short Message Services } \\ \text { SNS } & : \text { Social Networking Sites } \\ \text { SOC } & & \text { Sense of Community } \\ \text { SOVC } & : \text { Sense of Virtual Community } \\ \text { V } & : \text { Values } \\ \text { VC } & : \text { Virtual Community } \\ \text { WOM } & : \text { Word of Mouth }\end{array}$




\section{CHAPTER 1}

\section{INTRODUCTION}

The introduction begins with the motivation for this research, then describes the research background which introduces the Malay lifestyle blogging community. This is followed by a section on social commerce. The chapter ends by outlining the scope of the study, the significance of the research and the structure of the thesis.

\subsection{Motivations for the Research}

"Social media is about the people, not about your business. Provide for the people and the people will provide for you"

Matt Goulart

Founder and CEO of Ignite Digital

The online marketplace is changing. Today, there is a new phenomenon in the marketplace: social media, also known as social commerce. The rise of this phenomenon has resulted in a power shift from the marketers to individuals and communities. Customers no longer want to be talked at; instead, customers want firms to listen to them, engage, and respond appropriately (Kietzmann, Hermkens, McCarthy, \& Silvestre, 2011). Businesses need to embrace this change in order to fulfil customers' rising expectations (Baird \& Parasnis, 2011a, 2011b).

The adoption of social commerce by the business world has provided more opportunities to engage and to create relationships with customers. A report on Fortune 500 companies indicates that $83 \%$ of these businesses have already created accounts on Twitter, while $80 \%$ have Facebook brand pages (Barnes, Lescault, \& Andonian, 2014). This indicates that businesses are showing an increasing interest in social commerce as they believe that their activities in social media could improve sales. 
Nonetheless, has social commerce lived up to the hype? Smith (2015) argues that social commerce only drives a small share of total online retail sales. This could be because many businesses are still struggling to understand what customers really want. Despite the popularity of social commerce, Baird and Parasnis (2011a) discovered significant gaps between what businesses think consumers care about and what consumers say they want from their social media interactions with companies. In another paper, Baird and Parasnis (2011b) found that many businesses use social media, yet they argue that there is still much more that businesses can do to fully exploit the benefits social media offers. Their findings indicate that as businesses resolve to venture into social commerce, they need to reinvent customer relationships in order to turn 'likes' into purchases. This relates to the issue raised earlier by Kietzmann et al. (2011), showing the importance of forming relationships with the customers in order to successfully implement social commerce.

Social commerce has become a trend in Malaysia. However, the Borneo Post reported that the growth of social commerce in Malaysia cannot really be attributed to big global brands; rather it is due to many Malaysian online businesses that operate on a much smaller scale (Wong, 2012). The preference is to shop from small online shops hosted on social media such as blogs, Facebook and Instagram, which have played a huge role in making online shopping accessible for many people in Malaysia. This phenomenon could be influenced by the fact that the number of social media users in Malaysia is fairly high. According to Kemp (2016), in Malaysia, 59\% ${ }^{1}$ (approximately 18 million) of the population are active social media users. The most popular social media application as of March 2016 is Facebook (41\%), followed by Google+ (23\%), Instagram (22\%) and Twitter (16\%) 2 .

There are many questions that arise from this phenomenon. What drives the customers in Malaysia to purchase from micro-businesses in social commerce? What drives the micro-businesses to join the social commerce 'bandwagon'?

\footnotetext{
${ }^{1}$ Sources: UN, US Census Bureau; ITU, Facebook, GSMA Intelligence

2 Source: GlobalWebIndex, Q4 2015, based on a survey of internet users aged 16-64.
} 
Are these small businesses closing the gap between themselves and their customers more effectively than larger organizations? Does this have any connection with the relationships and interactions between the microbusinesses and the customers as raised by Kietzmann et al. (2011) and Baird and Parasnis (2011b)? This study attempts to uncover the root reasons behind this phenomenon and untangle the relationship between membership and participation in social commerce, focusing on the community of Malay lifestyle bloggers, which consists of both (i) bloggers, who are also the micro-business sellers that use social media to sell their products, and (ii) readers, who are also the customers in the community.

\subsection{Research Background}

The Malay lifestyle blogging community is a multiple platform community that consists of bloggers and their followers. Blogging has been a growing trend in Malaysia since the early 2000s. Initially, the postings were mostly about the bloggers' daily life (Hopkins, 2010a), and were followed only by family and close friends. As more people started blogging, the number of followers increased, especially when the readers found similarities between themselves and the lifestyle bloggers. The community shares traits of gender (mostly women), race (Malay), language used (Malay and English), educational background, hobbies and interests, taste in fashion, and so on.

Blogs have the ability to facilitate interaction between bloggers and their readers. They also provide opportunities for interactions between readers. The act of linking and commenting on other blogs also contributes to the spread of traffic from one blog to another. Characteristic of digital forms of social interaction, this is the reason that blogs are often known as social media or social software (Nasr \& Ariffin, 2008).

The increased use of blogs has also influenced social commerce growth in Malaysia. According to Wong (2010) and Yeung and Ang (2016), around 2008, many online stores also developed rapidly in Malaysia, and many of them are ecommerce blogs (or the term used in this study: blogshops). The practice of 
using blogs and other social media for e-commerce purposes is a popular form of online shopping in Malaysia.

Some of the Malay lifestyle bloggers have ventured into this model of business, using their blogs as a marketplace to sell a small range of products. Some have created new blogs for the business and linked them to their personal blogs. The response from members in the community has often been overwhelming. In time, more influential bloggers have joined the blogshop trend and have also started to use Facebook and Instagram to support the operation of their blogshops. Some have moved entirely to Facebook and Instagram and just use their personal blogs for promotion.

Figure 1.1 summarizes the timeline for the development of the blogging genre and monetization in blogging. It shows how the trends and genre of blogging have evolved and the changes in the medium of communication in general.
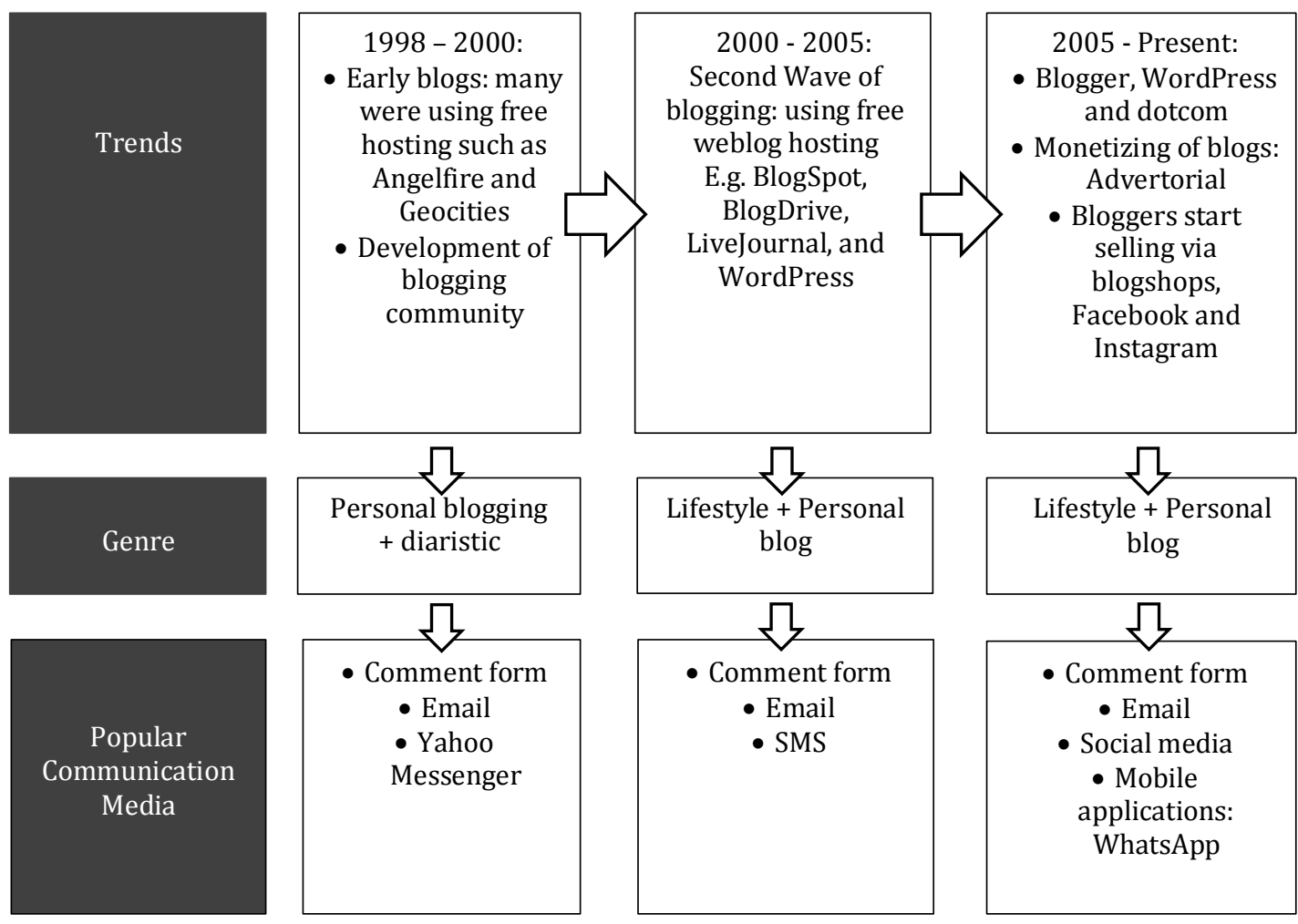

Figure 1.1: Timeline of the development of the Malay lifestyle blogging community 
Although the Malay lifestyle blogging community has adopted social commerce, the norms and practices in the community have not changed. The bloggers are still continuing their initial practice of blogging and connecting with their readers, combining it with personal posts and advertisements. The blog posts, whether personal or commercial, are often written in the same personal voice as they used to be, to engage with their readers.

\subsection{Social Commerce}

The emergence of Web 2.0 has encouraged Internet users to create their own content and has resulted in a growth in the number of virtual communities. From an e-commerce perspective, Web 2.0 has created new opportunities for reaching customers as well as promoting products. Web 2.0 technologies, such as social media, represent a paradigm shift for the marketing and advertising communities (O'Reilly, 2007; Tredinnick, 2006).

Kaplan and Haenlein (2010) claim that social media allows firms to engage in timely and direct end-consumer contact at relatively lower cost and higher levels of efficiency than can be achieved with more traditional communication tools. This makes social media relevant for all types of business from large multinational firms to small and medium sized companies.

The term social commerce was first coined in 2005 by Yahoo! Inc. It was introduced based on the concept of user generated content of online product information and advice features. It allowed customers to comment, review and rate the products on the 'Yahoo! Pick List' (Rubel, 2006; Wang \& Zhang, 2012). However the term as defined by Yahoo is no longer relevant, as the scope of social commerce has expanded since that time to include social media tools and content used in the context of e-commerce (Kaminoff, 2011).

Several attempts have been made by academic researchers and practitioners to re-define social commerce. At present, there is still debate regarding the definition and scope of social commerce. Stephen and Toubia (2010) define it as the marketplace where the individual sellers, instead of firms, are connected 
with each other through social networks, whilst Decker (2007), Gregoriadis (2007), Pagani and Mirabello (2011) and Rubel (2006) define it as a community of shoppers who share knowledge and sources on product information, which also includes assistance from trusted individuals on goods and services, sold online. Others define it as a subset of e-commerce that involves the use of social media to support social interaction and user contributions, which include the online buying and selling of products and services (Afrasiabi \& Benyoucef, 2011; Liang, Ho, Li, \& Turban, 2011; Marsden, 2009; Turban, Lee, King, Liang, \& Turban, 2012; Wang \& Zhang, 2012).

As the previous discussion illustrates, various kinds of social commerce exist, due to different settings as well as the different types of stakeholders involved. This study takes the position that business activity by both sellers and customers should be considered when defining social commerce, as commerce by its very nature involves both parties. Therefore, for the purpose of this study, social commerce will be defined as "online selling and buying activities using social media technologies and/or platforms within a participating community".

\subsection{Research Gaps}

Though social commerce has evolved quickly, it has received little attention in the Information Systems (IS) discipline compared to other fields (Wang \& Zhang, 2012). Recently, however, there has been a growing interest from researchers in social commerce. Past academic research has addressed issues related to the adoption and use of social commerce such as theoretical, conceptual and technical boundaries (Curty \& Zhang, 2011; Farivar \& Yuan, 2014; Hajli, 2012; Huang \& Benyoucef, 2013; Liang \& Turban, 2011; Lu, Fan, \& Zhou, 2016; Mandal, 2015; Mandal \& McQueen, 2012; Nosek \& McManus, 2008; Stephen \& Toubia, 2010), tools, systems and platform (Turban, Strauss, \& Lai, 2016a, 2016b) , social media (Kaplan \& Haenlein, 2010; Lee et al., 2016), and virtual communities and networks (Kim \& Srivastava, 2007; Liang et al., 2011; Ng, 2013; Sangwan, Guan, \& Siguaw, 2009; Sun, Wei, Fan, Lu, \& Gupta, 2016). 
Augar and Zeleznikow (2013) argue that the majority of social commerce related research has focused on medium to large organizations; evidence supports this claim (Culnan, McHugh, \& Zubillaga, 2010; Huang \& Benyoucef, 2013; Stephen \& Galak, 2010; Stephen \& Toubia, 2010). Furthermore, there are a rising number of research articles focusing on customers in social commerce (Afrasiabi \& Benyoucef, 2011; Guo, Wang, \& Leskovec, 2011; Kim \& Park, 2013), but very few on micro-businesses (Mandal, 2015; Mandal \& McQueen, 2012; Schaupp \& Bélanger, 2016) or individual sellers (Fletcher \& Greenhill, 2009).

Looking at past studies, a few important gaps have been found, which include (i) very few studies focusing on micro-businesses and their customers and (ii) the virtual communities studied have been limited to customers' communities, which will be explained next.

Firstly, as mentioned earlier in this section, there is a growing number of research articles on the customers' side of social commerce (Afrasiabi \& Benyoucef, 2011; Guo et al., 2011; Kim \& Park, 2013; Ng, 2013; Shin, 2013), but very few studies which focus on customers of micro-businesses. Brandtzæg and Heim (2009) argue that it is necessary for IS researchers to understand the goals of people who participate in social commerce, as it will be of benefit to micro-business sellers in developing strategies. Focusing solely on customers of larger businesses may lead researchers to miss some important factors that influence customers to participate in social commerce. Larger businesses may use very different approaches than micro-businesses to attract customers.

Secondly, much less is known about the motivations of micro-businesses to operate in a social commerce environment as compared to larger organizations, which have more resources and greater reputations. Although there are some studies that focus on why and how micro-businesses are using social media, there are further areas that need to be explored in order to fully understand the role and influence of social media adoption in micro-businesses, particularly in the area of virtual community participation. 
Thirdly, past studies have shown that while various virtual communities have been studied in a social commerce environment, many studies have been limited to brand communities and the interactions amongst customers themselves, rather than between customers and the business. This could explain why many businesses are still having difficulty in fully understanding why customers interact with them using social media without making any purchases, revealing a perception gap between a business and their customers (Baird \& Parasnis, 2011a). Therefore, this study argues that there is a need to explore other types of communities which nurture communication and ties between sellers and customers in order to fully recognize the role of the virtual community in social commerce from the perspective of the customers and micro-business sellers. A deeper understanding of the role the virtual community plays would provide more opportunities for researchers to understand how to exploit the role of the virtual community to refine the social commerce model. Thus it is important to address this gap.

This awareness of the role of the virtual community in e-commerce has led to an exploration of the factors that contribute to the motivation of those who venture into social commerce. In addition, although lifestyle bloggers participating in commercial activities have become a phenomenon in Malaysia, most discussions about the phenomenon have come from the practitioners' point of view.

\subsection{Scope of the Study}

This study aims to examine the main factors that influence non-brand community members to participate as sellers and buyers in social commerce. It focuses on members of the Malay lifestyle blogging community, which is a subset of the Malaysian blogosphere community. Blogs' characteristic ease of use means there are low barriers to starting up a social commerce business. An online store can be conveniently set up without any cost, merging blogging and business into one. As mentioned earlier, this group of bloggers also often use other social media such as Facebook and Instagram for their business. The purpose is to attract further customers from the same community, as well as 
potential customers outside the community. In other words, this community is using multiple social media platforms for social commerce implementation. At this point, for the members who venture into business, the relationship between bloggers and readers is no longer limited to those roles and moves towards a seller and customer relationship. This is what makes this community unique: the sellers are also members of the community rather than being positioned outside the virtual community.

Figure 1.2 illustrates the development of the community towards social commerce activities. It shows how the roles and the main activities of the community members have changed.

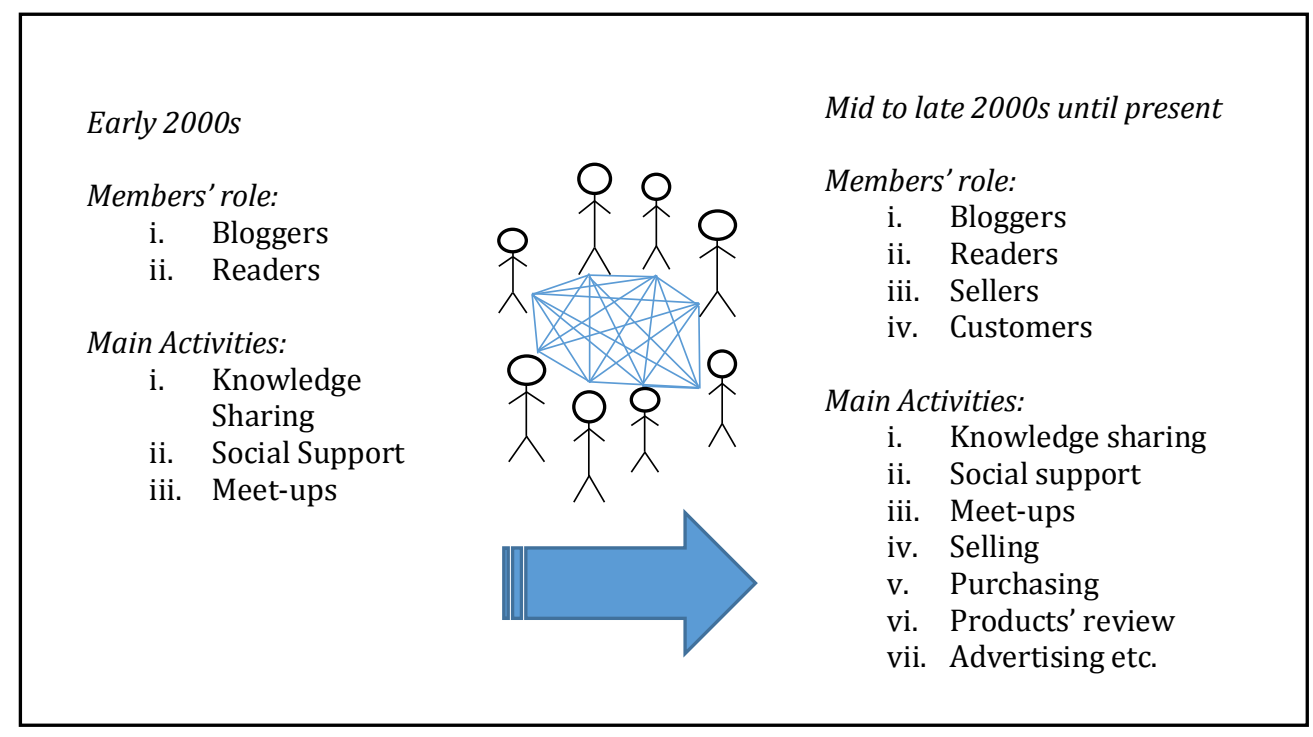

Figure 1.2: The growth of the community

\subsection{Research Methodology}

This study was conducted from the viewpoint of the interpretive paradigm. Qualitative research was carried out in order to answer the research questions. Case study research was chosen, as this strategy is suitable for the exploration. This means the phenomenon of social commerce was examined in a natural setting and no experimental controls or manipulation were involved.

There were two phases of data collection. Firstly, observation was conducted to identify and justify the community for this study. Secondly, the in-depth semi- 
structured interviews, which also included the use of the laddering technique, were conducted. Laddering is an in-depth interviewing technique used to develop an understanding of how consumers translate the attributes of products and services into meaningful associations with respect to self (Reynolds \& Gutman, 1988). It adapts means-end theory, which was originally a framework for comprehensively representing the consumer meanings that underlie product positioning (Gengler \& Reynolds, 1995).

Interviews were conducted with 20 sellers and 21 customers, aged 25-45 years old, who were participating actively in the Malay lifestyle bloggers' community. The participants were chosen from the same community because this study is trying to understand the relationship between participation in the community and participation in social commerce within the same community. Therefore sellers and customers from outside the community were not considered in this research.

Observation and content analysis were carried out to identify the sellers in the community. They were chosen based on their active participation as bloggers and sellers in the community. Only experienced bloggers (more than 3 years' experience) who had more than 1000 followers were considered as participants. Meanwhile for the customers, the participants chosen were those who read blogs at least 4-5 times a week, may or may not have had their own blog, actively communicated with other people in the community, be it with other readers or bloggers, and had experience purchasing goods and/or services from sellers in the same community. They were selected based on observations which were conducted at an earlier stage of the research in order to understand the selected community (i.e. their activities, communication etc.).

To avoid bias, the customers chosen for this research were those who were not also engaged in selling. They were also briefed about the research in order to make them understand that the questions being asked were about their role as customers and community members. Sellers who could also be customers in this community were briefed that the questions related to business should be answered as a seller, not from the point of view of a customer. 
Data was analysed according to the technique used. For example for laddering, three steps of analysis - (i) content analysis (coding), (ii) construction of an implication matrix and (iii) construction of a hierarchical value map (HVM) were used. For other types of data, a technique developed by Miles and Huberman (1994), which includes (i) data reduction, (ii) data display, and (iii) conclusion drawing and verifications, was used. In order to ensure the quality and rigour of this study, several steps were embedded. These include the concepts of credibility, transferability, dependability and conformability.

\subsection{Significance and Contribution of the Study}

This study is significant for social commerce research and those who venture into this marketplace. The major contribution to theory is the conceptualization of the sense of virtual community in social commerce into a framework that reflects the gaps identified from a review of relevant literature related to this topic. It explains the relationship between membership in a virtual community and commercial activities, not only to provide a better understanding of the phenomenon, but also to stimulate reflections on its current stage and its future directions.

In addition, the exploratory nature of this research discloses some potential topics for further investigation. Discussions resulting from this study may stimulate other researchers to explore further in this area, encouraging knowledge sharing and evolution, especially in the area of social commerce. This will add to the social commerce body of knowledge. For example, the influence of the characteristics of the community, such as the sense of virtual community, can be explored from different perspectives.

The findings also provide guidance for suitable approaches for the integration of Web 2.0 technologies within the business environment, in order to improve social commerce implementation, especially the interaction between the seller and the customer. This gives guidance on the issues of customer engagement and loyalty to a particular social commerce site. 
The findings can also be used as guidance to individuals regarding the formulation of appropriate business strategies, which will ultimately enhance operating performance in the social commerce environment. This can be achieved by educating the social commerce virtual communities on the major factors that can lead to the willingness of customers to proceed with transactions. It will help them to utilize IS technologies to create strong ties with their potential customers.

\subsection{Thesis Outline}

In order to answer the research questions with the above objectives, this thesis has been organized into the following chapters:

\section{Chapter 1: Introduction}

This chapter introduces the motivations, overview of the research background, social commerce, scope, methodology and the significance of the study.

\section{Chapter 2: Literature Review}

The purpose of this chapter is to discuss the topics that form the theoretical background for this study, starting with the theoretical foundation of this study, means-end theory. The literature on lifestyle bloggers, virtual communities, social support, trust and trust transfer theory is discussed. Furthermore past studies on social commerce are presented in this chapter. Research questions will be presented at the end of this chapter.

\section{Chapter 3: Research Methodology}

Chapter 3 describes the research methodology used to address the research objectives and to answer the research questions. It starts with the research paradigm for the study as well as describing the research strategy chosen for the study. Next, the research design and data collection procedure are explained. The approaches taken to ensuring quality and rigour are also 
included in this chapter. Finally the issues and challenges as well as ethical considerations for this study are presented.

\section{Chapter 4: Data Analysis}

Chapter 4 describes the data analysis phase. Data analysis procedures are explained followed by a discussion on laddering analysis. Next, the design of the semi-structured interviews and observation analysis are discussed. The chapter ends with the discussion of the inter-reliability test using Cohen's Kappa.

\section{Chapter 5: Case Descriptions}

This chapter presents the case description for this research which includes the background of Malaysia including demographic, cultural and socio-economic factors. In addition, in line with the ICT focus of this research, data on internet penetration, blogging and blogshops in Malaysia are also presented.

\section{Chapter 6: Findings}

This chapter reflects on the main findings of the research. The implication matrix and the hierarchical value map (HVM) are shown for both sellers and customers. Interview excerpts are presented as evidence. In addition, findings from semi-structured interviews and observations data are also discussed.

\section{Chapter 7: Discussion}

Chapter 7 addresses the research questions and the findings of this study. The discussion starts with community characteristics and practices which include the concept of social ties and homophily, the sense of virtual community, trust and social support. In addition, the motivational factors for both sellers and customers in the community are presented. The chapter ends by outlining the lessons learned from the findings. 


\section{Chapter 8: Conclusion}

Chapter 8 concludes the thesis by revisiting the findings. In addition, it highlights the theoretical and practical contributions, the limitations of the research, as well as suggestions of avenues for further research. 


\section{CHAPTER 2}

\section{LITERATURE REVIEW}

The aim of this chapter is to present a critical review of the literature with regard to the theoretical background of this research. As noted in the chronology of the study, this chapter will synthesize previous literature in order to identify what is common from previous research.

This chapter begins by introducing some of the key concepts used in this research. Firstly, in Section 2.1, the theoretical foundation of this research, means-end theory will be discussed. Secondly, theories that are related to the characteristics of the case chosen in this research will be explained in Sections 2.2, 2.3, 2.4 and 2.5. These theories are presented in order to examine the literature which is used to inform various aspects of the arguments included in this thesis.

Section 2.2 explains related literature on lifestyle bloggers and in the community. The topics covered include (i) the concept of blogshops that originated the social commerce activities in this community, (ii) the concept of social network theory, highlighting social ties and homophily within the community, (iii) the lifestyle blogging virtual community, which focuses on the concept of virtual community, and (iv) sense of virtual community dimensions, which are significant in developing an understanding of the community members.

In Section 2.3, this study examines the wider theoretical context of trust which is presumed to be related to the community's motivation to participate in social commerce. The literature on categories of trust, antecedents, as well as trust theory related to social networking platforms is presented. The literature on trust is extended in Section 2.4, where the discussion focuses on trust transfer theory. There is an explanation of how trust can be transferred from one environment to another and a discussions of past studies on trust transfer constructs. 
Section 2.5 presents the literature on social support to describe the ties strength in the community. The role and types of social support is examined.

Lastly, Section 2.6 will cover the working definition for social commerce and past studies on social commerce will be deliberated in Section 2.6.1. This is presented to highlight various leading definitions of social commerce that have been argued by many scholars and practitioners and to identify a suitable definition that works for the case. Past research on motivational factors or similar research will be presented in Sections 2.62 and 2.6.3.

The literature review will end by identifying the knowledge gaps found in the literature, an outline of the research objectives and research questions in Section 2.7. Figure 2.1 illustrates the relationship between the topics covered in this chapter.

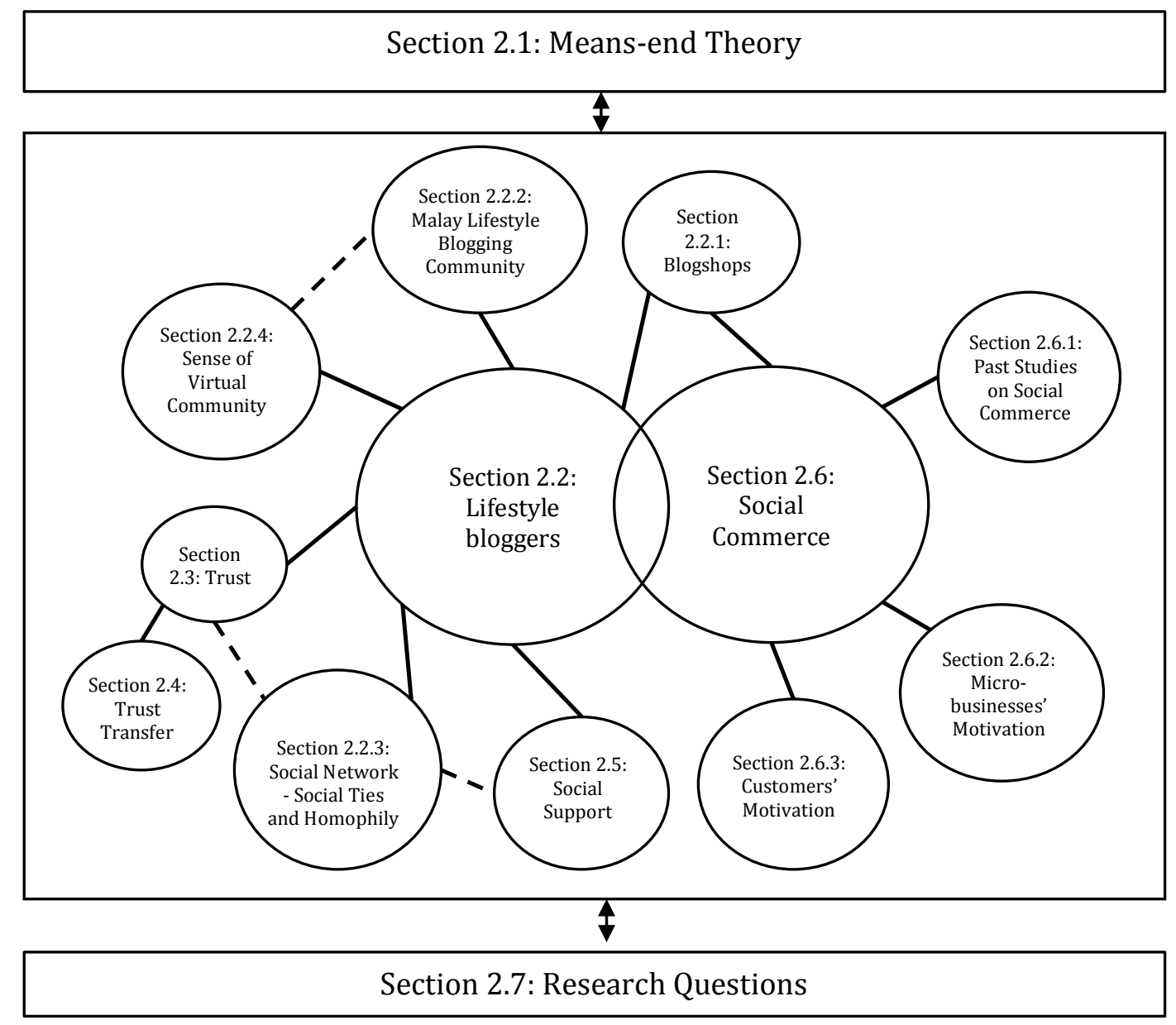

Figure 2.1: The relationship between the topics discussed in this chapter 


\subsection{Means-end Theory}

Means-end approach is a theory that can be used to investigate and to understand how decision makers choose a course of action that they perceive to be the most likely to lead them to achieve their goals (Costa, Dekker, \& Jongen, 2004; Hsiao, Ju Rebecca Yen, \& Li, 2012; Olson \& Reynolds, 2001). According to Costa et al. (2004), the original development and application of means-end theory was in the areas of marketing and advertising research (Gutman, 1982), and has been used by many scholars.

The means-end framework consists of three elements: (i) attributes, (ii) consequences, and (iii) values (Olson \& Reynolds, 2001). Product and service attributes are associated with consequences, or product benefits and risks, and even personal values that can help consumers fulfil their goals. The output is a value chain linking a product attribute to its functional consequences and the psychosocial (or emotional) consequences, and finally to the underlying personal values or goals of the purchase. In making decisions, it is necessary to focus on consequences (outcomes or experience) rather than attributes.

To apply the means-end theory, a method called laddering is used. Laddering operates by modelling knowledge as a set of hierarchies which helps to connect between the attributes, consequences and the values (goals). Veludo-deOliveira, Ikeda, and Campomar (2006) claim that this technique originated in the field of psychology when Hinkle (1965) developed a technique to model people's belief structures in a simple, systematic way, in order to establish individual's super-ordinate personal constructs.

According to Rugg et al. (2002), the laddering technique with the means-end approach has been adapted by marketing, advertising, architecture, information technology, and organizational management researchers. In IS research, the means-end approach has been used to understand the user experience (UX) or human-computer interaction research (Bleumers, Van den Broeck, Lievens, \& Pierson, 2012; Vanden Abeele, Gajadhar, \& De Schutter, 2009; Zaman, 2005), eliciting information for system development (Rugg et al., 
2002), SNSs and social media (Cha, Kweon, Choi, Won, \& Kim, 2014; Ho, Lin, \& Carlson Patrick, 2015; Matook, 2013; Pai \& Arnott, 2013), group purchase (Xiao, Guo, \& DAmbra, 2014) and website design (Subramony, 2002). The means-end approach has been used in academic research to identify influential factors (Frauman \& Cunningham, 2001; Klenosky, Gengler, \& Mulvey, 1999), motivation (Arsil, Li, Bruwer, \& Lyons, 2014; Bonne \& Verbeke, 2006; Ho et al., 2015; Lin \& Tu, 2012; van Huylenbroek et al., 2009), comparison between variables (Bourne \& Jenkins, 2005; Subramony, 2002; Vanden Abeele et al., 2009; Zaman, 2005), relationship between constructs (Pieters, Baumgartner, \& Allen, 1995), and new product development (Celis et al., 2013; Subramony, 2002). The studies that adapt means-end theory and laddering technique used the same underlying concepts but academic scholars usually use slightly different versions of the approach tailored to the purpose for which it is being used (Rugg et al., 2002).

This research was framed using the means-end theory as it is more independent as compared to virtual community-related theories which will be explained in the next section. The means-end theory suggests that personal values play the most dominant role in directing an individual's choice (Hawley, 2009). Meansend theory with laddering provides a focus and a direction for the "Why" (Why is it important?) questions where identifying the core values can have significant potential to inform the decision. According to Kuratko, Hornsby, and Naffziger (1997) the conventional interview methods produce a shallow understanding of what is going on and neglect the relationships between motives. The means-end approach has the ability to derive a unique perspective based on the personal meaning of members' participation. The approach provides a much richer understanding of the problem, rather than a general reported description as in a typical semi-structured interview. By using laddering, it is easier to link each factor listed by the sellers and customers and compare it to their past relationship.

The next section will explain the literature on the lifestyle bloggers as well as their relationship with the readers in their community. 


\subsection{Lifestyle Bloggers}

This study is focusing on the social commerce practices of the Malay lifestyle bloggers community, therefore it is important to address the concept of lifestyle bloggers, as well as the background of the community. This section will address the concepts related of social ties and homophily, and the sense of virtual community.

Bruns and Jacobs (2006) define blogging as the reverse-chronological posting of individually authored entries which include the capacity to provide hypertext links and often allow comment-based responses from readers. Communication in blogospheres does not occur in real time unlike instant messaging (Herring et al., 2005; Silva, Goel, \& Mousavidin, 2008). Rowse and Garrett (2012) claim that the contents of personal blogs are usually more personalised and conversational than purely informational websites.

Blogging has become a trend in Malaysia since early 2000 with various types of blogs being written as shown in Table 2.1.

\begin{tabular}{|c|c|}
\hline Genre & Description \\
\hline Personal & $\begin{array}{l}\text { - Focuses on personal events, thoughts, etc. } \\
\text { - Most common type } \\
\text { - Closely related to the lifestyle blog } \\
\text { - E.g.: www.liya-hopkins.blogspot.com }\end{array}$ \\
\hline Lifestyle & $\begin{array}{l}\text { - Focuses on personal activities, but of a more social nature } \\
\text { (parties, travelling, etc.). } \\
\text { - Closely related to the personal blog, but not so likely to } \\
\text { include rants, intimate thoughts, etc. } \\
\text { - E.g.: www.dianaishak.com }\end{array}$ \\
\hline $\begin{array}{l}\text { SoPo (Social- } \\
\text { Political) }\end{array}$ & $\begin{array}{l}\text { - Focuses on social and political commentary. } \\
\text { - Emphasises the discourse of free speech, etc. } \\
\text { - E.g.: www.papagomo.com }\end{array}$ \\
\hline Tech & - Focus on 'geek' topics: software, gadgets, etc. \\
\hline
\end{tabular}




\begin{tabular}{|c|c|}
\hline & - E.g.: www.winniekepala.com \\
\hline Food & $\begin{array}{l}\text { - Focus on making and eating food. } \\
\text { - Restaurant reviews, recipes, etc. } \\
\text { - E.g.: www.azlitamasammanis.com }\end{array}$ \\
\hline Blogshop & $\begin{array}{l}\text { - Using a blog as a way to sell goods online. } \\
\text { - E.g.: www.bajuborongmalaysia.blogspot.com }\end{array}$ \\
\hline Problog & $\begin{array}{l}\text { - Focus on ways of making money online. } \\
\text { - Often using the multi-level marketing (MLM) model. } \\
\text { - Affiliate schemes, eBooks. } \\
\text { - E.g.: www.greenlightcpa.blogspot.com }\end{array}$ \\
\hline Professional & $\begin{array}{l}\text { - The blog complements a person's offline professional } \\
\text { activity. } \\
\text { - Some politicians' blogs can come under this category. } \\
\text { - Corporate blogs. } \\
\text { - E.g.: www.najibrazak.com/en/blog }\end{array}$ \\
\hline Niche blogs & $\begin{array}{l}\text { - Focus on a narrow interest: Hobbies, Religion, Comic, } \\
\text { Parenting, Food, Tech etc. } \\
\text { - Useful for search engine optimisation (SEO). } \\
\text { - E.g.: www.detikislam.blogspot.com }\end{array}$ \\
\hline
\end{tabular}

Table 2.1: Blog genres in Malaysia (Adapted from Hopkins (2010a))

Based on Table 2.1, it can be seen that some of the blog genres are overlapping with each other. For example the lifestyle genre is closely related to personal genre, whilst technology and food blogs are the example of niche blogs.

According to Malaysian Communications and Multimedia Commission (2013), the most popular reasons to blog is in order to document their personal experiences and share them with others, with $37.2 \%$ of bloggers in Malaysia blogging for this reason. Most bloggers in Malaysia start off their blogs using the personal genre, which focuses on the everyday life and thoughts of the blogger (Hopkins, 2011). They then slowly turn to be more towards the lifestyle genre with some personal posts remaining as part of their blogging style. This study 
argues that the mixture of lifestyle and personal blogs should also be considered as lifestyle blogs as the lifestyle genre is fluid, as claimed by Hopkins (2010a). This argument can also be supported by the claim made by Abidin (2016), who notes that lifestyle bloggers posts are premised on the ordinary routine of their lives.

As the lifestyle genre developed, blogs became increasingly popular, attracting commercial interests (Hopkins, 2010a). Some of the lifestyle bloggers began to be paid by advertisers for a proportion of advertising space and advertorials in their blogs especially influential bloggers who could attract more readers. This motivated lifestyle bloggers to keep their readers engaged with their blogs with interesting posts which would eventually change the direction of their blogs. For example, Lövheim (2011) claims that apart from advertisements, the bloggers display their personal life in postings where they review, sell or arrange a competition based on certain products, or write about invitations to events and meetings. Smith (2010) found that bloggers often begin with a personal purpose to explore content possibilities in order to keep higher web traffic to their blogs. Therefore, usually bloggers tend to expand content considerations beyond original purposes. According to Smith (2010), at this stage bloggers will evaluate their participation in the blogging community and post something that could be interesting to be read by many readers, or they stick with their original intention to create something personal.

The previous discussion has shown that the blogosphere has evolved from a personal diaristic genre to a lifestyle blog genre. They have also become more commercialized. In Malaysia, lifestyle bloggers have engaged in a phenomenon called blogshops. This phenomenon not only arose amongst the lifestyle bloggers but also attracted the attention of those who were not used to blogging (Lim, Diaz, \& Dash, 2013). However, the non-bloggers who have blogshops are beyond the scope of this study which only focuses on the blogshops phenomenon for bloggers in the Malay lifestyle blogging community. The concept of blogshops is explained briefly in the next section. 


\subsubsection{Blogshop}

According to Shafie et al. (2011), a blogshop is a blog that acts as a shop or store that uses blogging facilities as their trading platform, offering personalized services to their customers. The same phenomenon has also emerged in Singapore and in some South East Asian countries from the mid2000s (Abidin, 2013a; Fletcher \& Greenhill, 2009; Lim et al., 2013; Wong, 2010; Yeung \& Ang, 2016). This point is also made by Lim et al. (2013) who argue that the practice of using blogs and other social media for e-commerce purposes can also be found in other South East Asian countries such as Indonesia, Thailand, the Philippines and Brunei although they use different terminology to describe blogshops.

Lim et al. (2013) claim that blogging and selling or purchasing via blogshops usually overlaps, which means these activities are not mutually exclusive. In addition, in Malaysia, bloggers also use other social media applications such as Facebook and Instagram to sell their products (Hassan, Toland, \& Tate, 2016). Using the same strategy as blogshops, the Facebook store and Instashop (Instagram) are used to sell and promote their products.

To explain how they manage to maintain their readership, while evolving into a different genre and adding commercial functions, the next section will discuss the relationship between lifestyle bloggers and their readers using the social network theory. This is followed by discussion on the concept of homophily and social ties.

\subsubsection{Lifestyle Blogs Community as Virtual Community}

Efimova and Hendrick (2005), Merelo-Guervos, Prieto, Rateb, and Tricas (2003) and Efimova and De Moor (2005) argue that the development of weblog conversational practices is a community-forming effect of blogging. This means, when bloggers share thoughts, express opinions, debate ideas, and offer suggestions interactively with the readers, it facilitates the formulation of special interest communities. 
Wei (2004) claims that blog communities are normally developed based on similar interests, which can form around numerous themes each with its own practices and behaviours. This is supported by Blanchard (2004) who claims that blogs have the potential to evolve into socially beneficial, self-sustaining virtual communities. Blanchard and Markus (2004) suggest that the blogosphere can be defined as a virtual community if it has the characteristics of virtual settlement. A virtual settlement is a common virtual place where people interact online (Chin \& Chignell, 2007; Jones, 1997).

This study focuses on the Malay lifestyle blogs community in Malaysia, particularly sub-groups that are involved in social commerce. Granovetter (1973) argues that strong ties consist of frequent interactions occurring at least twice a week, whereas weak ties are said to consist of interactions occurring less than that. In the Malay lifestyle blogs community, daily communication often starts in the comments' sections of an individual blog. From the comments sections, communication is expanded to other social media sites, for example Facebook, Instagram and Twitter as well as mobile applications such as WhatsApp. Therefore this study argues that this community describes the strong ties between members, particularly those who engaged with interaction in the community.

Jones (1997) suggests studying a community through its virtual settlement and proposes a set of conditions to explain it. The set of conditions includes (i) a minimum level of interactivity; (ii) a variety of communicators; (iii) a virtual-common-public space where a significant portion of community interactions occur; and (iv) a minimum level of sustained stable membership. Those conditions presuppose that there is a cyber-space with some kind of group interactions that can be studied to identify if a community exists.

However, in the case of a blog community it is usually difficult to find a single shared space as a place for a member to interact with other members. Efimova and Hendrick (2005) suggest an alternative approach for blog communities. They claim that in order to identify the virtual community in 
blogosphere, clues indicating the likelihood of a community presence and assumptions about norms and practices in it can be used as a starting point.

Efimova and Hendrick (2005) suggest that the following artefacts (refer to Table 2.2) can be used as indicators of a weblog community existence:

\begin{tabular}{|c|c|}
\hline Indicators & Definition \\
\hline Meme paths & $\begin{array}{l}\text { Indicate influential blogs as a starting point for analysis } \\
\text { to mapping paths between blogs, in order to identify the } \\
\text { social structures behind them. }\end{array}$ \\
\hline $\begin{array}{l}\text { Blogs reading } \\
\text { pattern }\end{array}$ & $\begin{array}{l}\text { Identify the reading list (blogrolls, RSS subscriptions, } \\
\text { shared blog lines accounts) and the relation between } \\
\text { reading lists for a group of people, as regular reading of } \\
\text { a blog is the starting point for establishing or } \\
\text { maintaining the relationship in blogosphere. }\end{array}$ \\
\hline Linking pattern & $\begin{array}{l}\text { Links helps to identify connections between blogs. This } \\
\text { is supported by Merelo-Guervos et al. (2003) and } \\
\text { Herring et al. (2005). }\end{array}$ \\
\hline $\begin{array}{l}\text { Weblog } \\
\text { conversations }\end{array}$ & $\begin{array}{l}\text { Discovering conversations could be a strong indicator } \\
\text { of a shared context and system of relations that enables } \\
\text { it (Herring et al., 2005). }\end{array}$ \\
\hline $\begin{array}{l}\text { "Tribe" marks, } \\
\text { group spaces } \\
\text { and blogger } \\
\text { directories }\end{array}$ & $\begin{array}{l}\text { Blogs may display indicators of belonging to a } \\
\text { particular community. }\end{array}$ \\
\hline
\end{tabular}

Table 2.2: The indicators of a weblog community existence

Blanchard (2004) argues that some blogs, especially active, popular and highly referenced blogs, may fit Jones's (1997) definition of a virtual settlement. Having argued that there is a virtual settlement in the Malaysian blogging community and a strong sense of community, this study therefore claims that the blog community in Malaysia fits the scope of a virtual community, which is the focus of this research. 
One of the main important concepts in a virtual community is the social network theory, which can be explained by the concept of social ties and homophily that will be described next.

\subsubsection{Social Network Theory: Social Ties and Homophily}

Social network theory proposes that an online community can be described as a social network composed of nodes and edges, representing individuals and relationships (Toral, Martínez-Torres, \& Barrero, 2010). According to Krause, Croft, and James (2007) social networks show who is connected to whom in the population and by what relationship.

According to Valenzuela, Park, and Kee (2009), individuals with a large and diverse network of contacts are thought to have more social capital than individuals with small social networks. They also suggest that the ties among the members differ based on the similarity they encounter in each other. This is because social capital is the resources available to people through their social interaction (Lin, 2001).

Social ties in social networks is related to the concept of homophily. According to McPherson, Smith-Lovin, and Cook (2001), homophily is the principle that contact between similar people occurs at a higher rate than among dissimilar people. Homophily in race and ethnicity creates the strongest divides, followed by age, religion, education, occupation, and gender in general (McPherson et al., 2001). The presence of homophily has important implications on how information flows along the social network (Currarini \& Vega-Redondo, 2013). Granovetter (1973) suggests that the stronger the tie connecting two individuals, the more similar they tend to be.

According to Gatignon and Robertson (1985) and Rogers (1983), the concepts of strength of ties and homophily are similar, or synonymous. However, this argument is challenged by Brown and Reingen (1987) who put a distinction between these constructs. According to Brown and Reingen (1987), homophily refers to the similarity in attributes individuals possess 
who are in relation (e.g., same or different social status), whereas tie strength is a relational property that manifests itself in different types of social relation. It shows that although ties can be formed based on homophily, tie strength is defined by the linear combination of time, emotional intensity, intimacy and reciprocity (i.e. mutuality) (Granovetter, 1973). The latter argument is also supported by several scholars such as Brown, Broderick, and Lee (2007), Granovetter (1981), McPherson, Popielarz, and Drobnic (1992) and Xiang, Neville, and Rogati (2010). Although the contexts of their studies were different, their findings show that tie strength can be influenced by homophily or vice versa.

There are two types of homophily (Lazarsfeld \& Merton, 1954; McPherson et al., 2001) which are status homophily and value homophily. Status homophily defines a similar social status characteristics such as race or religion, whilst value homophily is based on values, attitudes and beliefs, which is the tendency to associate with others who think in similar ways, regardless of differences in status.

Gilly, Graham, Wolfinbarger, and Yale (1998) found that the greater the homophily between communicators, the more persuasive the message of the communicator. In addition, Li and Du (2011) claimed that the greater the homophily, the greater the attention a reader will pay to a blog. This claim is also supported by the Malaysian Communications and Multimedia Commission (2013), that found when readers trust a medium, they tend to rely on that medium as their main source of information. Constant visits to the same blogs indicates that the readers are interested in getting to know the bloggers and able to influence the interactions between bloggers and their readers, subsequently strengthening their ties as blogs are able to foster social interaction (Boyd \& Ellison, 2007; Hodkinson, 2007). Haythornthwaite (2002) argues that more mediums are used for communication when the social ties getting stronger.

Abidin (2013a) discusses the concept of interconnectedness between the bloggers and their readers in Singapore, which includes (i) immediacy, (ii) 
constancy, (iii) exclusivity, (iv) intimacy and (v) quality. According to Abidin (2013a), readers often expect immediacy in their interaction, and remain online constantly. In addition readers interpret their interactions with bloggers as exclusive dyadic exchanges and perceived sense of intimacy with the bloggers. Abidin (2013a) also claims that readers expect the bloggers to fulfil their requests beyond what they are capable of. This expectation describes the quality that they expected from the bloggers. This situation happens because the readers have a sense of familiarity and closeness with the bloggers as the bloggers frequently update their blogs (Abidin, 2013a).

The previous discussion describes the concept of homophily and social ties in social networks, which is the basis of the relationship for a community of lifestyle bloggers and their readers. However, despite the advantages of homophily, past studies have discovered that it can have limitations. For example, Ibarra (1992) argues that gender differences in homophily within an organization may lead to gender inequalities in the organizational distribution of power. This is because men are more likely to form strong ties across multiple networks, therefore men appeared to gain greater network returns from similar individual and positional resources, as well as the benefit of the homophilous relationships. This is in contrast with women who are likely to obtain social support and friendship from other women. Therefore, women experience the disadvantages of homophily. This is similar to what was found by Roth (2004) where homophily is argued to contribute to patterns of discrimination in male-dominated occupations. Meanwhile, Woodson (2015) in his study of large law firms argued that many black associates were disadvantaged by their own homophily preferences, which led them to bond with each other and decline networking with more influential white partners. This is because mingling with their own race resulted in them having less relationship capital with colleagues, as compared to their white peers who had more social contact, and therefore they were less likely to receive sufficient mentorship support. This shows that associating too much with similar people based on the concept of 
homophily can lead to a risk of missed opportunities being offered by nonsimilar others.

The next section will discuss the sense of virtual community, which is one of the factors that can influence participation. The concept of sense of community is argued to be relevant to describe why the readers stick to the community even once the blogs have included the commerce elements.

\subsubsection{Sense of Virtual Community}

Sense of virtual community (SOVC) theory evolved from sense of community (SOC) theory by McMillan (1976). Sense of community is a feeling that members have of belonging; a feeling that members matter to one another and to the group, and a shared faith that members' needs will be met through their commitment to be together McMillan (1976). McMillan and Chavis (1986) proposed a definition of sense of community which contains four elements:

i. Membership - feeling of belonging or of sharing a sense of personal relatedness.

ii. Influence - a sense of mattering, of making a difference to a group and of the group mattering to its members.

iii. Integration and fulfilment of needs - the feeling that members' needs will be met but the resources received through their membership in the group.

iv. Shared emotional connection - the commitment and belief that members have shared and will share history, common places, time together and similar experiences.

The concept of SOC has been applied to the virtual community as the concept of SOVC. Thus, researchers such as Koh and Kim (2003), Blanchard (2007), Blanchard (2008), Blanchard and Markus (2004), Forster (2004) and Lin (2007) have tried to explain membership in virtual communities. SOVC is defined as a member's feeling of belonging, identity and attachment to each 
other in computer-mediated communication (Blanchard, 2007; Tsai, Cheng, \& Chen, 2011).

Nonetheless due to the different environment, some researchers doubt whether the traditional SOC measures can be applied to the virtual setting (Abfalter, Zaglia, \& Mueller, 2012). Despite the argument that SOC can't be applied to virtual community, other researchers however found evidence to support a different view of the virtual context. Obst, Zinkiewicz, and Smith (2002) in their research on SOVC found that the members of the virtual community experience SOC as found by McMillan and Chavis (1986). Researchers such as Koh and Kim (2003) and Blanchard and Markus (2004) further investigated McMillan and Chavis's SOC and found that although SOC components exist in SOVC, nonetheless, the components according to the different virtual communities. Blanchard and Markus (2004) propose that the differences could be due to the specific nature of interaction in the online environment.

Koh and Kim (2003) suggest the following as the components of SOVC:

i. Membership - feeling of belonging to a virtual community (Koh \& Kim, 2003); self-reinforcing aspect boundaries, emotional safety, personal investment (to become a valuable member), sense of belonging, identification with other group members and a common symbol system (Rosenbaum, Ostrom, \& Kuntze, 2005).

ii. Influence - making a difference in their virtual community (Koh \& Kim, 2003); members' perception of impact on the community and the amount of influence the community has over the individual member.

iii. Immersion - dominated by the start of flow caused by human-machine interaction (Koh \& Kim, 2003). According to Koh and Kim (2003), flow is the term used to describe the holistic sensation that people feel when they act with total involvement. The term is applicable for virtual community as the members tend to display immersive behaviour when participating in virtual community. Virtual community characteristics like anonymity, addictive behaviour, and voluntary behaviour (Koh \& 
Kim, 2003) may imply a state of immersion (Csikszentmihalyi, 1975; Kiesler, Zubrow, Moses, \& Geller, 1985; Young, 1996).

This study adopts the SOVC components as proposed by Koh and Kim (2003) to identify the SOVC in the community chosen for this research.

SOVC has been found by many researchers to be one of the important factors that can influence the sustainability of the community as well as promoting positive outcomes from the community (Sutanto, Kankanhalli, \& Tan, 2011). Tsai et al. (2011) claim that SOVC appears to lead to increased satisfaction and communication with the virtual community as well as to greater trust and social interaction. In addition, Ellonen, Kosonen, Tarkiainen, and Tonteri (2013) claim that the SOVC strengthens the online community and results in positive business-related outcomes. Meanwhile, Chen, Yang, and Tang (2013) found that SOVC plays full mediating roles in the relationship between attitude toward the virtual community and knowledge contribution intention in the community.

The previous discussion indicates that the SOVC is likely to influence members' participation behaviour, although Blanchard and Markus (2004) claim that SOVC is not uniform for each member due to the fact that members experience the SOVC based on their personal perception. Based on the discussion, this study concludes that the community is one of the most important elements that can influence the successful implementation of social commerce. This study suggests that in the Malay lifestyle blogging community, SOVC is likely to influence the members not only to continue participating in virtual community but also to participate in commerce activities within the community. Active participation from both businesses and customers is essential to support the business strategies in social commerce. This study proposes that the role of virtual community within the social commerce environment needs to be recognized in order to improve business strategies for those businesses that implement social commerce. 
Section 2.2 and its sub-sections discusses the concept of blogshops. In addition it also describes the blogging community. The next section will discuss the concept of trust and how it relates to this study. Trust is one of the important elements in maintaining the strength of social ties (refer to Section 2.2.3) is by having high level of trust in the community, particularly when it involves element of commerce.

\subsection{Trust}

Issues of trust have been studied by many scholars in the e-commerce and social commerce field. Lu, Zhao, and Wang (2010) stated that trust can be a major factor that affects the prosperity and success of e-commerce implementation. Therefore it is considered as an important topic that needs to be addressed in commerce related studies. As the community chosen for this study has element of both e-commerce and community interactions, the concept of trust in this section will mostly be reviewed from the perspective of e-commerce/social commerce, trust and social networking trust.

Many disciplines have their own definitions of trust. For example, Mayer, Davis, and Schoorman (1995) define trust in organizations as the willingness of a party to be vulnerable to the actions of another party based on the expectation that the other will perform a particular action important to the trustor, irrespective of the ability to monitor or control that other party. In regard with trust in e-commerce, Gefen (2000) defines it as a single dimension construct dealing with a consumer's assessment that the vendor is trustworthy, whilst Gao (2010) defines it as a willingness to rely on an exchange partner in whom one has confidence.

In e-commerce research, various antecedents of trust have been discussed as the trust concept is vital in this field. There are numerous factors that could influence online trust, such as (i) customer-brand and customer-product relationship (Laroche, Habibi, \& Richard, 2013), (ii) size of firm (Jarvenpaa, Tractinsky, \& Saarinen, 1999) and (iii) offline trust (Qing, Huang, \& Xu, 2008). 
Table 2.3 explains some of the previous works on trust antecedents based on the category of trust that have been explored in e-commerce related research. 


\begin{tabular}{|c|c|c|c|}
\hline Category & Definition & Trust Antecedents & Researchers \\
\hline Knowledge-based trust & $\begin{array}{l}\text { - Predictable trust based on the information } \\
\text { one has on the other party. } \\
\text { - Formed over time with increased knowledge } \\
\text { about each other, represents a relatively } \\
\text { strong bonding between two parties and is } \\
\text { practical for an exchange relationship } \\
\text { (Lewicki \& Bunker, 1995). } \\
\text { - Grounded in the knowledge of the other } \\
\text { trading partner (that is the trustee) which } \\
\text { allows the trustor to understand and predict } \\
\text { the behaviour of the trustee (Ratnasingham, } \\
\text { 1998). }\end{array}$ & $\begin{array}{l}\text { Familiarity; } \quad \text { Brand; } \\
\text { Reputation; } \quad \text { Website } \\
\text { quality; Customer service }\end{array}$ & $\begin{array}{l}\text { Hsu (2008); Lu et al. } \\
\text { (2010); Dong et al. (2015) }\end{array}$ \\
\hline Relational-based trust & $\begin{array}{l}\text { - Relational aspect of trust defines trust built } \\
\text { up over time as a result of repeated } \\
\text { interactions between the trustor and } \\
\text { trustee. }\end{array}$ & Reliability; Dependability & $\begin{array}{l}\text { Sherchan, Nepal, and Paris } \\
\text { (2013); Rousseau, Sitkin, } \\
\text { Burt, and Camerer (1998); } \\
\text { Hartmann, Klink, and }\end{array}$ \\
\hline
\end{tabular}




\begin{tabular}{|c|c|c|c|}
\hline & $\begin{array}{l}\text { - Information available to the trustor from } \\
\text { within the relationship itself forms the basis } \\
\text { of relational trust. } \\
\text { - Frequent, longer- term interaction leads to } \\
\text { the formation of attachments based upon } \\
\text { reciprocated interpersonal care and concern } \\
\text { as the emotion is included in the relationship } \\
\text { (McAllister, 1995). }\end{array}$ & & $\begin{array}{l}\text { Simons (2015); Whelan } \\
\text { (2016) }\end{array}$ \\
\hline Identification-based trust & $\begin{array}{l}\text { - Based on shared interests and values } \\
\text { (Lewicki \& Bunker, 1995). } \\
\text { - Based on empathy and common values with } \\
\text { the other trading partners' desires and } \\
\text { intentions, to the point that one trading } \\
\text { partner is able to act as an agent for the other } \\
\text { with the evolution of time (Ratnasingham, } \\
\text { 1998). }\end{array}$ & $\begin{array}{l}\text { Joint-values; Strong } \\
\text { emotional ties; Respect to } \\
\text { sellers }\end{array}$ & $\begin{array}{l}\text { Grabner-Kräuter and } \\
\text { Bitter (2015); Hernandez } \\
\text { and Jimenez (2011); } \\
\text { Tamjidyamcholo, Baba, } \\
\text { Tamjid, and Gholipour } \\
\text { (2013) }\end{array}$ \\
\hline
\end{tabular}




\begin{tabular}{|c|c|c|c|}
\hline Personality-based trust & $\begin{array}{l}\text { - Defined as the extent to which one displays } \\
\text { a consistent tendency to be willing to } \\
\text { depend on others across a broad spectrum } \\
\text { of situations and persons. }\end{array}$ & Propensity to trust & $\begin{array}{l}\text { Hsu (2008); Lu et al. } \\
\text { (2010); Pangil and Moi } \\
\text { Chan (2014); Karpiscak } \\
\text { and Gordon (2013) }\end{array}$ \\
\hline Institution-based trust & $\begin{array}{l}\text { - Individual's trust is affected by the norms } \\
\text { and rules of surrounding institution. } \\
\text { - One believes the necessary impersonal } \\
\text { structures are in place to enable one to act in } \\
\text { anticipation of a successful future } \\
\text { endeavour (Shapiro, Sheppard, \& Cheraskin, } \\
\text { 1992; Zucker, 1986). }\end{array}$ & $\begin{array}{l}\text { System assurances; Third } \\
\text { party assurances; } \\
\text { Situational normality }\end{array}$ & $\begin{array}{l}\text { Hsu (2008); McKnight, } \\
\text { Choudhury, and Kacmar } \\
\text { (2002); Lu et al. (2010); } \\
\text { Pavlou and Gefen (2004); } \\
\text { Lu, Zeng, and Fan (2016); } \\
\text { Amoroso (2013) }\end{array}$ \\
\hline
\end{tabular}




\begin{tabular}{|c|c|c|c|}
\hline Cognition-based trust & $\begin{array}{l}\text { - Trust was created based on information } \\
\text { gathered through the interaction sets. } \\
\text { - Involve a person's use of evidence and } \\
\text { analysis to form attributes of the trust } \\
\text { components, representing the rationale part } \\
\text { of human judgment, and distinguish it from } \\
\text { affect-based trust that stems from affective } \\
\text { bonds among individuals (McAllister, 1995). } \\
\text { - Low level of trust (Chen \& Dhillon, 2003). } \\
\text { - How trust is built on first impressions rather } \\
\text { than through experiential personal } \\
\text { interactions (Gefen, Karahanna, \& Straub, } \\
\text { 2003). }\end{array}$ & $\begin{array}{l}\text { Reliability; Integrity; } \\
\text { Competence; } \\
\text { Responsibility; Level of } \\
\text { familiarity }\end{array}$ & $\begin{array}{l}\text { McAllister (1995); } \\
\text { Rempel, Holmes, and } \\
\text { Zanna (1985); } \\
\text { Mayer et al. (1995); Goto } \\
\text { (1996); Cook and Wall } \\
(1980) ; \text { Chen, Rau, and } \\
\text { Kolz (2013). }\end{array}$ \\
\hline Personality-based trust & $\begin{array}{l}\text { - Trust can be traced to the infancy seeking } \\
\text { and receiving help from caretakers. }\end{array}$ & $\begin{array}{l}\text { Disposition to trust; } \\
\text { Situational decision to } \\
\text { trust }\end{array}$ & $\begin{array}{l}\text { Lu et al. (2010); Mansour, } \\
\text { Kooli, and Utama (2014) }\end{array}$ \\
\hline
\end{tabular}

Table 2.3: Trust antecedents based on categories of trust 
Table 2.3 shows that there are various factors that can influence trust in ecommerce related studies. Some of the categories are related to each other but were given different references as scholars explained them in different contexts. For example Coleman and Coleman (1994) refer the relational trust as identity-based trust, whilst McAllister (1995) refers it as affective trust.

Bloggers are said to be able to develop relational trust with their audience (Yang \& Lim, 2009). In addition, Colucci and Cho (2014) found that trust toward blogs by a blog reader is built on judgments along three dimensions: (i) content authenticity, curation, and the frequency of posts, (ii) design - aesthetics, organization, and image quality, and (iii) the perception of a blogger - perceived expertise/reputation and motives of the blogger. As this study is focusing on the prior relationship between bloggers and the readers and how it impacts their relationship as sellers and customers, this study proposes that the trust in this community is likely to be influenced by knowledge based trust (information about the bloggers; familiarity), cognition based trust (perceived similarity) and relational trust (repeated interaction).

Gefen (2000) argues that in other domains, trust is usually built up in a gradual manner through ongoing interactions as found by Hart and Saunders (1997) and Hosmer (1995), where ongoing interaction will create a belief in the ability, integrity and intention of the trusted. By having ongoing interactions, beliefs concerning the ability, integrity, and intentions of the trusted party will be acquired and will consequently influence their trust to the party as found by Kumar (1996), Mayer et al. (1995) and Ramaswami, Srinivasan, and Gorton (1997). Gefen (2000) argues that this type of trust-building requires extensive ongoing two-way interaction which is missing from interaction on the web. The argument made by Gefen (2000) was valid at the time of his study, before Web 2.0 technologies was introduced. Since the technology has changed, two-way interactions are now available in various social network platforms. Therefore, this study suggests that in a social commerce environment where communication between businesses and customers is possible, trust could be developed based on the ongoing interaction. 
In a social networking environment, Ridings, Gefen, and Arinze (2002) claimed that trust can be regarded as personal trust, where it exists between two unfamiliar parties. Sherchan et al. (2013) argue that the lack of trust in social networks goes against their vision of connecting like-minded people, as members may not feel comfortable expressing their opinions and sharing ideas.

According to Dwyer, Hiltz, and Passerini (2007), the trust on the Facebook platform and its community are likely to influence the willingness of the members to share information. However for a platform such as MySpace, trust is not as necessary in the building of new relationship. Dwyer et al. (2007) found that Facebook members use the site to manage relationships initiated offline which includes maintaining contact with people they already know whilst MySpace is more likely to be about creating a new relationship. Their findings show that social network platforms with different usage goals are likely to influence the way new friendships are built. In addition, Fogel and Nehmad (2009) found that Facebook as a platform has a greater sense of trust than MySpace. According to Fogel and Nehmad (2009), the reason is that Facebook users believe that their contract with Facebook will not be breached, which helps to maintain a level of trust. It influences Facebook users to share more of their personal information on Facebook. Meanwhile, MySpace users in Fogel and Nehmad's (2009) study believe that their contract with MySpace has been breached and hence do not maintain the same level of trust that is given for Facebook.

In terms of the willingness to share information, similar findings to Dwyer et al. (2007) have also been found by Shin (2010) who claims that trust leads to users' willingness to share information. Shin's (2010) findings show that trust in the ability of Facebook will lead to a user's tendency to share more information. Meanwhile Hampton, Goulet, Rainie, and Purcell (2011) found that there is a significant relationship between the use of social networking and trust, but only for those who use Facebook, not other social networking platforms. 
The previous discussion shows that the trust in social network studies can be viewed from different points of view, which include trust in the platform itself and trust in the members. Levels of trust vary and can be influenced by the goals of their usage. Nonetheless, many researchers (Dwyer et al., 2007; Fogel \& Nehmad, 2009; Hampton et al., 2011; Shin, 2010) have focused more on trust in the social network platform itself rather than trust between members, which is a gap in the research.

\subsection{Trust Transfer Theory}

The literature shows that trust may be transferred from one source to another source (Buntain \& Golbeck, 2015; Chen, Huang, Davison, \& Hua, 2015; Lee, Kang, \& McKnight, 2007; Qing et al., 2008; Stewart, 1999, 2003; Stewart \& Zhang, 2003; Wang, Shen, \& Sun, 2013). It is considered to be a cognitive process where trust is transferred when it is induced by the perception of relatedness between one source and another source of trust. The perception of relatedness includes their similarity, closeness and common fate.

Stewart (2003) has proven that the trust transfer from one target to another occurs based on perceived entitativity of the targets. According to Campbell (1958), perceived entitativity is the degree to which a collection of individuals is perceived as forming a group. By examining the manner of how perceived entitativity influences information processing where perceivers expect consistency, one can identify how perceptions of relatedness may cause the transfer to occur. Different types of interaction can cause perceptions of entitativity, therefore Stewart (2003) argues that the greater the perceived interaction and similarity between the unknown target and the trusted target, the more positive the initial trusting beliefs about the unknown target will be.

Trust transfer theory has been used in many diverse settings (Stewart, 2003). Buntain and Golbeck (2015) claim that research into trust transfer has become increasingly important in distributed networks, social networks and ecommerce. According to Lee et al. (2007) and Wang et al. (2013), the problem of lack of trust in e-commerce context is likely to be solved by the trust transfer 
process. In the online context it has been used to describe the roles of trust transfer e-commerce acceptance, purchase intention (Stewart, 2003), e-Word of Mouth (WOM) intention, e-commerce company trust and trust in platform (Shi \& Chow, 2015), and e-commerce website trust (McKnight, Choudhury, \& Kacmar, 2000).

Table 2.4 shows some of the trust transfer constructs for previous research in social commerce, e-commerce and the World Wide Web. The table explains how trust was transferred from one context to other different contexts.

\begin{tabular}{|c|c|c|}
\hline Scholars & Findings & Context \\
\hline $\begin{array}{l}\text { Chen and Shen } \\
\text { (2015) }\end{array}$ & - Trust in platform $\rightarrow$ Trust in Seller & $\begin{array}{l}\text { Purchase intention in } \\
\text { C2C online shopping }\end{array}$ \\
\hline $\begin{array}{l}\text { Qing et al. } \\
\text { (2008) }\end{array}$ & - Offline trust $\rightarrow$ Initial online trust & Purchase intention \\
\hline $\begin{array}{l}\text { Stewart } \\
\text { (1999) }\end{array}$ & $\begin{array}{l}\text { - Hypertext links trust } \rightarrow \text { Initial } \\
\text { trust on unknown websites } \\
\text { - Non-web business trust } \rightarrow \text { initial } \\
\text { trust on unknown websites }\end{array}$ & Websites trust \\
\hline $\begin{array}{l}\text { Lee, Park, and } \\
\text { Han (2011) }\end{array}$ & $\begin{array}{l}\text { - Trust in online shopping mall } \rightarrow \\
\text { Credibility of online customers } \\
\text { review }\end{array}$ & $\begin{array}{l}\text { Purchase intention in } \\
\text { e-commerce website }\end{array}$ \\
\hline $\begin{array}{l}\text { Shi and Chow } \\
\text { (2015) }\end{array}$ & $\begin{array}{l}\text { - Social commerce } r \text { trust } \\
\text { (information based } r \text { and } \\
\text { identification based) } \rightarrow \text { Company } \\
\text { trust }\end{array}$ & $\begin{array}{l}\text { E-WOM intention in } \\
\text { social commerce }\end{array}$ \\
\hline Ng (2013) & $\begin{array}{l}\text { - Trust in members (closeness and } \\
\text { familiarity) } \rightarrow \text { Trust in social } \\
\text { network community }\end{array}$ & $\begin{array}{l}\text { Purchase intention in } \\
\text { social commerce }\end{array}$ \\
\hline $\begin{array}{l}\text { McKnight et al. } \\
(2000)\end{array}$ & $\begin{array}{l}\text { - Institution-based trust } \rightarrow \text { Trust in } \\
\text { web business }\end{array}$ & $\begin{array}{l}\text { Trust intention } \\
\text { (Proposition) }\end{array}$ \\
\hline
\end{tabular}




\begin{tabular}{|l|l|l|}
\hline Jiang, Jones, & $\begin{array}{l}\text { Trusted Third Party Certification } \\
\text { and Javie }\end{array}$ & Online shopping \\
$(2008)$ & transaction & \\
\hline $\begin{array}{l}\text { Lu et al. } \\
(2010)\end{array}$ & $\begin{array}{l}\text { Trust in Member } \rightarrow \text { Trust in } \\
\text { vendor }\end{array}$ & $\begin{array}{l}\text { C2C purchase } \\
\text { intention }\end{array}$ \\
\hline
\end{tabular}

Table 2.4: Past studies on trust transfer theory

However, the existing literature on trust transfer in social commerce seems to ignore the influence of different types of community. Much of the trust transfer theory in the social commerce domain only focuses on specific brand communities that have been initiated by e-commerce companies. In addition, previous research gives too much attention to the relationship of members in a community of customers and tends to overlook the relationship between customers and micro-business sellers. This study argues that the trust transfer is likely to be happening in the selected community as the members change from their roles as bloggers and readers to sellers and customers. The trust that they hold as bloggers and readers could be transferred to trust as sellers and customers.

\subsection{Social Support in Virtual Community}

The strength of social ties, as explained in Section 2.2.3 can also be described by the practice of social support (Granovetter, 1973). Mathwick, Wiertz, and De Ruyter (2008) found that virtual communities are maintained by the normative influences that impose a moral responsibility to volunteer and to reciprocate. According to Baym (1997), Ridings and Gefen (2004), Preece (1999), Rheingold (1996) and Greer (2000), exchange of support among members is one of the characteristics of virtual community. Therefore, the concept of social support in virtual community will be explained further in order to understand the tie strength in the community.

Social support refers to members' experiences of being cared for, being responded to, and being helped by members. Thoits (1982) defines social 
support as the degree to which a person's basic social needs are gratified through interaction with others. Malecki and Demaray (2003) view social support as an individual's perception of general support or specific supportive behaviours from people in their social network. Ashton and Fuehrer (1993) claim that helping can be seen as a subtype of social support. In addition, Kahn and Antonucci (1980) and Norbeck, Lindsey, and Carrieri (1981) claim that liking, admiration, respect and love are considered as affective transaction that can influence members to provide social support. Wasko and Faraj (2000) claim that members of virtual community help others because "it is the right thing to do" and it indicates their moral obligation. In return they achieve intrinsic satisfaction and self-actualization (Wasko \& Faraj, 2000).

There are four types of social support, which include (i) emotional support (ii) instrumental support, (iii) informational support, and (iv) appraisal support (Barrera Jr, 1986; Barrera \& Ainlay, 1983; Hwang et al., 2011; Langford, Bowsher, Maloney, \& Lillis, 1997; Norbeck et al., 1981; Sarason, Shearin, Pierce, \& Sarason, 1987; Sarason, Sarason, Shearin, \& Pierce, 1987). Emotional support describes a basic provision of close personal relationships (Cunningham \& Wilkins, 2009). Tsuchihashi-Makaya, Kato, Chishaki, Takeshita, and Tsutsui (2009) define it as empathy and understanding, having positive effects, and encouraging expressions of feelings. It includes the verbal and non-verbal communication of concern and care, and involves listening, empathising, comforting, and reassuring (Aggarwal, Liao, \& Mosca, 2008; Helgeson \& Cohen, 1996).

Informational support is defined as advice, directives, or information communicated directly to an individual in coping with problems (House, 1981; Murray, 2000) whilst appraisal support involves the communication of information that is relevant to self-evaluation through processes such as social comparison, rather than problem solving (House, 1981). Often informational support is considered similar to appraisal support as it involves information given to other party. In addition, appraisal support which is described as support that happened when someone offers information that allows the other 
person to make an informed decision on their own (House, 1981) is also argued to be similar to emotional support (Wills, 1985).

Lastly, instrumental support is provision of tangible resources for solving practical problems (Wilson et al., 1999). Informational support is the most common social support practice in the community (Welbourne, Blanchard, \& Boughton, 2009). Meanwhile, Coursaris and Liu (2009), Braithwaite, Waldron, and Finn (1999), Chang (2009) and Hwang et al. (2011) argue that instrumental support is rarely provided in a virtual community as compared to informational and emotional support because of the virtual nature of the interaction.

Past studies have shown that many people join virtual communities mainly for dispelling their loneliness, finding encouragement, meeting like-minded others, and receiving companionship and social support (McKenna \& Bargh, 1999; Ridings \& Gefen, 2004; Sproull \& Faraj, 1997; Wellman \& Gulia, 1999). This shows that generally social support is a common practice in many virtual communities which also means that it is important to address the social support practice in virtual community related research.

Ridings and Gefen (2004) argue that friendships and social support are a central part of human life and interaction with others whilst Liang et al. (2011), found that in the social commerce environment, a direct outcome of social support is enhanced relationship quality, which is known to lead to higher customer loyalty.

Since the members of the community chosen for this study are involved in multiple roles, this study argues that the role of social support are likely to influence their relationship as bloggers and readers, as well as their relationship as sellers and customers.

\subsection{Defining Social Commerce}

In recent years, there has been increasing research interest in social commerce. For example, recently, many IS conferences have included social commerce 
related studies in their tracks, such as the Australasian Conference on Information System, and the International Conference on Information Systems.

Several attempts have been made by academic researchers and practitioners to define social commerce (refer to Table 2.5). At present, there is still debate among them regarding the definitions and scope of social commerce. One group of academics and practitioners defines social commerce as a community of shoppers who share knowledge and sources on product information, which also includes assistance from trusted individuals on goods and services sold online (Beach, 2005; Beisel, 2005; Decker, 2007; Gregoriadis, 2007; Pagani \& Mirabello, 2011; Rubel, 2006). This is similar to the definition by Raito (2007) who argues that social commerce is a trusted environment where customers dynamically contribute content for the referral and sale of goods or services through positive and negative feedback. However, Raito's definition is slightly different from the others as he specified that the trusted environment in social commerce is based on a network of friends and family only.

The second group argues that social commerce is a subset of e-commerce that involves the use of social media to support social interaction and user contributions, which assist the online buying and selling of products and services (Liang et al., 2011; Marsden, 2009; Turban et al., 2012; Wang \& Zhang, 2012). This is similar to the definition given by Gibbons (2008), Deragon (2008), Matsumoto (2009), Afrasiabi and Benyoucef (2011), and Weaver (2010), who define social commerce as the use of social media in the context of e-commerce or a form of commerce mediated by social media.

The third section consists of only one definition by Stephen and Toubia (2010), who define social commerce as the marketplace where the individual sellers, instead of firms; are connected with each other through social networks. Based on this definition, it is clear that Stephen and Toubia (2010) do not include customers' activities under the scope of social commerce. According to them, customers' activities within products or services sold via social media are referred to as social shopping. However, this argument has been challenged by other researchers. For example, Wang (2009) states that social shopping and 
social commerce are the same concept, which is a new type of e-commerce linking shopping and social networking through social media.

Based on these definitions, it can be seen that the term social commerce originated from the idea of knowledge sharing about goods and/or services among customers. This study argues that both activities by seller and customer via social media platforms should be considered when defining social commerce, as the nature of commerce involves both parties. Therefore, the definition by Marsden (2009), Gibbons (2008), Deragon (2008), Weaver (2010), Afrasiabi and Benyoucef (2011), Liang et al. (2011), Wang and Zhang (2012), and Turban et al. (2012) are adopted in this study as a working definition. As previously discussed, they define social commerce as a subset of e-commerce that involves social media technologies, community interactions, and commercial activities.

Therefore, for the purpose of this study, social commerce will be defined as:

"Online selling and buying activities using social media technologies and/or platforms within a participating community".

Table 2.5 compares definitions by several scholars and practitioners and identifies key themes and areas of commonality. 


\begin{tabular}{|c|c|c|c|c|c|c|c|c|c|}
\hline Group & Author & Definition & 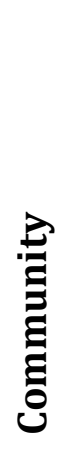 & $\frac{\pi}{\tilde{z}}$ & 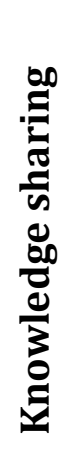 & 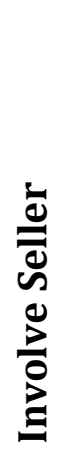 & 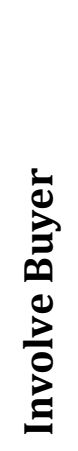 & 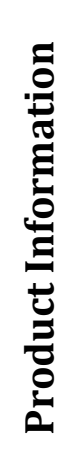 & 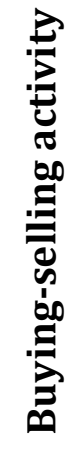 \\
\hline \multirow[t]{2}{*}{1} & Beach (2005) & $\begin{array}{l}\text { - Sources for product information and } \\
\text { advice from the community. For } \\
\text { example: The Shoposphere and Pick } \\
\text { Lists. It is a list of products on any topic, } \\
\text { and can include any of the } 90 \text { million } \\
\text { products available through Yahoo! } \\
\text { Shopping. }\end{array}$ & / & & / & & / & 1 & \\
\hline & Rubel (2006) & $\begin{array}{l}\text { - Places where people can collaborate } \\
\text { online, get advice from trusted } \\
\text { individuals, find goods and services and } \\
\text { then purchase them. }\end{array}$ & / & & 1 & & 1 & 7 & \\
\hline
\end{tabular}




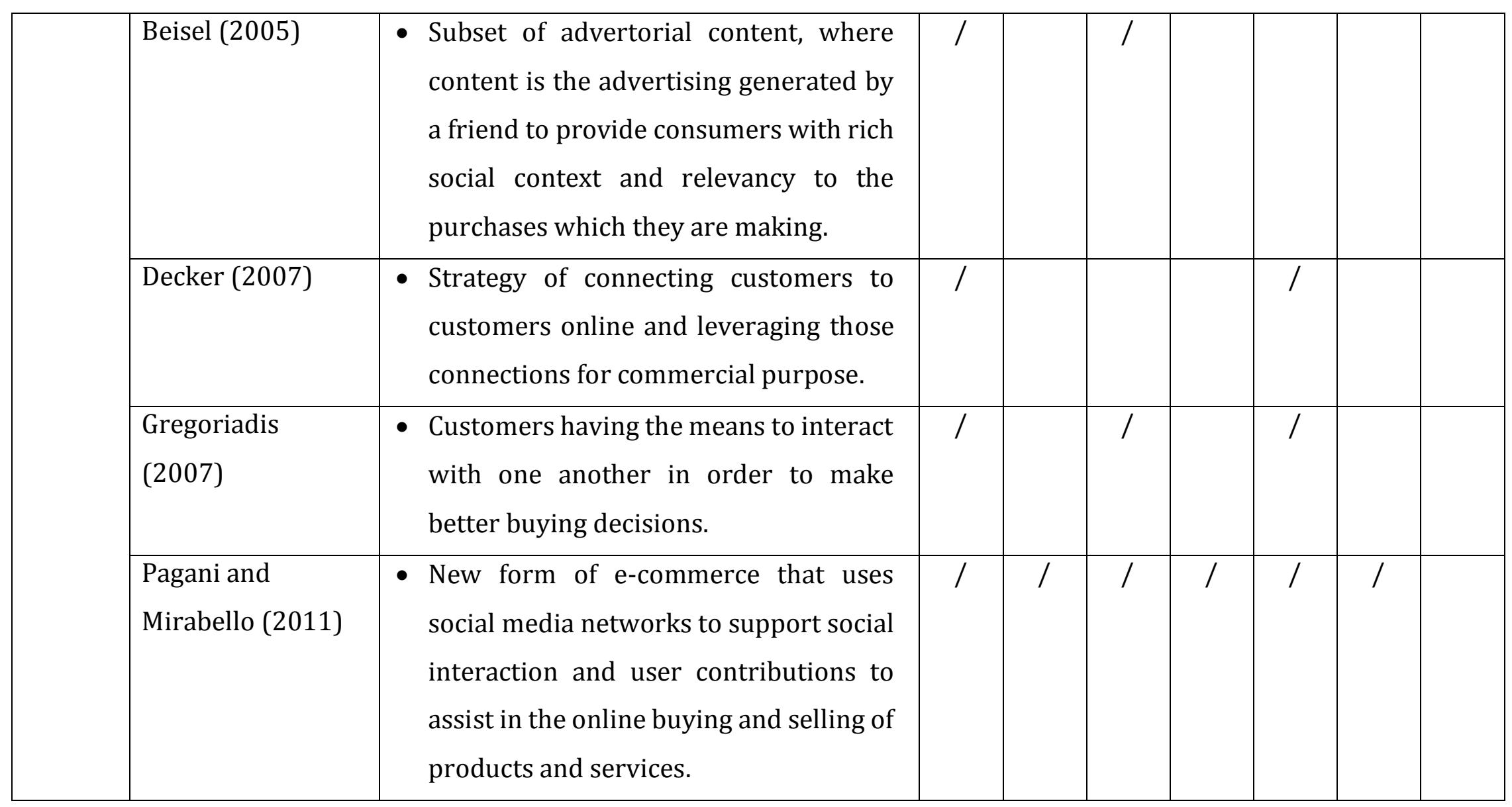




\begin{tabular}{|c|c|c|c|c|c|c|c|c|c|}
\hline & Raito (2007) & $\begin{array}{l}\text { - A trusted environment where friends, } \\
\text { family and acquaintances dynamically } \\
\text { contribute content to the referral and } \\
\text { sale of goods and services though } \\
\text { positive and negative feedback, } \\
\text { reviews, ratings and testimonials } \\
\text { regarding their experiences past \& } \\
\text { present. } \\
\text { - A trusted environment in which } \\
\text { prospective consumers make buying } \\
\text { decisions based on the advice of a } \\
\text { network of friends and family, not } \\
\text { strangers they don't know or trust. }\end{array}$ & / & & / & & 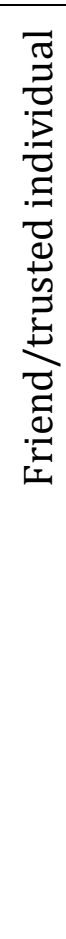 & / & \\
\hline 2 & Marsden (2009) & $\begin{array}{l}\text { - A subset of electronic commerce that } \\
\text { involves using social media, online } \\
\text { media that supports social interaction } \\
\text { and user contributions, to assist in the } \\
\text { online buying and selling of products } \\
\text { and services. } \\
\text { - The use of social media in the context of } \\
\text { e-commerce. }\end{array}$ & / & / & & / & / & / & / \\
\hline
\end{tabular}




\begin{tabular}{|c|c|c|c|c|c|c|c|}
\hline Liang et al. (2011) & $\begin{array}{l}\text { - Conducting various types of } \\
\text { commercial activities on social media to } \\
\text { take advantage of online social capital. }\end{array}$ & / & / & / & / & / & / \\
\hline $\begin{array}{l}\text { Wang and Zhang } \\
\text { (2012) }\end{array}$ & $\begin{array}{l}\text { - Social commerce is a form of commerce } \\
\text { mediated by social media and is } \\
\text { converging both online and offline } \\
\text { environments. }\end{array}$ & / & / & / & 1 & / & / \\
\hline $\begin{array}{l}\text { Turban et al. } \\
\text { (2012) }\end{array}$ & $\begin{array}{l}\text { - Social commerce is the second } \\
\text { generation of e-commerce that } \\
\text { promotes the activities conducted in } \\
\text { social networks or by using social } \\
\text { software. }\end{array}$ & / & / & / & / & / & / \\
\hline Gibbons (2008) & $\begin{array}{l}\text { - Monetizing social media sites. } \\
\text { - Applications that transform a profile } \\
\text { page on a social network into an online } \\
\text { store complete with payment } \\
\text { processing. }\end{array}$ & / & / & / & 1 & / & / \\
\hline Deragon (2008) & $\begin{array}{l}\text { - Conducting commerce using social } \\
\text { networks. }\end{array}$ & / & / & / & / & & / \\
\hline
\end{tabular}




\begin{tabular}{|c|c|c|c|c|c|c|c|}
\hline Matsumoto (2009) & $\begin{array}{l}\text { Enable consumers to browse, view, and } \\
\text { add products to a shopping cart, within } \\
\text { the context of a social site, like Facebook } \\
\text { or a blog. }\end{array}$ & / & / & / & / & / & / \\
\hline $\begin{array}{l}\text { Afrasiabi and } \\
\text { Benyoucef (2011) }\end{array}$ & $\begin{array}{l}\text { - Networks of sellers and networks of } \\
\text { customers; evolution of e-commerce } 1.0 \\
\text { (one to one interaction) into a more } \\
\text { social and interactive form of e- } \\
\text { commerce. }\end{array}$ & / & / & / & / & / & / \\
\hline Wang (2009) & $\begin{array}{l}\text { - A new type of e-commerce linking } \\
\text { shopping and social networking } \\
\text { through media. }\end{array}$ & / & / & / & / & / & / \\
\hline Weaver (2010) & - Selling with social media. & / & / & / & / & & / \\
\hline
\end{tabular}




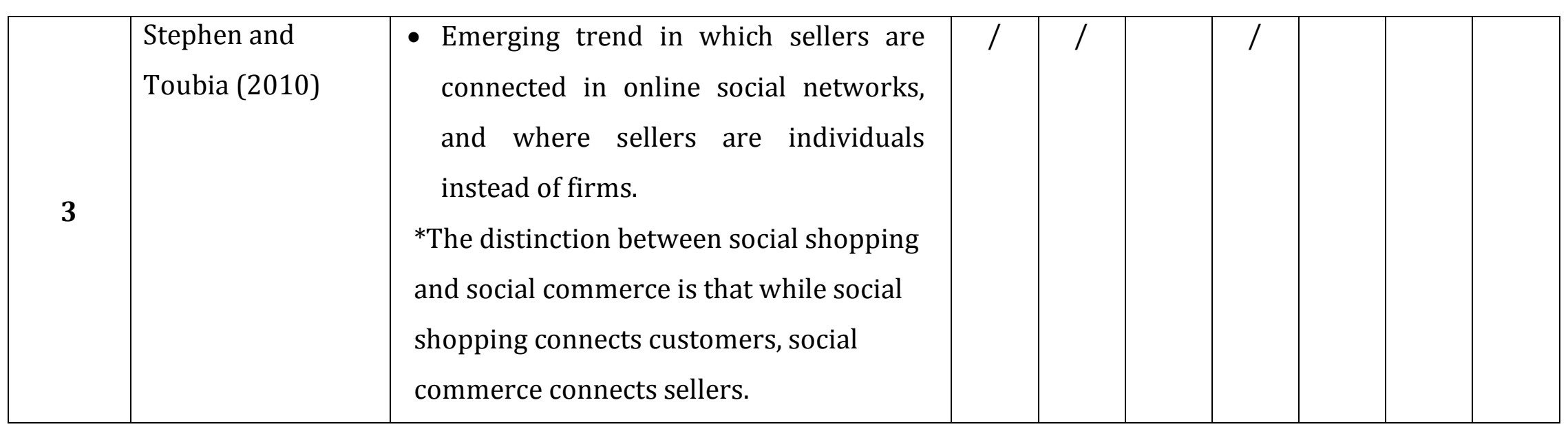

Table 2.5: Social commerce definitions (Adapted from Wang and Zhang (2012)) 


\subsubsection{Past Studies on Social Commerce}

Social commerce has recently attracted the attention of many scholars. It has been shown that previous studies on social commerce have explored various issues on the businesses, as well as the customers. In order to explain the past studies, the discussion will be based on the main focus for this study, (i) businesses and (ii) customers.

Evidence from the literature shows that for the businesses, the majority of social commerce related research has focused on medium to large organizations (Augar \& Zeleznikow, 2013). This includes studies on (i) social media/ social commerce strategy for businesses (Constantinides \& Fountain, 2008; Culnan et al., 2010; Jarvenpaa \& Tuunainen, 2012; Mangold \& Faulds, 2009; Michaelidou, Siamagka, \& Christodoulides, 2011; Parise \& Guinan, 2008; Saundage \& Lee, 2011; Schaupp \& Bélanger, 2016; Senadheera, Warren, \& Leitch, 2011), (ii) social commerce model (Kim, 2013; Wu, Xu, Mo, \& Liao, 2015; Yadav, De Valck, Hennig-Thurau, Hoffman, \& Spann, 2013), (iii) social commerce website design features (Curty \& Zhang, 2013; Huang \& Benyoucef, 2013), (iv) perceptions gap between businesses and customers (Baird \& Parasnis, 2011a), and (v) ROI measurement (Fisher, 2009; Hoffman \& Fodor, 2010).

The way micro-businesses operate social commerce is not very thoroughly researched as compared to the amount of work on larger organizations. Although there are some studies that focus on small businesses use of social media (Augar \& Zeleznikow, 2013; Lee, DeWester, \& Park, 2008; Mandal \& McQueen, 2012; Michaelidou et al., 2011; Stephen \& Toubia, 2010), the focus of their studies is on adoption. The direction of their research is different from this study as it doesn't take community interaction into consideration. This is because the phenomenon where businesses are part of the community is relatively new but has been widely practiced by some South East Asian countries as claimed by Abidin (2013a), Fletcher and Greenhill (2009), Lim et al. (2013) and Wong (2010). 
Hence, this study argues that there are further areas that need to be explored in order to fully understand the sellers' motivation. This is especially needed in the area of virtual community participation where most studies have focused on communities of customers. Micro-businesses that have good relationships with their customers should be emphasised in order to understand social commerce adoption for different models of implementation. This awareness of the role of relationships in virtual communities in e-commerce has led this study to explore the factors that contribute to the motivation of those who venture into social commerce. It is particularly important in social commerce because relationships are an essential foundation on which social commerce is built. Missing key items of information may lead to ambiguous conclusions in both virtual community and social commerce studies. The roles of social ties and homophily as well as the sense of virtual community need to be addressed in social commerce studies as these concepts are closely related to the relationships within a social commerce community.

Meanwhile, research on the customers of social commerce has explored the combination of (i) social commerce/brand community (Liang et al. 2011; Hajli, 2015; Zhang et al., 2014; Wang \& Hajli, 2014; Sun, Wei, Fan, Lu \& Gupta, 2016), (ii) customers' behavioural intention (Farivar, Yuan, \& Turel, 2016; Hsiao, Chuan-Chuan Lin, Wang, Lu, \& Yu, 2010; Liang et al., 2011; Todri \& Adamopoulos, 2014; Zhang, Lu, Gupta, \& Zhao, 2014), and (iii) trust (Bansal \& Chen, 2011; Farivar et al., 2016; Hsiao et al., 2010; Kim \& Park, 2013).

The studies that focus on the community in social commerce such as Liang et al. (2011), Hajli (2015), Zhang et al. (2014) and Wang \& Hajli (2014) have found that participation in social commerce is likely to be influenced by social support in the community. The communities studied by Liang et al. (2011), Hajli (2015), Zhang et al. (2014) and Wang \& Hajli (2014) include the micro-blogging community, Facebook community, Renren ${ }^{3}$ community and SinaWeibo $^{3}$ community. Although the nature of the said communities are

\footnotetext{
${ }^{3}$ Renren and SinaWeibo are the premier social network platforms in China.
} 
different as they are using different platforms that might influence how they practice social support, nonetheless, they found that social support is an important element in social commerce intention. These findings show that the inclusion of social support in social commerce research can contribute to our understanding of users' commercial behaviour.

Meanwhile, Hajli (2015) investigated social media constructs such as forums and communities, ratings and reviews, and recommendations and referrals, and the role such constructs play within social commerce environments. He found that consumers are increasingly using these constructs as a medium for social interaction. The interactions eventually lead them to become closer to each other, which influences their participation.

The previous discussions show that the studies that are related to community participation are mostly focused on the customers' community. Although the studies (Hajli, 2015; Liang et al., 2011; Wang \& Hajli, 2014; Zhang et al., 2014) were discovered to have significant findings related to relationship quality and social support, nonetheless the contexts chosen for their studies didn't include a consideration of the interaction between sellers and the customers in the same community, identifying a gap in this area of research. This study therefore argues that there is a need to understand sellers and customers in the same community as each community has certain unique characteristics that needs to be investigated in order to contribute new knowledge to the social commerce domain.

In addition, based on the previous studies by Baird and Parasnis (2011a), there exists perception gaps between businesses expectation and customers' motivation in social commerce. Thus, there is a need for scholars to explore the motivational factors for participation for both businesses and the customers in the same business environment. 


\subsubsection{Motivation to Participate in Social Commerce by Micro- businesses}

This section covers related studies on micro-businesses, particularly the goals of the micro-business owner for operating businesses. It is important to investigate the goals of micro-businesses in different contexts as it will give more insight for this study.

Micro-businesses are generally defined as businesses operating with fewer than nine employees (Storey \& Curran, 2000). According to Helen Samujh (2011), micro-businesses have an important role in contributing towards a stable and sustainable social and economic community environment. This research will use the term micro-business to describe the type of businesses run by the bloggers in this community. Note that the micro-businesses chosen in the scope of this study started their businesses after being engaged as bloggers in the community. In order to understand the sellers' motivation to participate in social commerce, there is a need to discuss past studies on the goals of micro-businesses.

Greenbank (2001) argues that the goal of micro-business owners in general relate to both business and personal objectives which include (i) personal economic objectives (i.e. high or higher income, satisfactory income, money for luxuries), (ii) personal non-economic objectives (e.g. job satisfaction, control, flexibility, reasonable hours), and (iii) business objectives (i.e. profit maximisation, survival, employment maintenance, business establishment, growth). Greenbank (2001) found that these objectives are influenced by individual context (relates to inherited or learned behaviours, abilities, perceptions and beliefs), social context (e.g. education, networks of friends) and economic context (economic desires and needs of business owner), hence the wide range of goals.

The motivational factors for the micro-businesses venture in social commerce or adopting social media have not been studied by many researchers. This study argues that the reason for this could be because of 
the obvious factors related to the advantages of using social media, for example cost-effectiveness and the potential of making profits.

Nonetheless there are several studies highlighting the factors for social media adoption by micro-businesses, such as Augar and Zeleznikow (2013) who found that absence of cost, minimal risk, pleasant experience on feedback, and competitive advantages are amongst the motivators. In addition, Mandal and McQueen (2012) found that micro-business owners use social media in order to achieve their goals which include (i) gaining new customers, (ii) engaging customers, and (iii) WOM marketing.

The following table (refer to Table 2.6) shows some of the advantages of adopting social media, Web 2.0, and/or social commerce by businesses. Although some of the advantages were briefly mentioned in previous research, this study argues that it is important to acknowledge it in order to understand more about the motivational factors for micro-businesses in social commerce participation. This is because by reviewing the advantages of Web 2.0 to the businesses, this study can investigate the opportunities that can be taken by the micro-business sellers by leveraging technology in their business. This study argues that the advantages of using these technologies could be represented as a motivator to participate in social commerce.

\begin{tabular}{|l|l|l|}
\hline Factors & Scholars & Context of Studies \\
\hline Business Opportunity & $\begin{array}{l}\text { Curty and Zhang } \\
\text { (2011); Wang and } \\
\text { Zhang (2012) }\end{array}$ & Social commerce \\
\hline $\begin{array}{l}\text { Marketing } \\
\text { Strategy/Opportunity }\end{array}$ & $\begin{array}{l}\text { Berthon, Pitt, } \\
\text { Plangger, and Shapiro } \\
(2012)\end{array}$ & \\
\cline { 2 - 3 } & $\begin{array}{l}\text { Curty and Zhang } \\
(2011)\end{array}$ & Social commerce \\
\hline
\end{tabular}




\begin{tabular}{|c|c|c|}
\hline $\begin{array}{l}\text { Increase Customer } \\
\text { Advocacy }\end{array}$ & $\begin{array}{l}\text { Baird and Parasnis } \\
\text { (2011a); Baird and } \\
\text { Parasnis (2011b) }\end{array}$ & Social CRM \\
\hline $\begin{array}{l}\text { New supporters } \\
\text { (Online Supporters) }\end{array}$ & $\begin{array}{l}\text { Naylor, Lamberton, } \\
\text { and West (2012) }\end{array}$ & $\begin{array}{l}\text { Best practices of the } \\
\text { use of social media to } \\
\text { bolster brand } \\
\text { evaluations }\end{array}$ \\
\hline $\begin{array}{l}\text { Potential for Making } \\
\text { Profit }\end{array}$ & $\begin{array}{l}\text { Crum (2010); Wang } \\
\text { and Zhang (2012) }\end{array}$ & Social commerce \\
\hline $\begin{array}{l}\text { Sustainability Issues } \\
\text { (Trust) }\end{array}$ & $\begin{array}{l}\text { Zhou, Zhang, and } \\
\text { Zimmermann (2013) }\end{array}$ & Social commerce \\
\hline \multirow[t]{6}{*}{ Cost-Effectiveness } & $\begin{array}{l}\text { Delerue and Hopkins } \\
\text { (2012) }\end{array}$ & Social commerce \\
\hline & Harris and Rae (2009) & Web 2.0 \\
\hline & $\begin{array}{l}\text { Singh, Davison, and } \\
\text { Wickramasinghe } \\
\text { (2010) }\end{array}$ & $\begin{array}{l}\text { Organisational use of } \\
\text { Web } 2.0 \text { technologies }\end{array}$ \\
\hline & $\begin{array}{l}\text { Augar and Zeleznikow } \\
\text { (2013) }\end{array}$ & $\begin{array}{l}\text { Small businesses } \\
\text { social commerce } \\
\text { adoption }\end{array}$ \\
\hline & $\begin{array}{l}\text { Cunningham and } \\
\text { Wilkins (2009) }\end{array}$ & Web 2.0 \\
\hline & $\begin{array}{l}\text { Jue, Marr, and } \\
\text { Kassotakis (2009) }\end{array}$ & Social media at work \\
\hline \multirow[t]{2}{*}{ Perceived Usefulness } & $\begin{array}{l}\text { Augar and Zeleznikow } \\
\text { (2013) }\end{array}$ & $\begin{array}{l}\text { Small businesses } \\
\text { social commerce } \\
\text { adoption }\end{array}$ \\
\hline & $\begin{array}{l}\text { Curty and Zhang } \\
\text { (2013) }\end{array}$ & Social commerce \\
\hline Perceived Ease of Use & $\begin{array}{l}\text { Augar and Zeleznikow } \\
\text { (2013) }\end{array}$ & $\begin{array}{l}\text { Small businesses } \\
\text { social commerce } \\
\text { adoption }\end{array}$ \\
\hline
\end{tabular}




\begin{tabular}{|l|l|l|}
\hline & $\begin{array}{l}\text { Curty and Zhang } \\
(2013)\end{array}$ & Social commerce \\
\hline Customer Engagement & $\begin{array}{l}\text { Augar and Zeleznikow } \\
(2013)\end{array}$ & $\begin{array}{l}\text { Small businesses } \\
\text { social commerce } \\
\text { adoption }\end{array}$ \\
\cline { 2 - 3 } & $\begin{array}{l}\text { Curty and Zhang } \\
(2011)\end{array}$ & Social commerce \\
\hline
\end{tabular}

Table 2.6: The advantages of venturing into social commerce for the businesses

In addition, this study argues that there is a need for scholars to dig deeper into the motivational factors for micro-businesses set up by the bloggers to venture into social commerce, where there could be different findings especially with regard to the nature of social media chosen by the bloggers. This is because the use of the social media is fluid and was adopted based on the judgement of the bloggers in the community.

\subsubsection{Customers' Motivation to Participate in Social Commerce}

Much research focuses on the motivational factors for customers to participate in social commerce as compared to the micro-businesses. The following table (refer to Table 2.7) shows the motivational factors that influence the customers or community members' participation in an online context which includes the intention to participate in e-commerce, social commerce and social networking sites, which is related to the context of this study.

\begin{tabular}{|l|l|l|}
\hline Motivation & Scholars & Context of studies \\
\hline Perceived Benefit & $\begin{array}{l}\text { Siegrist (2000); Siegrist, } \\
\text { Cvetkovich, and Roth } \\
(2000)\end{array}$ & Technology acceptance \\
\cline { 2 - 3 } & $\begin{array}{l}\text { Forsythe, Liu, Shannon, } \\
\text { and Gardner (2006) }\end{array}$ & $\begin{array}{l}\text { Perceived benefit of } \\
\text { online shopping }\end{array}$ \\
\hline
\end{tabular}




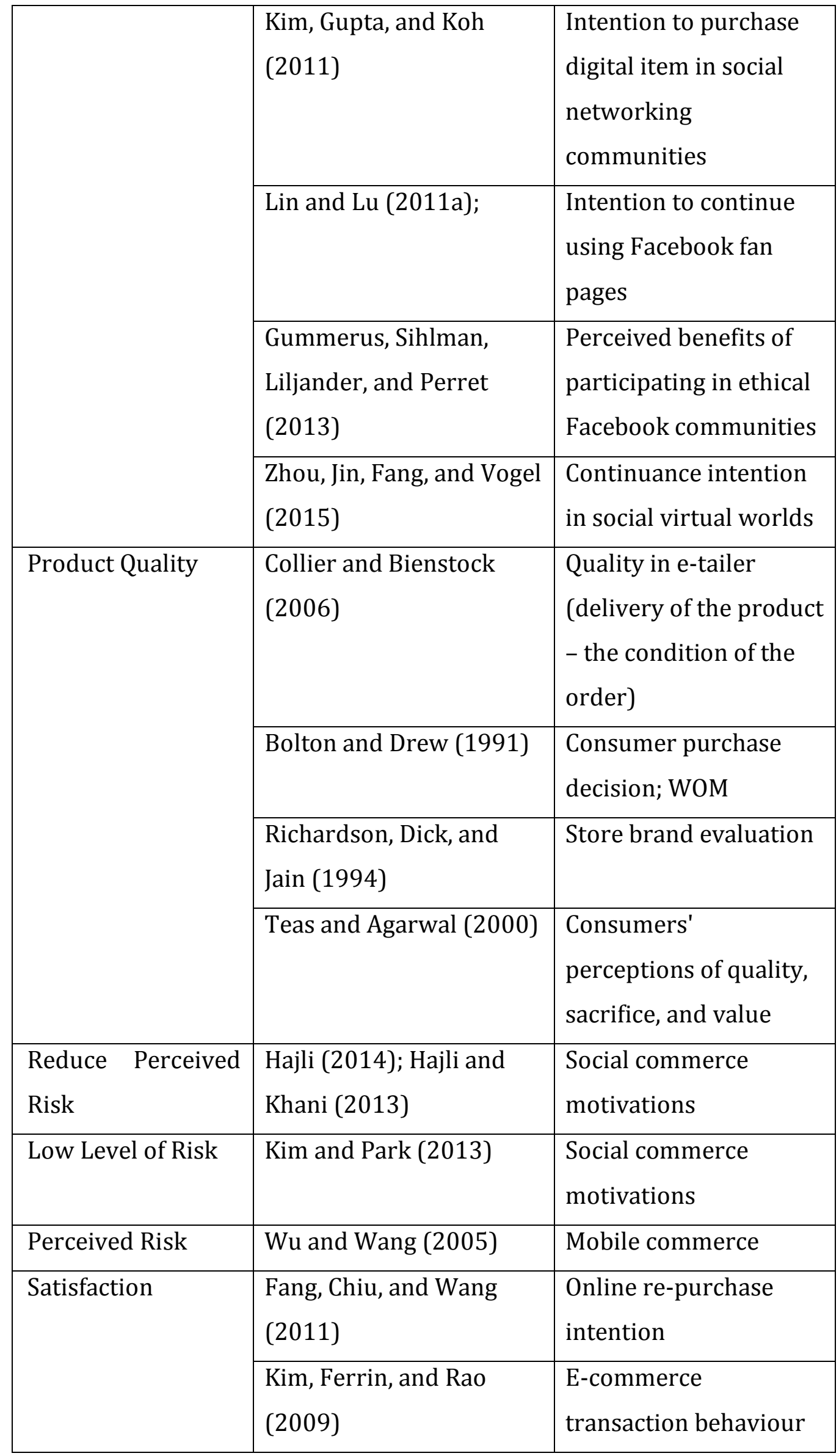




\begin{tabular}{|c|c|c|}
\hline Social Norms & $\begin{array}{l}\text { Boyd and Richerson } \\
\text { (2001); McAdams (1997) }\end{array}$ & Online community \\
\hline $\begin{array}{l}\text { Obligation to } \\
\text { Assess }\end{array}$ & $\begin{array}{l}\text { Woodruff and Flint } \\
\text { (2006) }\end{array}$ & Co-creation \\
\hline $\begin{array}{l}\text { Economics } \\
\text { Obligation }\end{array}$ & $\begin{array}{l}\text { Lundkvist and Yakhlef } \\
\text { (2004) }\end{array}$ & Co-creation \\
\hline \multirow[t]{2}{*}{ Loyalty } & $\begin{array}{l}\text { Baird and Parasnis } \\
\text { (2011a) }\end{array}$ & Social CRM \\
\hline & $\begin{array}{l}\text { Krishen, Trembath, and } \\
\text { Muthaly (2015) }\end{array}$ & Social Media Firm \\
\hline \multirow[t]{2}{*}{ E-loyalty } & $\begin{array}{l}\text { Srinivasan, Anderson, } \\
\text { and Ponnavolu (2002) }\end{array}$ & E-commerce \\
\hline & $\begin{array}{l}\text { Anderson and Srinivasan } \\
(2003)\end{array}$ & E-commerce \\
\hline Brand Loyalty & $\begin{array}{l}\text { Habibi, Laroche, and } \\
\text { Richard (2014) }\end{array}$ & Social media \\
\hline Status and Prestige & Rheingold (2000) & $\begin{array}{l}\text { Contribution to virtual } \\
\text { community }\end{array}$ \\
\hline Recognition & $\begin{array}{l}\text { Chan, Bhandar, Oh, and } \\
\text { Chan (2004) }\end{array}$ & $\begin{array}{l}\text { Virtual community } \\
\text { participation }\end{array}$ \\
\hline \multirow[t]{3}{*}{ Trust } & Kim and Park (2013) & $\begin{array}{l}\text { Social commerce } \\
\text { intention }\end{array}$ \\
\hline & Laroche et al. (2013) & Brand loyalty \\
\hline & Kim et al. (2009) & Trust in e-tailer \\
\hline $\begin{array}{l}\text { Familiarity and } \\
\text { Closeness }\end{array}$ & $\operatorname{Ng}(2013)$ & $\begin{array}{l}\text { Social commerce } \\
\text { intention }\end{array}$ \\
\hline \multirow[t]{3}{*}{ Social Support } & Hajli(2014) & $\begin{array}{l}\text { Social commerce } \\
\text { intention }\end{array}$ \\
\hline & Zhang et al. (2014) & $\begin{array}{l}\text { Social commerce } \\
\text { intention }\end{array}$ \\
\hline & Wang and Hajli (2014) & $\begin{array}{l}\text { Social commerce } \\
\text { intention }\end{array}$ \\
\hline
\end{tabular}




\begin{tabular}{|l|l|l|}
\hline \multirow{5}{*}{$\begin{array}{l}\text { Convenience } \\
\text { Perceived }\end{array}$} & $\begin{array}{l}\text { Liang et al. (2011) } \\
\text { Powli, Shanmugam, } \\
\text { intention }\end{array}$ & $\begin{array}{l}\text { Social commerce } \\
\text { intention }\end{array}$ \\
\cline { 2 - 3 } & $\begin{array}{l}\text { Ranganathan and } \\
\text { Ganapathy (2002) }\end{array}$ & $\begin{array}{l}\text { Efficiency of B2C e- } \\
\text { commerce website }\end{array}$ \\
\cline { 2 - 3 } & $\begin{array}{l}\text { Ozturk, Bilgihan, Nusair, } \\
\text { and Okumus (2016) }\end{array}$ & Mobile Hotel Booking \\
\cline { 2 - 3 } & $\begin{array}{l}\text { Okazaki and Mendez } \\
\text { (2013) }\end{array}$ & \begin{tabular}{l} 
Mobile commerce \\
\cline { 2 - 3 }
\end{tabular} \\
\cline { 2 - 3 } & $\begin{array}{l}\text { Jiang, Yang, and Jun } \\
\text { (2013) }\end{array}$ & $\begin{array}{l}\text { Consumer perceptions } \\
\text { of online shopping } \\
\text { convenience }\end{array}$ \\
\hline
\end{tabular}

Table 2.7: The motivations for online participations (social commerce activities, online purchasing, online communities etc.)

Table 2.7 has presented the motivational factors that are related to online participation which could be useful for this study. This includes the motivational factors for social commerce intention.

\subsubsection{Summary}

Section 2.6 has presented the gaps in social commerce studies which mostly represent the limitation of past studies to address the existence of various types of communities in social commerce practice. Various motivational factors have been found to describe the bloggers decision to adopt social commerce. Customers' behaviour towards social commerce however is likely different contexts or scope of studies is likely to represent different types of motivation. Therefore this study argues that although there are numerous studies on motivational factors, different types of community characteristics could draw different findings, particularly a community that has not originally been involved in commerce activities. 


\section{$2.7 \quad$ Research Questions}

This study found that there are important gaps needing to be explored. This is because these gaps could deliver some important findings to further develop the social commerce field as well as research on virtual communities.

Firstly, this study found that most research has explored the motivations to participate in social commerce for a community of customers, who mostly use a single platform for interaction or based on brand loyalty. This has left a gap in the social commerce domain where the understanding for a multiple platform community such as the blogosphere community is missing from the social commerce domain. In addition, most of the communities studied in previous research are customers' communities. This study argues that it is important to address the existence of a different types of social commerce implementation with different type of community settings. Therefore the motivation of the sellers and customers in this community need to be investigated.

Secondly, the Malay lifestyle blogging community operates in multiple social network platforms for both commercial and non-commercial activities. For some members in the community, the relationship has grown from being a relationship between bloggers and readers to being a sellers-customers relationship. As mentioned earlier in this chapter, commerce activities are associated with the concept of trust. Another gap is insufficient understanding of whether the trust the members have built based on their relationships in the community has any influence on their relationship as sellers and customers.

Thirdly, blogging in general has begun to attract scholarly attention. However personal bloggers, as well as lifestyle bloggers, are a category which have received less attention in academic studies (Brake, 2009; Cenite, Detenber, Koh, Lim, \& Soon, 2009; Hopkins, 2011). Nonetheless, according to Hopkins (2011), personal blogs and its related genre of lifestyle blog have attracted commercial interest. This is because of their capability to influence their readers. This study therefore argues that the relationship between the bloggers and the readers is worth investigating as it will deepen the understanding on how that 
relationship influences their participation as sellers-bloggers in commerce activities.

Considering these research gaps, this study aims to examine the main factors that influence non-brand community members to participate as sellers and buyers in social commerce.

In order to achieve the objectives, the following research questions need to be answered:

RQ1: What are the factors that motivate members of the Malay lifestyle blogging community to continue their participation in social commerce activities?

RQ1 (a): What are the factors that motivate sellers (bloggers) to venture into social commerce?

RQ1 (b): What are the factors that motivate customers (readers) to participate in social commerce?

RQ2: What is the relationship between the members' virtual community participation and their social commerce participation?

\subsection{Conclusion}

This chapter has highlighted the important topics related to the social commerce implementation which include the explanation of means-end theory that is used to frame the findings of this study. The discussion then focused on the lifestyle bloggers in Malaysia and the participation of the community in commerce activities, as well as how the social network theory and the SOVC related to this study. In addition past studies on the concept of trust, trust transfer theory and social support has also been described, followed by the explanation of social commerce concepts. This includes past studies on social commerce. Research gaps and research questions are also presented. The next chapter will describe the methodology used for this study. 


\section{CHAPTER 3}

\section{RESEARCH METHODOLOGY}

This section discusses the methodological perspective of the study. This research is conducted using the interpretive paradigm and a qualitative research methodology approach. This chapter also explains the selection of the case study research approach as a research strategy. The unit of analysis, case selection, case design, data collection and data analysis procedures are also discussed. Moreover, approaches taken to ensure the quality and rigor of the research and the role of researcher are also covered.

\subsection{The Research Paradigms}

"All research is based on some underlying assumptions about what constitutes valid research and which research methods are appropriate (Myers, 1997)".

The philosophical assumptions made by researchers regarding knowledge claims are referred to as the research paradigm or world view of the research. Creswell and Clark (2007) argue that the research paradigm is important as all research needs a foundation for its inquiry and inquirers need to be aware of implicit world views they bring to their studies. There are divergent philosophical concepts within IS research, which will be explained in the next sub-section.

\subsubsection{Philosophical Paradigm and IS Research}

Philosophical paradigms or epistemology refers to issues concerned with the question of what is or what should be regarded as more acceptable ways of obtaining knowledge or rules for knowing and how it can be obtained (Bryman, 2012; Myers, 1997; O'Leary, 2009). Orlikowski and Baroudi (1991) claim that there are three categories of epistemology that are philosophically distinct as ideal types. 
The first epistemology is the positivism paradigm. The positivist world view, which is most commonly held in science believes that the only authentic knowledge is based on sense, experience and positive verification. It was proposed by August Comte (1798-1857) who claims that experience is the foundation of knowledge. Positivist research assumes that only phenomena and hence knowledge confirmed by the senses can genuinely be warranted as knowledge. Positivist research attempts to test theory in order to understand phenomena (Myers, 1997). The purpose of theory is to generate hypotheses that can be tested and that will thereby enable explanations of laws.

The second epistemology is the interpretivism paradigm. For interpretive views, the knowledge that researchers gain from empirical research must be interpreted in terms of social mechanisms operating at the time. These enable the social scientist to grasp the subjective meaning of social action (Bryman, 2012). Interpretivists believe that reality and researcher cannot be separated, as social construction (such as language, culture and value) influences peoples' understanding of reality, and research can be carried out without having to predefine dependent and independent variables (Kaplan \& Maxwell, 2005).

The third paradigm listed by Orlikowski and Baroudi (1991) is about critical theorist. In critical research, the researchers assume that social reality is historically constituted and that it is produced and reproduced by people (Myers, 1997). The main goal of critical research is to expose inequities and conflict in society. Critical researchers investigate social systems with the idea of improving the systems and moving towards a more enlightened society.

As stated earlier, epistemology is important because it is fundamental to how we think. According to Anastas (2002), the epistemology will affect what kind of research will be conducted, thus it is vital for a researcher to determine their epistemology. The epistemology for this research will be discussed next. 


\subsubsection{Philosophical Approach for the Study}

The world view or epistemology for this study is interpretive or social construction. As stated by Walsham (1993), interpretive methods of research start from the researchers' basic knowledge of reality. Therefore, in contrast to the positivism paradigm, interpretive researchers believe that there is no objective reality which can be discovered by researchers and replicated by others. This is because there is a need for a better understanding through exploration of embedded meanings from the participants' interpretations. Thus, the study attempts to identify why the blogosphere community participates in social commerce from the participants' point of view. The data gathered from the community in this research were the participants' constructions of what they and their communities were doing. Thus, the interpretive stance was selected as the most appropriate for this research.

\subsection{Research Strategy}

This research used the qualitative approach to answer the research questions. According to Myers (1997), the qualitative research approach was developed in the social sciences to enable researchers to study social and cultural phenomena. It is conducted through intense and/or prolonged contact within a field or a situation, which reflects the everyday life of individuals, groups, societies, and organizations. The main purpose of qualitative research is not to generalize the findings, but to explore a unique interpretation of events (Merriam, 1988). This research explores an understudied area, the participation of the lifestyle bloggers from the Malaysian blogosphere community in social commerce; hence qualitative being the most appropriate strategy for this study.

\subsubsection{Case Study Research}

There are various qualitative research methods, such as action research, case study research, ethnography and grounded theory. Case study research was 
selected as the most suitable for this research. The following is a definition of case study research by Yin (2008), the most cited author in the area:

An empirical inquiry about a contemporary phenomenon, set within its realworld context - especially when the boundaries between the phenomenon and context are not clearly evident (Yin, 2008, Pg. 18).

Case study research can also be used for both interpretive and positivist study. As stated in Section 3.1.2, for this study, case study research is conducted with interpretive approach. The rational of choosing case study research to conduct the study, will be discussed next.

Firstly, case study research is relevant when the research questions are either in descriptive (What?) or exploratory (How? Why?) forms (Yin, 2013). Using case study research will help the researcher to understand the nature and complexity of processes taking place, as well as being an appropriate way to research an area in which few studies have been carried out. Bryman (2012) argues that case study research is suitable when there is little prior knowledge of what the variables of interest will be and how they will be measured. Thus, based on the literature, there is evidence of a lack of research focusing on both sellers and customers participating in the same virtual communities, making this topic suitable to be conducted using case study research. Furthermore the unique setting of the blogosphere community is quite complicated as it started from a community of bloggers and their readers and only over time did they started on commercial activities.

Secondly, case study research strategy is also suitable for the exploration. Yin (2009) claims that case study research methodology is useful when investigating in-depth contemporary phenomena and within a real-life context, especially when the boundaries between the phenomena and the context are not clearly evident. This is also supported in an earlier study by Benbasat, Goldstein, and Mead (1987) who stated that one of the characteristics of case study research is the focus on contemporary events. 
The study explores the concept of social commerce and social media, which is currently an emerging trend. Interest in this topic has risen recently due to many stimulating gaps that have yet to be filled by IS researchers. There is a need to investigate the phenomenon deeply in order to develop new knowledge of the chosen community.

Thirdly, the phenomenon of social commerce was examined in a natural setting and no experimental controls or manipulation was involved, which is one of the key characteristics of case study research (Benbasat et al., 1987; Yin, 2008). This is because the researcher using the case study approach develops the study based on a real life setting.

Finally, the study is also considered as broad and complex, which is another characteristic of case study research (Benbasat et al., 1987). The justifications for this view are as follows:

\section{i. From Blogosphere Community to Social Commerce}

This community starts with the interactions between the lifestyle bloggers community and their readers. After a few years, they started to sell products and services to the other members, changing the nature of the community. Nonetheless, they still continued with the blogosphere activities such as knowledge sharing, asking for opinion, discussion on certain topics and so on. This phenomenon is complicated as the members relationships with each other are not only as blogger-readers but they are also connected in a sellercustomer relationship. There are some concerns about this type of community, which includes (i) no single shared space (no single platform for interaction), and (ii) lack of clear boundaries or membership (Efimova \& Hendrick, 2005) which make it complex. The nature of the blogosphere community makes it suitable for the case study approach whereby the boundaries can be defined by grouping the cases under certain characteristics which will be explained in Section 3.3.1. 


\section{ii. Has Various Implementation Models}

There are a few different models in implementing social commerce by the businesses in general which indicates that this area of study is very broad. In this community, sellers used non standardized implementation. Each may use a different method of communication, trading, payment and delivery, leading to a broad range of practices and different ways for customers to interact with the sellers and other customers. Different implementation will eventually create different opportunities and threats which create complexity for the scope of this study.

\section{iii. Uses Different Web 2.0 Platforms}

There are various Web 2.0 platforms which can be utilised in the blogosphere community setting as well as their commerce activities' setting. For example, members are using one or more social media platform to communicate as well as selling their products. Different platforms are likely to impact the communication between social commerce community members in different ways.

\subsubsection{Case Design: Single Case Design}

Case study research can be implemented by selecting a single case or multiple cases. Deciding between single and multiple-case design is a primary distinction in designing case study research (Yin, 2003). According to Yin, single case design is most appropriate for testing a critical case in a well-formulated theory or in an extreme/unique case, when documenting the precise nature of a phenomenon is not well understood. It is also suitable for a representative case, if the researcher wants to capture the conditions of a commonplace situation. Revelatory cases (previously non-accessible phenomenon) and longitudinal cases are also suitable for the single case approach.

Multiple case design on the other hand, is suitable for replication logic. The cases must be carefully selected. According to Yin (2003), multiple-case 
design is meant to predict similar results (literal replication) or predict contrasting results, but for predictable reasons (a theoretical replication).

The previous discussion on single and multiple case designs indicates that the choice of a single case study is more compelling for this study as it allows the exploration of representative cases, which specifically focus on the blogosphere community. Willis (2014) argues that the various forms of single case study analysis can provide a nuanced, empirically-rich, holistic account of specific phenomena, which explains a specific phenomenon in the chosen community, where the activities progress from knowledge sharing related activities to commerce activities. The argument made by Willis (2014) is supported with a claim from Yin (2013) that generalization is not an issue for single case study as it does not represent a specific sample, but a theoretical proposition. The characteristics of this community fall nicely under the category mentioned by Yin (2013). Due to the unique characteristics of this community, the study will not use it as a representation of other communities that participate in social commerce.

\subsubsection{The Unit of Analysis}

The unit of analysis is related to the fundamental problem of defining what the case is all about. It can be an individual, group, or organization. This research focuses on the community as the unit analysis. The cases of analysis are the blogosphere community members who are involved in social commerce. 


\subsection{Research Design and Data Collection Procedure}

The research was conducted following the design as below:-

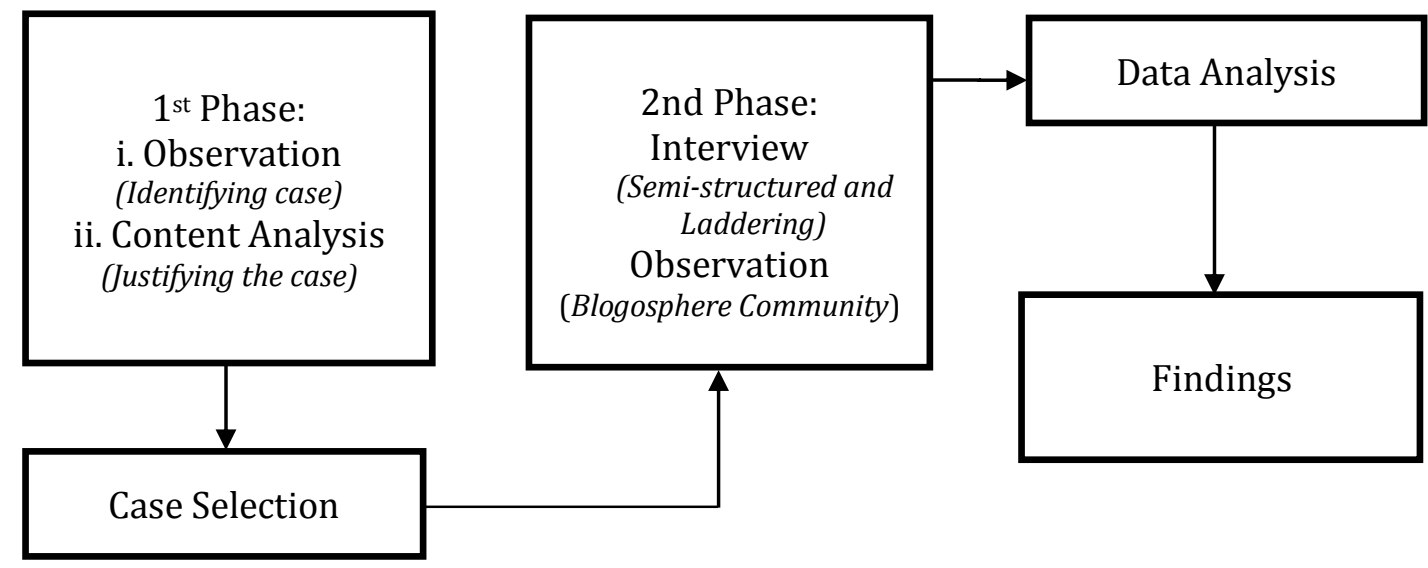

Figure 3.1: Research design process

The data collection procedures, which includes two different phases as explained in the following table:

\begin{tabular}{|l|l|l|}
\hline Phase & Phase one & Phase two \\
\hline Objective & Selection of case & Data Collection \\
\hline Method & Observation (Identifying & In-depth interview \\
& case); Content Analysis & (Laddering and semi- \\
& (Justifying the case) & Structured interviews ); \\
& & Observation \\
\hline
\end{tabular}

Table 3.1: Data collection procedures

\subsubsection{Phase One}

The objective of phase one is to select a suitable case for this research. Case selection is an important aspect of case study research. Purposive sampling which focuses on particular characteristics of the population that are of interest, was used for the selection of a case. Purposive sampling is 
characterised by the use of judgement and a deliberate effort to include presumably typical groups in the sample (Klinger, 1986).

The sampling process for the study will be explained next. The following diagram (refer to Figure 3.2) illustrates the sampling process.

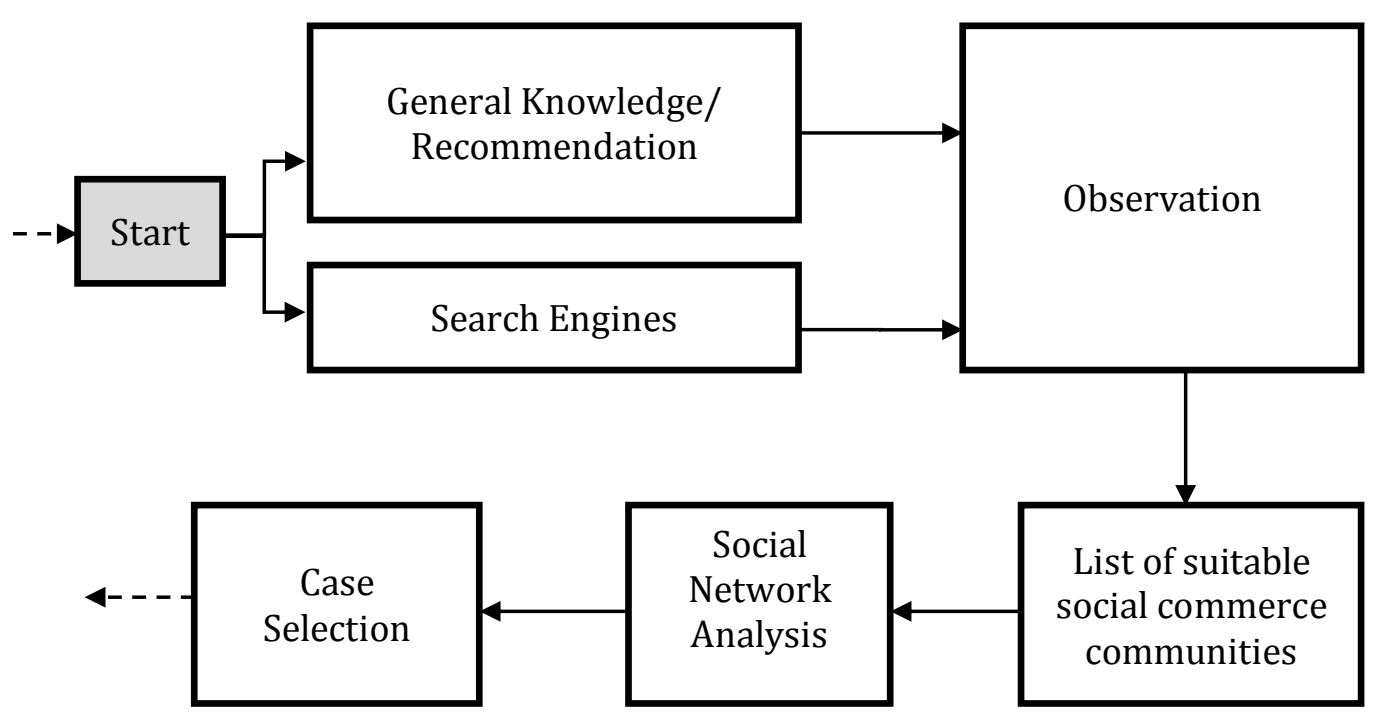

Figure 3.2: Selection of case process

The first was based on the preliminary observation. Observation was conducted for the purpose of identifying suitable communities, which will be discussed next.

\subsubsection{Observation}

Observation has been conducted to provide information about the social commerce activities of potential businesses. At this stage, the information was only to be used to identify the suitable community and businesses. For the first phase, only the interactions in social media group/pages that were open to public were chosen for observation. This was to ensure that there would be no ethical issues regarding the observation process.

As mentioned before, purposive sampling was used to identify a potential virtual community. Since a list of all social commerce communities was not available and the population was not known, the sampling procedure 
started with the compilation of potential virtual communities available on the internet, particularly in the Malaysian environment.

The list was compiled using two methods. Firstly, the search for suitable communities was based on general knowledge of the social commerce activity in Malaysia. Recommendations from prominent persons who are involved in social commerce businesses were also taken into consideration. Secondly, search engines were also used to get a list of social commerce sites. Several keywords based on products and services were used to capture the sites. For example "Virtual community + Malaysia"; "Community in Malaysia"; "Community Malaysia Forum"; "Malaysia forum online community" and so on. Search engines that were used in this process are Google, Bing and Yahoo, which are among the top search engines on the Internet. This process was done in the 2 months from September to November 2013. Upon completion of the search, the public communications between members in the virtual communities were observed to identify those communities integrated with social commerce elements.

The list of sites was studied in order to choose a suitable case. The researcher observed related activities carried out within the community in order to select a suitable virtual community that participated in commerce activities on top of the non-commerce activities, as well as to set the boundaries for this research. The observation covered the following aspect in order to identify:

i. Characteristics of the virtual communities (i.e. Pattern of interaction (Porter, 2004); fluid communication - different degree of virtualness, sometimes facilitated via face-to-face encounter (Wilson \& Peterson, 2002));

ii. The members and their level of participations (Blanchard \& Markus, 2004); level of sense of virtual community (Koh \& Kim, 2003);

iii. Commerce-related activities in the community; and

iv. Social commerce constructs (Hajli, 2015). 
In addition, as purposive sampling was being used as a sampling technique, the final selection for investigation was also based on the objective of the research and the judgement of the researcher. The selection was conducted based on the discussion between the researcher and supervisors, taking into consideration the gap found in the literature review. Previous studies have shown that most of the studies conducted on virtual communities were directed either to the communities of commerce or brand communities. Therefore this study found that the most suitable community for this research was the sub-group of Malaysia blogosphere community which is the Malay lifestyle blogging community consisting of both bloggers and readers. The uniqueness of this community as compared to the rest of communities listed in the observation is that it started with sharing their lifestyle to their readers and then after a few years they started to participate in commerce activities.

There were debates amongst researchers on whether the blogosphere could be considered as a virtual community (Blanchard, 2004). Therefore the next stage of phase one will explain how the Malay lifestyle blog community is in fact a virtual community.

\subsubsection{Content Analysis (Justifying the Case)}

There is growing evidence of social structures evolving around blogs and how these social structures influence norms and practices of blogging (Efimova \& Hendrick, 2005). Wei (2004) claims that normally blog communities are developed based on similar interests and it can form around numerous themes with its own practices and behaviours. This is supported by Blanchard (2004) who claims that blogs have the potential to evolve into socially beneficial, self-sustaining virtual communities. Nonetheless, there are some concerns about this type of community, which include (i) no shared space, and (ii) lack of clear boundaries or membership (Efimova \& Hendrick, 2005). It leads to researchers facing 
very specific problems: where to start looking for a weblog community and which indicators to look for.

Blanchard and Markus (2004) suggest that a blogosphere can be defined as a virtual community if it has the characteristics of virtual settlement. A virtual settlement is a virtual place where people interact while examining artefacts (Chin \& Chignell, 2007). Jones (1997) suggests studying a community through artefacts of its virtual settlement and proposes a set of conditions to explain it: (i) a minimum level of interactivity, (ii) a variety of communicators, and (iii) a virtual common-public-space where a significant portion of community interactions occur, and (iv) a minimum level of sustained stable membership. Those conditions presuppose that there is a cyber-space with some kind of group interaction that is studied to identify if there is a community there.

However, in the case of blog communities it is usually difficult to find a single shared space as a place for a member to interact with other members. Efimova and Hendrick (2005) and Merelo-Guervos et al. (2003) suggest an alternative approach for blog communities. They claim that in order to identify the virtual community in blogosphere, weak clues indicating the likelihood of a community presence and assumptions about norms and practices in it can be used as a starting point.

Figure 3.3 shows the alternative approach suggested by Efimova and Hendrick (2005). The starting point for identification is to indicate the likelihood of a community presence and assumptions about norms and practices in the community. 


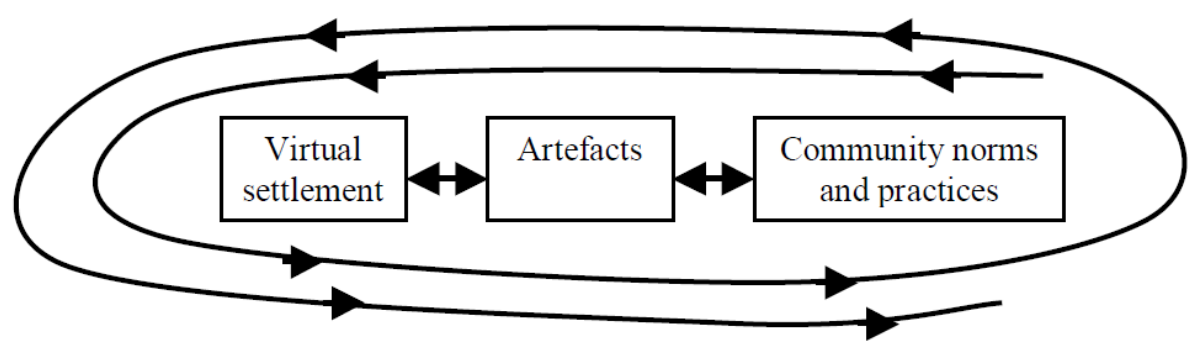

Figure 3.3: Approach to identifying blog communities (adapted from Efimova and Hendrick (2005))

Efimova and Hendrick (2005) suggest that the following artefacts can be used as indicators of a weblog community existence (i) meme paths, (ii) blogs reading pattern/ linking pattern, (iii) weblog conversations, (iv) Indicators of events, and (v) "Tribe" marks, group spaces and blogger directories. The observation based on the indicators were done from December 2013 to February 2014.

\section{a. Meme paths}

Meme paths suggest the identification of influential blogger as a starting point for analysis to then find mapping paths leading to other blogs in order to identify the social structures behind them. This study has chosen a lifestyle blogger who is very influential in this community. Hanis Zalikha started her blog in 2008. She was listed amongst the Top 10 Fastest Rising People in Google Malaysia Top Searches in 2010, according to annual trend analysis by Google Zeitgeist. In addition, her blog was also listed in InTrend fashion and lifestyle magazine as one of the Top 50 Malaysian Best Blogs 2010. She was also nominated in Nuffnang Asia-Pacific Blog Awards for Best Celebrity Blog category and was shortlisted as a finalist. She has appeared in media and has 45784 (as of December 2013) followers. This places her as one of the most influential bloggers in Malaysia. Hanis's blog falls under the category of lifestyle blogs which is the target community for this research, therefore it was chosen to be the starting point for the content analysis 
in order to identify the social structure behind the lifestyle bloggers group.

\section{b. Blogs reading pattern/Linking pattern}

These artefacts identify the reading list (e.g. blogrolls and RSS subscriptions) and the relation between reading lists for a group of people, as well as identifying connections between blogs. This is because regular reading of blogs and then linking to other blogs are the starting point for establishing or maintaining the relationship in blogosphere. Links help to identify connections between blogs. This argument is supported by Merelo-Guervos et al. (2003) and Herring et al. (2005).

From Hanis's blog, more than 50 links to other lifestyle bloggers were found. The first 20 blogs were taken as a sample. For each blog, 10 random links were taken to be analysed using NodeXL. NodeXL is an open source software that can be used to analyse the connection in social media.

The following table (refer to Table 3.2) lists all the links associated with the 20 blog links taken from Hanis's list. The list was uploaded into the NodeXL template downloaded from nodexl.codeplex.com in order to identify the linking pattern.

\begin{tabular}{|c|c|c|c|c|}
\hline Blogger A & Blogger B & Blogger C & Blogger D & Blogger E \\
\hline Ladynoe & Diana & Ceera & Peej & Ceera \\
Proudduck & Peej & Neena & Choyaya & Jemah \\
Amyz & Tina & Proudduck & Proudduck & Peej \\
Cikdaun & Ceera & Akma & Imyours & Filla \\
Filla & Pinkstel & Elly & SH & Elly \\
Pinkstel & Tijah & Peej & Jemah & Shila \\
Pipi & Elly & Choyaya & Pinkstel & Budu \\
Ayin & Filla & Sepet & Sepet & Qery \\
\hline
\end{tabular}




\begin{tabular}{|c|c|c|c|c|}
\hline $\begin{array}{l}\text { Tina } \\
\text { Naga }\end{array}$ & $\begin{array}{c}\text { Ladynoe } \\
\text { Neena }\end{array}$ & $\begin{array}{l}\text { Idayu } \\
\text { Babies }\end{array}$ & $\begin{array}{l}\text { Nani } \\
\text { Filla }\end{array}$ & $\begin{array}{l}\text { Hanis } \\
\text { Moon }\end{array}$ \\
\hline Blogger F & Blogger G & Blogger $\mathrm{H}$ & Blogger I & Blogger J \\
\hline Forty & Peej & Akiss & Hanis & Hanis \\
\hline Maria & Filla & Liyana & Liyana & Filla \\
\hline Ladynoe & Elly & Cikdaun & Moon & Elly \\
\hline Life & Moon & Nani & Peej & Peej \\
\hline $\mathrm{Pg}$ & FatinLiyana & Peej & Tijah & Nani \\
\hline izyahya & Diana & Filla & Puisi & Jemah \\
\hline Xiaxue & Alia & Ladynoe & Ahmad & Jumi \\
\hline Pipi & Safiyyah & gadis & Budu & Proudduck \\
\hline Nani & Illy Arifin & FTM & Pipi & Moon \\
\hline Drive & Yuyu & XS2 & Filla & Kathyjem \\
\hline Blogger K & Blogger L & Blogger M & Blogger N & Blogger 0 \\
\hline Ikamadera & Amyz & Peej & Ladynoe & Peej \\
\hline Cikdaun & Ikamadera & Ceera & Chics & Hanis \\
\hline Ahsue & Ahsue & Sepet & $\mathrm{SH}$ & Supermom \\
\hline Pnut & Pinkstel & Filla & Proudduck & Ceera \\
\hline Jemah & Budu & Elly & Tina & Elly \\
\hline Sepet & Pnut & Bidan & Moon & Filla \\
\hline Ceera & Naga & Tijah & Akiss & Proudduck \\
\hline Diana & Tokrimau & Blogserius & Elly & Pinkstel \\
\hline Nina & Hanis & Proudduck & Ceera & Chics \\
\hline Syazwani & Proudduck & PinkStel & Maria & Sepet \\
\hline Blogger $\mathbf{P}$ & Blogger Q & Blogger $\mathrm{R}$ & Blogger S & Blogger T \\
\hline Sepet & Filla & Rambling & Moon & Ikamadera \\
\hline Jemah & Proudduck & Emiyusuf & Naga & Cikdaun \\
\hline Filla & Peej & curmalay & Tokrimau & Ahsue \\
\hline Peej & Jujue & Hanis & Ladynoe & Amyz \\
\hline Elly & Choyaya & Gadis & Hanis & Hanis \\
\hline PinkStel & Jemah & Pipi & Curmalay & Peej \\
\hline Fatin & Sepet & Smallkitchen & FTM & Pipi \\
\hline
\end{tabular}




\begin{tabular}{|c|c|c|c|c|}
\hline Kathyjem & Moon & Imyours & Op & Naga \\
Cikepal & Irfa & Tijah & Fatin & Tokrimau \\
Moon & Leo & Ceera & Kumprix & Op \\
\hline
\end{tabular}

Table 3.2: Link lists for 20 lifestyle bloggers (Retrieved on 23 September 2013)

The following diagram shows the linking pattern generated by NodeXL, with each dot representing a blogger:

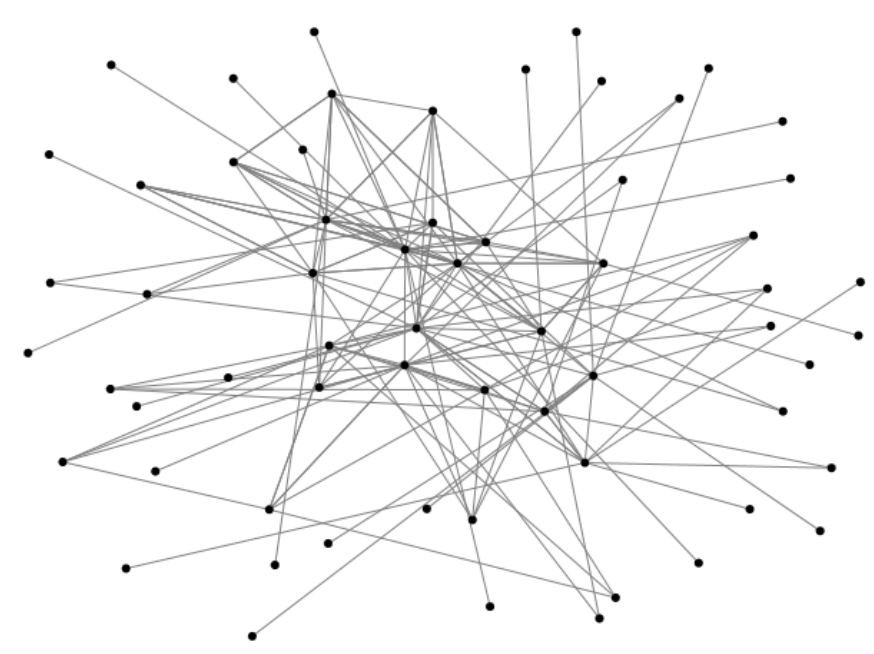

Figure 3.4: Linking pattern

The diagram shows that most of the bloggers are connected to each other, which indicates that the bloggers are likely to have a relationship with other bloggers.

In addition to the analysis done by using NodeXL, a manual crossimpact analysis was done in order to show the cross analysis of interconnectedness between bloggers and other bloggers in the community. Note that the data set is the same 20 bloggers chosen for the NodeXL analysis (refer to Table 3.2).

Both NodeXL analysis and cross analysis (refer to Table 3.3) show that the bloggers share the same regular reading which indicates the likelihood of them having a relationship in the blogosphere. 


\begin{tabular}{|c|c|c|c|c|c|c|c|c|c|c|c|c|c|c|c|c|c|c|c|c|}
\hline & $\mathrm{A}$ & B & $\mathrm{C}$ & D & $\mathrm{E}$ & $F$ & $\mathrm{G}$ & $\mathrm{H}$ & I & $\mathrm{J}$ & $\mathrm{K}$ & $\mathrm{L}$ & $\mathrm{M}$ & $\mathrm{N}$ & 0 & $\mathrm{P}$ & $\mathrm{Q}$ & $\mathrm{R}$ & $S$ & $\mathrm{~T}$ \\
\hline $\mathrm{A}$ & & & $\mathrm{x}$ & & & & & & & & $\mathrm{x}$ & $\mathrm{x}$ & & & & & & $\mathrm{x}$ & $x$ & \\
\hline B & & & $x$ & & & & & & & $\mathrm{x}$ & & & & $\mathrm{x}$ & & $x$ & $\mathrm{x}$ & $\mathrm{x}$ & & \\
\hline $\mathrm{C}$ & & & & & $x$ & & $x$ & & & & & & & $\mathrm{x}$ & & $x$ & $\mathrm{x}$ & & & \\
\hline $\mathrm{D}$ & & & $\mathrm{x}$ & & $\mathrm{x}$ & & $\mathrm{X}$ & & $\mathrm{x}$ & & & & $\mathrm{x}$ & $\mathrm{x}$ & & & & & & \\
\hline$E$ & & & $\mathrm{x}$ & $x$ & & & & & & & & & $x$ & $x$ & & $x$ & $\mathrm{x}$ & & & \\
\hline $\mathrm{F}$ & & & & & & & & & $\mathrm{x}$ & & & & & & & & & $\mathrm{x}$ & $\mathrm{x}$ & \\
\hline $\mathrm{G}$ & & & $\mathrm{x}$ & $\mathrm{x}$ & & & & & & & & & & $\mathrm{x}$ & & & $\mathrm{x}$ & & & \\
\hline $\mathrm{H}$ & & & $\mathrm{x}$ & & & $\mathrm{x}$ & & & $\mathrm{X}$ & & & $\mathrm{x}$ & & $x$ & & & & $\mathrm{x}$ & & \\
\hline I & & & $x$ & $\mathrm{x}$ & & & & & & $\mathrm{x}$ & & & & $\mathrm{x}$ & & & & & $x$ & \\
\hline $\mathrm{J}$ & & & $x$ & $\mathrm{x}$ & & & & & $\mathrm{x}$ & & & & $\mathrm{x}$ & $\mathrm{x}$ & & & $\mathrm{x}$ & & & \\
\hline $\mathrm{K}$ & $\mathrm{x}$ & & & & $\mathrm{x}$ & & & & & & & $x$ & $x$ & & & $\mathrm{x}$ & & & & $\mathrm{x}$ \\
\hline $\mathrm{L}$ & $x$ & & & & & & & & & & $\mathrm{x}$ & & & & & & & & & $\mathrm{x}$ \\
\hline $\mathrm{M}$ & & & $\mathrm{x}$ & & $\mathrm{x}$ & & & & & $\mathrm{x}$ & & & & $\mathrm{x}$ & & $\mathrm{x}$ & $\mathrm{x}$ & & & \\
\hline $\mathrm{N}$ & & $x$ & & $\mathrm{x}$ & & $\mathrm{x}$ & & & & & & & & & & $\mathrm{x}$ & $\mathrm{x}$ & & & \\
\hline 0 & & $x$ & $\mathrm{x}$ & & $\mathrm{x}$ & & & & & & & & & & & $x$ & $\mathrm{x}$ & & & \\
\hline $\mathrm{P}$ & & & $\mathrm{x}$ & $\mathrm{x}$ & $\mathrm{x}$ & & & & & & & & $x$ & $\mathrm{x}$ & $\mathrm{x}$ & & & & & \\
\hline$Q$ & & & $x$ & $x$ & $x$ & & $x$ & & & & & & X & $\mathrm{X}$ & & & & & & \\
\hline $\mathrm{R}$ & & & & & & & & & & $\mathrm{x}$ & & & & & & $x$ & & & $\mathrm{x}$ & \\
\hline$S$ & & & & & & & & & & & & & & & & $x$ & & $\mathrm{X}$ & & \\
\hline $\mathrm{T}$ & & & & & & & & & & & $x$ & $x$ & & $\mathrm{X}$ & & & & & $\mathrm{x}$ & \\
\hline
\end{tabular}

Table 3.3: Cross analysis of interconnectedness between bloggers

\section{c. Weblog conversations}

According to Herring et al. (2005), weblog conversations could be a strong indicator of a shared context and the system of relations that enables it. Therefore there is a need to observe the conversation between the bloggers.

It was found that the conversation between the bloggers and their readers (who may or may not be a blogger) includes the following:

i. Comments on blog - discussion or feedback of the blog post.

ii. Email and smart phone texting applications - some bloggers published the screen shots of their private conversation with their readers on their blogs or social media accounts to (i) share 
the opinion of their readers or generate discussions on certain issues, (ii) to spread information, and (iii) seek opinions.

iii. Social media accounts - Facebook status, comments on Instagram or conversations via Twitter, including private messages.

Based on the findings, it shows that the bloggers were having active conversations with some of the readers. It shows that readers would also respond to each other's comments. Some of them continued the conversation on their personal space, leaving a link for those interested to join the conversation. In addition, there were also remarks from the bloggers saying that they were honoured by the support shown by the community of bloggers as most of them were very helpful when any of them were in need.

Some of the bloggers acknowledged their loyal readers who could also be loyal readers of other blogger. This evident from the screen names they used, where it shows that the readers are from the same circle of followers. The conversations show that the readers know most of the bloggers and vice versa.

\section{d. Indicators of events}

Indicators of events are seeking for any mention of face-to-face meetings or participation in online events. It can be used to indicate existing relations between bloggers. Based on the observation, it was found that some of the bloggers had organized face-to-face meetings with other bloggers (or readers). The meetings included:

i. Bloggers meet-ups - advertised events, sponsored events, personal events - wedding/birthday party, annual gathering.

ii. Impromptu meet-ups when they visited others' hometowns (vacation/outstation).

In addition they also participated in online events such as group discussions, offering help and support when needed (e.g. personal 
shopper etc.) The evidence shows that the bloggers are likely to have a close relationship with each other.

\section{e. "Tribe" marks, group spaces and blogger directories}

The tribe marks, group spaces and blogger directories, may display indicators of belonging to a particular community. It has been observed that the bloggers know each other and use their personal space to accommodate their discussions. Those who have the same interest develop sub groups based on their interests. They may join one or more sub-groups within the lifestyle blogosphere community. Some examples of the sub-groups are:

i. Groups of writers (e.g.: Sindiket Soljah) - gather those who have a talent to write, to sell indie books online.

ii. Parenting theme - discussion on topics like cloth diapers vs disposable diapers, pro-vaccine vs anti-vaccine, breastfeeding etc.

\section{f. Conclusion}

As a conclusion, based on all indicators and the observations made of this community, this study has concluded that the Malay lifestyle blogs community falls under the virtual community category. The analysis done at this stage has proven that the blogosphere community has the characteristics of virtual settlement which is a cross-platform via the personal page of each blogger. This community can be defined as a virtual community as it has the characteristics of virtual settlement.

To support the findings, literature search on this group of bloggers has been conducted. Cranefield (2009) argues that in blog-based communities, discussions are neither bounded nor facilitated, but instead are distributed amongst the blogs of members who employ practices such as tagging, RSS feeding and social bookmarking, to monitor the conversation. The argument is in line with what was found 
in this community. Tagging, RSS feeding, and social bookmarking have been used widely in this community which update them with any new replies in their conversations. In addition, Ahmad (2011) in his study on the Malaysian blogosphere considers the blogosphere a virtual community, based on the interview data he gathered from bloggers in Malaysia, which includes the lifestyle bloggers. This shows that the researcher has acknowledged the blogosphere to be defined as a virtual community.

Based on the indicators and literature, this study suggests that the lifestyle blogs community is a virtual community. Although the boundaries of the lifestyle bloggers community can't be define clearly like the typical virtual community, the indicators show that they have a stable enough core to be considered a virtual community.

\subsubsection{Phase Two}

After the selection of the case, phase two data collection was conducted. The objective of the data collection in phase two was to address the research objectives and answer the research question. The following diagram (refer to Figure 3.5) illustrates the phase two process.

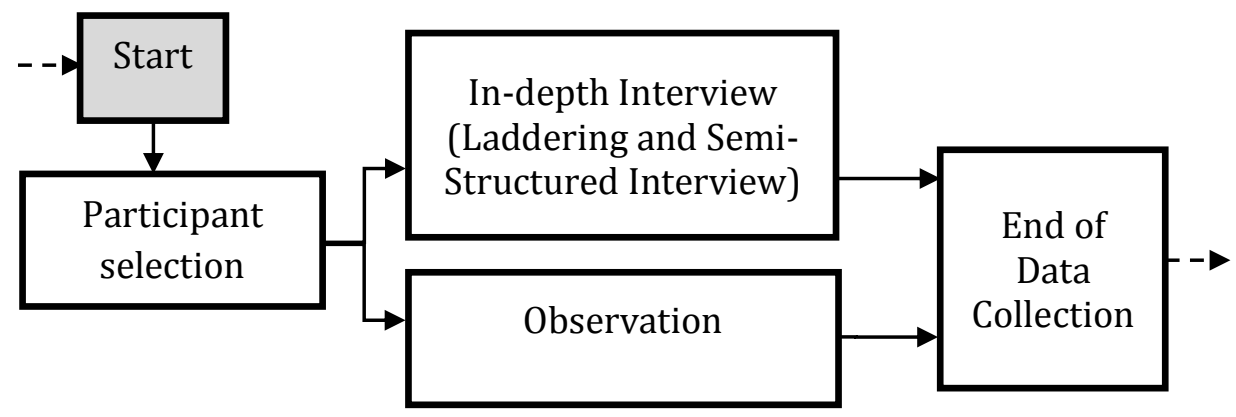

Figure 3.5: Phase two data collection process 


\subsubsection{Participant Selection}

The lifestyle blog community consists of the bloggers and their readers. The readers may or may not be bloggers. Note that not all members in this community participate in the commerce activities. Therefore, there is a need to classify the members to ensure that the members that were chosen have experience with social commerce activities in the community.

There were a few steps taken in order to select suitable participants. To select sellers, the basic criteria used were as follows:

i. Experienced bloggers (more than 3 years of blogging).

ii. More than 1000 followers in any of their social media accounts (not restricted to blog).

iii. Communicates frequently with the readers via blog or any social media platforms.

iv. Selling products using blog and other social media.

For the customers, the following criteria were used:

i. Follows/reads lifestyle blogs.

ii. Communicates with bloggers and other members.

iii. Has experience purchasing from bloggers.

An email was sent to potential participants in order to get their agreement to participate. The emails included some information about the research (refer to Appendix A).

Sellers were identified from the observation explained in Section 3.3.1.2. In addition, suggestions by customers and snowballing techniques were also used. Meanwhile for the selection of customers, bloggers in the community were asked to help the researcher by publishing the advertisement about the research to community members in their circle. 
The content of the advertisement included information about the research and the characteristics of customers that were needed in this research.

Sellers were also asked to nominate anyone in their circle that fitted the characteristics given in the advertisement. Other than that, snowballing technique was also used to identify the participants. Confirmed participants were asked to suggest other potential participants, whether sellers or customers. Potential participants were also chosen based on the observation in the public space of sellers' Facebook pages and were approached personally by the researcher.

A total number of 20 sellers and 21 customers from the community were interviewed for phase two. The interviews took around 45 minutes to one hour. The following are the demographic backgrounds of the participants:

\begin{tabular}{|c|c|c|c|c|c|c|c|}
\hline Category & $\mathbf{N}$ & Gender & Race & \multicolumn{2}{|c|}{ Age } & \multicolumn{2}{|c|}{$\begin{array}{l}\text { Experience in } \\
\text { the community }\end{array}$} \\
\hline Sellers & 20 & Female & Malay & $\begin{array}{l}25-34 \\
35-44 \\
>44\end{array}$ & $\begin{array}{l}=14 \\
=5 \\
=1\end{array}$ & $\begin{array}{l}\text { 5-7 years } \\
\text { 8-10 years } \\
>10 \text { years }\end{array}$ & $\begin{array}{l}=6 \\
=6 \\
=8\end{array}$ \\
\hline Customers & 21 & Female & Malay & $\begin{array}{l}25-34 \\
35-44\end{array}$ & $\begin{array}{l}=11 \\
=10\end{array}$ & $\begin{array}{l}\text { 3-4 years } \\
\text { 5-7 years } \\
\text { 8-10 years } \\
>10 \text { years }\end{array}$ & $\begin{array}{l}=6 \\
=9 \\
=4 \\
=2\end{array}$ \\
\hline
\end{tabular}

Table 3.4: Demographic data for the participants

Refer to Appendix B and C for the products of the sellers and purchasing history of buyers.

\subsubsection{In-Depth Interview}

This research has gathered data using in-depth, open-ended interviews, which consist of laddering and semi-structured interviews. Data collection was conducted over 5-6 months. 
Before the field work, the semi-structured and laddering questions were reviewed by the supervisors to ensure that every single item was covered based on the research problem. Peer-review was also done with a few selected PhD students to get opinions on the suitability of the questions. Pilot interviews with sellers and customers were also carried out to identify any inappropriate questions. Before the data collection, the interview questions were submitted to the Human Ethics Committee of Victoria University of Wellington for approval (refer to Section 3.6).

Both of the in-depth interview techniques will be explained next.

\section{a. Laddering}

Laddering is an in-depth interviewing technique used to develop an understanding of how consumers translate the attributes of products and services into meaningful associations with respect to self (Reynolds \& Gutman, 1988). This is the main source of data for this research. The reason why laddering was chosen to be the main source is because laddering uses the means-end framework, which provides a much richer understanding of how participants derive a unique perspective based on the personal meaning of their behaviour (Gengler \& Reynolds, 1995).

Veludo-de-Oliveira et al. (2006) claim that the technique originally started off in the field of psychology when Hinkle (1965) developed a technique to model people's belief structures in a simple, systematic way, in order to establish individual's super-ordinate personal constructs. According to Rugg et al. (2002), the technique has since been adapted by marketing, advertising, architecture, information technology, and organizational management researchers. The laddering technique involves a tailored interviewing format using primarily a series of directed probes in order to reveal customers' motives for choosing any particular product or services (Russell et al., 2004). The questionnaire was set up in a manner where the 
participants have to answer questions one by one based on their previous answers. According to Grunert and Grunert (1995), participants are expected to give answers in such a way that the sequence of the replies reflects increasing levels of abstraction.

Originally, this technique uses a hierarchical organization of consumer perceptions and product knowledge to get to the root reason for the purchase (Reynolds \& Gutman, 1988; Wansink, 2003) , which includes (i) product's attribute (Attribute), (ii) consequences of product use (Consequence) and (iii) individuals' values (Core Values). However, for this research, the focus of the laddering technique was on the members' participation in social commerce and what motivates them to participate. This means the Attribute (A) will denote the attribute of the activities in social commerce, and the Consequence (C) is the consequence of their participation in those particular activities. And finally, the Core Values (V) is the root reason or goals behind the participations.

These core values serve as a basis for an evaluative judgement, which is the basis for interpreting value. As mentioned earlier, evaluative judgement in this study is used in the sense of including the overall evaluation of a social commerce participation experience by both sellers and customers. As mentioned before, the core values from the laddering technique are used to determine the root reason behind their participation and the factors contributing to that participation.

Using the laddering technique within an in-depth semi-structured interview is classified as soft laddering, whilst the other type of laddering, which is either a paper-based or a computer-based structured questionnaire, is called hard laddering. Hard laddering a lacks of depth and richness when compared to soft laddering. This is because the participants' answers in hard laddering are static and can't be explored more deeply. In soft laddering, participants are allowed to provide more than one reason or explanation of their answers, thus soft 
laddering were used for this study (Russell et al., 2004). Furthermore, according to Russell et al. (2004), soft laddering is more suitable for exploratory type research.

There are a few steps involved in collecting laddering data. The researcher needs to determine the attributes which will be used as a starting point for the laddering technique. This is called the elicitation technique. An elicitation technique prompts subjects to generate relevant attributes associated with the object(s) studied. Based on previous research done by Bech-Larsen and Nielsen (1999), Reynolds and Gutman (1988), Grunert and Grunert (1995), Reynolds and Gutman (2001) and Costa et al. (2004), there are five major elicitation techniques that can be used in laddering. The techniques that were considered for this study are as follows:

i. Free elicitation - participants are asked to come up with the selfrelevant attributes which are most important to them (BechLarsen \& Nielsen, 1999; Grunert, Beckmann, \& Sørensen, 2001).

ii. Triadic sorting - providing the participants with sets of three activities in social commerce and repeatedly asking about the similarity of the combinations of two with the other one (Kelly, 1955; Reynolds \& Gutman, 1988).

iii. Free sorting - the participants form groups on the basis of all the related activities in social commerce based on similarity or difference of certain aspect(s) in other groups. The groups can consist of as many or as few activities as the participants please. Then they will be asked how the activities in the groups are alike, and how they differ from the other groups (Bech-Larsen \& Nielsen, 1999).

iv. Ranking - the respondents are asked to decide the priority of the activities according to preference and to state the causes for the ranking (Bech-Larsen \& Nielsen, 1999). 
v. Choose from a list of attributes - the participants are provided with a list of possible attributes or activities. The attributes on the list must be generated in some way. This is often done by the use of a focus group or another qualitative technique (Bech-Larsen \& Nielsen, 1999).

According to Grunert et al. (2001), the selection of the techniques is dependent on the aim of the study. This study is only focus on activities that are related to the social commerce in the virtual community. Thus this study uses a combination of choosing from a list of attributes and free elicitation. The elicitation techniques for this study will be explained next.

Firstly, to choose from a list of attributes, a list of activities were generated from the data gathered in phase one, which is observation. Participants were asked to pick the one activity in social commerce in which that they participate most.

To adapt free elicitation techniques, they were also encouraged to add their own preferences on top of what was itemized in the list. They were also allowed to choose more than one activity if they were not sure which activities they had done most in social commerce.

The activity which each participant choose is named as their attribute. Based on their attribute, participants were pushed up a ladder with "why" questions. For example: Why is it (the attribute) important to you? From this stage, probing questions that examine some of the consequences associated with the attribute were asked (Wansink, 2003) until the values behind the activity is clear.

The following is a sample of one of the laddering interviews:

Activity: Product Review

Q: Why is it important for you to write a review? 
A: There is a demand for it from the followers. That's a normal thing in this community.

Q: Can you explain more about the demand?

A: It was some sort of request. For example if I wrote in my blog about the new facial product that I used, some of them will ask me, how does it work? Was it good... and because we have a good relationship, I try my best to fulfil it. It was a good idea too for them to suggest it for me... It helps me to create useful contents for my blogs.

Q: Why is it important for you to fulfil their request?

A: I think it can lead me to new followers, especially when people use the Google search on any particular product, so they may end up reading my blog.

Q: What matters most about having new followers?

A: I think of every new follower as being a potential buyer. It is important to have a customer who is also a follower in order to keep them coming to my blogshop and keep on buying products.

Q: Why is that important?

A: It will help me to keep running my business.

Table 3.5: Laddering questions

The laddering technique is done simultaneously with the semistructured interviews and the details of how it was analysed will be explained in the next chapter.

\section{b. Semi-structured Interview}

Semi-structured interviews were used for this study as they are designed to extract the interviewee's ideas and opinions on the topic of interest, relying on the interviewer to ask relevant follow up questions based on the answer given by the participant. The data from the semistructured interview is used to further explain the findings from the laddering technique. For example if their answer to the why questions 
is short and straight forward, there is a need for the researcher to probe more on the subject matter. It is also used in between the why series questions to avoid the participants being bored or burdened with the why questions.

The basic questions were prepared in advanced based on the proposition which includes the behavioural intention, their participation in blogosphere community and social commerce, their sense of virtual community, customer-seller relationship and their activities in the community. Some of the questions are adapted from previous online community and social commerce research such as Blanchard and Markus (2004) and Koh and Kim (2003). Follow up questions based on the participants' answers were needed to get indepth information regarding particular topics. Thus, interview questions were slightly different for each interview.

Refer to Appendix D for the interview protocol.

\section{c. Observation}

Public online conversations between the virtual community members, such as discussion groups, Facebook wall posts, blog comments, and discussion threads, were reviewed thoroughly in order to identify the sense of virtual community. This includes the membership, influence and immersion which are suggested by Koh and Kim (2003). The observation data is used to explain the laddering findings. In addition it is also used to confirm that what has been claimed by the participant is correctly understood by the researcher.

\section{d. Pilot Study}

There were four pilot interviews conducted with two sellers and two customers. The issues found during the pilot study include (i) the tendency of participants to become tired of a series of "why (why is that important) questions", (ii) it was tedious, and (iii) it was difficult to 
keep track of various ladders. However these issues were solved by switching to other questions first if the participants have problems keeping up with the "why" questions and asking the questions later. In addition, the researcher does not need to press the participants for the answers. The researcher also needed to take their time to note some keywords while asking, in order to keep track of ladders.

\subsection{Approaches to Ensuring Quality and Rigour}

Golafshani (2003) argues that reliability and validity in qualitative methods serve a different purpose when compared to quantitative methods. According to Lincoln and Guba (1985), to establish a good quality study, the qualitative paradigm uses terms such as credibility, neutrality or conformability, consistency or dependability, and applicability or transferability. This is supported by Shenton (2004), who discusses Guba's constructs that include: (i) credibility, (ii) transferability, (iii) dependability, and (iv) conformability as an important criterion to pursue a trustworthy study. These four constructs were embedded in the study.

\subsubsection{Credibility}

Firstly, the concept of credibility was embedded in the study. According to Lincoln and Guba (1985), credibility is vital in establishing trustworthiness in qualitative research as it deals with the congruity of the findings as compared to reality. This is because the true value is obtained from the discovery of human experiences as they are lived and perceived by informants. To promote confidence in the study, member-checking was carried out. Participants were asked to review and give their feedback on the interview transcripts.

In addition, peer-checking was also conducted. This was done collectively after data analysis had been completed and after the submission and the discussion of the coding with the supervisors. Supervisors verified the coding before the peer-checking. Peer checking involved colleagues, with 
experience in qualitative research methods reviewing coding of data to confirm the categories and themes that emerged from the data. The researcher prepared several anonymous excerpts from the interview together with its code. In this study, data from laddering techniques, which is the main data has been reviewed and coded by four colleagues. Four PhD students were asked to review the coding to see if there is any other themes arose and amendments were carried out based on their suggestions. The verification using Cohen's Kappa will be explained in detail in the next chapter (refer to Section 4.4).

\subsubsection{Transferability}

Secondly, transferability was also embedded in the study. Transferability is similar to external validity in quantitative studies, which means the research can be applied to other situations. In order to apply the study to other situations, some steps can be followed. For example, Guba (1981) suggested that purposive or theoretical sampling should be done instead of representative sampling, so this research used purposive sampling in order to ensure transferability (refer to Section 3.3.1.1).

\subsubsection{Dependability}

Thirdly, the dependability constructs to enable future researchers to repeat the work, was also enforced. To address dependability issues, thorough understanding of the research is needed; thus researchers need to include research design and implementation, and operational details of data gathering. The research design and implementation, and operational details of the data gathering have been planned in detail, as elaborated in the previous sub-section (refer to Section 3.3.1).

\subsubsection{Conformability}

Finally, the conformability construct was also be embedded in this research. Conformability is a concept which leads to objectivity; the result must be based on the experiences and ideas of the informants, not the preferences of 
researchers. An audit trail is needed in order to trace the step by step decision making process and procedures described in the detailed methodological description. For this study, raw data, coding process (data reduction) and every process note is kept safe for an audit trail.

\subsection{Issues and Challenges}

Some issues that were faced during the implementation of this study will be discussed in this section.

Firstly, since this research relies partly on interviews to obtain contextual data, several potential limitations (Marshall \& Rossman, 1994) in using an interviewing technique have been recognized. These limitations include concerns regarding bias, since the sample is limited to a small group of key informants. Moreover, the interview technique makes replication difficult; inevitably, variations occur during the interview procedure, and results may be at least somewhat dependent upon the setting of the interview and the characteristics of the interviewer. This might lead to generalizability issues. Another weakness of the interview technique is inaccuracy due to poor recall of the interviewee or the tendency of interviewee to share only what they think the interviewer wants to hear. To address this problem, an observation was performed.

Secondly, some of the participants from Malaysia preferred to be interviewed in their first language. This may have led to the loss of data during the translation. Translated data could mislead the researcher into different meanings or contexts to what was actually said by participants. To address this problem, a Malaysian fluent in English and Malay was asked to review the audio and written transcriptions and help with translation.

Thirdly, ethical issues are another challenge in this study in the data collection phase. To ensure that this research adhered to ethical principles, the researcher obtained approval from the Human Ethics Committee, Victoria University of Wellington prior to the data collection. This approval is in accordance with the 
VUW Human Ethics Policy. The next section will explain the ethical considerations for this research.

\subsection{Ethical Considerations}

This research involves the members in the Malay lifestyle blogging community. In dealing with the human ethics issue, participants were reassured by informing them that this research would follow certain regulatory guidelines. In ensuring that this research adhered to ethical principles, human ethics approval was obtained from the Human Ethics Committee, Victoria University of Wellington prior to the data collection, which shows that research conformed to the university's Human Ethics Policy (refer to Appendix E).

\subsection{Conclusion}

This chapter has explained the approach taken in this research to address the research questions. The next chapter will discuss the data analysis for all three phases of the data collection. 


\section{CHAPTER 4}

\section{DATA ANALYSIS}

This section discusses the data analysis process for each of the techniques used in this study. It started with laddering analysis which consists of content analysis and the construction of the implication matrix and the hierarchical value map (HVM). This is then followed by the data analysis for the supporting data which include semi-structured interviews and observation data. The chapter concludes with the inter-reliability test using Cohen's Kappa.

\subsection{Data Analysis Procedures}

The data analysis was done in three separate ways based on the type of data (i.e. laddering data; semi-structured interview data and observation). Analysis was done in parallel with data collection. For the semi-structured interviews and the laddering techniques, transcriptions of individual interviews were prepared before the data analysis started. This mean that each interview was transcribed as soon as the interview ended. Express Scribe Transcription Software was used to assist with the transcription process. The transcriptions were sent back to the participants for confirmation. This was because the researcher encountered some difficulty understanding certain terms or potentially misleading facts in the transcriptions. The data analysis started after the confirmation process was completed.

The next section will explained the laddering analysis.

\subsection{Laddering Analysis}

The data collected from laddering interviews was analysed separately for sellers and customers because of the different activities in which they participate. Both sellers and customers laddering data were analysed using three steps in laddering analysis as suggested by Reynolds and Gutman (1988). 
The steps consist of the following:

i. Content analysis (coding) - The list of factors which influence members' participation are obtained through content analysis.

ii. Construction of an implication matrix - Summaries of the connections between each attribute, consequence, and value.

iii. Construction of a hierarchical value map (HVM) - The HVM provides information about the key benefits customers emphasize when they participate in social commerce and the corresponding attributes which are associated with those benefits. In addition, how benefits are related to customers' personal values/goals can be explained through the paths in HVM. These paths indicate the customer decision making process which start from attributes and end in values/goals.

The next section discusses in detail the analysis for laddering techniques.

\subsubsection{Content Analysis}

Content analysis for laddering serves to reduce the raw data in order to facilitate interpretation of the data (Reynolds \& Gutman, 1988). It consists of two steps: data reduction (coding) and categorizations, which are based on the suggestion of Reynolds and Gutman (1988). Data reduction involves the consolidation of constructs with the same underlying ideas. Generally both inductive and deductive coding were used in this research. Figure 4.1 describes the process of content analysis in general.

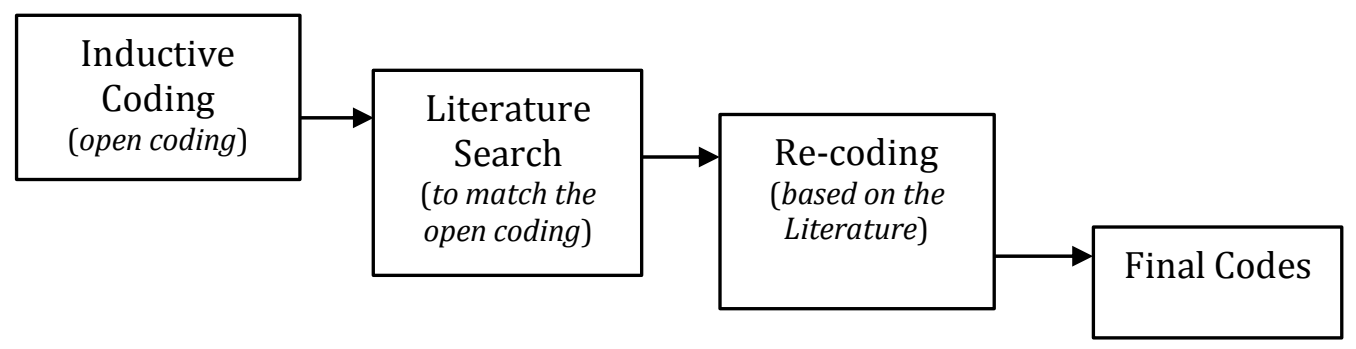

Figure 4.1: Coding process 
Figure 4.1 shows that the main coding was conducted inductively, which begins with open coding. This is conducted by generating the categories, followed by classification of the categories. Based on this coding, the researcher then compared the coding with the existing literature. If suitable definitions were found to describe the inductive coding, the terms and definitions were adopted for the final coding. Each code and construct was properly defined in a list of definitions to avoid the existence of redundant codes and constructs. In order to ensure the reliability of the coding, the data were coded in three different cycles. This was to ensure that the transcripts were thoroughly analysed for coding.

The following diagram shows sample of the coding process.

\begin{tabular}{|c|c|}
\hline Transcript & Coding \\
\hline $\begin{array}{l}\text { You said you also helped them with the suggestion to } \\
\text { improve their business. Why is it important for you } \\
\text { to do that? } \\
\text { I think that's what is so special about this community. } \\
\text { We always tried our best to give constructive feedback } \\
\text { to the bloggers. Bloggers are mostly like a celebrity in } \\
\text { this community. We adore them because they } \\
\text { somehow show a good example as a role model in the } \\
\text { community. So we love to help them. That is the } \\
\text { practice }\end{array}$ & Social Norm \\
\hline $\begin{array}{l}\text { Why is it important to practice that? } \\
\text { It will help them in their business, so I want to help } \\
\text { them }\end{array}$ & Social Support \\
\hline $\begin{array}{l}\text { Why does helping them matter to you? } \\
\text { I think it could be because we feel that we should help } \\
\text { them. I mean the readers and bloggers. I feel that as a } \\
\text { Muslim, I have a responsibility to support Muslim's }\end{array}$ & $\begin{array}{c}\text { Sense of } \\
\text { Obligation }\end{array}$ \\
\hline
\end{tabular}


product and as a member in the community, if I have the capability to help, I should help.

So what is important about that? What matters most about your feeling of being responsible to help?

We know them. They are our friends so it feel good to

Self-Esteem have a chance to contribute something to your friends.

Table 4.1: Coding sample

The final codes were then discussed with the supervisors for verification. Corrections were made based on the supervisors' comments. After the researcher and supervisors had agreed with the final codes and constructs, the peer-checking process was conducted in order to verify the codes. The inter-reliability coding process is explained in detail in Section 4.4.

After coding, a categorization process was conducted to categorize the constructs into different dimensions. This was done by first classifying all responses into the three basic $\mathrm{A} / \mathrm{C} / \mathrm{V}$ (Attributes/Consequences/Values) levels. A set of summary codes was developed to reflect the ladders of A-C-V elements (constructs). 28 raw elements based on both deductive and inductive coding were obtained for the sellers' laddering data, whilst 49 raw elements were found for customers' laddering data. A total of 24 unique elements were finalized based on the sellers' ladders, whilst 29 unique elements were finalized for the customers' ladders. Refer Appendix F for a complete list of ladders.

Figure 4.2 and Table 4.2 show an example of categorization process. 


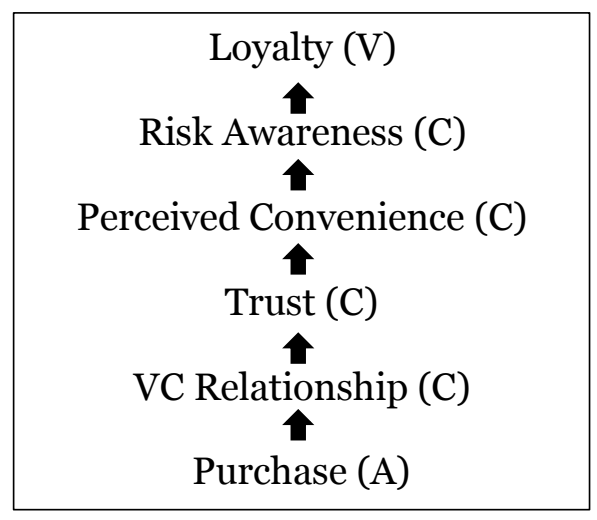

Figure 4.2: Sample of ladder

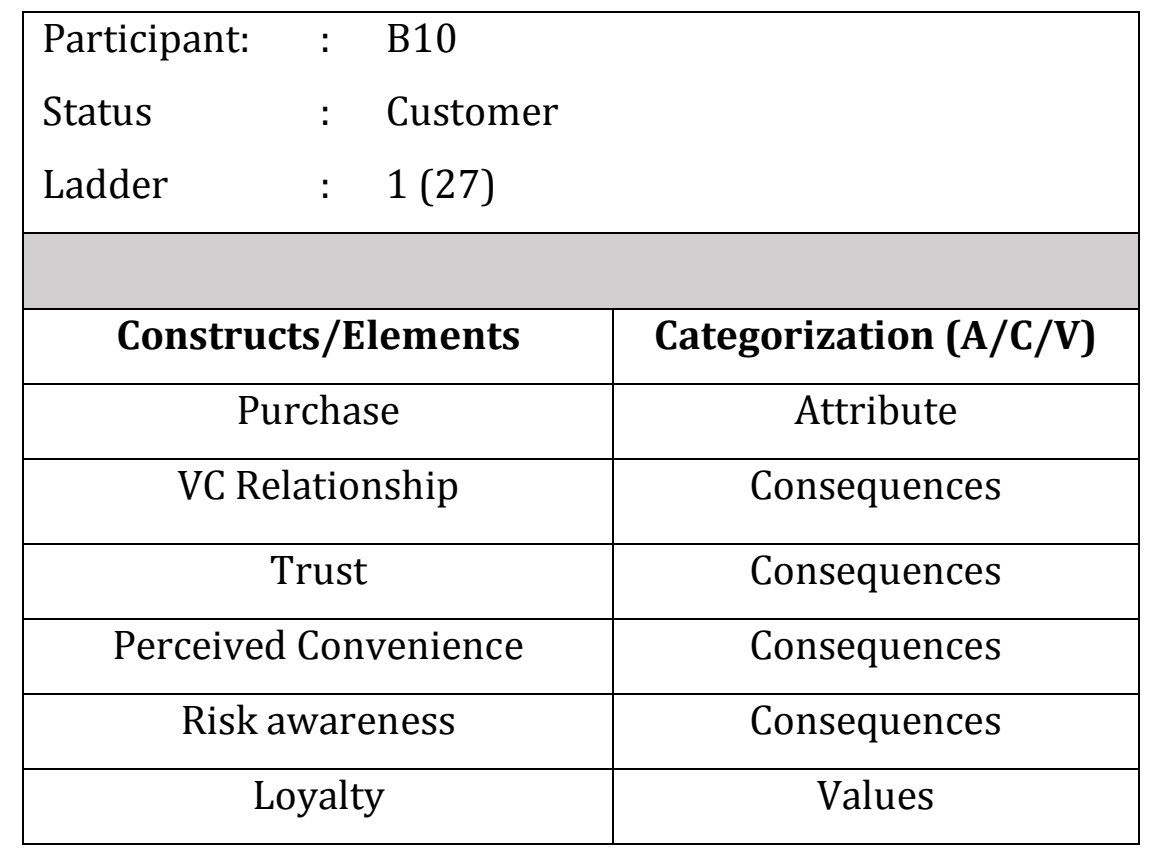

Table 4.2: Coding and categorization process

Table 4.3 and Table 4.4 show the content codes summary for this study.

\begin{tabular}{|l|l|}
\hline $\mathbf{A} / \mathbf{C} / \mathbf{V}$ & Elements \\
\hline Attributes & 01 Selling \\
\cline { 2 - 2 } & 02 Product Review \\
\hline Consequences & 03 Sense of Obligation \\
\cline { 2 - 2 } & 04 Social Support \\
\cline { 2 - 2 } & 05 Reputation \\
\cline { 2 - 2 }
\end{tabular}




\begin{tabular}{|c|c|}
\hline & 06 New Media Attitude \\
\hline & 07 Knowledge Sharing \\
\hline & 08 WOM \\
\hline & 09 Social Norms \\
\hline & 10 Customer Trust \\
\hline & 11 Perceived Convenience \\
\hline & 12 Potential Customers \\
\hline & 13 Business Opportunity \\
\hline & 14 Cost-Effectiveness \\
\hline & 15 Perceived Risk \\
\hline & 16 Customer Engagement \\
\hline & 17 Competitive Advantage \\
\hline & 18 Technical Knowledge \\
\hline & 19 Financial Security \\
\hline & 20 Personal Achievement \\
\hline Values & 21 Self Esteem \\
\hline & 22 Profit \\
\hline & 23 Business Sustainability \\
\hline & 24 Satisfaction \\
\hline
\end{tabular}

Table 4.3: Summary of the content codes for sellers

\begin{tabular}{|l|l|}
\hline $\mathbf{A} / \mathbf{C} / \mathbf{V}$ & Elements \\
\hline Attributes & 01 Purchasing \\
\cline { 2 - 2 } & 02 Reading Review \\
\cline { 2 - 2 } Consequences & 03 Giving Business Input \\
\cline { 2 - 2 } & 05 New Relationship \\
\cline { 2 - 2 } & 06 WOM attitude \\
\cline { 2 - 2 } & 07 Product Variety \\
\cline { 2 - 2 } & 08 Social Support \\
\cline { 2 - 2 } & 09 Social Norms \\
\cline { 2 - 2 }
\end{tabular}




\begin{tabular}{|c|c|}
\hline & 10 Sense of Obligation \\
\hline & 11 Social Image \\
\hline & 12 Trust \\
\hline & 13 Product Information \\
\hline & 14 Decision Quality \\
\hline & 15 Product Quality \\
\hline & 16 Perceived Convenience \\
\hline & 17 Risk Awareness \\
\hline & 18 Perceived Benefit \\
\hline & 19 Group Buying \\
\hline & 20 Response Time \\
\hline & 21 Status of Purchase Order \\
\hline & 22 Self-Image \\
\hline & 23 Product Review \\
\hline & 24 Creating Value \\
\hline & 25 Technical Knowledge \\
\hline & 26 Personal Standard \\
\hline Values & 27 Self Esteem \\
\hline & 28 Loyalty \\
\hline & 29 Satisfaction \\
\hline
\end{tabular}

Table 4.4: Summary of the content codes for customers

Upon finalizing the unique constructs for both sellers and customers' data, the next step is to develop the implication matrix.

\subsubsection{Using Ladderux to Construct the Implication Matrix}

The implication matrix is a square matrix that displays the number of times each element leads to every other element (Saaka, Sidon, \& Blake, 2004). In other words, it is used to summarise the connections between each attribute, consequences, and main values elements for all ladders in this study. 
The implication matrix was developed by Ladderux software, which is an automated software developed for laddering data analysis that provides a hierarchical value map as output. The content codes were keyed into Ladderux, according to the type of participants (i.e. sellers; customer). Figure 4.3 shows the interface to key in the codes. Codes were set up according to the $\mathrm{A}-\mathrm{C}-\mathrm{V}$.

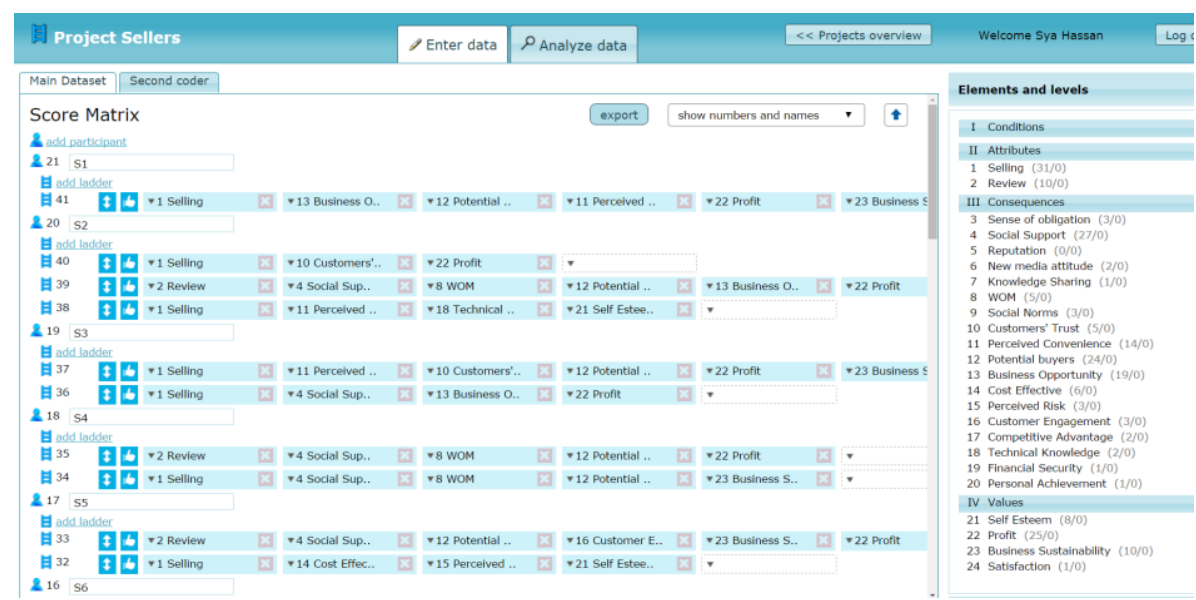

Figure 4.3: Creating ladders using Ladderux software

After completing the data entry for Ladderux, the software then converted the data to the implication matrix as shown in the following figure:

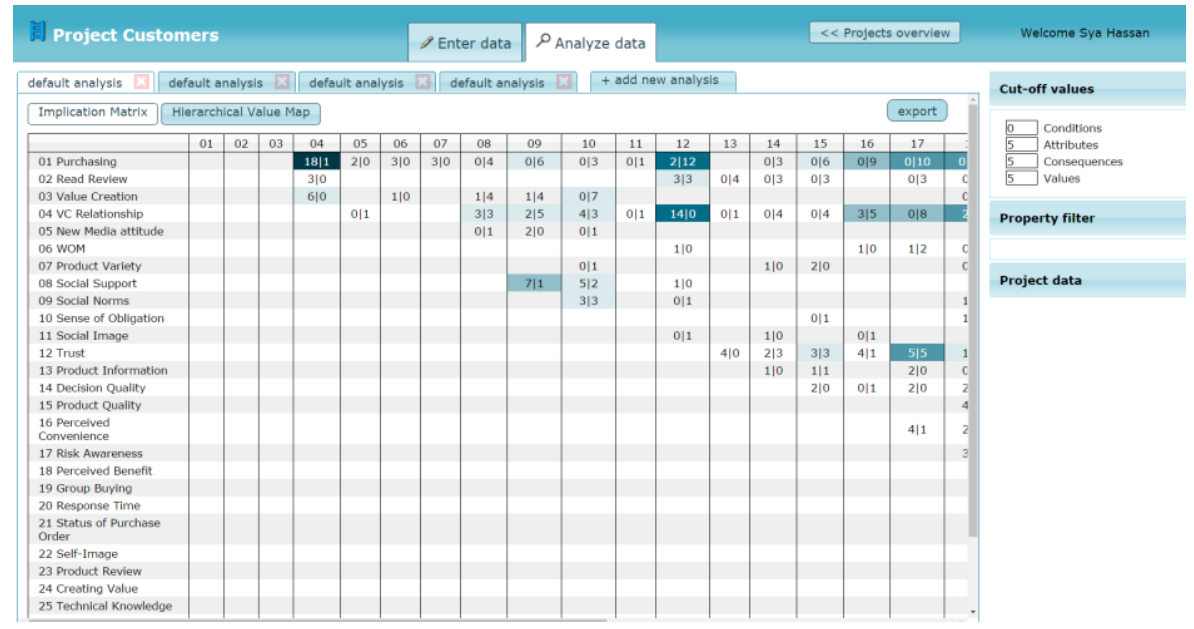

Figure 4.4: Implication matrix in Ladderux software

Refer to Table 6.2 and Table 6.3 in Chapter 6 for the full implication matrix for both sellers and customers. 


\subsubsection{Development of Hierarchical Value Map for Sellers}

Once the implication matrix was completed, the data was converted to construct HVM. This step was also conducted automatically by using Ladderux software.

HVM demonstrates the relationships between concepts by showing the links between the attributes, consequences, and values. To construct a HVM from the implication matrix, adjacent relations needed to be developed first. Adjacent relations were formed based on the situation: if $A \rightarrow B$ and $B \rightarrow C$ and $\mathrm{C} \rightarrow \mathrm{D}$, then a chain A-B-C-D is formed (Reynolds \& Gutman, 1988). The HVM is gradually built up by connecting the chains by considering all the linkages in the implication matrix. Usually, the HVM does not display all the elements and linkages in the implication matrix. A cut-off value of 5 was selected as suggested by Reynolds and Gutman (1988). Thus, only the relations value above the cut-off level was considered. Refer to Figure 6.2 and Figure 6.6 for sellers and customers' HVM obtained by drawing all linkages that were exceeded the cut-off level of 5.

When converting the implication matrix table into HVM, some of the elements were discarded automatically by Ladderux based on the cut-off value of 5. Therefore, in the case of sellers, the elements included for the HVM are (i) perceived convenience, (ii) social support, (iii) potential customers, (iv) business opportunities, (v) profit, (vi) business sustainability, (vii) selfesteem, and (viii) cost-effectiveness.

Meanwhile for the customers, the elements for HVM include (i) VC relationship, (ii) trust, (iii) product quality, (iv) perceived benefit, (v) risk awareness, (vi) social support, (vii) social norms, (viii) perceived convenience, (ix) sense of obligation, (x) satisfaction, (xi) self-esteem and (xii) loyalty.

The completion of HVM is the final stage of laddering data analysis. The findings were then integrated with other findings from the semi-structured 
interviews and observations in order to get an overall views of the case as explained in Section 4.3.

\subsection{Semi-structured Interview and Observation Data Analysis}

Miles and Huberman's (1994) interactive model of qualitative data analysis (refer to Figure 4.5) consisting of three concurrent flows of activity; namely data reduction, data display, and conclusion drawing/verifications were used as a guideline for the semi-structured interview and observation data analysis. This study adopted this model for those data.

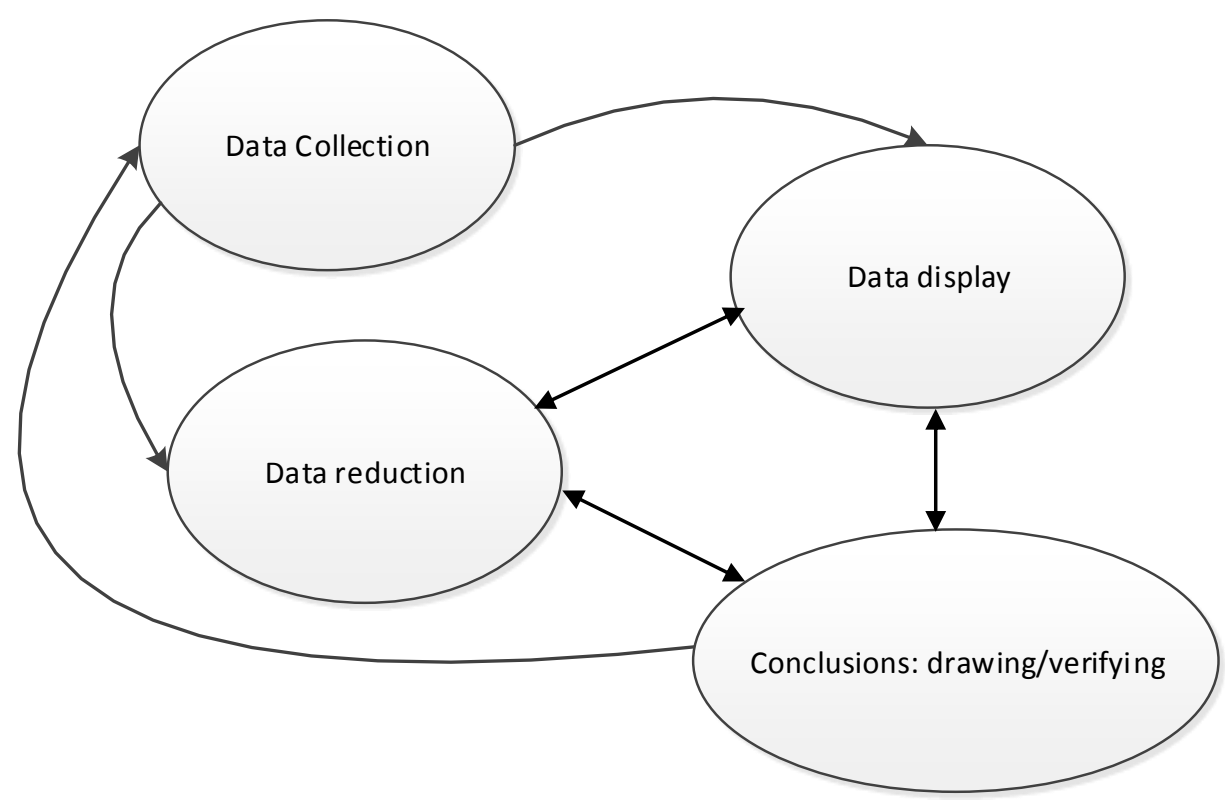

Figure 4.5: Component of data analysis: Interactive model (source: Miles and Huberman (1994))

\subsubsection{Data Reduction}

The data were coded, analysed and grouped into certain themes, in the same way as coding the laddering findings. The coding was mainly based on the theme created for laddering data to ensure consistency. In addition, new constructs and themes were also developed based on the data. This describes the combination of deductive and inductive coding. Unnecessary data that was not related to the research questions was omitted. 
The coding for observation data was done manually as the data was compiled in a mixed form (i.e. in text and images). The following table shows how the coding was conducted for observation data.

\begin{tabular}{|c|c|c|}
\hline Original Data & Converted to text & Code \\
\hline $\begin{array}{l}<\text { The descriptions of } \\
\text { data source }> \\
\text { E.g. Blog, Facebook etc. }\end{array}$ & $\begin{array}{l}<\text { Text description with English } \\
\text { translation }>\end{array}$ & $\begin{array}{l}<\text { deductive } \\
\text { and inductive } \\
\text { coding }>\end{array}$ \\
\hline
\end{tabular}

Table 4.5: Sample of coding for observation data

\subsubsection{Data Display}

As for the data reduction stage, the analysis was done in a deductive manner. For semi-structured interviews and observation data, the main ideas that help explaining the laddering findings were identified and grouped together.

Table 4.6 shows how comparisons were made before making final conclusions for the research.

\begin{tabular}{|l|l|l|l|}
\hline \multirow{2}{*}{ Main Data } & \multicolumn{3}{|c|}{ The explanation for construct as described by: } \\
\cline { 2 - 4 } & \multicolumn{3}{|c|}{ Supporting data } \\
\hline $\begin{array}{l}\text { Laddering } \\
\text { Constructs }\end{array}$ & $\begin{array}{l}\text { Overall } \\
\text { Interview Data }\end{array}$ & Conclusion \\
\hline $\begin{array}{l}<\text { coding } \\
\text { based on } \\
\text { laddering }>\end{array}$ & $\begin{array}{l}<\text { findings from } \\
\text { semi-structured } \\
\text { interview }>\end{array}$ & $\begin{array}{l}<\text { findings from } \\
\text { observation }>\end{array}$ & $\begin{array}{l}<\text { Conclusion } \\
\text { and the } \\
\text { explanation }>\end{array}$ \\
\hline
\end{tabular}

Table 4.6: Data display to explain each motivation found in this research

\subsubsection{Drawing Conclusions}

The documents used to display the main data and its relationship with other findings were used to identify the core meaning of the data in order to draw conclusions. A comparison was made for both sellers and customers' data to 
identify the similar motivational factors for both sellers and customers as the study would be representing the community as a whole (refer to Figures 6.11 and 8.1).

The relationship between their participation in the virtual community and the participation in social commerce were identified to address the research questions. The characteristics of the community alongside the relevant findings were also analysed to identify the activities conducted in the community and how it can influence the sense of virtual community. In addition, any meaningful or symbolic content that was beyond the context of the study was also highlighted in order to draw conclusions. This process was repeated until a state of saturation was achieved where further analysis produced minimal or no changes to the existing concepts or categories.

\subsection{Inter-rater Reliability using Cohen's Kappa}

Cohen's Kappa was used to check the reliability of the codes. It is a measure of reliability that has been used extensively in a variety of different settings (Guggenmoos-Holzmann, 1996). According to McHugh (2012), inter-rater reliability is important as it represents the extent to which the data collected in the study is a correct representation of the variables measured.

Four PhD students who have experience in qualitative research, particularly the coding process, were selected for the reliability test. They were given eight sets of data which contained four sets of customers and four sets of sellers' laddering transcripts. In addition they were also given a list of definitions. They needed to choose a suitable code(s) from the list of definitions to match with the data.

The first session of peer-checking was conducted at the School of Information Management meeting room, whilst the other session was done via Skype. The peer-checking sessions were done in the presence of the researcher. The role of the researcher in this meeting was mainly to further explain the definitions of codes to the participants. This was because the codes were based on the literature and some were quite technical and needed further explanation. The 
analysis was done based on Cohen's Kappa reliability test on a formatted excel file. Tables 4.7 and 4.8 show the report for the reliability test.

\begin{tabular}{|l|l|l|l|l|}
\hline & Coder 1 & Coder 2 & Coder 3 & Coder 4 \\
\hline Researcher & 0.8586572 & 0.80565371 & 0.929099 & 0.964508 \\
\hline Coder 1 & & 0.718640094 & 0.841176 & 0.85874 \\
\hline Coder 2 & & & 0.752868 & 0.823217 \\
\hline Coder 3 & & & & 0.929141 \\
\hline
\end{tabular}

Table 4.7: The comparison of Cohen's Kappa value for each coder

\begin{tabular}{|l|l|}
\hline \multicolumn{2}{|c|}{ Cohen's Kappa for Inter-Rater Reliability } \\
\hline Number of Items & 60 \\
\hline Number of Raters & 5 \\
\hline Number of Categories & 29 \\
\hline Raters & $\begin{array}{l}\text { Researcher, Coder 1, Coder 2, } \\
\text { Coder 3, Coder } 4\end{array}$ \\
\hline Cohen's Kappa & 0.848170123 \\
\hline
\end{tabular}

Table 4.8: The Cohen's Kappa value for inter-rater reliability test

The interpretation of Cohen's Kappa (McHugh, 2012) value for this study (Cohen's Kappa $=0.848170123$ ) shows that the level of agreement of each coder is strong where the percentage of data that is reliable is between $64 \%$ and $81 \%$. The reliability of this data is less than $82 \%$ due to the fact that none of the coders had been involved with a similar field, therefore their coding was based $100 \%$ on the definition provided during the coding process. Nonetheless, after the reliability test was done, some of the coding was revised in order to ensure that all measures had been taken to improve the coding. This step was done before converting the data to implication matrix and HVM.

\subsection{Conclusion}

This chapter has presented the data analysis for this research for each type of data collected in this study. The next chapter will discuss the case descriptions. 


\section{CHAPTER 5}

\section{CASE DESCRIPTION}

This section looks at the background of the case chosen for this study. This is to provide a picture of the setting of the case. Note that the case description will mostly discuss the culture, language and religion related to the Malays since the community chosen is the Malay lifestyle bloggers community.

\subsection{Background of Malaysia}

Malaysia covers an area of about 330,396 square kilometres, and is made up of 13 states in Peninsular (Johor, Kedah, Kelantan, Melaka (Malacca), Negeri Sembilan, Pahang, Perak, Perlis, Pulau Pinang (Penang), Selangor, Terengganu as well as the Federal Territories of Kuala Lumpur and Putrajaya) and the states of Sabah and Sarawak on the island of Borneo as well as the Federal Territory of Labuan (Economic Planning Unit, 2015). Figure 5.1 shows a map of Malaysia.
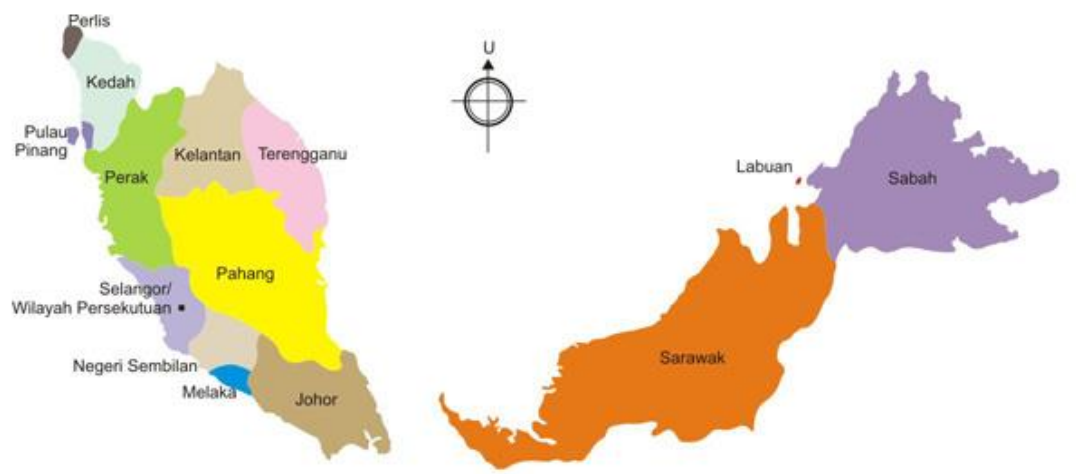

Figure 5.1: Map of Malaysia

Kuala Lumpur (refer to Wilayah Persekutuan on Figure 5.1) is the capital city, as well as the largest urban and metropolitan area in Malaysia, followed by Georgetown (capital city of Pulau Pinang) while Johor Bahru (capital city of Johor) is the third largest metropolitan area. 


\subsection{Demographic Background}

The current population of Malaysia based on the 2010 census is 28,334,135 and the projected population for 2014 was estimated at 30,097,000 (Economic Planning Unit, 2015). Malaysia is a multi-ethnic country with the main ethnic groups of Malay, Chinese and Indian. Malays and other indigenous peoples of Malaysia are called Bumiputera. Other ethnic groups include Kadazan Dusun, Bajau and Murut in Sabah as well as Iban, Bidayuh and Melanau in Sarawak (Economic Planning Unit, 2015).

The main language in Malaysia is Malay, whilst English is used as a second language. Islam is the official religion of Malaysia at 61.3\%. Table 5.1 shows the demographic background of Malaysia including the population by ethnic group, language and religion.

\begin{tabular}{|c|c|c|}
\hline \multicolumn{3}{|c|}{ Demographic background of Malaysia } \\
\hline Population* & \multicolumn{2}{|l|}{$30,097,000$} \\
\hline \multirow{7}{*}{$\begin{array}{l}\text { Population by } \\
\text { ethnic group* (as } \\
\text { of } 2014 \text { ) }\end{array}$} & Bumiputera & $18,846,000(62.61 \%)$ \\
\hline & • Malay & $15,239,000(50.63 \%)$ \\
\hline & - Other Bumiputera & $3,607,000(11.98 \%)$ \\
\hline & Chinese & $6,601,000(21.93 \%)$ \\
\hline & Indian & $1,995,000(5.63 \%)$ \\
\hline & Others & $260,000(0.86 \%)$ \\
\hline & Non-Malaysian citizens & $2,395,000(7.96 \%)$ \\
\hline \multirow[t]{3}{*}{ Language } & Main Language (Official) & Malay \\
\hline & Second Language & English \\
\hline & Other Major languages & $\begin{array}{l}\text { Mandarin, Tamil, other } \\
\text { Chinese dialects }\end{array}$ \\
\hline \multirow[t]{4}{*}{ Religion** } & Islam (Official religion) & $61.3 \%$ \\
\hline & Buddhism & $19.8 \%$ \\
\hline & Christianity & $9.2 \%$ \\
\hline & Hinduism & $6.3 \%$ \\
\hline
\end{tabular}




\begin{tabular}{|l|l|l|}
\hline & $\begin{array}{l}\text { Confucianism, Taoism and } \\
\text { other traditional Chinese folk } \\
\text { religion }\end{array}$ & $2.6 \%$ \\
\cline { 2 - 2 } & $\begin{array}{l}\text { No religion } \\
\text { Other religions or no } \\
\text { information }\end{array}$ & $0.5 \%$ \\
\hline $\begin{array}{l}\text { *Population projection based on the Population and Housing Census of 2010, } \\
\text { adjusted for under enumeration } \\
\text { ** Estimated }\end{array}$
\end{tabular}

Table 5.1: Demographic background of Malaysia (source: Economic Planning Unit (2015))

The Bumiputera, consisting of Malay descendants and other indigenous peoples in Malaysia, are the majority in Malaysia. The Bumiputera are given priority over non-Bumiputera in order to increase Bumiputera representation in many facets of life.

Malays are Muslim as stated in Article 160(2) of the Federal Constitution,

"The term 'Malay' refers to persons who meet the following four criteria: First, the person must profess the religion of Islam. Second, the person must habitually speak the Malay language. Third, the person must conform to Malay custom. Fourth, the person must have roots in the country by way of birth or descent in Peninsular Malaysia or Singapore 4 in one of the following four ways: (i) he was before August 31, 1957, born in the Federation (of Malaya) or in Singapore, or (ii) born of parents, one of whom was born in the Federation (of Malaya) or in Singapore, or (iii) was on August 31, 1951 domiciled in the Federation (of Malaya) or in Singapore, or (iv) is the issue of any of the above persons" (Fernandez, Hawley, \& Pridaza, 1975).

\footnotetext{
${ }^{4}$ The article no longer applies to Singapore, as it declared independence from Malaysia in 1965
} 


\subsection{Cultural}

The culture of Malaysia draws on the varied cultures of the different people of Malaysia. There are Malay-medium, Mandarin-medium and Tamil-medium schools in Malaysia, the fact of which provides some level of insight into the ethnic differences. Many Malaysians feel more comfortable amongst their own race. According to Kuppusamy (2006), a survey conducted by independent Merdeka Centre for Opinion Research clearly shows that the various races in Malaysia live peacefully but separately.

Malaysian cultural values are based on courtesy, tolerance and harmony. Malaysian usually avoid direct answers, particularly negative answers in order to prevent disagreement and preserve harmony (Kamarudin, 2013). As this study focuses on Malays, the discussion on this section will only focus on Malay culture.

Osman-Gani and Tan (2002) found that the Malay in general are nonconfrontational and choose to avoid hurting relationships. Although their research is based on the Malay in Singapore, this study argues that in general the Malay in Malaysia have the same traits. Malay culture is centred on the diverse religious values of Islam which believes that that success, failures, opportunities and misfortunes result from fate or the will of God. For example, the Malays will tend not to rely on empirical evidence or hard facts, but prefer to be guided by subjective feelings combined with the Islamic faith in a business context, when formulating ideas and making decisions (Kamarudin, 2013).

According to Abdullah (1996), Malays tend to build relationships first before getting down to business. Abdullah (1996) observed that Malays see the development of relationships as a form of 'ice-breaker' which can smooth the flow of conversation and enable both parties to assess one another. This is in contrast to Westerners, who Abdullah (1996) claims, tend to be more direct and explicit to do the business. 


\subsection{Socio-Economic}

Malaysia is a developing economy in Asia which, in recent years, has successfully transformed from an exporter of raw materials into a diversified economy. The country is a newly industrialised country (NIC). According to Singal and Wokutch (2016), NICs are developing countries that have achieved a higher standard of living and closed the gap in living standards between themselves and the developed countries such as the US, Japan and Western Europe. Examples of NICs are Turkey, Thailand, Malaysia, Mexico, Brazil, Argentina, South Africa and India.

Malaysia has made significant progress in the past few decades, establishing itself as an upper middle income nation (Economic Planning Unit, 2010). Nonetheless, Malaysian economists feels that there is a serious imbalance between income and the prices of goods, and that it will not be easy for the government to meet its high-income target by 2020 (The Straits Times, 2015). The goods and services tax that was implemented in April 2015 has affected the consumer sentiment as people's purchasing power has dropped. In addition, the increase in electricity tariffs by an average $15 \%$ to $16.9 \%$ in 2014 , the increase of sugar prices by $14 \%$ and gasoline by $11 \%$ in 2013 has also raised the cost of living and decreased the purchasing power in Malaysia, particularly among middle-class households (Rochan, 2014).

The following tables (refer to Tables 5.2, 5.3 and 5.4) show some data about Malaysia. Table 5.2 shows the data for GDP growth, inflation rate and unemployment rate in Malaysia in 2014, whilst Table 5.3 shows the mean monthly gross household income by ethnic group and strata in 2014. In addition, Table 5.4 shows the poverty rate in Malaysia in 2014. 


\begin{tabular}{|l|c|c|}
\hline Category & $\mathbf{2 0 1 3}$ & $\mathbf{2 0 1 4}$ \\
\hline GDP growth rate (\%) & 4.7 & 6.0 \\
\hline Inflation rate (\% p.a) & 2.1 & 3.2 \\
\hline Unemployment rate (\%) & 3.1 & 2.9 \\
\hline
\end{tabular}

Table 5.2: GDP growth, inflation rate and unemployment rate in Malaysia in 2014 (source: Economic Planning Unit (2015))

\begin{tabular}{|l|l|c|}
\hline \multicolumn{2}{|l|}{ Category } & MYR $^{*}$ \\
\hline Ethnic Group & $\begin{array}{l}\text { Bumiputera } \\
\text { (Malay and aboriginal) }\end{array}$ & 5,548 \\
& Chinese & 7,666 \\
\cline { 2 - 3 } & Indians & 6,246 \\
\cline { 2 - 3 } & Others & 6,011 \\
\hline Strata & Urban & 6,833 \\
\cline { 2 - 3 } & Rural & 3,831 \\
\hline \multirow{2}{*}{$* 1.00 \mathrm{MYR}=0.244504$ USD } & \\
\hline
\end{tabular}

Table 5.3: Mean monthly gross household income by ethnic group and strata in 2014 (source: Economic Planning Unit (2015))

\begin{tabular}{|l|c|}
\hline \multicolumn{2}{|c|}{ Incidence of poverty } \\
\hline Category & Percentage \\
\hline Overall & $0.6 \%$ \\
\hline Rural & $1.6 \%$ \\
\hline Urban & $0.3 \%$ \\
\hline \multicolumn{2}{|c|}{ Incidence of hard-core poverty } \\
\hline Category & $0.1 \%$ \\
\hline Overall & $0.2 \%$ \\
\hline Rural & $0.0 \%$ \\
\hline Urban & Percentage \\
\hline
\end{tabular}

Table 5.4: Poverty rate in Malaysia in 2014 (source: Economic Planning Unit (2015)) 
Table 5.2 shows the increase of inflation rate from $2.1 \%$ in 2013 to $3.2 \%$ in 2014. This figure explains the raised cost of living and the decreased purchasing power in Malaysia. Meanwhile, Table 5.3 shows that the Malays on average have the lowest mean monthly gross household income as compared to other ethnic groups in Malaysia. Table 5.4 shows that the poverty rate is higher in rural areas as compared to urban areas in Malaysia.

\subsection{Internet Penetration in Malaysia}

The Malaysian Government is encouraging the development of ICT in this country. There are numerous national ICT initiatives and policies designed to drive ICT development in Malaysia. Special funds have also been set up for this purpose. As a result, Malaysia has shown a significant growth with improved access to computers and the internet for citizens.

According to Malaysian Communications and Multimedia Commission (2015a), in the Industry Performance Report 2014, Malaysia's mobile phone penetration rate had breached $148.5 \%$. Meanwhile, household broadband penetration rate reached $70.4 \%$ as at the end of March 2015, showing that an increasing number of Malaysians have adopted the online or digital lifestyle.

In addition, there is a paradigm shift in viewing trends, from traditional television to online and social networking platforms in Malaysia, where in 2014, the growth of data services was between 25\% and 40\% (Malaysian Communications and Multimedia Commission, 2015a). Tey (2015) claims that the social media landscape in Malaysia is viewed as vibrant, with most of the Malaysian population turning to social media platforms to have their voices heard. In their Internet Users Survey 2014, Malaysian Communications and Multimedia Commission (2015b) found that $87.1 \%$ internet user in Malaysia use internet for social networking and virtual community. Malaysian Communications and Multimedia Commission (2015a) has also claimed that the rise of social media, including mobile application, offers opportunities for ecommerce and online shopping to grow. 


\subsection{Blogging in Malaysia}

As of January 2016, Malaysia ranked $7^{\text {th }}$ highest for social media usage penetration with a rate of 59\% (Kemp, 2016; The Statistic Portal, 2016) as compared to other countries, which shows that many Malaysians spend time on social media. Malaysia has also come second highest in South East Asia where 91\% of its internet population has engaged in social media.

Blogging is a popular activity and has become a trend in Malaysia since late $90 \mathrm{~s}$, with estimated numbers of bloggers ranging from hundreds of thousands (Hopkins, 2010b) to as high as two million (Bernama, 2010), ranking the country among the highest in the world after Indonesia and the European Union (Utusan Malaysia, 2008). According to Malaysian Communications and Multimedia Commission (2015b), it is difficult to find statistics which reveal the exact number of users of various blogging platforms in Malaysia.

\subsection{Lifestyle Blogging in Malaysia}

In the year 2000, bloggers in Malaysia created a forum for their members to interact, calling themselves Geng Jurnal, which means group of bloggers. The forum platform didn't last for long due to the rise of Facebook and other social networking sites. The members continued blogging and kept in touch using other platforms. At this stage of their relationship, most of them have met faceto-face via various projects including an annual gathering. Meanwhile, there were more newcomers to the blogging community in mid-2000s as blogging became more popular. This was especially when bloggers realized that they could earn money by blogging via Google AdSense ${ }^{5}$ and Nuffnang 6 .

\footnotetext{
${ }^{5}$ Google AdSense is an advertising placement service by Google, which is designed for website publishers who want to display advertisements on website pages. If the visitors view or click the ads, the owners or in this case the bloggers, will earn money.

${ }^{6}$ Nuffnang is a blog advertising company that acts as the middleman between advertisers and bloggers. Nuffnang signs up bloggers and plans out an integrated social media advertising campaign based on the blogger's popularity, readership and hits, which are tracked by the web analytics of their blogs. Nuffnang uses a revenue share model where they get paid by the advertiser then pay bloggers based on the number of visitors.
} 
The following are general characteristics of the chosen community for this research:

- The ratio of male and female bloggers is unknown as there are no statistics available. However most of the influential bloggers encountered during the observation phase by this study were women, hence only women bloggers were chosen as participants.

- Most bloggers and readers in this community are middle-class Malaysian.

- Most active and influential lifestyle bloggers in the community are women aged between 25 and 45 . However this data is estimated based on the observation done in this study.

- Age and gender of the readers are not available. Nonetheless, based on the observation, most of the readers are women around the same age group as the bloggers.

- Many blogs are written in informal Malay language.

- Most of the famous lifestyle bloggers reside in Kuala Lumpur and Selangor which is the central part of Malaysia. Therefore it is easier for them to attend Nuffnang and commercial events. Apart from these events, bloggers also gather for many occasions such as housewarming or birthday parties. Sometimes they set a date to hang out and have a potluck party with other bloggers or readers. These face-to-face activities create stronger ties between them.

- Multiple platforms community: In the early years, comments sections on blogs were used for public communications and emails were used for private conversations with their readers. For those who had already developed initial trust, they exchanged phone number as it was easier for them to communicate. When they started to use other social media platforms (Facebook and Instagram), the communication was mostly done on Facebook as it was easier to tag people for notification on the platforms. They also used smart phone applications such as WhatsApp7.

7 89\% of Malaysians are WhatsApp users 
- The sub-groups - usually bloggers have their own sub-groups and followers based on their s as well as similarities between them. For example Mommy bloggers (parenting), Sindiket Soljah (indie books), etc.

Table 5.5 shows some s of the lifestyle bloggers in Malaysia and the numbers of their followers. From the table, it can be seen that the lifestyle bloggers are using multiple platforms to connect with their followers and the number of followers differs in each of the platforms, depending on the preference of the followers. In addition, the total number of followers by Google Friend Connect do not indicate the actual number of followers of each blog. This is because many of the bloggers, as well as the followers do not subscribe to the service. Therefore other indicators such as monthly unique visitors and total page view can be used as alternative indicators for the popularity of the blogs. Some data is not available as the bloggers choose not to subscribe to the services. 


\begin{tabular}{|c|c|c|c|c|c|c|}
\hline \multirow[b]{2}{*}{ Blogger } & \multicolumn{3}{|c|}{ Blog } & \multirow[b]{2}{*}{ Facebook } & \multirow[b]{2}{*}{ Instagram } & \multirow[b]{2}{*}{ Twitter } \\
\hline & $\begin{array}{c}\text { Followers } \\
\text { subscribed via } \\
\text { Google Friend } \\
\text { Connect* }\end{array}$ & $\begin{array}{l}\text { Monthly unique } \\
\text { visitor (Source: } \\
\text { hypestat.com)** }\end{array}$ & $\begin{array}{c}\text { Total page } \\
\text { view }\end{array}$ & & & \\
\hline Hanis Zalikha & 41820 & 4,830 & $\mathrm{~N} / \mathrm{A}$ & $\begin{array}{c}\text { Followers: 1.3M } \\
\text { Friends: N/A }\end{array}$ & $2.3 \mathrm{M}$ & $252 \mathrm{~K}$ \\
\hline Red Mommy & $\mathrm{N} / \mathrm{A}$ & 128,760 & $\mathrm{~N} / \mathrm{A}$ & $\begin{array}{c}\text { Followers: } 15.6 \mathrm{~K} \\
\text { Friends: N/A }\end{array}$ & 9632 & 8801 \\
\hline Elly Irfan & 1426 & 19,320 & $\mathrm{~N} / \mathrm{A}$ & $\begin{array}{l}\text { Followers: N/A } \\
\text { Friends: } 4962\end{array}$ & $12.4 \mathrm{~K}$ & 288 \\
\hline Peej Burhan & 2205 & 4500 & $14.8 \mathrm{M}$ & $\begin{array}{c}\text { Followers: N/A } \\
\text { Friends: N/A }\end{array}$ & 8797 & 2197 \\
\hline Fillanie & 4562 & 2,100 & $32.4 \mathrm{M}$ & $\begin{array}{l}\text { Followers: N/A } \\
\text { Friends: } 4053\end{array}$ & $17.6 \mathrm{~K}$ & 1947 \\
\hline Diana Ishak & $\mathrm{N} / \mathrm{A}$ & 56,610 & $\mathrm{~N} / \mathrm{A}$ & $\begin{array}{c}\text { Followers:17.6K } \\
\text { Friends: } 5000\end{array}$ & 5650 & $\mathrm{~N} / \mathrm{A}$ \\
\hline Sepet & 4573 & 600 & $10.8 \mathrm{M}$ & $\begin{array}{c}\text { Followers: } 352 \\
\text { Friends: N/A }\end{array}$ & $12.8 \mathrm{~K}$ & 583 \\
\hline
\end{tabular}




\begin{tabular}{|c|c|c|c|c|c|c|}
\hline Neena & 1910 & 33,150 & $7.2 \mathrm{M}$ & $\begin{array}{l}\text { Followers: N/A } \\
\text { Friends: } 2860\end{array}$ & 4876 & $\mathrm{~N} / \mathrm{A}$ \\
\hline Ceera & $\mathrm{N} / \mathrm{A}$ & 3600 & $\mathrm{~N} / \mathrm{A}$ & $\begin{array}{l}\text { Followers: } 605 \\
\text { Friends: } 4971\end{array}$ & $11.3 \mathrm{~K}$ & 2174 \\
\hline Kathy & 1545 & 29,910 & $8.5 \mathrm{M}$ & $\begin{array}{c}\text { Followers: N/A } \\
\text { Friends: N/A }\end{array}$ & 8817 & $\mathrm{~N} / \mathrm{A}$ \\
\hline \multicolumn{7}{|c|}{$\begin{array}{l}\text { *Data is based on the number of subscriptions using Google Friend Connect }{ }^{8} \text { and do not represent the actual number of } \\
\text { followers } \\
{ }^{* *} \text { The number of monthly unique visitors depends on the number of updates on the blog. Some bloggers used other } \\
\text { platforms to connect with their readers (i.e. Instagram; Facebook) }\end{array}$} \\
\hline
\end{tabular}

Table 5.5: The number of followers for a sample of 10 lifestyle bloggers

\footnotetext{
${ }^{8}$ Google Friend Connect has been closed down in 2012, however data can still be accessed on these blogs as of May 2016
} 


\subsection{Blogshop}

Many Malaysian bloggers started online businesses in the mid-2000s and this model of online business is referred to as a blogshop. Although there are many individuals and businesses, this study only focuses on the blogshops that are run by Malay lifestyle bloggers. In Malaysia, lifestyle bloggers use their personal blogs to sell their products. They mix up their personal post, advertising posts and so on, and use tagging to make it easier for their readers to find a post. Some create new blogs for the business with links provided in their personal blogs. Lifestyle bloggers with separate blogs for their businesses usually make frequent updates about their business in their personal blogs in order to promote their businesses. Note that there is no standard implementation of how these bloggers handle their blogshops.

When other types of social media applications developed in late 2000s, there was a shift in the online shopping trend from buying and selling through blogshops to the Facebook store, and nowadays bloggers also use Instagram (otherwise known as Instashop). Some use multiple platforms for their businesses. Although some have shifted their operations to other platforms, most lifestyle bloggers still sustain their personal blogs with personal posts with links and updates about their businesses.

The following are the characteristics of the business operations in general.

\begin{tabular}{|l|l|}
\hline Characteristics & Descriptions \\
\hline Flexible & $\begin{array}{l}\text { Many of the sellers state their terms and } \\
\text { conditions for the customers. However, the } \\
\text { terms and conditions are quite flexible, } \\
\text { allowing the customers to negotiate. }\end{array}$ \\
\hline Ordering system & $\begin{array}{l}\text { Multiple systems } \\
\text { 1. Via customized forms on their blog. } \\
\text { 2. Via private messages (SMS, social media, } \\
\text { WhatsApp, email) } \\
\text { 3. Via comment sections }\end{array}$ \\
\hline
\end{tabular}




\begin{tabular}{|c|c|}
\hline Shipping & $\begin{array}{l}\text { - Multiple options - Via post or by hand } \\
\text { delivery. } \\
\text { - Some of the sellers state a specific day for } \\
\text { shipping and they will update the tracking } \\
\text { number on multiple platforms. Some send } \\
\text { personal messages via SMS or WhatsApp, } \\
\text { email or social media to update the tracking } \\
\text { number. }\end{array}$ \\
\hline $\begin{array}{l}\text { Communication with } \\
\text { customers }\end{array}$ & $\begin{array}{l}\text { - Via SMS, WhatsApp, email or private message } \\
\text { (Facebook, Instagram) }\end{array}$ \\
\hline Pricing & $\begin{array}{l}\text { Many display the prices on their online shop } \\
\text { but some sellers prefer the customers to text } \\
\text { them to discuss the price }\end{array}$ \\
\hline Payment method & $\begin{array}{l}\text { - Online transfer, PayPal (not a popular } \\
\text { option), and cash on delivery }\end{array}$ \\
\hline
\end{tabular}

Table 5.6: General descriptions on how the sellers manage their online store

Table 5.6 shows that the implementation of online business in this community are flexible and can be changed from time to time. As the technology emerged, the bloggers take the advantage to adopt latest social media technology in order to strengthen-up their business operations. Many of the businesses provides multiple options for ordering, payment and shipping which provide convenience for the customers.

\subsection{Boundary and Roles in Malay Blogging Community}

Figure 5.2 describes the boundary of the community selected in this study. Malay lifestyle bloggers are part of the Malaysian blogosphere which intersects with the social commerce in Malaysia. This study will only focuses on the members of Malay lifestyle blogging community that participate in social commerce. 


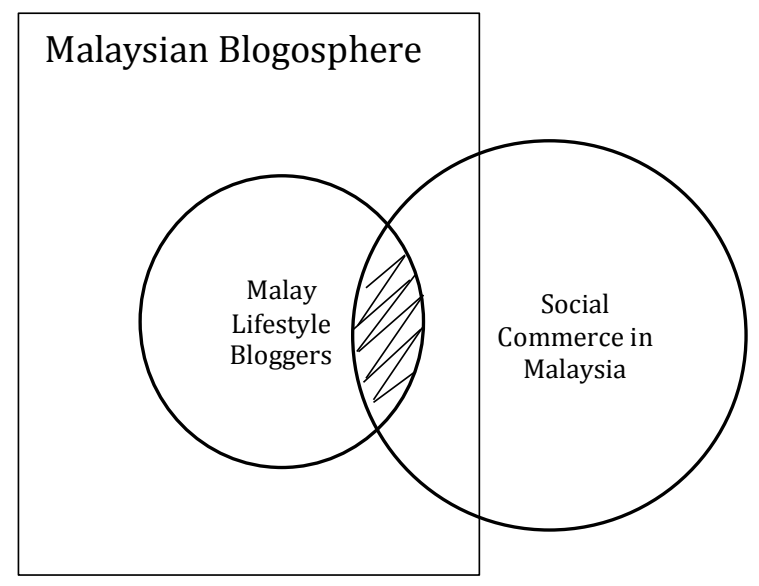

Figure 5.2: Boundary of the community selected in this study

The following table shows how the members can be grouped according to their roles in the community. The classifications in Table 5.7 are explained in detail in Table 5.8.

\begin{tabular}{|c|c|c|}
\hline & \multicolumn{2}{|c|}{ Roles in community in general } \\
\hline $\begin{array}{l}\text { Roles in } \\
\text { commerce } \\
\text { activities }\end{array}$ & Bloggers & Readers \\
\hline Sellers & $A^{2}$ & B \\
\hline Customers & co & D \\
\hline $\begin{array}{l}\text { Non- } \\
\text { sellers/ } \\
\text { customers }\end{array}$ & $\mathrm{E}$ & $\mathrm{F}$ \\
\hline
\end{tabular}

Table 5.7: Classification of members' role in social commerce activities 
Characteristics (included but not limited to)

Type A

- Mostly famous or influential bloggers.

- Sell products/services via blog (personal blogs or blogshop) and/or other social media medium.

- Product Reviewer - Own initiatives without any engagement from third party

- Advertiser - advertise (paid/ unpaid) others' businesses (community or noncommunity members) via blog.

\section{Type C}

- Bloggers.

- Product reviewer.

- Advertiser - advertise (paid/ unpaid) others' businesses (community or noncommunity members) via blog.

- Purchase from members in the community.

- Not involved in selling in the community.

\section{Type E}

- Bloggers.

- Read other blogs.

\section{Type B}

- Includes active and non-active readers.

- Sell product/services using blog (blogshop) and/or other social media medium (i.e. Facebook; Instagram).

- Sell own branding or resellers of existing product in the market.

- Pay influential bloggers to advertise their business.

\section{Type D}

- Readers.

- Have experience with purchasing from members in the community.

\section{Type F}

- Readers.

- Have no experience as sellers or customers in the community. 
- Have no experience as sellers

or customers in the community.

Table 5.8: Characteristics of the members

Based on Figure 5.7 and Table 5.8, this case includes the sellers from category A and customers from category C and D to participate in this study. This selection is important in order to address the research questions. As the study is trying to investigate the continuance intention behaviour, only members who had experience selling and purchasing were included in the case. In addition, only sellers who own a blog (refer to Section 3.3.2.1) will be selected as participants. This is because bloggers are the core participants in this community and are well-known to the other members as compared to the readers. It is important to choose the bloggers in order to put boundaries for the customers so that the customers can be chosen from those who have experience buying from the bloggers in the community, not the general sellers on social media.

\subsection{Conclusion}

The case description explained the background of the community which is one of the sub-groups of the Malaysian blogosphere. The descriptions of the country's demographic, social economic cultural as well as the information about the community are important in order to draw the conclusion for the findings. The next chapter will discuss the research methodology. 



\section{CHAPTER 6}

\section{FINDINGS}

This chapter presents the results for this research. As mentioned in the previous chapters, this study involves two different groups of participants; hence the findings will be discussed in two separate sections for sellers and customers. The discussion starts with an introduction, followed by a description of the full implication matrix and HVM for sellers, before breaking the HVM into several paths based on the relationships from attribute to values (A to V). Related data from semi-structured interviews data and observation is also included to support the claims made for each chain. This is followed by the same discussion for customers. In addition, other related significant findings such as the type of participation and the sense of virtual community which support the laddering data are also presented in this chapter.

\subsection{Introduction}

The motivations of the members in this community were investigated using the laddering technique and the details of their participations were probed using semi-structured interview data. The main data representing the layers of motivation will be presented for both sellers and customers. Meanwhile the other findings will be presented according to the main themes found in the laddering.

The following attributes were chosen by the participants as the most common commerce-related activities they performed in the community:

- Sellers: Selling; Product Review

- Customers: Purchasing; Reading Reviews; Giving Business Input (Cocreation)

The consequences and values layers will therefore be developed based on these attributes. Note that the constructs for this section are referred to as elements 
as suggested in laddering technique. In addition, the term sellers will be used interchangeably with bloggers, whilst the term customers will be used interchangeably with readers.

The flow of the findings will be presented according to the following diagram:

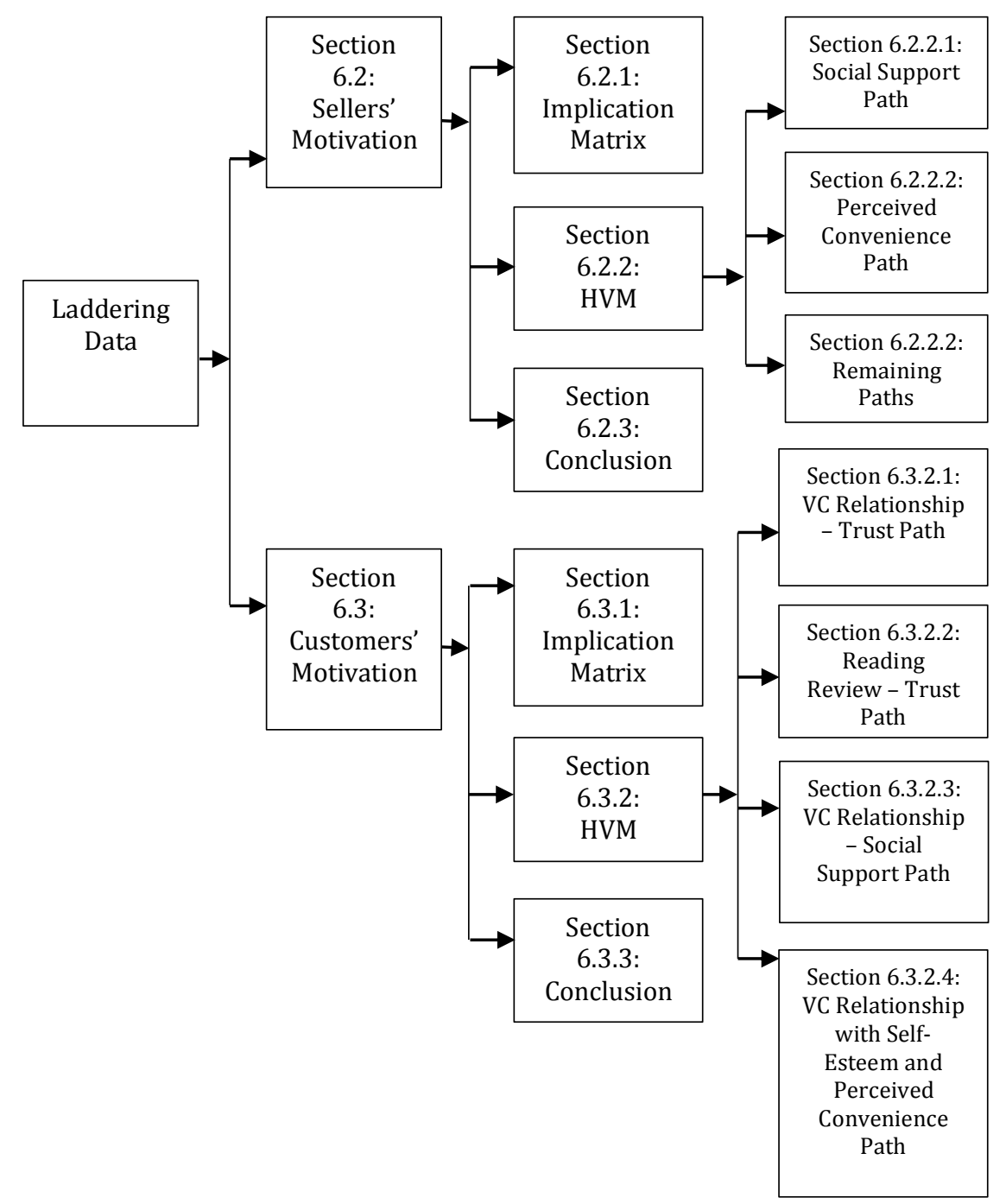

Figure 6.1: The flow of findings based on the laddering data

Figure 6.1 shows that the findings are represented based on the type of participants i.e. sellers and customers. For both types of participants, the implication matrix will be explained first, followed by the HVM. Section 6.2.2 will explain the HVM for sellers, which will be divided by path: (i) social support path, (ii) perceived convenience path, and (iii) the remaining paths. Meanwhile, for customers' findings, section 6.3 .2 will present the HVM based on the 
following: (i) VC relationship - trust path, (ii) reading review - trust path, (iii) VC relationship - social support path, and (iv) VC relationship with self-esteem and perceived convenience paths.

The next section discusses the laddering data as illustrated in Figure 6.1.

\subsection{Sellers' Motivational Factors}

This section discusses the findings for the sellers. It includes the explanations of the relationships between the elements based on the A-C-V, starting from the implication matrix and the final elements in HVM. The relationships are explained based on direct and indirect linkages that show the strength of the relationships between elements.

Several elements with more than 5 direct and indirect linkages were derived from laddering data as the motivational factors for sellers to continue their participation in social commerce. The elements are presented as follows:

\begin{tabular}{|c|c|c|}
\hline Attributes & $\begin{array}{l}\text { Consequences (Benefit } \\
\text { Layer) }\end{array}$ & Values (Goals layer) \\
\hline Selling; & Perceived Convenience; Social & Business Sustainability; Cost- \\
\hline Product & Support; Potential Customers; & Effectiveness; Profit; Self- \\
\hline Reviews & Business Opportunities & Esteem; \\
\hline
\end{tabular}

Table 6.1: Motivational factors based on benefit and goal layers

\subsubsection{Sellers' Implication Matrix}

As mentioned before (refer to Section 4.2.2) the implication matrix is used to summarize the connections between attributes, consequences and values. In order to create the implication matrix for both sellers and customers, a total of $41 \mathrm{~A}-\mathrm{C}-\mathrm{V}$ ladders were developed for 20 sellers. As the ladders are based on the activities listed by the sellers, one seller could have one or at most three activities; hence the number of ladders is more than the number of participants. 
There are two types of connection that exist between elements: (i) direct and (ii) indirect relations. In A-C-V ladders, a direct connection between two elements exists when one element has a direct link to the other element, without any intermediary element in the same ladder. An indirect link between two elements occurs when the two elements are mentioned in the same ladder, but separated by one or more intermediary elements. In this study, participants listed 434 linkages with a total of 165 direct links and 269 indirect links.

Table 6.2 shows the sellers' implication matrix. As can be seen in the table, selling behaviour has a strong relationship with the social support element, which has 13 direct and 5 indirect relationships. The selling behaviour also has a strong relationship with the perceived convenience element (5 direct; 9 indirect), the business opportunity element (5 direct; 11 indirect) and so on. The columns shaded blue indicate the level of relationship between the elements. Darker shades indicate a stronger relationship than light shades.

However, it should be noted that the implication matrix is not the final step for laddering methods. Although it provides an indication of direct and indirect relationships, it still includes the weak relationships between elements of this study that need to be eliminated. This is because only a stable set of relations will be considered for HVM. Therefore, strong relationships between elements will be presented in Section 6.2.2 that describe the HVM.

\subsubsection{Sellers' HVM}

HVM is developed by using only the relations with a value above the cut-off level of 5 which is recommended by Reynolds and Gutman (1988). The cutoff criterion determines which connections should be included in the HVM in order to reduce the complexity of the HVM (Veludo-de-Oliveira et al., 2006). It also helps to increase the clarity of the HVM. Thus from 24 elements, only 10 elements were left in the HVM. Figure 6.1 shows the full HVM for the sellers. This study found that the main business-related activities carried out 


\begin{tabular}{|c|c|c|c|c|c|c|c|c|c|c|c|c|c|c|c|c|c|c|c|c|c|c|c|c|}
\hline & 01 & 02 & 03 & 04 & 05 & 06 & 07 & 08 & 09 & 10 & 11 & 12 & 13 & 14 & 15 & 16 & 17 & 18 & 19 & 20 & 21 & 22 & 23 & 24 \\
\hline 01 Selling & & & & 13.5 & & 2.0 & & 0.3 & 2.1 & 1.3 & 5.9 & 1.16 & 5.11 & 2.4 & 0.3 & 0.1 & 0.1 & 0.2 & 0.1 & 0.1 & 0.6 & 0.18 & 0.8 & 0.1 \\
\hline 02 Review & & & 1.2 & 8.1 & & & 1.0 & 0.2 & & 0.1 & & 0.7 & 0.3 & & & 0.2 & 0.1 & & & & 0.2 & 0.6 & 0.2 & \\
\hline 03 Sense of Obligation & & & & 3.0 & & & & & & & & & & & & 1.0 & & & & & 1.1 & & 0.1 & \\
\hline 04 Social Support & & & & & & & & 5.0 & 2.0 & 0.2 & 4.1 & 9.8 & 8.7 & 0.1 & 0.2 & 0.2 & 1.0 & & & & 1.4 & 0.18 & 0.5 & \\
\hline 05 Reputation & & & & & & & & & & & & & & & & & & & & & & & & \\
\hline 06 New Media Attitude & & & & & & & & & 1.0 & & 1.1 & 0.1 & & & & 0.1 & 0.1 & & & & & 0.2 & & \\
\hline 07 Knowledge Sharing & & & & & & & & & & 1.0 & & 0.1 & 0.1 & & & & & & & & & 0.1 & & \\
\hline 08 WOM & & & & & & & & & & 2.0 & & 3.0 & 0.3 & & & & & & & & & 0.3 & 0.2 & \\
\hline 09 Social Norms & & & & & & & & & & & 0.1 & 1.2 & 0.2 & & & & 0.1 & & & & & 0.2 & 0.1 & \\
\hline 10 Customer Trust & & & & & & & & & & & 1.0 & 2.0 & 0.3 & & & & & & & & & 2.2 & 1.1 & \\
\hline 11 Perceived Convenience & & & & & & & & & & & & 6.5 & 4.1 & 1.2 & 1.0 & 1.0 & 1.0 & 2.0 & & & 0.4 & 1.5 & 0.5 & \\
\hline 12 Potential Customers & & & & & & & & & & & & & 10.1 & 1.1 & 0.1 & 1.0 & 1.1 & & & & 2.1 & 9.7 & 1.6 & \\
\hline 13 Business Opportunity & & & & & & & & & & & & & & 1.1 & 1.1 & & & & 1.0 & 0.1 & 0.3 & 7.6 & 1.3 & \\
\hline 14 Cost-Effectiveness & & & & & & & & & & & & & & & 1.0 & & & 1.0 & & & 0.1 & 2.0 & 3.0 & 0.1 \\
\hline 15 Perceived Risk & & & & & & & & & & & & & & & & & & & & & 2.0 & 1.0 & & \\
\hline 16 Customer Engagement & & & & & & & & & & & & & & & & & & & & & & 1.0 & 2.0 & \\
\hline 17 Competitive Advantage & & & & & & & & & & & & & & & & & & & & & & 1.1 & & \\
\hline 18 Technical Knowledge & & & & & & & & & & & & & & & & & & & & & 1.0 & & 0.1 & \\
\hline 19 Financial Security & & & & & & & & & & & & & & & & & & & & 1.0 & 0.1 & & & \\
\hline 20 Personal Achievement & & & & & & & & & & & & & & & & & & & & & 1.0 & & & \\
\hline 21 Self Esteem & & & & & & & & & & & & & & & & & & & & & & & & \\
\hline 22 Profit & & & & & & & & & & & & & & & & & & & & & & & 2.0 & 1.0 \\
\hline 23 Business Sustainability & & & & & & & & & & & & & & & & & & & & & & & & \\
\hline 24 Satisfaction & & & & & & & & & & & & & & & & & & & & & & & & \\
\hline
\end{tabular}

Table 6.2: Sellers' implication matrix 


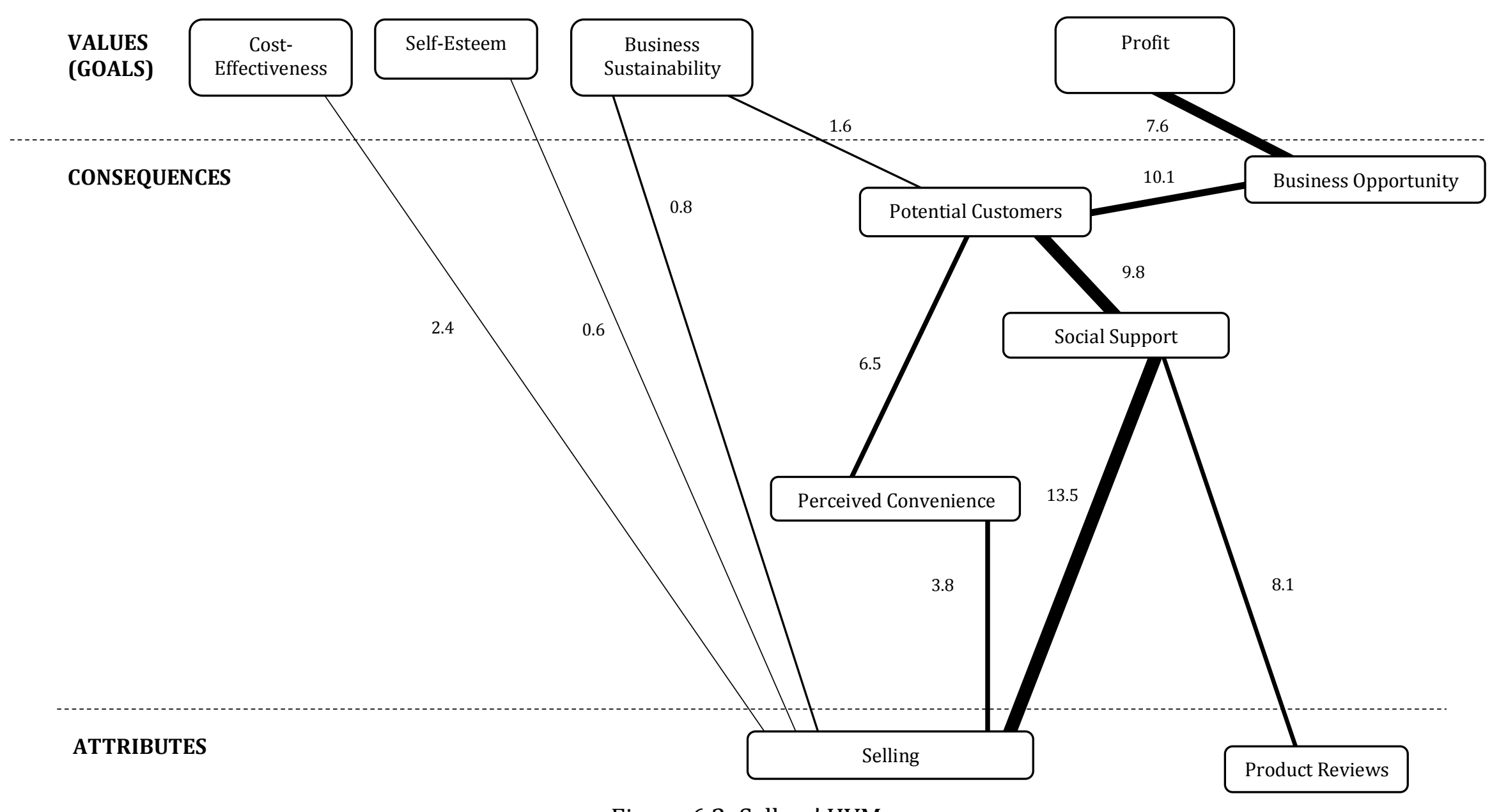

Figure 6.2: Sellers' HVM 
by sellers in the community are (i) selling and (ii) product reviews. In this chapter, the word 'goals' will used to represent the values level in the HVM, therefore the goals for engaging in social commerce are (i) profit, (ii) business sustainability, (iii) cost-effectiveness, and (iv) self-esteem.

As seen in Figure 6.1, (i) social support and (ii) perceived convenience are the two most basic factors when the sellers decide to participate in selling and providing product reviews in this community. To understand how these two factors (social support and perceived convenience) can lead to sellers' higher motivation levels (for sellers' participation), and what the corresponding attributes associated with each of these two basic motivations are, the relationship chains (A to V) were extracted from the HVM. The chains were chosen according to the basic factors: (i) social support, and (ii) perceived convenience. Data from semi-structured interviews and observations (if any) were also used to support the claims in the paths.

\subsubsection{Social Support Path}

Social support in this study is defined as members' experiences of being cared for, being responded to, and being helped by other community members. It was mentioned 27 times in 41 ladders for sellers.

The findings show that the sellers continue to sell products and/or services and write product reviews because by doing so they get social support from the customers, as shown in Figure 6.3. It shows that it is important for them to engage in the activities because they obtain social support from the community members.

The findings show that selling behaviour has a relationship of 13.5 with social support. As a relatively strong relationship in the HVM, it indicates that the sellers acknowledge the importance of social support in the community in order to successfully sell their product to the community. 
Meanwhile, product reviews in this study are defined as reviews of goods and/or services used by the sellers in their daily lives. This includes paid reviews of goods and services provided by other sellers, whether sellers from the community or other sellers outside the community. The study indicates that the relationship between product reviews and social support is 8.01. This is relatively high as product reviews were mentioned in only 10 out of 41 ladders. This shows that 8 out of 10 sellers provide product reviews because they were aware it would gain them social support that would eventually help them with their goals in commercial activities.

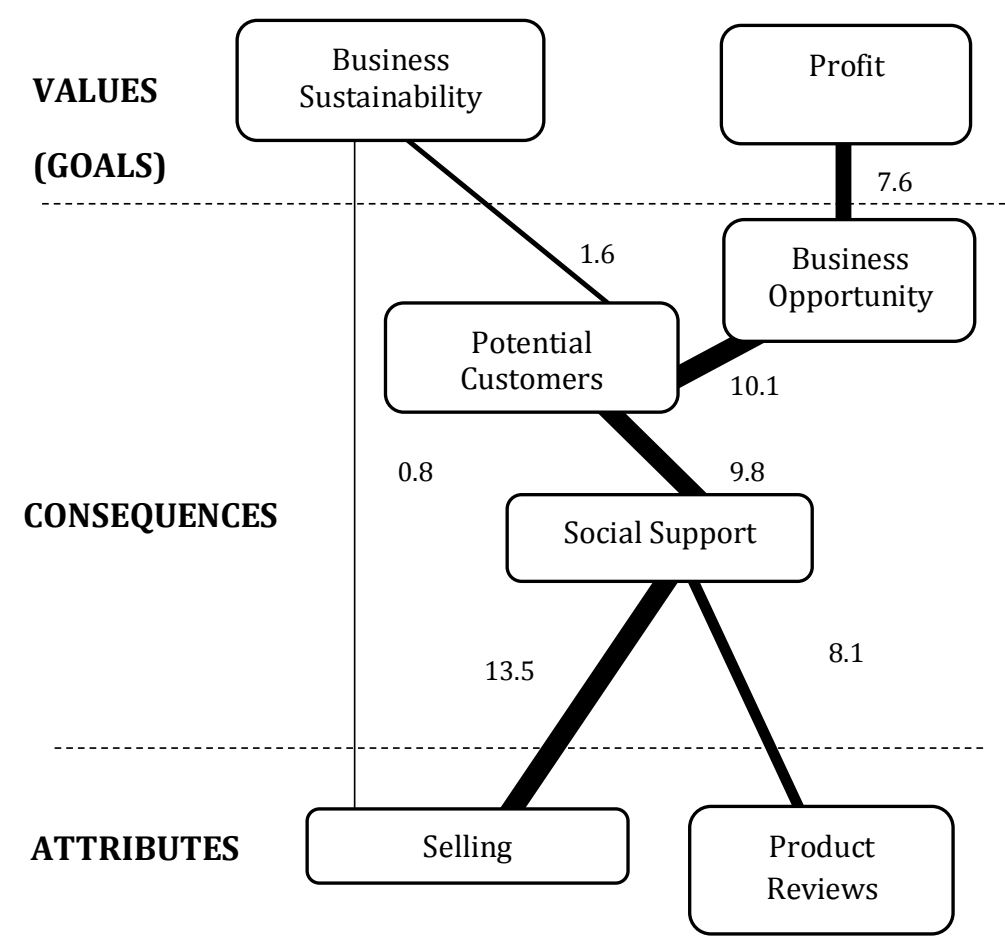

Figure 6.3: Social support path

\section{The Relationship between Selling and Social Support}

The following excerpts explain the selling - social support relationship.

"I think it's important to start small and sell them to my readers first. I know my readers will support my business; even if they don't buy, they still help to promote my business, so that's the idea of selling to the readers before starting something big" - Participant S1. 
"I have seen other bloggers get support from the readers, so that's the reason I started it with this community. They might not buy what I sell but they can help me with ideas or spread the news about my business" - Participant S16.

The evidence shows that the sellers are aware of the practice of providing social support for the members; therefore, they anticipated that they would receive the same support.

\section{The Relationship between Product Reviews and Social Support}

Meanwhile, the following excerpts explain the review - social support relationships:

"The readers like the reviews. They want to know more about the products. And usually, those who request product reviews are the same members who always give constructive feedback and ideas about my business. They support my business. That's why I spend the time to provide them with some reviews" - Participant S19.

"This is like give and take. The reviews could help them to know more about certain products and it also helps them to make a decision. When you provide something for the community, they will usually give something back to you. I didn't realize my readers love to read the reviews but they kept on asking me if I could do more reviews. And after that I did it seriously. Sometimes sellers in the community send their products for me to review. So I was basically motivated by the support of members in the community" Participant S2.

The excerpts show that bloggers provide reviews of popular products because they want to share their first-hand experiences with the readers. By doing so, bloggers were expecting support from their readers when they ventured into social commerce.

Figure 6.3 also shows that there is no direct relationship between writing a review with both 'potential customer' and 'business opportunities' 
elements. However, the supporting data have shown that sellers are aware of the importance of writing the product reviews in order to gain more customers and obtain more business opportunities.

This can be explained by the following excerpts:

"I think it [product reviews] can lead me to potential customers especially when people doing a Google search about product reviews might end up finding my blog" - Participant S5.

"It works like this. When you give a good review, usually your followers will share the review on their social media sites. Sometimes it goes viral so with that I get new followers. And because I am a seller, this benefits me in terms of more opportunities to expand my business" - Participant S2.

The previous excerpts show that, when sellers complete product reviews, they may be able to attract attention from people who are searching for specific product reviews via a Google search. In addition, sellers also anticipate that reviews may be shared by the followers and may potentially go viral in social media. This creates the potential for them to get new followers and/or customers, which in turn creates new business opportunities.

\section{The Relationship between Social Support and Strong Ties in the Community}

Social support for the sellers (or bloggers before they got involved in business) was found to be in line with the good relationships or strong ties they had in the community before participating in social commerce. Sellers believe it was also possible because the members trusted them. In addition, having witnessed the overwhelming support from the community members, sellers believe members are likely to support them if they participate in social commerce because of their strong ties. This is evident in the following excerpts: 
"The friendship is quite strong. I like the way they support each other. Although I didn't know anyone at first they were very welcoming. It wasn't hard to fit in." She added: "This includes any business related stuff. They back you up if any of your customers accuse you of something. For example if people leave bad comments related to your business, they will share their side of the story to help clear the seller's name. We protect each other based on trust" - Participant S11.

Another seller, Participant S4 states: "I guess this [social support from members] is because the bonding is quite strong although it was just based on online conversation. We have mutual understanding and trust" whilst Participant S19 stated: "I am happy with what's happening in the community. Some people see it as a waste of time but the truth is there is overwhelming knowledge sharing happening in this community. People are really supportive even if you don't really know them, like, they are just your readers but they are willing to help you with anything they can. They are also helping me with my business".

The previous excerpts from Participants S4, S11 and S19 show that the strong ties and trust between members explain why the community members provide support to the sellers although it is not shown in the HVM. This finding is similar to what is perceived by the customers which will be explained in Section 6.3.2.3.

\section{The Relationship between Social Support and Sense of Obligation}

This research also found that from the sellers' view, social support has a certain degree of relation to sense of obligation of their readers, although it is not directly shown in the sellers' HVM (refer to Figure 6.2), as illustrated in the following excerpts.

"I think it [why she got help from the community] could be because I always answer their questions about breast feeding. I am pro-breastfeeding and always go to seminars related to EBM, NIP and so on... so they often ask me 
about that. So when I struggled when I was first starting the business, they helped out" - Participant S21.

"They sent me emails regarding their problems. But none of this I shared on my blog because they didn't want to share their problem with the public. Well... I didn't expect them to return the favour but I can see that some of them started to share about my business, things like testimonials and such. Some have even become my customers" - Participant S8.

"And it is easier to get their help. In regard to my business, I think the friends [from the community] that I made along the way are those who helped me with my online business" - Participant S1.

Hence, sellers notice that the sense of obligation to return favours is also a factor in why the community gives support to the sellers. Next, the types of social support will be presented.

\section{Types of Social Support}

The results indicate that there are four types of social support that exist in the community: informational support, appraisal support, emotional support, and instrumental support. These are the main categories of social support (refer to Section 2.5). The social support subsequently motivates sellers to venture into social commerce and aim for the higher goals of (i) profit and (ii) business sustainability.

The practice of social support from the sellers' point of view is discussed next.

\section{Emotional Support}

Evidence from the interview excerpts shows that emotional support among the community members can either be from the bloggers to readers or readers to bloggers. 
Participant S11 claims that the social support practices in the community are a result of their social ties, as shown in the following excerpts:

"Actually in my opinion, because we shared a lot about ourselves, our families and life, so people tend to feel connected to each other. Therefore, we feel that we should support each other. Like emotional support. If you have any problem, just spill it to someone you trust in the community, they will try to help you by sharing your problem anonymously to get more opinions from others. Things like that. And it doesn't stop there. We also get some support related to our business. As a blogger, you try to help as much as you can because you know they are also there for you when you need support".

Although some of the support does not initially relate to the business environment, sellers believe the support in the community eventually leads to emotional support in regard to business. This is evident in the following excerpts:

"They are mostly concerned about my family because I always share about my family. But sometimes if I rant on Facebook or blogs saying that I'm too tired handling the business or want to give up due to work stress, the readers send me private messages saying that I shouldn't give up. They help me to go through the emotional phase, so I am really thankful for such support and it motivates me to work harder" - Participant S2.

"Yes, the support is usually personal but I do get support for my business too. They usually give moral support when I am down or feel like I can't do the business anymore. I don't even know some of them but they say that they are my silent readers. And sometimes they help to promote my business" Participant S14.

Instrumental Support

This study found that the sellers are likely to be motivated by the instrumental support given by members. Instrumental support refers to 
the various types of tangible aid and services that other members may provide to the sellers. The results specify that the type of help that the sellers get from members includes purchasing a product although they do not really need it, providing testimonials for sellers, updating social media accounts about the sellers and/or the product, tagging friends on their page or a seller's page, technical help (setting up new accounts etc.) and so on. The help not only comes from members who are not sellers in the community but also other sellers. For example, if they are selling the same product, they allow other sellers to use testimonials from their customers.

The following excerpts support previous arguments. Participant S4 said "The support system [in this community] is not just about emotional support but also in monetary form. This includes purchasing". That statement by Participant S4 is supported by Participant S20: "Most of the time I ask them to provide a testimonial. But I do get them voluntarily as well. And other sellers from the community who sell the same products sometimes allow us to use their testimonials. This is because we support each other".

Participant S2 also made a statement related to tangible aid: "Most of them shared the status on Facebook. And from what I heard from my customers, mostly from word of mouth, they told me their friends recommended me. Normally they would tell me where they got to know about my business".

\section{Informational Support}

This study found that informational support also contributes to the goals of sellers in this chain. Informational support involves providing individuals or groups with information that they can use to help themselves (House, 1981). Examples of informational support include advice, guidance, suggestions, directives and information on how to address certain issues. Generally, the lifestyle blogging community, bloggers and readers, consistently exchange their knowledge which includes travel information, parenting and so on. Knowledge sharing has been one of the norms for this community as stated by Participant S14: 
"This community is awesome. I found that they had a great relationship. They were really supportive and helpful. It was fun. We shared lots of information".

The informational support in this community not only covers general daily life but also includes business related information, as evident in the following excerpts:

"They were the ones who convinced me to use FB Page \& IG for my business, or stuff to get, like the popular ones in Malaysia. They informed me about trending stuff for netizens" - Participant S9.

"One of the customers is also doing business, so she invited me to join her Facebook group about marketing, promotion, products and time management. So in that group they coached us on how to promote our product. Well, it's not really coaching but a sort of support group for small businesses" - Participant S15.

"They even tell me the type of paper that they think is better for packaging and where to get a better quality paper and bubble wrap" - Participant S2.

The excerpts show that the community members (who may or may not be their customers) support the sellers by sharing information about the demand in the market. Members also provide practical solutions that may improve business, such as information about marketing strategy, packaging and so on.

\section{Appraisal Support}

Lastly, there is evidence showing that community members participate in giving appraisal support to sellers which is the least well defined of the four types as it was said to be similar to emotional and informational support. Appraisal support happens when someone offers information that allows the other person to make an informed decision on their own 
(House, 1981). It allows a person to appraise their current situation but does not tell them outright what should be done.

Sellers claimed that the members' requests for them to sell to the community were one of the reasons they started selling. The requests apparently gave them ideas on starting their online businesses. This is an example of appraisal support in the community, as evident in the following excerpts:

"Actually it started with a request from readers. They wanted the same stuff that I am wearing, hence they asked me to sell it to them. They gave me a few suggestions and tell me that they trust my judgement. It helped me to choose which would be the best things to sell as a start-off" - Participant S7.

"I started to sell second hand clothes or what nowadays they refer to as preloved clothes. I just sell them to my blogger friends or my blog readers, posting it on my blog saying that I want to do spring cleaning and such. I love shopping so I have lots of clothes that I need to clear from my closet. So after a while, some of the followers started to ask me why I don't sell new clothes as well. I never thought of that before so I started to ask around on how to get stock and I got various feedback from my blogs' followers. One of them even gave me details of the process since she knows some of the people involved in this business. There are a few options which help me to make my decision as there is always someone I can turn to" - Participant S11.

Previous discussions on four types of social support show that the willingness of members of this community to support each other is likely to be very strong. The factors influencing social support practices will be presented in Section 6.4.4.

Next, this study will further explain the higher level elements in this path, which are the potential customers and business opportunities, as well as the goals of participating in social commerce, which are profit and business sustainability. 


\section{The Upper Level Elements in the Social Support Path}

This study first discusses the relationship between the social support factors and the upper level element of the path, which is the potential customers. Potential customers in this study refers to both the potential customers from the community and also the netizens in general. The direct and indirect relationship between social support and potential customers (9.8) is proven to be high, as shown in the HVM. This relationship is portrayed by the following excerpts:

"...and if you spend enough time in this community you can see that most bloggers sell something because they know they can attract their readers". This view is also shared by Participant S21 who said, "I take that as I already have potential customers. So I know this is a good opportunity for me to start a business. The customers are already there" - Participant S1.

"I see them [the readers] as potential customers. I think that because I am close to my readers, I can get good feedback. That was my real intention when I started the business. It's more trial and error at first. I was hoping to get some support from them because that's normally what they do when someone in the community starts a business" - Participant S19.

Most of the sellers were confident that they could attract community members because of the endless support they got from them. This is due to the good relationships and sense of obligation in the community, as explained before.

The next level in the social support path is the connection between the potential customers' element and the business opportunity element. In this study, business opportunity is defined as the opportunity for bloggers to start or maintain their business. Based on the evidence, this study showed that potential customers they obtained from social support gave the sellers the confidence to start a business or venture into social commerce. 
The following excerpts show the relationship between potential customers and business opportunity in this chain:

"They are the ones who gave me the idea regarding the business opportunity. Often I saw that other bloggers who started their business got a lot of support from community members so I think it's better to target them as my potential customers" - Participant S15.

"I am currently actively blogging so I think it is important for me to grab the opportunity while I still have avid followers. The market is already there" Participant S7.

The excerpts show that social support among the community members from selling and product review activities leads to the social support in business and, subsequently an open market for them with potential customers as well as business opportunities. The opportunity to start a business with a ready market influences the main goals of this chain, which are profit and business sustainability.

\subsubsection{Perceived Convenience Path}

The second highest motivational factor for sellers' participation in social commerce is perceived convenience. Perceived convenience refers to the perception of the sellers when the selling process lowers the cognitive, emotional and physical burdens for them.

Figure 6.4 shows that selling is the only attribute which contributes to perceived convenience. The results show that perceived convenience was mentioned 14 times in 41 ladders. Perceived convenience in this sense is referred to as the convenience of using social media applications. Although it is a weak link as compared to the selling - social support relationship (refer to Figure 6.3), the result shows that the efficiency of social media is likely to influence the sellers' participation in social commerce. 


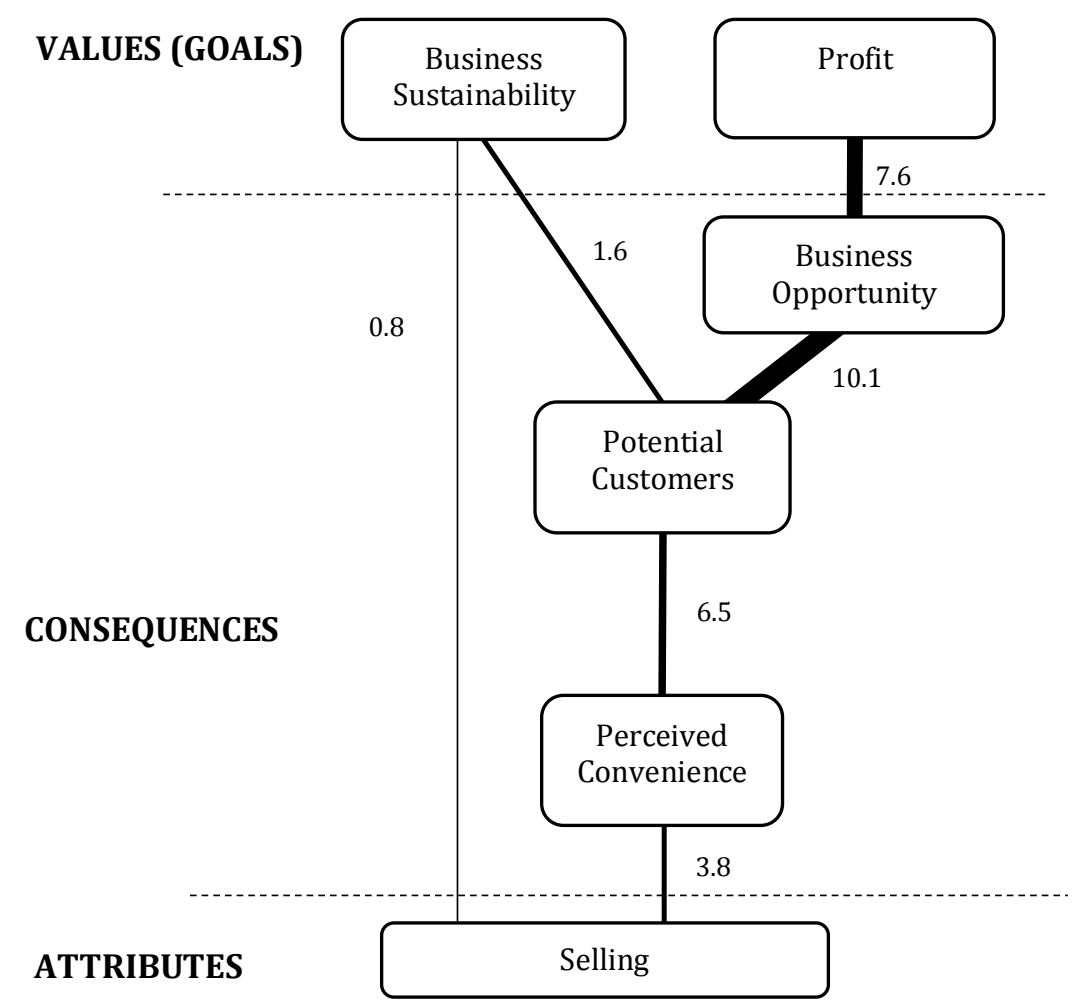

Figure 6.4: Perceived convenience path

\section{The Upper Level Elements in the Perceived Convenience Path}

As can be seen in Figure 6.4, the results show that the perceived convenience path is similar to the social support path (refer to Section 6.2.2.1). The difference is in the number of direct and indirect linkages held by the perceived convenience - potential customers relationship (6 direct, 5 indirect) and the social support - potential customers relationship (9 direct and 8 indirect). The linkages show that the social support potential customers relationship is stronger than the perceived convenience - potential customers relationship. This result shows that the sellers believe that social support from the community can attract more potential customers as compared to relying on social media without any support from community members. Having the convenience of using social media, the sellers believe that they can get more potential customers. It can further lead to business opportunities and finally achieve profit and business sustainability, which are the main goals of the sellers. 
Participants indicate that perceived convenience basically includes the ease of use of social media apps, better communication and easy access to target customers as displayed in the excerpts. According to Participant S1, "I think it will be easier to do the marketing because most of my readers subscribe to my blog and they also follow my Instagram and they are also in my Facebook. So basically I just need to update about the product in my social media".

Participant S2 mentions the ease of use: "It's really easy to use the apps", whilst Participant S14 refers to better communication: "I think it makes it easy for me to communicate with the customer".

The results also indicate that the perceived usefulness of social media apps is likely to be the factor of getting more potential customers. This can be seen in the following excerpts:

"I can use it [social media application] efficiently and I think that leads to an easy start for me because I target my followers to be my customers" Participant S10.

"I want to sell the product to the community members so it is important that I use a channel that can reach them. They are always online. They read my blog almost every day. It's our daily routine. They are so into Facebook because that's where we usually hang out. So that's the reason why I sell through social media: to reach them" - Participant S11.

The findings also suggest that from the sellers' perspective, the availability of potential customers is most likely to influence the business opportunity as explained before in the social support path (refer to Section 6.2.2.1). As shown in the following excerpt, Participant S5 claims: "I think it will lead customers to keep on coming to my blogshop and buying products and this will help me to keep running my business", whilst Participant S6 said: "It can bring more customers, and more customers means more profits, therefore I can keep on selling the product." 
In conclusion, this path shows that the business opportunity is an important element that needs to be targeted in order to achieve profit and business sustainability. It also suggests that the sellers realize the potential of using blogs and/or social media applications to sustain their businesses. Figure 6.4 also shows that there are other unknown factors (8 indirect linkages) that indirectly influence business sustainability by selling in social media.

\subsubsection{The Remaining Paths in Sellers' HVM}

The HVM reveals that there are two other paths in the HVM that do not have intermediate factors to achieve goals. Based on Figure 6.5, the elements that connect selling to cost-effectiveness and self-esteem seem to be missing from the HVM. These paths are considered weak which will be explained next.

Cost-effectiveness is defined as being economical in terms of what is received for the money spent on the business. This is possible because of low operational costs and low marketing costs. However factors related to community participation that may contribute to cost-effectiveness goals for the sellers in the community are unknown. This is likely to be due to the presence of various other factors perceived by the sellers in the community.

As shown in Figure 6.5, the selling - cost-effectiveness path has two direct linkages which means that there are sellers who sell in the community because they wanted to increase their self-esteem. There are also four indirect linkages which shows that other factors contributing to the path from selling to cost-effectiveness remain unknown. This shows that factors contributing to cost-effectiveness are weak and were therefore eliminated from the HVM. 


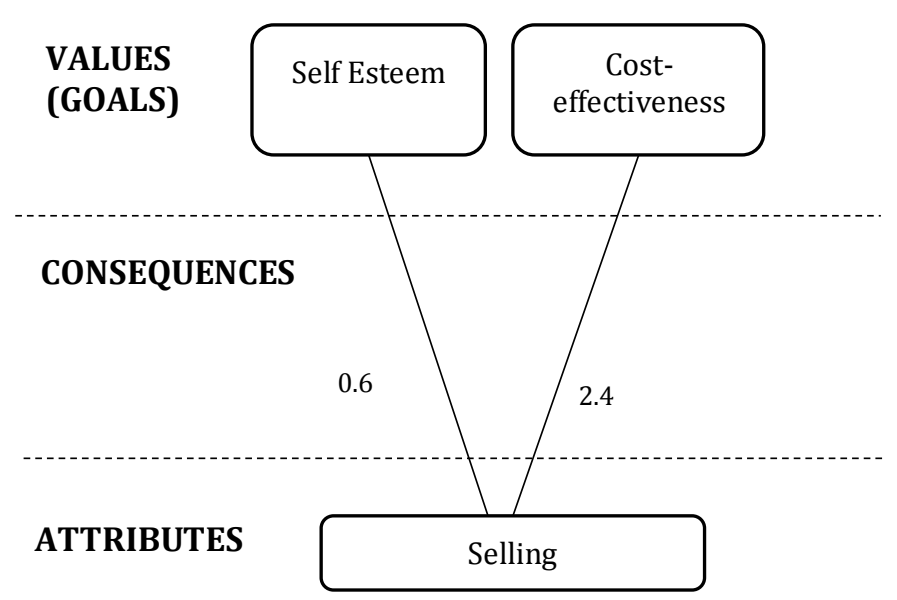

Figure 6.5: Other paths in sellers' HVM

Meanwhile, self-esteem refers to the evaluative dimension of the self that includes feelings of worth, pride or discouragement. The relationship between selling and self-esteem is low with linkages of 0.6. Therefore, as with the selling - cost-effectiveness path, this study argues that although self-esteem is one of the main goals, it is not clear whether the self-esteem felt by the sellers is related to their participation in the community. This is because the evidence shows that it is likely to be influenced by personal reasons as stated by the following participants:

"I never thought I could be successful in business. Although it is just small, I think I started it well and it build up my confidence" - Participant S2.

"I was afraid that if I failed, people would look down on me, so it's better to start small but steady rather than aiming big without a solid plan" Participant S5.

\subsubsection{Summary}

The sellers' findings show that their participation in the virtual community is likely to help them to pursue their goals which are business-sustainability and profit. In order to achieve their goals, they are influenced by the perceived convenience of doing business using social media and by getting support from the community members. This is because the support and the 
convenience give them more potential customers and business opportunities.

\subsection{Customers' Motivational Factors}

This sub-section discusses the findings for customers which includes the customers' implication matrix and HVM. Several elements with more than 5 direct and indirect linkages were derived from laddering data as the motivational factors for customers to continue their participation in social commerce.

The elements are presented as follows:

\begin{tabular}{|c|c|c|}
\hline Attributes & $\begin{array}{l}\text { Consequences (Benefit } \\
\text { Layer) }\end{array}$ & Values (Goals layer) \\
\hline Customer & $\begin{array}{l}\text { VC Relationship; } \text { Trust; } \\
\text { Perceived Convenience; Social } \\
\text { Support; Social } \quad \text { Norms; } \\
\text { Product Quality; Perceived } \\
\text { Benefit; Risk Awareness }\end{array}$ & $\begin{array}{l}\text { Loyalty; Sense of Obligation; } \\
\text { Self-Esteem; Satisfaction }\end{array}$ \\
\hline
\end{tabular}

Table 6.3: Motivational factors based on benefit and goal layers

\subsubsection{Customers' Implication Matrix}

The total number of ladders developed for customers' data is 46 . There are 564 linkages in the implication matrix, with a total of 201 direct and 363 indirect links. The linkages between purchasing and VC relationship denote the strongest relationship in customers' data. Refer to Table 6.3 for the customers' implication matrix. 


\begin{tabular}{|c|c|c|c|c|c|c|c|c|c|c|c|c|c|c|c|c|c|c|c|c|c|c|c|c|}
\hline & 04 & 05 & 06 & 07 & 08 & 09 & 10 & 11 & 12 & 13 & 14 & 15 & 16 & 17 & 18 & 19 & 20 & 21 & 22 & 23 & 24 & 25 & 26 & 27 \\
\hline 01 Purchasing & 18.1 & 2.0 & 3.0 & 3.0 & 0.4 & 0.6 & 0.3 & 0.1 & 2.12 & & 0.3 & 0.6 & 0.9 & 0.10 & 0.11 & & 0.1 & 0.1 & 0.2 & 1.0 & 0.1 & & 1.0 & 0.8 \\
\hline 02 Reading Reviews & 3.0 & & & & & & & & 3.3 & 0.4 & 0.3 & 0.3 & & 0.3 & 0.3 & & & & & & & & & 0.2 \\
\hline 03 Giving Business Input & 6.0 & & 1.0 & & 1.4 & 1.4 & 0.7 & & & & & & & & 0.3 & 0.1 & & & & & & 1.0 & & 0.3 \\
\hline 04 VC Relationship & & 0.1 & & & 3.3 & 2.5 & 4.3 & 0.1 & 14.0 & 0.1 & 0.4 & 0.4 & 3.5 & 0.8 & 2.9 & & 0.1 & 0.1 & & & & & & 1.5 \\
\hline 05 New Media attitude & & & & & 0.1 & 2.0 & 0.1 & & & & & & & & & & & & & & & & & 0.2 \\
\hline 06 WOM & & & & & & & & & 1.0 & & & & 1.0 & 1.2 & 0.2 & 1.0 & & & & & & & & 0.1 \\
\hline 07 Product Variety & & & & & & & 0.1 & & & & 1.0 & 2.0 & & & 0.2 & & & & 0.1 & & 0.1 & & & \\
\hline 08 Social Support & & & & & & 7.1 & 5.2 & & 1.0 & & & & & & & & & & & & & & & 1.4 \\
\hline 09 Social Norms & & & & & & & 3.3 & & 0.1 & & & & & & 1.0 & & & & & & & & & 3.2 \\
\hline 10 Sense of Obligation & & & & & & & & & & & & 0.1 & & & 1.0 & & & & & & 1.0 & & & 1.3 \\
\hline 11 Social Image & & & & & & & & & 0.1 & & 1.0 & & 0.1 & & & & 0.1 & & & & & & & 1.0 \\
\hline 12 Trust & & & & & & & & & & 4.0 & 2.3 & 3.3 & 4.1 & 5.5 & 1.6 & & 0.1 & & & & & & & 0.5 \\
\hline 13 Product Information & & & & & & & & & & & 1.0 & 1.1 & & 2.0 & 0.1 & & & & & & & & & 0.1 \\
\hline 14 Decision Quality & & & & & & & & & & & & 2.0 & 0.1 & 2.0 & 2.2 & & 1.0 & & & & & & & 0.2 \\
\hline 15 Product Quality & & & & & & & & & & & & & & & 4.0 & & & & 0.1 & 1.0 & 1.0 & & & 1.1 \\
\hline 16 Perceived Convenience & & & & & & & & & & & & & & 4.1 & 2.1 & & 1.0 & 1.0 & & & & & & 0.2 \\
\hline 17 Risk Awareness & & & & & & & & & & & & & & & 3.1 & & & 1.0 & & & & & & 1.1 \\
\hline 18 Perceived Benefit & & & & & & & & & & & & & & & & 1.0 & & & 1.0 & 0.1 & & 1.0 & & 3.0 \\
\hline 19 Group Buying & & & & & & & & & & & & & & & & & & & & & & & & \\
\hline 20 Response Time & & & & & & & & & & & & & & & & & & & & & & & & 0.1 \\
\hline 21 Status of Purchase Order & & & & & & & & & & & & & & & & & & & & & & & & \\
\hline 22 Self-Image & & & & & & & & & & & & & & & & & & & & & & & 1.0 & 1.0 \\
\hline 23 Product Review & & & & & & & & & & & & & & & & & & & & & & & & \\
\hline 24 Creating Value & & & & & & & & & & & & & & & & & & & & & & & & \\
\hline 25 Technical Knowledge & & & & & & & & & & & & & & & & & & & & & & & & \\
\hline 26 Personal Standard & & & & & & & & & & & & & & & & & & & & & & & & 0.1 \\
\hline 27 Self Esteem & & & & & & & & & & & & & & & & & & & & & & & & \\
\hline 28 Loyalty & & & & & & & & & & & & & & & & & & & & & & & & \\
\hline 29 Satisfaction & & & & & & & & & & & & & & & & & & & & & & & & \\
\hline
\end{tabular}

Table 6.4: Customers' implication matrix 


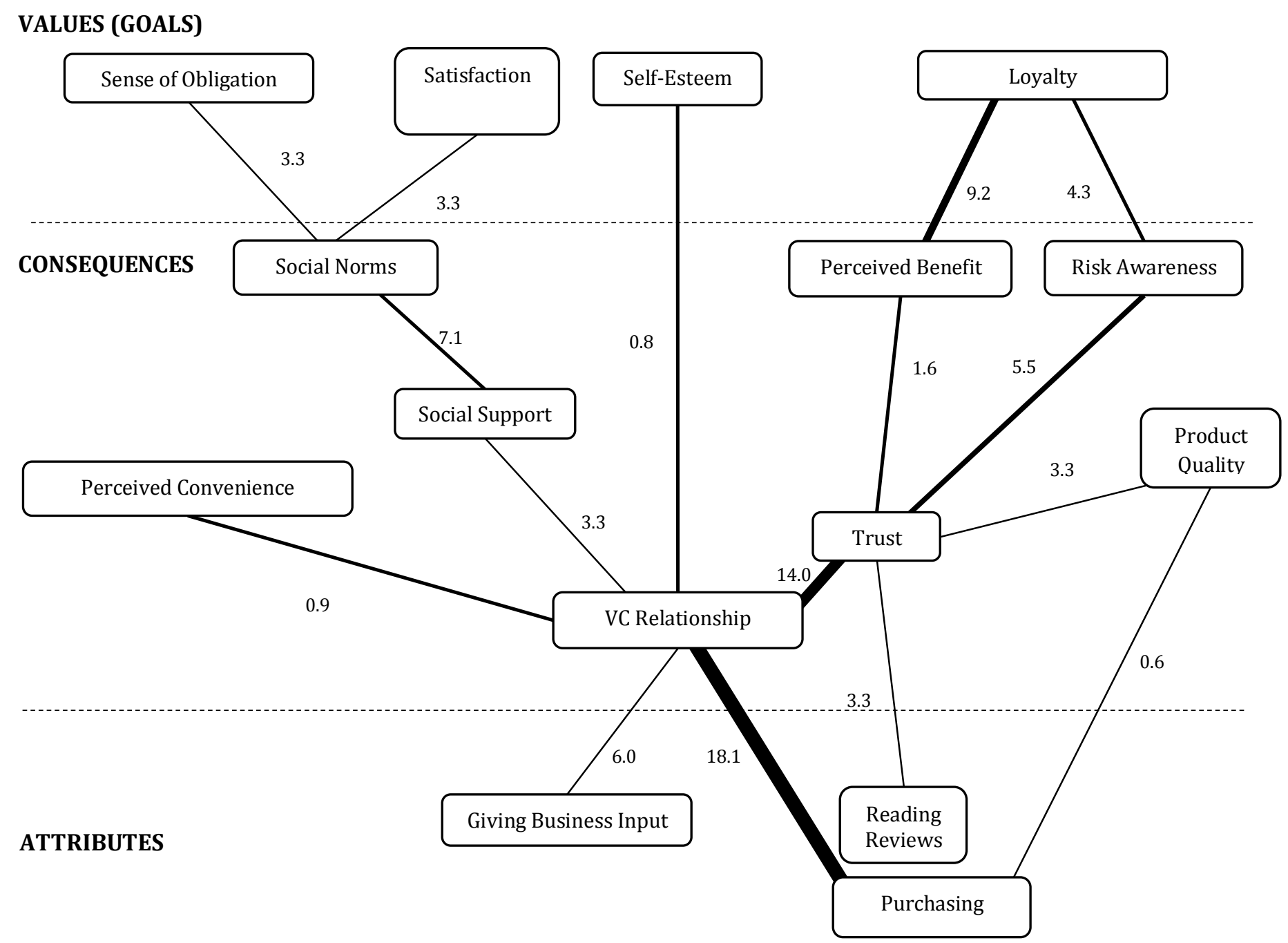

Figure 6.6: Customers' HVM 


\subsubsection{Customers' HVM}

Customers' HVM is constructed by reducing from 29 down to elements to 15 elements. Figure 6.6 shows the full HVM for the sellers. This study found that the main social commerce activities carried out by customers in the community were (i) purchasing, (ii) reading reviews and (iii) giving business input (include any actions that can increase the worth of goods, services or business operations).The HVM also shows that the main goals for engaging in social commerce are (i) loyalty, (ii) self-esteem, (iii) satisfaction, and (iv) a sense of obligation. In addition, as seen in Figure 6.6, there were three basic motivations when customers decided to participate in this community, namely (i) virtual community, (VC) relationship (purchasing - $V C$ relationship; giving business input - VC relationship), (ii) trust (reading review - trust) and, (iii) product quality (purchasing - product quality).

VC relationship is mentioned 28 times in 46 customers' ladders, making it the strongest factor in why community members wanted both to purchase and to give business input to the sellers in social commerce settings. The connection between purchasing activities with a VC relationship denotes 18.1 linkages, whilst the connection between giving business input activities and VC relationship is 6.0 linkages. Purchasing activities also lead to product quality with 6 indirect linkages. Meanwhile, reading review activities lead to trust, which is mentioned 20 times in 46 ladders with 3 direct linkages and 3 indirect linkages. However there is no direct linkage between reading review activities and a VC relationship.

The previous explanations show that the purchasing done by members and the business input they give to sellers are mainly influenced by their bloggerreader relationship. However, reading the reviews that were made available by the bloggers has not been influenced by their relationships in the community.

In order to understand how higher level motivations are connected to their lower level motivations in social commerce, and what the corresponding 
attributes associated with basic motivations are, the relationship chains (A to $\mathrm{V}$ ) were extracted from the HVM. The chains were chosen based on the main path in the HVM, which is the VC relationship. Therefore, the findings will be discussed based on (i) VC relationship - trust path, (ii) reading reviews - trust path, and (iii) VC relationship - social support path. In addition, VC relationship with self-esteem and perceived convenience path will also be discussed. Data from semi-structured interviews and observations (if any) were also used to support the findings.

\subsubsection{VC Relationship - Trust Path}

Figure 6.7 presents the extracted HVM for the VC relationship - trust path. The attributes or activities involved in this path include purchasing and giving business input.

VC relationship is defined as the personal friendship developed among members in the blogosphere community. These relationships are often developed through publics and private online communications, and sometimes develop into face-to-face interactions to pursue a common topic of interest. The relationships are built based on previous interactions, experiences, and learning of others in the virtual community environment. On the other hand, trust refers to the confidence a person has in what other members (sellers) will do, based on their previous interactions. 


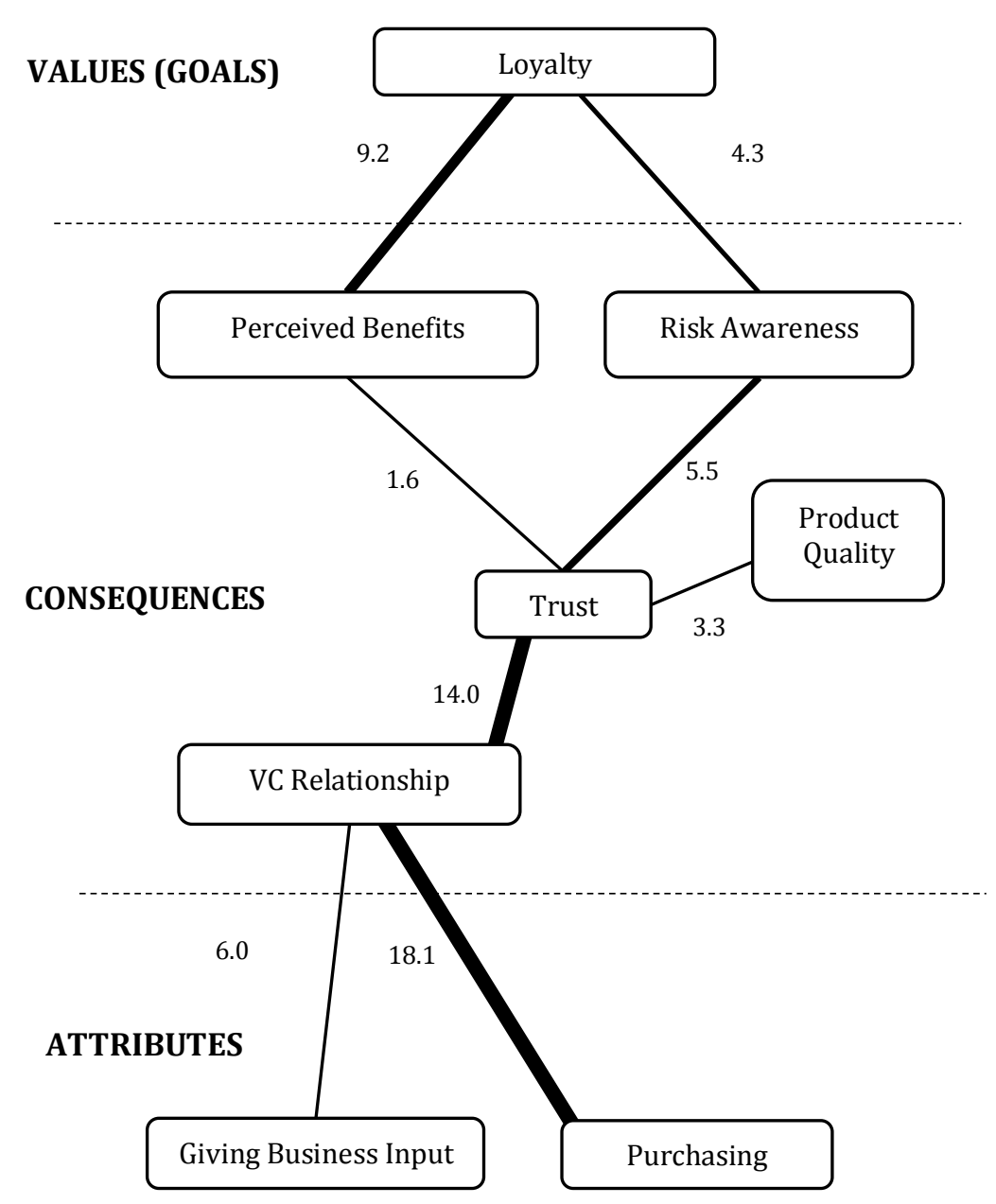

Figure 6.7: VC relationship path

The findings suggest that the basic thing that sparks customers' participation in purchasing and giving business input to the sellers in social commerce is the relationships they have in the community. The following excerpts are consistent with this claim:

"I just bought stuff from people who are my friends in the community. Most of them are famous bloggers who I have been friends with for years. So when they started selling online, I preferred to buy from them" - Participant B2.

"I have a good relationship with them so I actually feel sorry for them because some of them don't even know how to use certain basic functions, so I feel that I have to do something to help them" - Participant B12. 
"I prefer to buy from someone I am familiar with. I know the community members so that's why I prefer to buy from them" - Participant B17.

Results indicate that having good relationships in the community is what is most likely to influence the social commerce participations. This finding is consistent with the finding from the sellers' side, where the sellers acknowledge that their good relationships in this community influenced them to participate in social commerce. The supporting data shows that the relationship is influenced by the presence of homophily, tie strength and the SOVC (refer to Section 6.4).

\section{The Relationship between VC Relationship and Trust}

As shown in Figure 6.7, VC relationship can lead directly to trust. The direct link from VC relationship is equal to 14 which is relatively high. The fact that the VC relationship only has a direct relationship with trust shows that that having relationships in the community is important to developing trust. Customers admitted that it was their trust in the bloggers in the community to motivate them to participate, as shown in following excerpts:

"I know a lot about them, from our conversations, from what they're saying on their social media account, so it developed trust, and because of our good relationship, I believe that risk of being cheated by the sellers are low" Participant B2.

"Online shopping is not safe, so it is important for us to know the sellers in order to trust them" - Participant B7.

"I think they can be trusted as they have a reputation they need to maintain as a blogger. They simply won't cheat" - Participant B16.

The excerpts show that the trust they had as members of the community to the bloggers is transferred to their relationship as seller and customer. Next, the upper level elements in this path will be discussed. 


\section{The Upper Level Elements in VC Relationship - Trust Path}

It is apparent in Figure 6.7 that trust can lead to perceived benefits and risk awareness. Risk awareness refers to a situation where customers are aware of the uncertainty and possible adverse consequences of engaging in an activity. Meanwhile, perceived benefits refer to customers' perception provided by the complete shopping experience, not only product acquisition but also including any tangible or intangible benefits they gain from the purchase or participation in community.

This study found that customers acknowledge the value that they might get (perceived benefits) and acknowledge the risk (risk awareness) they might have if there is no trust in their social commerce participation. However, for the trust-perceived benefits path, the indirect linkages were stronger (1.6) than direct linkages. This means that there must be unknown factors that lead from trust to perceived benefits. The excerpt from Participant B17 explains the direct relationship from trust to perceived benefits:

"The experience of online shopping can be exhausting if we choose the wrong sellers... Although we do have a consumers' tribunal, but it is very tedious. So I just want to experience something that is simple and easy without having to worry about what might happen with the transactions. We need to be comfortable because for me, if we want to enjoy the product we purchase, we need to experience an enjoyable purchasing process as well".

Meanwhile for the trust - risk awareness path, the direct and indirect linkages which are 5.5 are considered moderate, as risk awareness was mentioned 11 times in customers' section. The following excerpts explain the relationship:

"If I know the seller, the risk is at least lower compared to buying from a stranger outside the community" - Participant B3. 
"Trust is important because we never know what will go wrong when you buy online" - Participant B14.

"And the trust that we built from the friendship makes it comfortable to deal with them. It's like the probability we get cheated is low" - Participant B14.

The results show that risk awareness and perceived benefits have direct and indirect relationships with the goals of why customers participate in social commerce, which is loyalty to the sellers in the community. Customers' perceived benefits has a stronger relationship with loyalty (9.4) whilst risk awareness to loyalty is 4.3. This shows that customers acknowledge that developing trust from their relationships will lead to achieving higher goals, as shown in the following excerpts.

"I don't have to worry much about the deal. And that also means that there will be high possibility I will return to the same sellers. To think of it, yes, most of the time, I buy things from the same sellers when I realized there is no risk" - Participant B10.

"I think everyone will agree with me on this. Whenever we made a purchase, we want everything to be right. We must feel satisfied with everything. This includes both the product we paid for and how the sellers treat us. So if everything is ok, I think it makes me feel satisfied and I will surely buy more" - Participant B7.

"If the risk is low, I would choose to buy from the same sellers" - Participant B7.

"I think for a seller to have their customer return to them, they should be aware that there is risk. If there is no risk in the process, people will come back to you" - Participant B15.

The last element connected in the VC relationship - trust path is the product quality. Although the linkage is quite low with 3.3, it shows that customers realize the importance of relationship and trust in the 
community in order to attain a good quality product. Participant B3 stated: "the last thing you want to go through is to be cheated by the sellers. Not only in terms of losing money and not getting our stuff, but also in terms of the quality of the products".

\subsubsection{Reading Reviews - Trust Path}

As shown in Figure 6.8, the reading review activities has direct and indirect linkages of 3.3 with trust. Although the relationship is not as strong as VC relationship - trust linkages, the reading review activities are mainly motivated by trust as they have only been mentioned for six times in the ladders. Therefore, the 3.3 linkages are considered to be significant for this path. There are also several other unknown elements that contribute to trust.

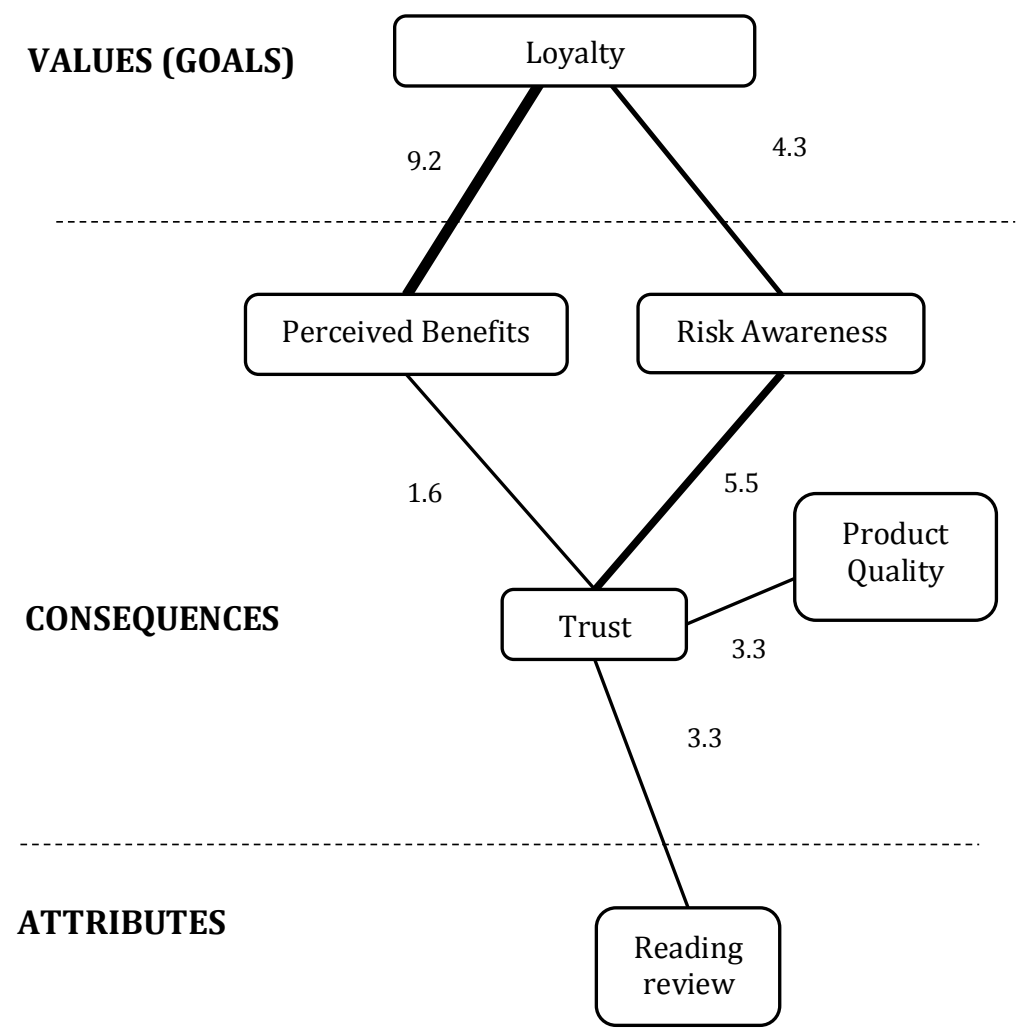

Figure 6.8: Reading review - Trust path 
The following excerpts prove the relationship:

"The reason why I read their review is because I trust their review. Trust is important because we know that we are getting the correct information. And I get to know about new product in the market" - Participant B9.

"I think their reviews are mostly trustworthy and reliable" - Participant B20.

"Reading a review from someone we know and trust can help us make decisions especially regarding the quality of the products" -Participant B17.

The previous excerpts show that customers participate in reading the reviews provided by members of the community because they believe the information they acquire from people they know are reliable. It can help them to identify products with good quality.

The upper level elements in this path are similar to the $V C$ relationship trust path. It includes product quality, perceived benefits, risk awareness and loyalty as explain in the $V C$ relationship - trust path in Section 6.3.2.1.

\subsubsection{VC Relationship - Social Support Path}

Figure 6.9 shows the VC relationship - social support path. The activities involved in this path are (i) purchasing and (ii) giving business input. Social support in this research refers to a members' experiences of being cared for, being responded to, and being helped by other blogosphere community members, or the other way around. The linkages between VC relationship and social support are likely to be moderated with a direct and indirect linkages of 3.3 as compared to the VC relationship - trust path.

This linkages show that the relationship in the community lead customers to give social support to the sellers. These findings indicate that the relationship between bloggers and readers plays a significant role in influencing the members to participate as customers. There are also some 
unknown indirect influences from their relationships that can lead to the social support.

The findings also show that the customers acknowledge that the social support given is not only limited to personal support but also support that is related to the business. Consistent with the findings in the sellers' section (refer to Section 6.2.2.1), the social support in this sections also found the existence of four types of social support from customers to sellers, namely emotional support, instrumental support, informational support and appraisal support.

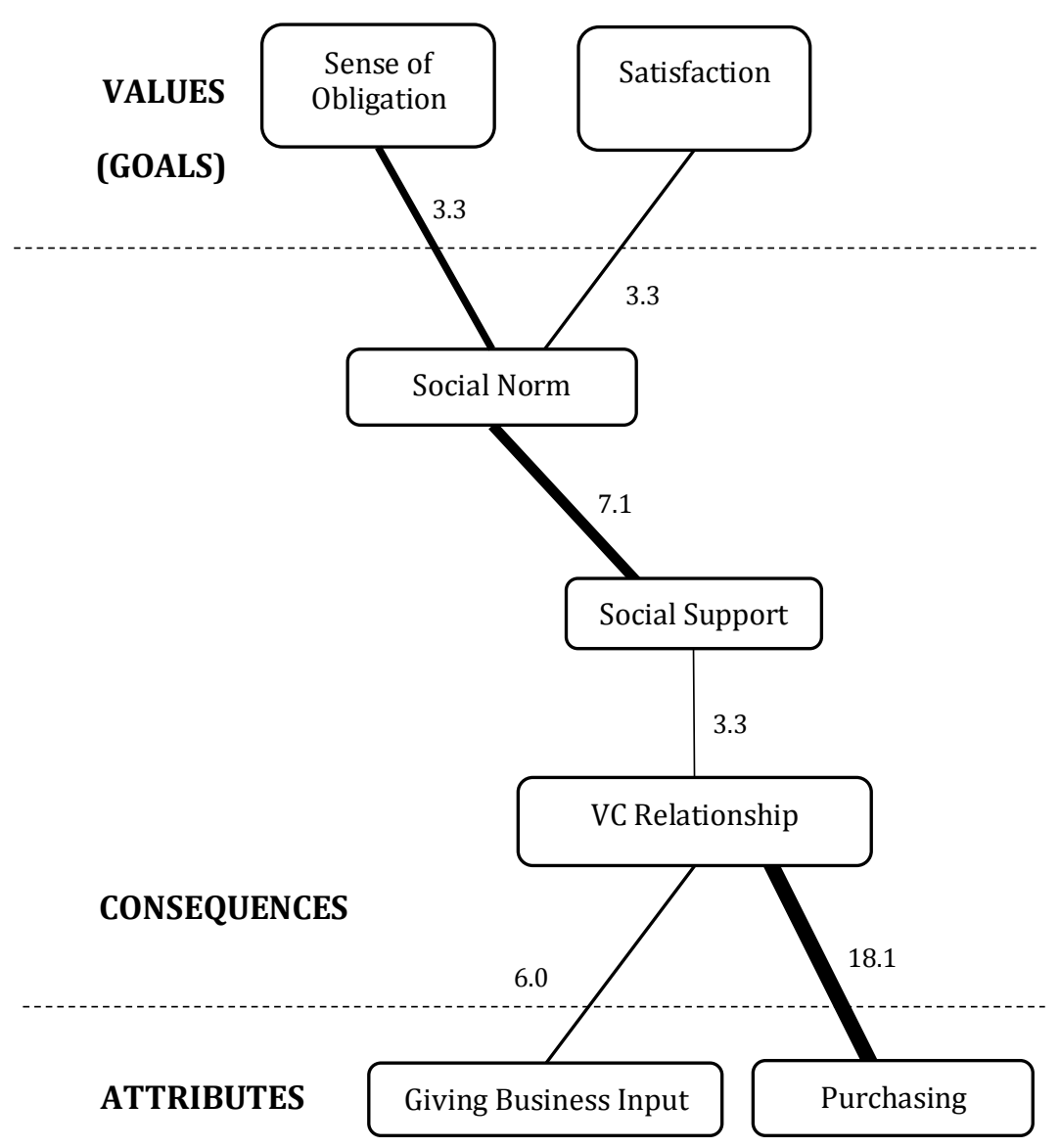

Figure 6.9: VC relationship - Social support path

The following excerpts show the social support noted by the participants:

"I want them to use my comments or testimony for their business. It can help them to promote their businesses. I think it is important for her to have such 
feedback so that she can use it for her business. For advertisement or marketing"- Participant B4 (Instrumental support).

"Usually readers are more supportive in term of giving them motivation; some even buy stuff from the bloggers whatever they sell, just for the sake of encouraging them to do business" - Participant B13 (Emotional and Instrumental support).

"I saw many complaints from customers saying that they missed the post and it took time to search for it. I have bought a lot of stuff online so I have learned from other sellers... as I find it is more practical to have the list on their blog as well, so that's the reason I gave them such a suggestion. I just want to help. Because I happen to know about it" - Participant B5 (Informational Support).

"I also tell them that they should try to expand their market using other social media such as Facebook or Instagram. Facebook and Instashops are major hits nowadays. It is easier to search for products using hashtags" Participant B7 (Appraisal Support).

The types of social support practiced by the customers are similar to what are perceived by the sellers (refer to Section 6.2.2.1). The factors influencing social support practices are presented in Section 6.4.4. Next, the upper level elements in this path will be discussed.

\section{The Upper Level Elements in VC Relationship with Social Support}

Being aware of the practice of giving social support is one of the reasons why customers provide social support to others in the community. This explains the next upper element in this path, social norms. Social norms is defined as the appropriate behaviour of members in a blogosphere community or the pattern of behaviour in a community, or culture, accepted as normal and to which a member is expected to conform. In other words, it refers to doing what other people are doing in the community. The direct relationship from social support to social norms is 
7 which is stronger than the indirect relationship (1). Findings indicate that customers are likely to give social support because everybody else also did the same thing. This shows the strong sense of virtual community can influence customers to participate in social commerce because they want to do things others are doing in the community.

"That's what everybody else doing is in this community. We always buy from the blogger, no matter what they sell. It's like a trend or something" Participant B2.

"I think that's what so special about this community. We always try our best to give feedback to the bloggers. Bloggers are mostly like celebrities in this community. We adore them because they are somehow good role models in the community. So we love to help them. That is the practice" - Participant B3.

"I think everybody in this community is supporting each other. You can see it clearly especially when the sellers come out with a new product. Sometimes, you just buy something not because you need it but because you wanted to try it because it is your friends who sell it" - Participant B13.

The upper elements of social norms are (i) sense of obligation and (ii) satisfaction, which are the values or motivations for the customers to participate in social commerce in this path. The direct and indirect linkages between social norms and both elements are 3.3.

Findings for the social norms and sense of obligation path will be discussed first. Sense of obligation refers to members' commitment, to maintaining community relationships. The direct linkages from social norms to sense of obligation is the same the indirect linkages (3.3), which denotes a weak linkage. However, when compared to the total number of sense of obligation mentions in this study, which is 10 times, this can be considered a moderate relationship. The reason why customers feel that they need to conform to social norms is because they feel obligated to the 
community. The reasons include (i) nationalism, (ii) benevolence and (iii) a sense of responsibility as evidenced in the following excerpts:

"There are certain small things that they can improve. I think they might not notice it so a customer can take the responsibility to tell them what's wrong and give suggestions to them. I just feel like doing so" - Participant B6.

"Sometimes, you just buy something not because you need it but because you want to try it because it is your friends who sell it. And I feel I should be good to them too, like others. I feel like it's my job to help them because everybody is doing the same" - Participant B19.

"I think it could be because we feel that we should help them. I mean the readers and bloggers. I feel that as a Malay, I have a responsibility to support Malay's products and as a member in the community, if I have the capability to help, I should help" - Participant B3.

"Seriously, yes [bought the product without any intention to buy at first]. Sometimes we just asked about the product out of curiosity. The seller... that was the first time I asked the seller regarding the product. Before this it was just a conversation that was unrelated to business. I kept on asking this and that... The seller nicely spends time to entertain me. Actually I don't have any intention to buy. At the end, I was like "what am I doing?" I feel bad about it because she is really nice so I ended up buying the product because she has spent her time entertaining all my questions. The way she interacts with me makes me end up buying the product." - Participant B3.

Next, the relationship between social norms with satisfaction will be discussed. Satisfaction refers to the fulfilment of their wishes, expectation or needs. The direct and indirect linkages of 3.3 means the social norms are not the only reason for customers' satisfaction. There are several unknown factors in the relationship. These findings indicate that the social norms lead to the satisfaction of the customers in the community, as shown in the following excerpts: 
"I think it is because everyone in my circle has bought from this seller. She's kind of famous. So it's like I am proud to tell people that this year I bought Eid cookies from Hanis. So it's like I am not left behind. I don't know how to explain it. I think I'm happy if I can do the same as other people in my circle" - Participant B13.

"Because they [community members] are doing the same. I just want to give back to the community. I think it's probably because it is your responsibility in this community as a member. I am satisfied because I am able to contribute" - Participant B19.

\subsubsection{VC Relationship - Self-Esteem and VC Relationship - Perceived Convenience Path}

Figure 6.10 shows the linkages between VC relationship with self-esteem and VC relationship with perceived convenience. Both have a weak relationship with no direct linkages. The indirect linkages between VC relationship and self-esteem is 8, whilst the indirect linkages between VC relationships with perceived convenience is 9 . This finding shows that some unknown factors exist that link VC relationship with both paths. However other data has shown that amongst the factors are because of the ease of use of social media and ease of communication with the sellers.

For the VC relationship - perceived convenience path, data from semistructured interviews shows that customers are likely to feel at ease when they know the sellers or they are in a good relationship with the sellers, as evidenced below:

"It is easier to ask them about the product... I mean I don't have to be formal with them. I can text or PM them anytime" - Participant B4.

"It is convenient that way. I mean, if anything went wrong, we can straight away ask them about it without having to feel anxious having to deal with someone we don't know that might not respond the way we want them to respond to the situation" - Participant B5. 
"It is easy to communicate with the sellers because we already know them from their blogs, and some of them have already become my friends in Facebook" - Participant B6.

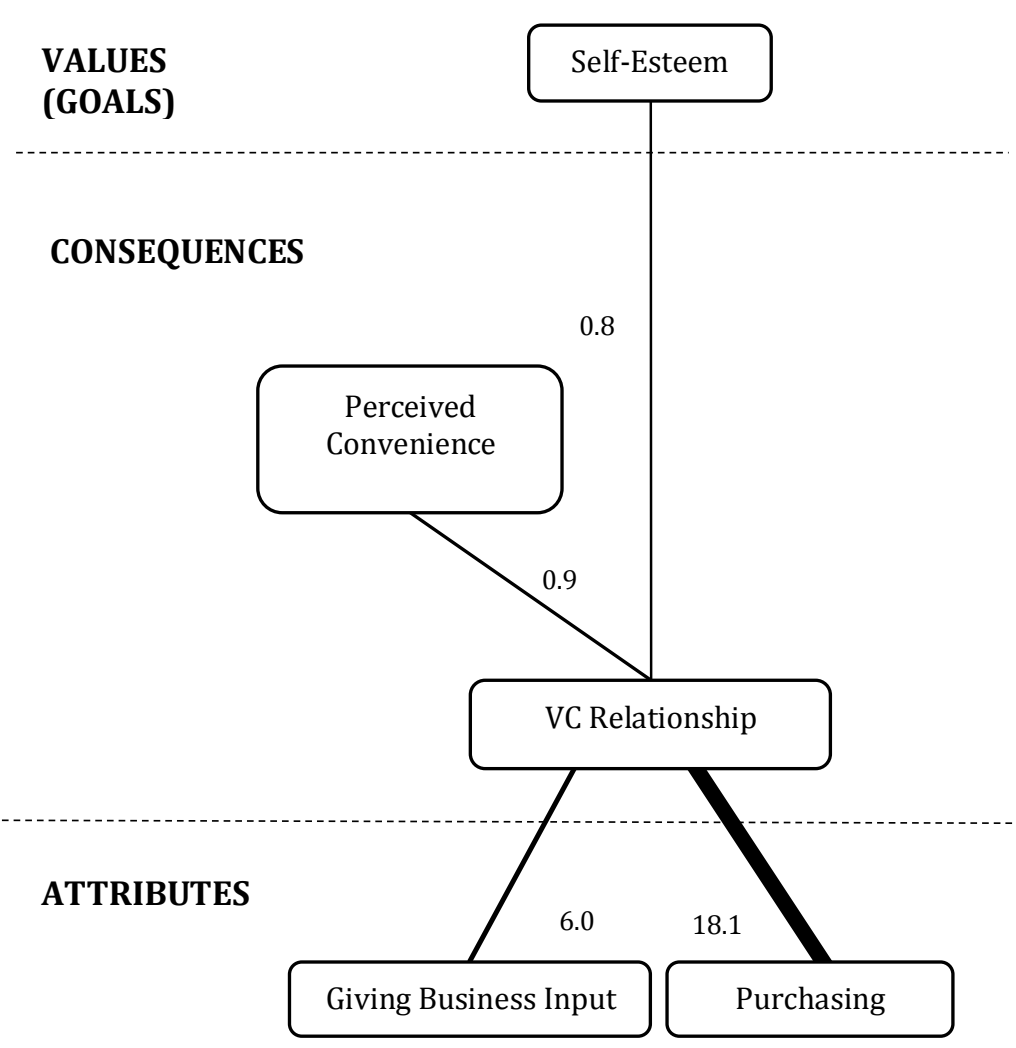

Figure 6.10: VC relationship - Perceived convenience path and VC relationship - Self-esteem path

Meanwhile for the VC relationship - self-esteem path, result shows that the relationship with famous bloggers is one of the influential factors for the customers to feel good about themselves and boost self-esteem in the community.

The following excerpts prove the claims:

"Bloggers are famous in the community. People in this community will be really proud when they have a good connection with the sellers. Even just as a buyer, it feels great" - Participant B4. 
"I don't want to be left behind when they update about the stuff they've bought. I am competitive like that. I wanted to be in the circle... I will not be happy about it if I am left behind... I guess that makes me nearly as good as everyone else" - Participant B21.

"It makes me feel good to buy from them... shows that I am part of this community" - Participant B10.

The findings show that although the VC relationship elements do not directly influence perceived convenience and customers' self-esteem, due to various unknown reasons, the VC relationship has some level of influence on these two elements.

\subsubsection{Summary}

The customers' findings show that participation in the virtual community are likely to help them to achieve their goals, such as fulfilling their sense of obligation, satisfaction, loyalty and self-esteem. In order to achieve their goals, they are influence mostly by homophily and their sense of virtual community, which shapes their relationships with other members. Consequently they are able to provide social support to the sellers, trust them, as well as enjoy the convenience of dealing with the sellers.

Section 6.2 and 6.3 have explained the motivational factors for both sellers and customers, and the relationship between those factors. The next section will explain the other findings of this research.

\subsection{Other Findings}

This section discusses the findings from the semi-structured interviews and observations. It confirms the findings from the laddering data as well as providing the reasons behind the motivational factors for both sellers and customers. 


\subsubsection{Reasons for Participating in Blogging Community}

In the context of this study, participation includes blogging and engaging as a reader as well as participating in activities organized within the community. This study found that the main reasons for members to commit to the community are to find friendship, sharing a feeling of similarity between them (homophily), to socialize with other members, as an alternative media to follow, to gain social support, gain knowledge or get new information, to have the chance to share their opinions, and to earn extra money. Many of the readers claimed that they are attracted to read blogs because of the similarity they have with the bloggers whether being the same gender, same background and so on.

The following is selected evidence for members' participation in the community.

\begin{tabular}{|l|l|c|}
\hline Reasons & Evidence & Participants \\
\hline Friendship & I wanted to have friends. & $\mathrm{S} 13$ \\
\cline { 2 - 3 } & $\begin{array}{l}\text { It is more to get more friends: as a Muslim, I } \\
\text { believe that friendship is important, and } \\
\text { maintaining a friendship is also important. I } \\
\text { want to make friends because I believe my } \\
\text { religion taught me to make friends with } \\
\text { everybody. I want to create contacts and I am } \\
\text { happy to have more friends to discuss gossip, } \\
\text { business, and family. }\end{array}$ & B3 \\
\hline Similarity & $\begin{array}{l}\text { I think the main thing is connecting with like- } \\
\text { minded people with same interest so that's why } \\
\text { I still go and read their blogs. }\end{array}$ & B10 \\
\cline { 2 - 4 } & $\begin{array}{l}\text { Usually they share about their personal lives, so } \\
\text { I feel close with them, especially as there are }\end{array}$ & B14 \\
\hline
\end{tabular}




\begin{tabular}{|c|c|c|}
\hline & $\begin{array}{l}\text { some similarities between me and them, so } \\
\text { starting from that point, I feel close with them. }\end{array}$ & \multirow[b]{2}{*}{ B2 } \\
\hline & $\begin{array}{l}\text { I think she is similar to me. Her life, } \\
\text { commitment, opinions are similar to mine, so I } \\
\text { enjoy interacting with her }\end{array}$ & \\
\hline \multirow[t]{2}{*}{ Socializing } & $\begin{array}{l}\text { After I get married the world for me is my work } \\
\text { and my family, so socialising in the virtual } \\
\text { world is great. Sometimes I meet them face-to- } \\
\text { face. }\end{array}$ & S6 \\
\hline & $\begin{array}{l}\text { I think it's important because actually when we } \\
\text { read a blog, it is kind of like we socialize with } \\
\text { an even bigger community than just our } \\
\text { friends. }\end{array}$ & B1 \\
\hline \multirow[t]{2}{*}{$\begin{array}{l}\text { Alternative } \\
\text { media }\end{array}$} & $\begin{array}{l}\text { News from newspaper and television are } \\
\text { suffocating nowadays. There is too much } \\
\text { political influence that actually makes me stop } \\
\text { reading the newspaper or watch news on } \\
\text { television. But I still need to know what's } \\
\text { happening outside there. So blogs are the } \\
\text { alternative media for me. Bloggers re-write or } \\
\text { maybe share opinions in a way that you didn't } \\
\text { feel mad when you're reading it. }\end{array}$ & $\mathrm{S} 15$ \\
\hline & $\begin{array}{l}\text { Nowadays we can get extra info that we can't } \\
\text { get from television or newspaper from blog }\end{array}$ & B8 \\
\hline $\begin{array}{l}\text { Social } \\
\text { Support }\end{array}$ & $\begin{array}{l}\text { The support system is superb. I like it when } \\
\text { people share their problems and almost all of } \\
\text { the problems come with solutions or at least } \\
\text { some possibilities of solutions by the members. } \\
\text { People care. }\end{array}$ & S20 \\
\hline
\end{tabular}




\begin{tabular}{|c|c|c|}
\hline & $\begin{array}{l}\text { New knowledge, friendship... and what I like } \\
\text { most is the emotional support from members. }\end{array}$ & $\mathrm{B} 20$ \\
\hline \multirow[t]{2}{*}{$\begin{array}{l}\text { Gain } \\
\text { Knowledge/ } \\
\text { Information }\end{array}$} & $\begin{array}{l}\text { Some people see it as a waste of time but the } \\
\text { truth is there is an overwhelming amount of } \\
\text { knowledge sharing happening in this } \\
\text { community }\end{array}$ & S19 \\
\hline & $\begin{array}{l}\text { There's a lot of information I get from the } \\
\text { blogger. So the blog actually helps me gain } \\
\text { information }\end{array}$ & \\
\hline \multirow[t]{2}{*}{$\begin{array}{l}\text { Share } \\
\text { opinions }\end{array}$} & $\begin{array}{l}\text { It's like a place where normal people like us } \\
\text { have a chance to let others (know)... I mean, to } \\
\text { share our opinions on certain issues. The person } \\
\text { might not be an expert but somehow their } \\
\text { opinion is more logical. }\end{array}$ & B8 \\
\hline & $\begin{array}{l}\text { So the involvement with this community is not } \\
\text { only regarding the product reviews butyou can } \\
\text { get something else out of it. Before this I didn't } \\
\text { know the importance of breast milk. But luckily } \\
\text { parents nowadays are knowledgeable; we have } \\
\text { been exposed with information about } \\
\text { breastfeeding even we are working, how to } \\
\text { pump and store the milk, and we are also } \\
\text { exposed to all the gadgets and such that we } \\
\text { never knew existed before. }\end{array}$ & B9 \\
\hline \multirow[t]{2}{*}{ Earn money } & $\begin{array}{l}\text { I also get some money by advertising other's } \\
\text { products on my blogs. }\end{array}$ & $\mathrm{S} 21$ \\
\hline & I want to have a side income by blogging. & $\mathrm{B} 21$ \\
\hline
\end{tabular}

Table 6.5: Reasons to participate in the blogging community 
The table shows a mixture of sellers and customers' view. This evidence shows that members of this community regardless their roles (bloggers or sellers, readers or customers), are having similar thoughts when they participate in the community. These findings are important to draw the relationship between their participation as bloggers and readers in the community with their participation in social commerce.

\subsubsection{Factors Influencing Members' Relationships}

This study found that the relationships in the Malay lifestyle blogging community were influenced by homophily, tie strength, and the SOVC. Homophily can be described as the tendency of individuals to associate and bond with similar others. As mentioned in Section 6.4.1, one of the reasons for participating in the community is perceived similarity between members. This has encouraged them to bond, which shows that they are actually experiencing the presence of homophily. The homophily in this community has influenced the tie strength among its members, and subsequently influenced the relationships in the community. This is evident in the following excerpts:

"The friendship in this community is developed based on the similarity we had. Most of us have a similar background. I love to read Blogger A's and Blogger $B$ 's blog because I also have three girls. It is so funny that my girls are just like theirs, with all the drama. If we have time we always talk about our girls. It creates bonding between us. We become closer" - Participant B21.

"When you meet like-minded people, it is easier to connect with them. That is what I experience in this community. I like making friends with people similar to me. I get close to some of the bloggers because of this. It's easier to understand them. We support each other. We trust each other because we know each other quite well" - Participant B6.

"We become close friends because we share the same ideas on parenting" Participant B10. 
Other interview excerpts that describe the homophily in this community can be seen in Tables 6.4, 6.5 and 6.6. The explanation of the SOVC and how it affects relationships in this community is explained in Section 6.4.6.

\subsubsection{Factors Influencing Trust}

Trust in the community is influenced by the relationships as shown in the customers' HVM (refer to Section 6.3.2.1). How the relationship between sellers and the customers can influence the trust can be explained by their relationship as bloggers and readers, which includes homophily, consistency of blog post, the reputation of the bloggers, familiarity with the bloggers and offline meetings.

The following table shows the factors related to their relationships that lead the customers to trust the sellers.

\begin{tabular}{|l|l|c|}
\hline Factors & Evidence & Participants \\
\hline Homophily & $\begin{array}{l}\text { I think some of the bloggers are similar to me; } \\
\text { their thinking and lifestyle and values. So I } \\
\text { think I can trust them. }\end{array}$ & B8 \\
\cline { 2 - 3 } & $\begin{array}{l}\text { I read their blogs frequently and I think we } \\
\text { are living the same life. Struggling with kids } \\
\text { and work. She shares a lot of tips on how to } \\
\text { manage things better. I think I can trust her } \\
\text { with my secrets. }\end{array}$ & B17 \\
\hline Consistency & $\begin{array}{l}\text { I have been following her for a few years and } \\
\text { I can remember all her stories and I know she } \\
\text { doesn't lie about her life because the stories } \\
\text { are consistent. }\end{array}$ & B11 \\
\cline { 2 - 4 } & $\begin{array}{l}\text { No conflicting stories in her posts. I know she } \\
\text { is being honest with the readers. }\end{array}$ & B10 \\
\hline
\end{tabular}




\begin{tabular}{|c|c|c|}
\hline \multirow[t]{2}{*}{ Familiarity } & $\begin{array}{l}\text { We always communicate to discuss about our } \\
\text { daughter. I am familiar with her way of } \\
\text { thinking. I think that is one of the reasons I } \\
\text { trust her. }\end{array}$ & B6 \\
\hline & $\begin{array}{l}\text { She is very nice to me. I always ask her a lot of } \\
\text { questions because I am a first time mum so I } \\
\text { always panic about everything but she } \\
\text { always make me feel better. I trust her. So } \\
\text { when she start with the business I knew I } \\
\text { could trust her. }\end{array}$ & B2 \\
\hline \multirow[t]{2}{*}{$\begin{array}{l}\text { Offline } \\
\text { meetings }\end{array}$} & $\begin{array}{l}\text { I went with my friend to Nuffnang events and } \\
\text { I met some bloggers there. They are exactly } \\
\text { like what they show in their blogs. It was fun } \\
\text { meeting them. }\end{array}$ & B20 \\
\hline & $\begin{array}{l}\text { We always have gatherings because we live in } \\
\text { the same neighbourhood. It is more fun to } \\
\text { meet face-to-face because we can talk about } \\
\text { a lot of things. }\end{array}$ & B10 \\
\hline \multirow[t]{2}{*}{ Reputation } & $\begin{array}{l}\text { I don't know all bloggers, but I know most of } \\
\text { them can be trusted because they have a } \\
\text { reputation they need to maintain. }\end{array}$ & B2 \\
\hline & $\begin{array}{l}\text { I think the reputation of the blogger is very } \\
\text { important. Their reputation takes years to } \\
\text { build. }\end{array}$ & B9 \\
\hline
\end{tabular}

Table 6.6: Why customers trust sellers

\subsubsection{Factors Influencing Social Support Practices}

As mentioned in Sections 6.2.2.1 and 6.3.2.3, social support is one of the motivations for both sellers and customers to participate in social commerce. In the case of sellers, they are aware of the support given by the members, 
including their customers, to them. Meanwhile, customers are willing to provide social support for the sellers. The following table explains the factors influencing social support practices in the community from both sellers' and customers' point of view.

\begin{tabular}{|c|c|c|}
\hline Factors & Evidence & Participants \\
\hline \multirow[t]{2}{*}{ Social ties } & $\begin{array}{l}\text { Because we are friends... so, of course I } \\
\text { wanted to help her. }\end{array}$ & B19 \\
\hline & $\begin{array}{l}\text { We are close. So that could be the reason } \\
\text { why we don't mind helping each other. }\end{array}$ & S4 \\
\hline \multirow[t]{2}{*}{ Social norms } & $\begin{array}{l}\text { Everyone in this community helps each } \\
\text { other. So I guess I should do the same. }\end{array}$ & B10 \\
\hline & $\begin{array}{l}\text { Maybe it is because everyone supports each } \\
\text { other in the community. }\end{array}$ & S1 \\
\hline \multirow[t]{2}{*}{$\begin{array}{l}\text { Sense of } \\
\text { obligation }\end{array}$} & $\begin{array}{l}\text { We are quite close so I think it is our } \\
\text { responsibility to support them in any way } \\
\text { we could. Especially as most of the sellers } \\
\text { are Muslim. }\end{array}$ & B7 \\
\hline & $\begin{array}{l}\text { She doesn't know how to do it so I think I } \\
\text { should help. }\end{array}$ & B21 \\
\hline \multirow[t]{2}{*}{$\begin{array}{l}\text { Return good } \\
\text { deeds }\end{array}$} & $\begin{array}{l}\text { Sometimes it's for moral support as well } \\
\text { when I'm feeling down when doing my PhD. } \\
\text { And nowadays when I'm feeling down like I } \\
\text { am the worst mother or something so I go to } \\
\text { their blog and read and then sometimes the } \\
\text { experience they share is similar to what am } \\
\text { I going through. So I think that's kind of } \\
\text { moral support. And I also wanted to do the } \\
\text { same for others, supporting them. }\end{array}$ & B10 \\
\hline & $\begin{array}{l}\text { I think it is how I wanted to give back to the } \\
\text { community. }\end{array}$ & B2 \\
\hline
\end{tabular}




\begin{tabular}{|l|l|c|}
\hline Admiration & $\begin{array}{l}\text { The readers, sometimes they looked up to } \\
\text { you [sellers] so I guess it has something to } \\
\text { do with that as well. It's like you have } \\
\text { already known each other for years so you } \\
\text { didn't mind helping each other. Yeah, I think } \\
\text { so. }\end{array}$ & S20 \\
\cline { 2 - 3 } & $\begin{array}{l}\text { I am not sure, but it could be because the } \\
\text { bloggers in the community are some sort of } \\
\text { idols. So maybe that's why we get so much } \\
\text { help. }\end{array}$ & \\
\hline
\end{tabular}

Table 6.7: Factors influencing the social support practices

Table 6.7 shows that the ties between members, norms, sense of obligation, returning good deeds and admiration are among the factors influencing social support practices.

\subsubsection{Type of Participation in the Malay Lifestyle Blogging Community}

There are three types of participation in lifestyle bloggers community, which differ based on the level of participation. The types of participation include (i) active members, (ii) silent readers and (iii) lurkers.

Active members are bloggers or readers who actively participate by posting articles on their blogs, following blogs, leaving comments on others' blogs, as well as interacting among themselves, not only in the blogosphere platform but also on other social media platforms such as Facebook, Twitter, Instagram and so on. In addition, they may participate in face-to-face gatherings and maintain their communication via smart phone applications such as WhatsApp, Telegram, and Line. This improves the interconnectedness between members. According to Abidin (2013a), perceived interconnectedness is experienced by readers as a result of having followed these commercial bloggers closely over a long period, and having 
received continuous bite-sized updates about their daily affairs. The following are evidence for these findings:

"I consider myself an active member as I always participate in the discussions and I can say that I read blogs every day. But that is depending on their updates" - Participant B12.

Meanwhile, silent readers are those members who silently follow the blog post and the public conversation on other members' blogs, or social media accounts. The silent readers only voice their opinions when they feel they need to do so or if the topics capture their interest. Usually the relationship between silent readers and other members are based on what they share on blogs or social media. Being a silent reader in this community means having less communication. However this group of readers avidly follows the blogs of their choice and is up to date with what is going on in the community from their reading. Therefore, they also feel the interconnectedness; just like active members. One of the reasons is likely because they are inspired by what the bloggers are sharing on their blogs. Some of the silent readers communicate privately with bloggers to share about their problems whether anonymously or not. This situation has developed the interconnectedness between them and the bloggers, even with less personal communication as compared to active members.

"I rarely comment openly even if the topics are interesting because I hate the limelight. But sometimes I send private message to share my opinion" Participant B1.

The last group of members in the community are inactive silent readers who only wander in the community without making any contact or being attached to any bloggers. This type of participant is defined as a lurker. Lurkers are invisible participants, who may read and access community content but do not visibly contribute to the shared online spaces of the online community to which they belong (Cranefield, Yoong, \& Huff, 2015). Technically, the lurkers are very similar to the silent readers, as both of these groups are likely to be 
invisible. However, the lurkers in this community context do not have any perceived interconnectedness as a result of their lack of participation.

"I am sure there are some people who read the blogs just to grab important information. I have friends who read blogs but do not participate in any discussion" - Participant B7.

The findings suggest that the bonding between members of the blogosphere community is not merely on the surface. This phenomenon shows that the members have somehow developed feelings of trust out of their respect for bloggers in the community. In return, bloggers also start to get to know their own readers via social media.

During the interview, it is obvious that the active participants thought highly of the bloggers. Their writings about daily life were found interesting by the readers especially when they shared something that could be learned and/or practiced by the readers. This has consequently develop the respect among the readers. Bloggers have become a role models or idols for their followers. They have developed trust between them to the extent of sharing their personal problems such as monetary or marriage problems. Bloggers are usually really careful how they discuss the members' problems as mishandling may tarnish their reputation. They are obligated to give advice and keep the problem anonymous if there is a need to ask for public opinion. The discussions are usually perceived as being very helpful by the members. Hence the reason why readers are so fond of these bloggers.

\subsubsection{Level of the Sense of Virtual Community (SOVC)}

SOVC is defined as the members' feelings of membership, identity, belonging, and attachment to a group that interacts primarily through electronic communication with their virtual community (Blanchard, 2007). The dimension of SOVC includes membership, influence and immersion (refer to Section 2.2.4). Evidence suggests that the participants in this community are 
likely to have experienced the SOVC, which is explained in the following section.

\subsubsection{Membership}

The members of the community show the characteristics of membership dimension of SOVC. Membership is the feeling of belonging to the community. The following table shows the indicators for membership dimension.

\begin{tabular}{|l|l|c|}
\hline Indicators & Evidence & Participants \\
\hline Homophily & $\begin{array}{l}\text { We share a lot about ourselves, our } \\
\text { families and lives, so people tend to feel } \\
\text { connected to each other especially when } \\
\text { we have similar backgrounds. }\end{array}$ & B11 \\
\cline { 2 - 3 } & $\begin{array}{l}\text { Ifeel like I am part of the group although } \\
\text { I haven't met many of them. Maybe it's } \\
\text { because all of us are similar to each } \\
\text { other. When you read the blog, you will } \\
\text { end up laughing at yourself because you } \\
\text { also share the same issues. }\end{array}$ & B17 \\
\hline Bloggers & $\begin{array}{l}\text { When I asked about anything, the } \\
\text { bloggers would always respond. } \\
\text { Although sometimes we know they are } \\
\text { busy, they will at least respond by saying } \\
\text { they will get back to me when they are } \\
\text { free. That's why I feel like I belong in this } \\
\text { community. }\end{array}$ & B18 \\
\cline { 2 - 2 } & $\begin{array}{l}\text { Ilike the way they handle the discussion. } \\
\text { think this is why I enjoy being part of the } \\
\text { community. }\end{array}$ & B19 \\
\hline
\end{tabular}




\begin{tabular}{|c|c|c|}
\hline \multirow[t]{2}{*}{$\begin{array}{l}\text { Frequent } \\
\text { blog updates }\end{array}$} & $\begin{array}{l}\text { When I first joined this community, I felt } \\
\text { like I knew the bloggers because they } \\
\text { always updated their blogs; it feels like } \\
\text { they are talking to you. }\end{array}$ & B5 \\
\hline & $\begin{array}{l}\text { When you read the blog every day you } \\
\text { get attached to them. }\end{array}$ & B9 \\
\hline \multirow[t]{2}{*}{$\begin{array}{l}\text { Members' } \\
\text { identification }\end{array}$} & $\begin{array}{l}\text { Yes, I am familiar with other members } \\
\text { because they always appear when we } \\
\text { have discussions, mostly on Facebook. }\end{array}$ & B21 \\
\hline & $\begin{array}{l}\text { I know them [other members] because } \\
\text { we are mutual friends on Facebook. We } \\
\text { follow the same bloggers so basically we } \\
\text { are everywhere. }\end{array}$ & B14 \\
\hline \multirow[t]{2}{*}{ Offline ties } & $\begin{array}{l}\text { Meeting them in small gatherings makes } \\
\text { me feel more attached to them. }\end{array}$ & B3 \\
\hline & $\begin{array}{l}\text { Maybe it's because we always go out for } \\
\text { dinner so it makes me close to them. }\end{array}$ & B11 \\
\hline
\end{tabular}

Table 6.8: Evidence of membership dimension

Note that the homophily has been discussed in Section 6.4.2, which shows that homophily influences the trust between members in the community. This study has also found that homophily is also influencing the feeling of membership. Evidence shows that homophily, frequent blog updates, members' identification and offline ties influence the readers to feel close to the bloggers. They are also influenced by their respect and admiration towards the bloggers enthusiasm when dealing with them.

\subsubsection{Influence}

Influence in SOVC context describe the ability for the members to influence and to be influenced by other members in the community. The 
members have shown that they are likely to be influenced by other members in the community as shown in the following excerpts:

\begin{tabular}{|l|l|c|}
\hline Factors & Evidence & Participants \\
\hline Compelling & $\begin{array}{l}\text { Although I never meet any of them, their } \\
\text { writing is very powerful that it even } \\
\text { makes you think twice about certain } \\
\text { decisions. }\end{array}$ & B9 \\
\cline { 2 - 3 } & $\begin{array}{l}\text { That's why they were call influential } \\
\text { bloggers, they know how to convince } \\
\text { people even just through their writing. }\end{array}$ & B20 \\
\hline Strong ties & $\begin{array}{l}\text { We are quite close and sometimes I } \\
\text { follow her parenting style because I } \\
\text { respect the way she handles her } \\
\text { daughter. }\end{array}$ & B2 \\
\cline { 2 - 3 } & $\begin{array}{l}\text { Yes, I was inspired by her passion for } \\
\text { gardening. Recently, I have started to } \\
\text { do a little bit of gardening. }\end{array}$ & S2 \\
\hline
\end{tabular}

Table 6.9: Evidence of influence dimension

As the community started from blogging, the written form of communication has proven to be the most influential form of communications. In addition, their strong ties have also encouraged the members to inspire members or be inspired by others, which subsequently influence their behaviour.

\subsubsection{Immersion}

Koh and Kim (2003) describes immersion as the holistic sensation that people feel when they act with total involvement. The following table presents the factors for immersion in this community. 


\begin{tabular}{|c|c|c|}
\hline Factors & Evidence & Participants \\
\hline \multirow[t]{2}{*}{$\begin{array}{l}\text { Multiple visit } \\
\text { to blogs }\end{array}$} & $\begin{array}{l}\text { It feels like I am missing something if I } \\
\text { don't read it frequently... I always refresh } \\
\text { to see if there is new update. I spend more } \\
\text { time than I expect navigating their blogs. }\end{array}$ & B11 \\
\hline & $\begin{array}{l}\text { It's fun to know what other people are up } \\
\text { to. It's like you got addicted to social } \\
\text { media. It is the same thing for this } \\
\text { community. Usually we will read blogs } \\
\text { every day. It's addictive. }\end{array}$ & B16 \\
\hline \multirow{2}{*}{$\begin{array}{l}\text { Enjoy Face- } \\
\text { to-face } \\
\text { meeting }\end{array}$} & $\begin{array}{l}\text { I was excited when I met her at the } \\
\text { shopping complex. }\end{array}$ & B18 \\
\hline & $\begin{array}{l}\text { I think I am more active now after having } \\
\text { met them. I really like this community } \\
\text { because at least I know them now. }\end{array}$ & B7 \\
\hline \multirow[t]{2}{*}{$\begin{array}{l}\text { Volunteering } \\
\text { behaviour }\end{array}$} & $\begin{array}{l}\text { I love to help them, that's the least I can } \\
\text { do for the community }\end{array}$ & S3 \\
\hline & $\begin{array}{l}\text { I am not sure, but I guess I have some } \\
\text { responsibility to help them. }\end{array}$ & S7 \\
\hline
\end{tabular}

Table 6.10: Evidence of immersion dimension

Table 6.10 shows that multiple visits to blogs to check the latest update, face-to-face meetings and volunteering behaviour are evident, showing that members are immersed in the community.

\subsubsection{Level of the SOVC}

The discussion on SOVC has shown that the members in this community are likely to experience the SOVC. Nonetheless this study found that the 
level of SOVC differs based on the level of participation. Table 6.11 shows evidence for members having different levels of the SOVC.

\begin{tabular}{|l|c|}
\hline Evidence & Participants \\
\hline $\begin{array}{l}\text { I don't really feel I belong to the community although I } \\
\text { am addicted to reading blogs. Maybe because I rarely } \\
\text { communicate with the members. }\end{array}$ \\
\hline $\begin{array}{l}\text { I don't think everyone is into this community. You will } \\
\text { actively participate when the discussion is related to you } \\
\text { so it depends. There are times when I don't feel like I } \\
\text { belong to the community and sometimes it is close to my } \\
\text { heart. }\end{array}$ \\
\hline
\end{tabular}

Table 6.11: Level of SOVC

The table shows that some of the members may have experienced all dimensions, therefore the level of SOVC is considered high as compared to the one who does not experience all dimensions.

\subsubsection{Summary}

Section 6.4.6 has discussed the three dimensions of the SOVC and how the members show evidence of membership, influence and immersion. Findings also show that the level of SOVC differs for each member, depending on their participation level. Based on the findings represented in this section, this study argues that the SOVC has influenced the relationship they have with bloggers in the community.

\subsection{Eliminated Elements}

As mentioned before in Sections 6.2.2 and 6.3.2, some elements were omitted from the HVM. Having these elements in the implication matrix shows that there are other factors that influence members' motivation. However, because only a few members mentioned them, these elements were removed as a result of having a weak relationship with other elements. 
In the case of sellers, the following elements were removed: (i) reputation, (ii) new media attitude, (iii) knowledge sharing, (iv) WOM, (v) social norms, (vi) customers trust, (vii) economic value, (viii) customer engagement, and (ix) sense of obligation. Meanwhile for the customers, the following elements are not included in the HVM: (i) new media attitude, (ii) WOM, (iii) product variety, (iv) social image, (v) product information, (vi) decision quality, (vii) group buying, (viii) reviews, (ix) creating value, (x) technical knowledge, and (xi) personal standards.

\subsection{Main Findings Revisited}

This study suggests the presence of homophily, the strong ties between members, and experiencing a sense of virtual community lead the Malay lifestyle blogging community members to have good relationships. These characteristics have also influenced the motivation of members to participate in social commerce as explained in this chapter.

The following table revisited the benefit and values layers for both sellers and customers:

\begin{tabular}{|l|l|l|}
\hline Layers & Benefit & Values \\
\hline Sellers & $\begin{array}{l}\text { Perceived Convenience; Social } \\
\text { Support; Potential Customers; }\end{array}$ & $\begin{array}{l}\text { Business Sustainability; Cost- } \\
\text { Effectiveness; Profit; Self- } \\
\text { Business Opportunities }\end{array}$ \\
\hline Customer & $\begin{array}{l}\text { VC Relationship; Trust; } \\
\text { Perceived Convenience; Social } \\
\text { Support; Social Norms; } \\
\text { Product Quality; Perceived }\end{array}$ & $\begin{array}{l}\text { Loyalty; Sense of Obligation; } \\
\text { Senefit; Risk Awareness }\end{array}$ \\
\hline
\end{tabular}

Table 6.12: The benefit and values layers for both sellers and customers

The benefit and values layers of the HVM (refer to Sections 6.2.2 and 6.3.2) are considered to have more explanatory power to explain the motivation better than the attributes layer (López-Mosquera \& Sánchez, 2011). This is because 
those benefits and values are the elements that underlie individuals' active, conscious and observed behaviour (Fishbein \& Ajzen, 1975). By breaking the motives for the three layers, certain behaviours and/or choices are more likely to be uncovered than by using conventional methods that will often only produce a very shallow understanding of what is going on (Grunert \& Grunert, 1995).

Figure 6.11 shows the main motivations for the members (both sellers and customers at a highly summarised level), to continue participating in social commerce activities.

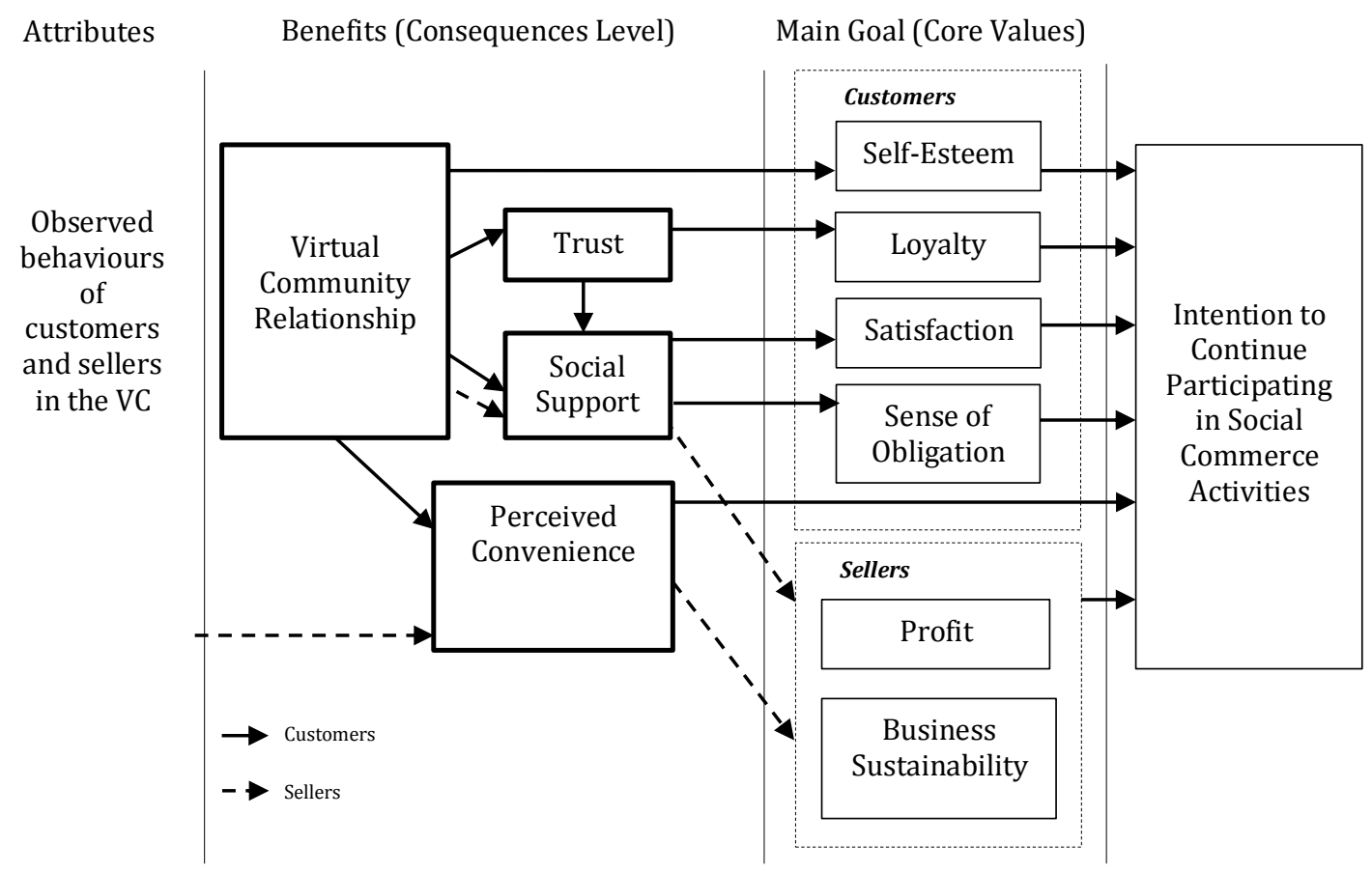

Figure 6.11: The main motivations of both sellers and customers

The figure explain how the main motivational factors lead the sellers' and customers' main goals. Note that on the highly summarised level there are two goals associated with sellers' motivational factors, which are (i) profit and (ii) business sustainability, whilst the customers' goal are (i) loyalty, (ii) sense of obligation, (iii) self-esteem and (iv) satisfaction. The motivation that leads to the goals are the social support and the perceived convenience. 
Meanwhile, Figure 6.12 shows the key findings of this research. The diagram shows two dimensions of participation in this community: (i) the community participation dimension, and (ii) the social commerce participation dimension. The first dimension will be explained next.

In the community participation dimension, the level of participation was found to be influencing the community characteristics. The homophily in the community shaped the norms and practice of the community, the tie strength, and SOVC amongst members, created trust in the relationship and promoted social support in the community. The general members' roles in this community are bloggers and readers who used social media platforms and mobile apps to communicate.

The social commerce dimension in the diagram highlights the roles of sellers and customers in the community. The implementation of social commerce in this community includes the multi-platform, multi-payment and multi-delivery options for the customers.

As shown in the diagram, the trust and norms developed in the community participation dimension were transferred to the social commerce participation dimension. This means the social relationship between the bloggers and their readers drives their commercial relationship. The transformation from the social commerce dimension to the social commerce dimension was motivated by their goals in participation as explained before in Figure 6.11. Figure 6.12 has also highlighted the transformation from one dimension to the other as influenced by the culture, ethnicity and religious belief of the members. 


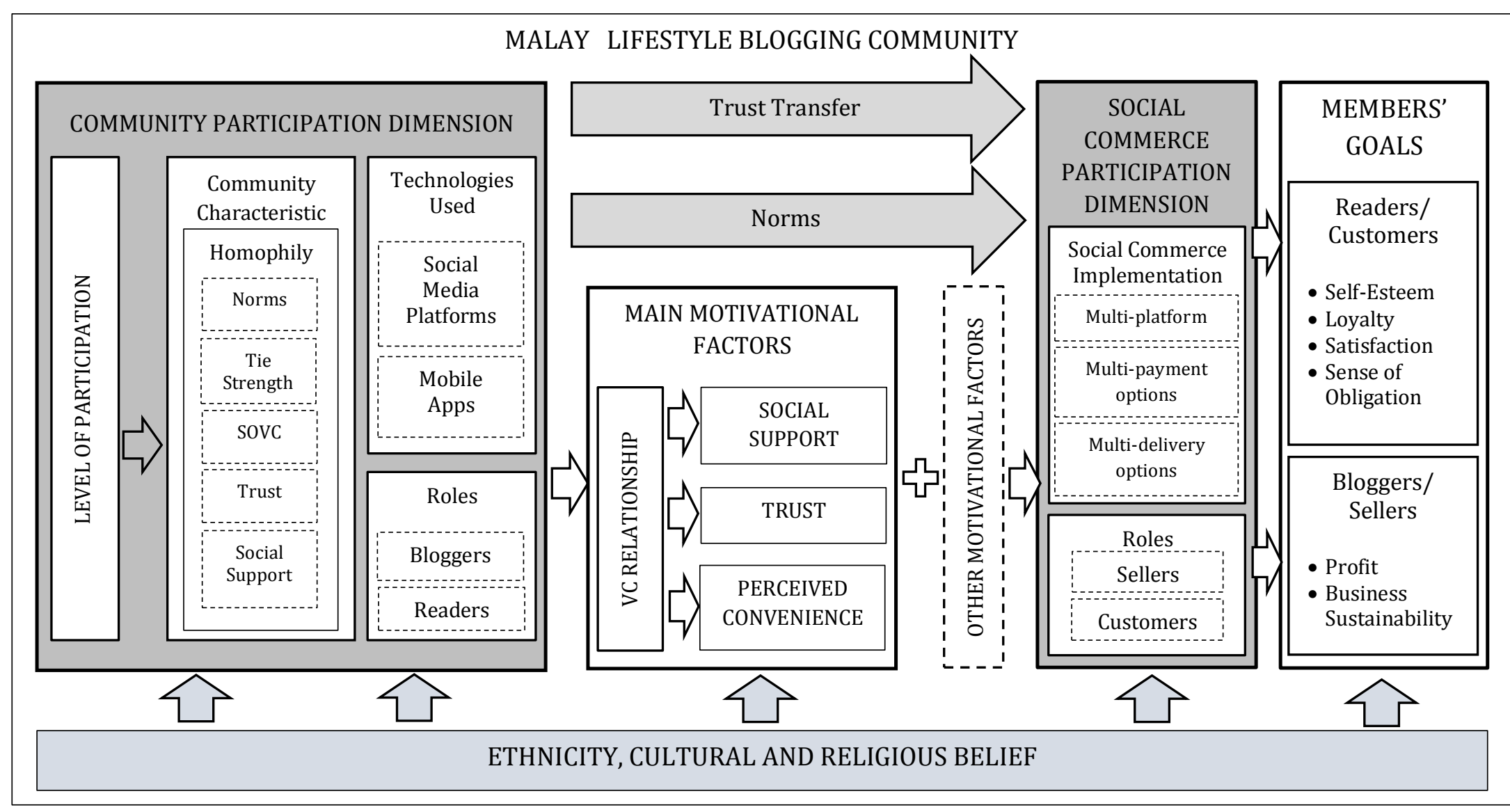

Figure 6.12 Key Findings of this research 


\subsection{Conclusion}

Laddering theory assists in uncovering underlying motivations by asking a series of questions that start with observed attributes or behaviours, then lead through to the benefits that participants derive from those behaviours, and the underlying values they represent. Based on the means end theory, the attributes layer includes those observed behaviours in the community. These are the starting point for understanding customers' and sellers' motivations. Attributes (in this case, observed behaviours) include listing and selling products, posting product reviews and promotions, communicating with community members purchasing products, reading reviews, co-creating and so on.

The findings show that the main factors that influence the sellers and customers motivations to participate in commercial activities are mainly because of the relationship in the community. Although the sellers' findings did not directly acknowledge the VC relationship in the HVM, the social support that was perceived by the sellers in the community showed that the social support they gained from the community was a result of their good relationships between the community members. 


\section{CHAPTER 7}

\section{DISCUSSION}

This chapter presents a discussion focusing on the two research questions, based on the main findings from both the academic literature and the empirical data. Later sections describe the overall lessons learned from the findings. This chapter is concluded with a brief summary.

\subsection{Introduction}

Overall, the motivations for participation in social commerce for this community can be summarized around a few key themes. Past relationships that the customers had with the bloggers in the community led the community members to trust the bloggers when they started to sell the products. Trust influences them to buy because if they purchase from someone they know, the risk is lower when compared to purchasing from strangers, as well as being sure of the quality of products advertised by the sellers.

The customers feel that there is a need for them to provide social support because they want to help the sellers by purchasing and help them to spread the word about the business. There are various reasons for this phenomenon, which include (i) they consider the members to be their friends; therefore they should help their friends, (ii) they have received some help from the sellers or seen them help others which makes them want to do the same for the sellers, (iii) most of the sellers are of the same gender, race and religion; therefore customers feel an obligation to support their business, and (iv) they want to contribute as it is a norm for the members to support each other in the community.

Furthermore, they perceive participation in the virtual community as more convenient. The stores are easily accessed through social media that they use daily. They can easily negotiate the price, ask for free gifts, and customize their orders, such as packaging a present and so on. Sellers in this community are also 
flexible in term of payments; they provide multiple payment options, such as online transfer, cash on delivery and PayPal.

Although relationship and trust were not clearly found as motivational factors for the sellers, the sellers acknowledged that the social support they gained from the customers was the result of strong ties, the SOVC and trust of their customers. In addition sellers also perceived that by using social media and selling in the community, it was more convenient for them to initiate commerce activities in the community.

All of these main motivations from the consequences layers are supposed to have more explanatory control than the attributes level for explaining the members' behaviour (refer to Figures 6.2 and 6.6). In this chapter, these themes (relationship, trust, social support and perceived convenience) will be discussed in detail, based on the research questions, which are revisited next.

\subsection{Research Questions Revisited}

The primary goal of this research is to examine the main factors that influence the Malay lifestyle blogging community members to participate as sellers and customers in social commerce. In order to achieve the objectives, the following research questions need to be answered:

RQ1: What are the factors that motivate members of the Malay lifestyle blogging community to continue their participation in social commerce activities?

RQ1 (a): What are the factors that motivate sellers (bloggers) to venture into social commerce?

RQ1 (b): What are the factors that motivate customers (readers) to participate in social commerce? 
RQ2: What is the relationship between the members' virtual community participation and their social commerce participation?

This chapter addresses these research questions by using the following structure:

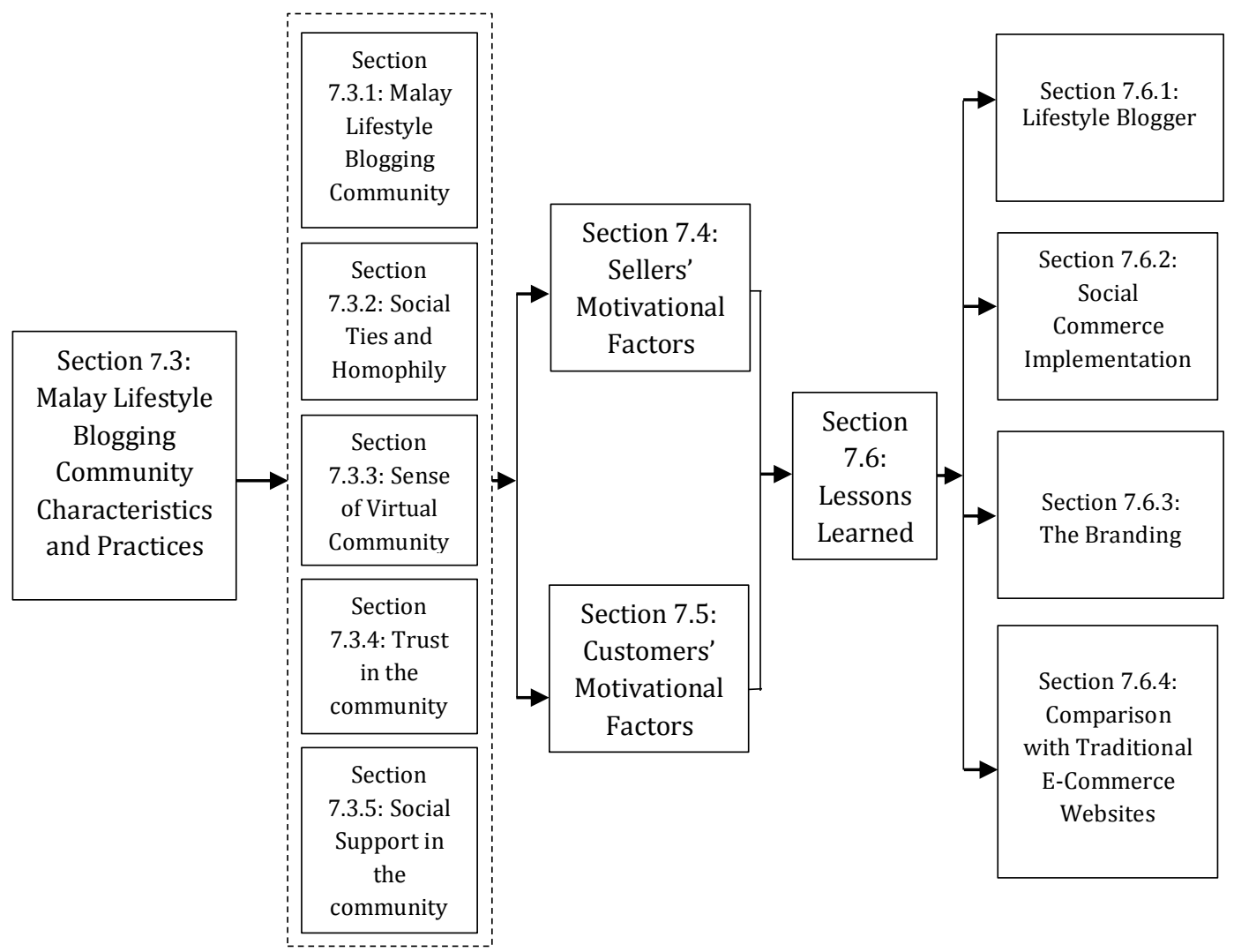

Figure 7.1: The structure of this chapter.

Section 7.3 discusses the Malay lifestyle blogging community in terms of its characteristics, as well as its common practices. Section 7.4 addresses RQ1 (a), whilst Section 7.5 addresses RQ1 (b). The transitions from Section 7.3 to Section 7.4 and Section 7.5 describe how the community characteristics and practices influence the members' participation in social commerce, which addresses RQ2.

This study focuses only on the bloggers as sellers and readers as customers. Therefore, in this chapter, the term sellers will be used interchangeably with bloggers, whilst the term customers will be used interchangeably with readers. 


\subsection{The Community Characteristics and Practices}

Empirical findings from the combination of laddering, semi-structured interviews and observations show that the relationships in the community influence some of the bloggers' motivations to proceed with online business. They also influence the readers' motivation to participate in commerce activities. Empirical evidence points to the characteristics of the community as an influence on the motivations. Therefore, this section will discuss the characteristics of the community, which can be explained by social network theory, the concepts of homophily and social ties, sense of virtual community, level of participation, trust and social support. These characteristics will be used to describe the findings of this research.

\subsubsection{Social Network Theory: Social Ties and Homophily}

Social network theory proposes that an online community can be described as a social network composed of nodes and edges, representing individuals and relationships (Toral et al., 2010). Social networks show who is connected to whom in the population and by what relationship (Krause et al., 2007). According to Krause et al. (2007), relationships in a network can represent any type of social behaviour. This includes helping to create social capital and strengthening weak and latent ties.

The findings show that the ties between members in the community are strong. The reason that this community has strong ties can be explained by the concept of homophily. Homophily is defined as the tendency of individuals to associate and bond with similar others. According to McPherson et al. (2001), this means that people's personal networks tend to be homogenous with regard to many social-demographic, behavioural and intra-personal characteristics. The homophily principle suggests that people with shared characteristics are more likely to relate to one another (McPherson et al., 2001) and create bonding. This argument by McPherson et al. (2001) is confirmed by the findings of this study where the members reported that they started following other members because they perceived 
them to be similar, and the more characteristics they share with the bloggers, the closer they feel to them (refer to Section 6.4.1). This is because the members can easily determine that other bloggers are similar to themselves by reading the blog contents. Blogging allows a high degree of selfpresentation and high self-disclosure (Kaplan \& Haenlein, 2010) as well as sharing. Therefore by reading the blogs, members learn more about the other members and they can decide whether to create ties with them based on their judgement of their similarity. This study extends the findings by showing the similarity can be measured by members by reading the content of the blogs.

Gilly et al. (1998) found that the greater the homophily between communicators, the more persuasive the message of the communicator, which is in this study, the bloggers and to a lesser extent the readers in this community. This study found that the more similar the members were to others, the more frequently they would read the blogs and interact. This confirms the findings of Valenzuela et al. (2009) who suggest that the ties among the members differ according to the similarity they encounter in each other. The findings are also in line with the claim made by Li and Du (2011) who found that the greater the homophily, the greater the attention a reader would pay to a blog. Most blogs are interactive in the sense that they provide visitors with the opportunity to post comments (Lenhart \& Fox, 2006). The members of this community started by commenting on each other's blogs and have expanded their interactions into different spaces such as social media applications and cross-platform mobile messaging applications. This is because blogs can foster social interaction that leads to connections between people who would not have met offline, which is in line with the arguments by Hodkinson (2007) and Boyd and Ellison (2007). This community which uses a variety of social media platforms to communicate opens up more opportunities for members to interact and get to know each other better. By following blogs and social media accounts, they become more familiar with the background of the bloggers. Engaging in discussions with other members, they start to share issues and problems and give social 
support to each other, which eventually leads to them creating strong ties and experiencing the SOVC. This is consistent with the social network theory where tie strength is dependent on the amount of time people spend together, along with such factors as levels of emotional intensity, mutual confiding, and reciprocation (Granovetter, 1973).

In addition, the findings in this community confirm the arguments by Valenzuela et al. (2009) and Lin (2001) by showing that the members were connected to each other in this community based on their similarity, and that the connection has increased their social networks and social capital as they interact more with each other. Valenzuela et al. (2009) argue that individuals with a large and diverse network of contacts are thought to have more social capital than individuals with small social networks. This is because social capital is a resource made available to people through their social interactions (Lin, 2001).

The findings of this study also support arguments about homophily by Brown and Reingen (1987) and Granovetter (1973) where the stronger the tie connecting two individuals, the more alike they tend to be (Granovetter, 1973). The findings also support findings by Brown et al. (2007), Granovetter (1981), McPherson et al. (1992) and Xiang et al. (2010) who claimed that tie strength can be influenced by homophily or vice versa. This can be explained by one of the SOVC dimensions, i.e. influence (refer to Sections 6.4.6.2 and 7.3.2.2). The findings show that members have a tendency to influence or to be influenced by other members in the community, as a result of the strong ties created in the community.

The findings on the identification of strong ties are also consistent with the argument made by Haythornthwaite (2002) who claimed that the stronger the social ties are, the more media the members used to make contact with each other. In addition, members will also be more successful in adding new media to their repertoire or adapting it to meet their needs, which is the case in this community (refer to Section 6.4.5). As shown in the findings chapter, the community members use multiple media to communicate with each 
other including blogs, Facebook, Instagram, Twitter and some smart phone applications such as WhatsApp, WeChat, Telegram, Line and so on.

Another aspect to be explained about the relationship between homophily and social ties in this community is the demographic background of Malaysians. As Malays, participants of this research are likely to be influenced by homophily to create strong ties as many Malaysians are most comfortable amongst their own races (refer to Section 5.3). This finding is in line with McPherson et al. (2001) who argue that strong homophily is found on race and ethnicity. This factor is an effect of the gaps between races in Malaysia. Different races in Malaysia can be described as living 'peacefully but separately' as claimed by a survey conducted by the Merdeka Centre for Opinion Research (Kuppusamy, 2006).

Social support is argued to be one of the characteristics of strong ties (Granovetter, 1973). Generally, the community members were proven to have strong ties with each other as they demonstrated a high level of social support as shown in the findings (refer to Sections 6.2.2.1 and 6.3.2.3). The concept of social support will be explained in Section 7.3.5.

Another important factor that helps to explain the relationships in this community is the sense of virtual community theory, which will be discussed next.

\subsubsection{Sense of Virtual Community (SOVC)}

SOVC is defined as the members' feelings of membership, identity, belonging, and attachment to a group that interacts primarily through electronic communication with their virtual community (Blanchard, 2007). This study found that the experience of SOVC influenced their relationships in the community, which then motivated them to participate in social commerce. These findings are in line with Ellonen et al. (2013) that the SOVC strengthens brand-community, brand-loyalty and brand-related WOM intentions. Although they studied a different type of community, their 
findings imply that SOVC reflects positively on the online community and results in positive business-related outcomes, as was found in this study. In addition, this study is also confirming the claim by Sutanto et al. (2011) who stated that the key to virtual community sustainability is maintaining the members' SOVC.

According to Koh and Kim (2003), there are three dimensions of SOVC, which include (i) membership, (ii) influence and (iii) immersion. The members in this community have been proven (refer to Section 6.4.6) to have experienced the sense of virtual community as explained in the following sub-sections:

\subsubsection{Membership}

The first dimension of SOVC is membership. Membership in SOVC describes the social theory identity defined by Tajfel and Turner (1979) which describes a person's sense of who they are based on their group membership. Tajfel and Turner (1979) proposed that the groups (e.g. social class, family, football team etc.) which people belonged to were an important source of pride and self-esteem. Groups give members a sense of social identity: a sense of belonging to the social world. Those community members who share some particular qualities are the ingroup whilst members without those qualities are considered the outgroup. The findings show that the members in this community had strong feelings of belonging to this community, which will be explained next.

Firstly, the membership dimension in this community is likely to be exhibited by the concept of homophily as explained earlier in Section 7.3.1. There are two types of homophily (Lazarsfeld \& Merton, 1954; McPherson et al., 2001): status homophily and value homophily. Status homophily defines a similar social status characteristic such as race or religion, whilst value homophily is based on values, attitudes and beliefs, which is the tendency to associate with others who think in similar ways, regardless of differences in status. In the Malay lifestyle blogger 
community, both types of homophily exist, confirming the claim made by Lazarsfeld and Merton (1954) and McPherson et al. (2001). According to the participants in this research, many of the members share the same gender (female), race (Malay) and religion (Islam) which make it easier for them to mingle as they share a similar culture, religious beliefs and values (refer to Section 5.3). In addition, sharing the same views on such things as hobbies or parenting styles also binds the members together and strengthens the feeling of belonging to the group.

Secondly, in the Malay lifestyle blogging community, influential bloggers act as leaders, providing their followers with frequent updates and responses to comments while organizing online and offline activities with them. They showed their passion by communicating with others. This is in line with the claim made by Koh and Kim (2003) that membership is affected by the enthusiasm of the community's leaders.

Thirdly, the findings confirm the claim made by Abidin (2013a) where readers are more attached to the community if there are frequent updates by the bloggers as it makes the readers keep reading and waiting for the next update. This is because the readers become more connected to the blogs and the bloggers. Websites such as wikiHow and Copypress.com in their tips for blogging also suggest that frequent updates will keep the readers returning to the blogs.

Fourthly, the bloggers often act as intermediaries who link the readers to each other. For example, if any reader needs opinions about certain issues, bloggers will share those issues on their blogs or Facebook, opening up opportunities for members to discuss the issues. Making the discussion available to the readers helps members to get to know the identity of other bloggers and readers. This finding shows that the sense of virtual community develops because the members can recognize other members' names in postings which is in line with the findings of Blanchard and Markus (2002) who reported that this was an important first step in experiencing SOVC. 
Fifthly, as this community does not have a common shared space in which members can interact and keep in touch, other than following blogs, they usually also follow each other's social media accounts in order to maintain their relationships. By following each other's social media accounts, members reported that they started to know more about the other members and developed a better understanding of other members' identities. This finding supports the argument of Blanchard and Marcus (2007) who found that identification of identities based on postings or conversations was likely to influence the members to feel more attached to the community as compared to simply recognizing screen names.

Sixthly, in general this study argues that offline ties among blogosphere members are likely to have a positive impact on their membership in the online community. This finding is consistent with earlier studies showing that face-to-face meetings are important to nurture the virtual community and make stronger virtual links as claimed by Beniger (1987) and Burgos et al. (2005).

\subsubsection{Influence}

The second dimension of SOVC is influence, which occurs when members are influencing other members of their community in certain acts. Firstly, the findings (refer to Section 6.4.6.2) show that members have a tendency to be influenced by other members in the community in making their decisions, which is in line with the argument of Keller and Berry (2003). The bloggers in this community influence people with their writings on various matters. This finding is consistent with Agarwal, Liu, Tang, and Yu (2008) who claim that influential bloggers can affect fellow bloggers and readers, lead trends, and affect group interests in a community. Comments and opinions by non-blogging members in this community are also likely to have some degree of influence on the members.

Secondly, regarding the sense of influence, this study was consistent with the findings of Koh and Kim (2003) that offline activities are not likely to 
have an impact on the members' perceived influence in the community. Offline activities or face-to-face meetings are usually important for online community members as they have the ability to reinforce their connection to the group and their desire to stay active within the group (Matzat, 2010). Nonetheless in this community the offline activities do not have any impact on the influence they perceived in the community. This is likely to be because, in this community, members can always share their thoughts in their blogs which has been proven by the findings to have a high impact on influencing others in this community. Furthermore, the strong ties between members have the tendency to inspire other members to think or act alike (Brown et al., 2007; Brown \& Reingen, 1987) as explained in Section 7.3.1. Therefore even without offline activities, members can still influence others, or be influenced by others to follow certain trends or make decisions based on what they read on the blogs.

\subsubsection{Immersion}

The third dimension of a sense of virtual community is immersion, where members feel a strong need, if not compulsion, to use the site (Reich, 2010), or in this case, the blogs and community. Koh and Kim (2003) describe it as the holistic sensation that people feel when they act with total involvement. The term is applicable to the virtual community as the members tend to display immersive behaviour.

This study found evidence of immersion behaviour in this community (refer to Section 6.4.5.3). Firstly, Koh and Kim (2003) argue that immersion behaviour is not affected by offline activities. However, in contrast to their findings, this study found that offline activities were likely to be one of the factors affecting immersion. This is because followers look forward to meeting their favourite bloggers face-to-face after getting to know the bloggers through their writing. One example of offline activities is members' gathering to get to know each other. Face-toface meetings make members feel enjoyment which related to another finding by Koh and Kim (2003). Enjoyability is defined as enjoyment or 
playfulness derived from the community's content and interactions with other members. Koh and Kim (2003) argue that enjoyability is likely to lead the members to feel immersed in the community. It was found that the Malay lifestyle blogging community members generally enjoyed their interaction, whether face-to-face or through their online interactions with other community members. Therefore this study argues that both offline activities and enjoyability are related in the context of this community as factors that affect the immersion behaviour.

Secondly, the blogosphere community members are likely to have the traits of addictive behaviour. Addictive behaviour includes (i) visiting the blog many times a day to see if there is any update, (ii) leaving messages for bloggers asking them to update their blogs, and (iii) not being satisfied with short blog posts as they want to read more. Volunteering behaviour is also evident. This includes (i) volunteering to assist when any of the members needed help and (ii) volunteering to provide information to other members. These findings on addictive and volunteering behaviour are consistent with the concept of immersion by Koh and Kim (2003), Young (1996), Csikszentmihalyi (1975) and Kiesler et al. (1985). It shows that as the members become more immersed in the community, they are willing to do more for other members. In this study, this includes participating in social commerce.

The previous discussions have shown that the members in this community have experienced SOVC. Nonetheless, this study found that the level of SOVC differs based on the individual (refer to Section 6.4.6.4), confirming Blanchard and Marcus' (2004) argument, who suggest that SOVC is not uniform for each participant. There are different levels of participation that can be used to describe their level of SOVC.

\subsubsection{Level of Participations}

Blanchard and Markus (2004) identified three types of members: (i) leaders, (ii) participants and (iii) lurkers. Generally the level of participation found in 
this study is consistent with their previous work. This study found that the level of SOVC was different for the three types of participants in this community, i.e. (i) active participants, (ii) passive participants and (iii) lurkers.

The active participants in this community are the members who regularly communicate and participate in community activities, online or offline. This is similar to leaders as defined by Blanchard and Marcus (2004). Leaders in the Malay lifestyle blogging community can be either bloggers or readers, whoever usually leads the discussion of interesting topics. This finding supports the claim made by Tonteri, Kosonen, Ellonen, and Tarkiainen (2011) who suggest that both reading and posting messages support the development of SOVC.

The characteristics of silent readers in the lifestyle bloggers community is consistent with the characteristics of passive and private participants in Blanchard and Marcus' (2004) study where passive participation means the members seldom communicate or comment publicly on blog posts, or any social media account, but they still have strong attachments to the bloggers as a result of reading the blogs, following postings on social media accounts on a daily basis, as well as communicating privately with some of the members. This is because the blogosphere promotes intimacy between bloggers and the readers. Although this group of members does not show their participation level publicly, they considered themselves silent readers and occasionally helped the bloggers in particular activities, such as spreading the word about members' businesses. This type of participation is found to be at either high or moderate levels of SOVC.

Meanwhile, lurkers are the members who are not connected to the community, just reading blogs to get useful information without contributing to any of the members. This is consistent with Blanchard and Marcus' (2004) definition of lurkers. This study does not highlight the roles of lurkers in this community, so based on the definition of lurkers itself, this study argues that 
they have low levels of SOVC. Further studies may be needed to fully understand this type of participation.

The previous discussion shows that the members of the Malay lifestyle blogging community create relationships among themselves in the community as explained by the social network theory, social ties, homophily, and SOVC. The explanation of how members develop that trust will be outlined next.

\subsubsection{Trust in the Community}

Trust is essential in a virtual community. In the blogosphere community, there are several ways to produce trust. Firstly, members choose to follow blogs because of perceived similarity and homophily between themselves and the bloggers based on the blog posts, as explained in Section 6.4.1. The findings (refer to Section 6.4.3) show that homophily and perceived similarity in the community are likely to influence trust. This phenomenon is consistent with the argument by $\mathrm{Lu}$ et al. (2010) who define perceived similarity as a trust building mechanism where trust is established based on common characteristics the trustor perceives of the trustee, including interests, values, and demographic traits.

Secondly, there is a consistency in blog posts that members have been following for years. Reading the blogs frequently allows members to see the consistencies of the bloggers' thoughts and attitudes. Members believe that when the bloggers show consistency in their blog posts, especially in personal posts about their family and personal life, it shows that the bloggers are telling the truth. According to Blanchard and Markus (2002), people who communicate electronically with unknown others are understandably concerned about whether the others actually are who they say they are. The consistency of the blog posts demonstrates information quality as defined by Kim and Park (2013) which generates trust in the bloggers. 
Thirdly, it was found that the reputation of bloggers in this community was developed based on the blog posts, as well as the interactions they had with other members in social media. This is in line with Boyd (2006) who argues that social interactions using social media were perceived by the reader as more direct, personal and authentic as compared to other media (i.e. television and radio). Therefore, members can easily judge the character of the bloggers, and whether they can be trusted. In addition, frequent social media updates by the bloggers has increased members' sense of familiarity and closeness to lifestyle bloggers which confirms the claim made by Abidin (2013a). Familiarity refers to the trust building mechanism where individuals get to know each other through interactions and then predict others' behaviours based on the information they obtain from this interactive process (Lu et al., 2010). Members believe that the bloggers will not do anything that will jeopardize their reputations in the community. This finding is in line with the claim made by Sherchan et al. (2013) who argue that trust can be built up over time as a result of repeated interactions between the trustor and trustee. The information available to the trustor from within the relationship itself forms the basis of relational trust.

Fourthly, in this research, it was found that community members do not only hold online meetings but also engage in off-line meetings. Public reports in social media of such meetings became part of the social life of this community. Blanchard and Markus (2002) argue that face-to-face communication is often viewed as a necessary precondition for trusting online relationships. Nonetheless for most of the community members, the face-to-face communication is not the main reason for trust development as the members often develop trust before they meet. As explained before in this section, the perceived similarity and homophily, the consistency of blog posts, and the interactions they had in the community influence the production of trust. Face-to-face communication in this community is viewed as an element that strengthens the trust, not the necessary precondition for trusting as claimed by Blanchard and Markus (2002). 
This study has also confirmed the findings in previous research which include (i) closeness and familiarity (Ng, 2013), (ii) communities are more likely to increase trust (Hajli, 2015), and (iii) shared values among members (Lin \& Lu, 2011a; Sitkin \& Roth, 1993; Tsai \& Ghoshal, 1998) as being some of the factors that influence trust in a virtual community.

Meanwhile the findings also contradict some of the research from the ecommerce literature which identifies the factors that influence online trust such as (i) customer-brand and customer-product relationships (Laroche et al., 2013), and (ii) offline trust (Qing et al., 2008). The contradictions are likely to be because of the different context of the study as well as the different development of the community in this study which started as a knowledge sharing community. This community started to practice commerce activities over a period of years as compared to the typical brand community platforms which are mostly created by the firms for their customers. Nonetheless although the platforms used are different, it was proven that the consequences of trust are similar to what has been found in previous e-commerce research where trust can both reduce the risk and provide benefits (Kim et al., 2009; Siegrist, 2000; Siegrist et al., 2000).

The previous discussion has indicated that the trust in the community is developed based on homophily and perceived similarity, consistency of blog posts, interactions, and face-to-face meetings. The type of trust in this study conforms to the characteristics of knowledge based trust (Hsu, 2008; Lewicki \& Bunker, 1995; Lu et al., 2010; Ratnasingham, 1998) where information about the bloggers based on their reading increases the members' knowledge about the bloggers, therefore creating the trust. In addition, it also confirms the cognition based trust, where trust is developed through experiential personal interactions (Chen \& Dhillon, 2003; Cook \& Wall, 1980; Gefen et al., 2003; Goto, 1996; Mayer et al., 1995; McAllister, 1995; Rempel et al., 1985). Lastly, it is also in line with the concept of relational trust where repeated interaction helps to develop trust towards the members (McAllister, 1995; Rousseau et al., 1998; Sherchan et al., 2013). 


\subsubsection{Social Support Practices in the Community}

Social support refers to a member's experiences of being cared for, being responded to, and being helped by other members of a community. Social support has become one of the benefits that members obtain by joining this community. Past research by Baym (1997), Ridings and Gefen (2004), Preece (1999), Rheingold (1996) and Greer (2000) found that the exchange of support among members is one of the characteristics of a virtual community. This section will explain why members practise social support.

Firstly, social support between bloggers and members is a result of, and reinforces, the strong ties between members in the community as explained in Sections 6.4.4 and 7.3.1. Readers have developed strong ties with bloggers and therefore provide social support to each other. This finding complies with the claim made by Ridings and Gefen (2004) where individuals join online communities and participate in a group because they seek social support and friendship in the community.

Secondly, the readers practice social support because of their admiration for the bloggers. The readers look up to the bloggers and want to do their best to help when the bloggers are in need. This finding supports the argument by Kahn and Antonucci (1980) and Norbeck et al. (1981) where liking, admiration, respect and love are considered affective transactions that can influence members to provide social support.

Thirdly, the practice of giving social support in the community has changed the norms in this community. This study found that members provide social support to others because they need to conform to the social norms as it will enhance their sense of belonging in the community. These findings support the claim by Mathwick et al. (2008) who found that virtual communities are maintained by the normative influences that impose a moral responsibility to volunteer and to reciprocate. 
Lastly, the members in this community provide support because they are aware of their obligation to help others. This moral obligation indicates that participants help others because "it is the right thing to do" as claimed by Wasko and Faraj (2000). The factors that influence their sense of obligation to provide social support include (i) nationalism, (ii) benevolence, (iii) sense of responsibility and (iv) homogeneity (refer to Section 6.3.2.3). The findings also confirm the claim by Wasko and Faraj (2000) that helping members who are in need make them feel satisfied. The feelings of obligation can also be explained by the nature of the members who are generally Muslims. The values of Muslims, although this depends on how religious they are, are based on the belief that that everything in this life results from fate or the will of God. This view has encouraged the community members to practice social support whereby many believe that if they help others, they will get help too in the future.

The previous discussion has shown that social support practices are most likely to be influenced by the tie strength amongst the members. In addition they are also likely to be influenced by the norms, the sense of obligation and admiration to offer help to the members.

One of the social support practices (refer to Sections 6.2.2.1 and 6.3.2.3) in this community is providing information, advice or suggestions to other members, known as informational support. In general, the bloggers will share their activities on their blogs, and usually readers will ask for more information when they are interested in certain topics. Popular topics are parenting, eateries and traveling. These topics receive a lot of questions from the readers. Bloggers and other readers who have knowledge about the subject matter will answer the questions. The readers also approach the bloggers to get advice on certain issues, for example decision making. This is similar to the Singaporean lifestyle blogging community where readers seek advice from bloggers (Abidin, 2013a). Informational support is the most common social support practice in the community which is in line with the claim made by Welbourne et al. (2009). 
Another common type of social support in a virtual community is emotional support (Welbourne et al., 2009), which is also the case for this community. Emotional support is the expression of empathy, love, trust and caring amongst the community members. The community practices emotional support by encouraging the members who are having tough times, such as losing family members or undergoing stressful events. When members shared about their hardship, usually readers would express their empathy and encouragement towards them. This is done by leaving messages on their blogs or social media accounts.

The practice of instrumental support was also found in this community. Instrumental support is a form of social support which encompasses the concrete, direct ways people assist others (Langford et al., 1997) which includes tangible support such as financial assistance. There are cases where bloggers have helped to collect money to help the members in need. There are also cases where bloggers have lent money to readers. However this practice is not common, which is consistent with Coursaris and Liu (2009), Braithwaite et al. (1999), Chang (2009) and Hwang et al. (2011) who claim that instrumental support is rarely observed in a virtual community as compared to informational and emotional support because of the virtual nature of the interactions.

The last type of support that is practiced by the community is appraisal support. Appraisal support is sometimes referred to by scholars as a type of informational support which provides help to reassess or redefine circumstances, often in a manner that helps make them more positive or reveals new information that could be helpful, or a different way to look at things (Braithwaite et al., 1999). This is being practised by the community by providing various options for members such as travelling options and so on.

\subsubsection{Summary}

Section 7.3 and its sub-sections discuss the relationships between members and the characteristics of the community. Table 7.1 shows a summary of the 
main findings for this section and a comparison between these findings and past studies by several researchers. 


\begin{tabular}{|c|c|c|c|}
\hline \multirow[t]{2}{*}{ Topics } & \multirow[t]{2}{*}{ Findings of this study } & \multirow[t]{2}{*}{ Past studies } & Status \\
\hline & & & $\begin{array}{c}\text { Confirm/ } \\
\text { Disconfirm/Extend }\end{array}$ \\
\hline \multirow[t]{8}{*}{$\begin{array}{l}\text { Social ties and } \\
\text { homophily }\end{array}$} & $\begin{array}{l}\text { This community used multiple media for communications } \\
\text { that indicates that the strong social ties amongst the } \\
\text { members. }\end{array}$ & Haythornthwaite (2002) & Confirm \\
\hline & $\begin{array}{l}\text { Homophily: Perceived similarity influenced the readers to } \\
\text { create bonding with bloggers. }\end{array}$ & McPherson et al. (2001) & Extend \\
\hline & $\begin{array}{l}\text { Tie strength differs amongst members based on similarity } \\
\text { between them. }\end{array}$ & Valenzuela et al. (2009) & Extend \\
\hline & $\begin{array}{l}\text { The more similar the members with others, the more } \\
\text { frequently they will read the blogs and interact. }\end{array}$ & Du and Wagner (2006) & Confirm \\
\hline & $\begin{array}{l}\text { Strong ties in the community can be explained by the strong } \\
\text { social support. }\end{array}$ & Granovetter (1973) & Confirm \\
\hline & \multirow{2}{*}{$\begin{array}{l}\text { Members determine homophily and similarity based on } \\
\text { what they read in blogs. }\end{array}$} & Brown et al. (2007) & Extend \\
\hline & & Boyd and Ellison (2007) & Confirm \\
\hline & Blogs foster interaction and lead to connection. & Hodkinson (2007) & Confirm \\
\hline
\end{tabular}




\begin{tabular}{|c|c|c|c|}
\hline \multirow[t]{8}{*}{ SOVC } & $\begin{array}{l}\text { A sense of virtual community is experienced in this } \\
\text { community. }\end{array}$ & Koh and Kim (2003) & Confirm \\
\hline & $\begin{array}{l}\text { Identification of members by following multiple social } \\
\text { media accounts. }\end{array}$ & $\begin{array}{l}\text { Blanchard and Markus } \\
\text { (2004) }\end{array}$ & Extend \\
\hline & $\begin{array}{l}\text { There are two types of homophily in this community which } \\
\text { include status homophily and value homophily and it } \\
\text { influences the membership dimension in SOVC. }\end{array}$ & $\begin{array}{l}\text { Lazarsfeld and Merton } \\
\text { (1954); McPherson et al. } \\
\text { (2001) }\end{array}$ & Extend \\
\hline & $\begin{array}{l}\text { Membership dimension is affected by influential bloggers } \\
\text { who act as leaders in the community. }\end{array}$ & Koh and Kim (2003) & Extend \\
\hline & $\begin{array}{l}\text { Bloggers act as intermediaries who link readers to each } \\
\text { other, promoting recognition of members' screen names in } \\
\text { the community. }\end{array}$ & $\begin{array}{l}\text { Blanchard and Markus } \\
\text { (2002) }\end{array}$ & Extend \\
\hline & $\begin{array}{l}\text { Following each other's social media allows the community } \\
\text { to develop a better understandings of members' identities. }\end{array}$ & $\begin{array}{l}\text { Blanchard and Markus } \\
\text { (2002) }\end{array}$ & Extend \\
\hline & $\begin{array}{l}\text { Members' decision making is influenced by the other } \\
\text { members. }\end{array}$ & $\begin{array}{l}\text { Keller and Berry (2003); } \\
\text { Agarwal et al. (2008) }\end{array}$ & Confirm \\
\hline & $\begin{array}{l}\text { Offline activities are not likely to impact the members' } \\
\text { perceived influence. }\end{array}$ & Koh and Kim (2003) & Confirm \\
\hline
\end{tabular}




\begin{tabular}{|c|c|c|c|}
\hline & $\begin{array}{l}\text { Immersion behaviour in this community is likely to be } \\
\text { influenced by offline activities. }\end{array}$ & Koh and Kim (2003) & Disconfirm \\
\hline & $\begin{array}{l}\text { There is evidence of addictive and volunteering behaviour } \\
\text { that explain the concept of immersion. }\end{array}$ & $\begin{array}{l}\text { Koh and Kim (2003); } \\
\text { Young (1996); } \\
\text { Csikszentmihalyi (1975); } \\
\text { Kiesler et al. (1985) }\end{array}$ & Confirm \\
\hline & $\begin{array}{l}\text { Level of SOVC is different for each member, depending on } \\
\text { the three types of participation in this community, which } \\
\text { include (i) active participation, (ii) passive participation } \\
\text { and (iii) lurkers. }\end{array}$ & $\begin{array}{l}\text { Blanchard and Markus } \\
\text { (2004); Blanchard and } \\
\text { Markus (2002) }\end{array}$ & Extend \\
\hline Trust & $\begin{array}{l}\text { Homophily and perceived similarity in the community are } \\
\text { likely to influence trust. }\end{array}$ & Lu et al. (2010) & Extend \\
\hline & $\begin{array}{l}\text { The consistency of the blog posts demonstrates the } \\
\text { information quality which generates trust in the bloggers. }\end{array}$ & Kim \& Park (2013) & Extend \\
\hline & $\begin{array}{l}\text { Frequent social media updates increase members' sense of } \\
\text { familiarity and closeness to lifestyle bloggers. }\end{array}$ & Abidin (2013a) & Confirm \\
\hline & $\begin{array}{l}\text { The reputation of bloggers was developed based on the blog } \\
\text { posts and the interaction they had in social media. }\end{array}$ & Boyd (2006) & Confirm \\
\hline
\end{tabular}




\begin{tabular}{|c|c|c|}
\hline $\begin{array}{l}\text { Trust can be built up over time as a result of repeated } \\
\text { interactions between the trustor and trustee. }\end{array}$ & Sherchan et al. (2013) & Confirm \\
\hline $\begin{array}{l}\text { Face-to-face communication in this community is not a } \\
\text { necessary precondition for trusting online relationships. } \\
\text { Instead, it is viewed as an element to strengthen trust that } \\
\text { has been produced in a virtual environment. }\end{array}$ & $\begin{array}{l}\text { Blanchard and Markus } \\
\text { (2002) }\end{array}$ & Extend \\
\hline \multirow[t]{2}{*}{$\begin{array}{l}\text { Factors influencing trust are related to the relationships in } \\
\text { the community. }\end{array}$} & $\begin{array}{l}\text { Ng (2013); Lin and Lu } \\
\text { (2011b); Hajli (2015); Tsai } \\
\text { and Ghoshal (1998); Sitkin } \\
\text { and Roth (1993) }\end{array}$ & Confirm \\
\hline & $\begin{array}{l}\text { Laroche et al. (2013); } \\
\text { Jarvenpaa et al. (1999); Lu } \\
\text { et al. (2010); Qing et al. } \\
\text { (2008) }\end{array}$ & Disconfirm \\
\hline $\begin{array}{l}\text { Characteristics of trust in this community conform to the } \\
\text { characteristics of knowledge based trust, cognition based } \\
\text { trust and relational trust. }\end{array}$ & $\begin{array}{l}\text { Hsu (2008); Lewicki and } \\
\text { Bunker (1995); Lu et al. } \\
\text { (2010); Ratnasingham } \\
\text { (1998); Chen and Dhillon }\end{array}$ & Confirm \\
\hline
\end{tabular}




\begin{tabular}{|c|c|c|c|}
\hline & & $\begin{array}{l}\text { (2003); Cook and Wall } \\
\text { (1980); Gefen et al. (2003); } \\
\text { Goto (1996); Mayer et al. } \\
\text { (1995); McAllister (1995); } \\
\text { Rempel et al. (1985); } \\
\text { Rousseau et al. (1998); } \\
\text { Sherchan et al. (2013) }\end{array}$ & \\
\hline \multirow[t]{3}{*}{ Social support } & $\begin{array}{l}\text { Liking, admiration, respect and love are considered } \\
\text { affective transactions that can influence members to } \\
\text { provide social support. }\end{array}$ & $\begin{array}{l}\text { Kahn and Antonucci } \\
\text { (1980) and Norbeck et al. } \\
\text { (1981) }\end{array}$ & Extend \\
\hline & $\begin{array}{l}\text { Social support practices in the community include } \\
\text { informational support, emotional support, appraisal } \\
\text { support and instrumental support. }\end{array}$ & $\begin{array}{l}\text { Welbourne et al. (2009); } \\
\text { Langford et al. (1997); } \\
\text { Coursaris and Liu (2009); } \\
\text { Braithwaite et al. (1999); } \\
\text { Chang (2009); and Hwang } \\
\text { et al. (2011) }\end{array}$ & Extend \\
\hline & $\begin{array}{l}\text { The practice of social support are considered as norm in this } \\
\text { community. }\end{array}$ & Mathwick et al. (2008) & Confirm \\
\hline
\end{tabular}




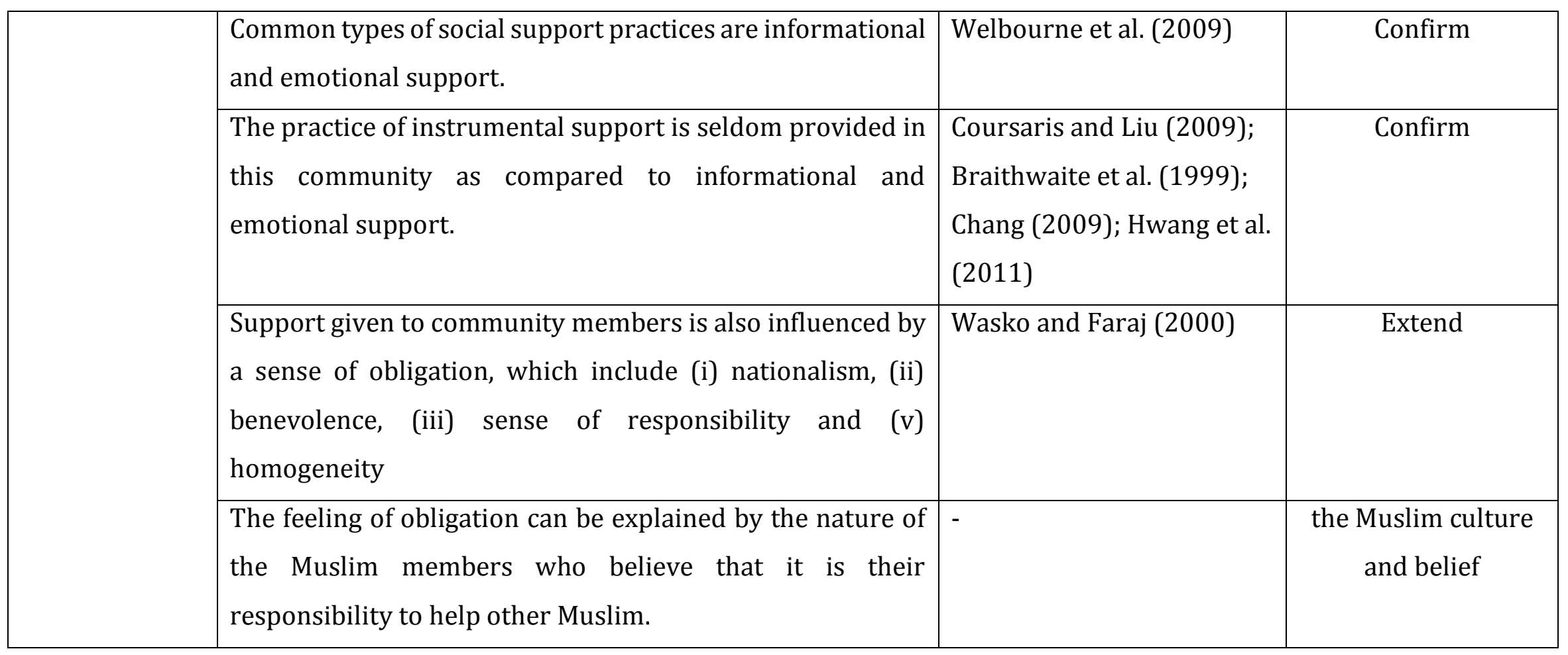

Table 7.1: Summary of the main findings 
The next section will uncover the influence of their relationship and the community characteristics which enable the bloggers to successfully venture into social commerce as well as motivating readers to participate.

\subsection{Motivational Factors for the Sellers in the Community}

Sellers seek profit and business sustainability as goals for their involvement in online business. In addition, cost-effectiveness and self-esteem are also goals for starting their micro-businesses. The main motivational factors that lead them to achieve their goals are the social support from the community members and convenience that is provided by the nature of the social commerce in this community.

\subsubsection{Social Support from the Community Members}

As illustrated by the findings (refer to Section 6.2.2.1), sellers acknowledge that they are aware of the social support provided by community members, who may or may not be their customers. As sellers participate more in social commerce, they get more support from members, including their customers. According to the sellers, the customers help in terms of giving new business ideas, WOM, feedback on business transactions, suggestions for packaging and so on, extending their 'bloggers-readers' support to the businesses run by the bloggers. They acknowledge that social ties influence the members to provide social support. Although it was not shown clearly in the HVM, data from the interviews show that the social support that they gained from the customers is a result of their social ties in the community (refer to Section 6.2.2.1). In addition, the Malay sellers in this community tend to build relationships first before getting down to business, which is in line with the claim by Abdullah (1996). This shows that culture of Malay people influences the close tie between sellers and customers, and subsequently have created the opportunities for them to get support from their customers.

The findings show social support from the community has given the sellers access to more customers which provides them with more business 
opportunities and sustains their businesses. By obtaining more business opportunities, sellers make more profit and sustain their businesses which were the goals for them starting their online businesses.

It is generally accepted that businesses venture into social commerce in order to access more customers, to gain more opportunities and to sustain their businesses, as well as to make a profit (Baird \& Parasnis, 2011a; Crum, 2010; Curty \& Zhang, 2013; Mandal \& McQueen, 2012; Naylor et al., 2012; Wang \& Zhang, 2012). This study has yet to find any research showing that social support from customers to sellers is positively related to those factors (potential customers, business opportunities, business sustainability and profit). Although there is past research that discusses social support in business, the context of social support covered is different. For example, Brüderl and Preisendörfer (1998) explore the support from strong ties (support from spouse/life-partner, parents, friends, and relatives; including emotional support from spouse) and weak ties (support from business partners, acquaintances, former employers, and former co-workers). Their study focuses on network support and the success of newly founded businesses, and has no relation to virtual community participation.

\subsubsection{Convenience: As Perceived by Sellers}

The concept of convenience for online businesses usually focuses more on customers' convenience, rather than that of the businesses. However in this community, sellers also experience the convenience of doing their business in the community, particularly by targeting their blogs' readers as their first group of the customers, taking advantage of the social support given by the members.

In addition sellers also experience convenience by the use of social media applications. The use of social media applications, such as Facebook and Instagram make it easy for sellers to promote, to sell and to communicate with their customers. The ease of use and perceived usefulness of social media has assisted them in their businesses and making it convenient for the 
sellers to conduct online business. These findings are consistent with the classic Technology Acceptance Model (TAM) theory (Davis, 1989), which emphasizes the importance of usefulness and ease of use in technology adoption. This finding confirms a later, social-specific study by Augar and Zeleznikow (2013) who found that small business owners adopted social commerce because of the TAM characteristics of ease of use and usefulness. Sellers in the Malay lifestyle blogging community believe selling in social media gives them the convenience of doing business and gaining access to potential customers who are their blog's readers.

\subsubsection{Other Relevant Motivational Factors for Sellers}

As mentioned in Sections 7.4.1 and 7.4.2, the social support by the members in the community and the convenience of using social media technology has positive consequences such as giving sellers more access to potential customers. This finding supports the claim made by Naylor et al. (2012) that one consideration that businesses need to address is how to target new supporters. As the sellers are connected to this community, it is easy for potential customers to get access using links provided by other bloggers. This finding supports the claim by Stephen and Toubia (2010) that social networks between sellers act as 'virtual shopping centres' by helping customers browse between shops, therefore improving the accessibility of the network's shops.

The findings also show that by accessing more potential customers, sellers are able to create more opportunities for their businesses. This finding is in line with the claim made by Curty and Zhang (2013) and Wang and Zhang (2012) that the business perspective in the framework of social commerce embraces opportunities for retailers in social commerce. It also supports Berthon et al. (2012) who claim that social media creates changes in the world of marketing where businesses can fully utilize social media as long as the marketers understand and know how to engage with customers as compared to traditional marketing using other media such as television advertising. 
This study assumes another factor that influences bloggers to venture into business is because they want to get extra income as the inflation rate in Malaysia is increasing which has also raised the cost of living and decreased the purchasing power particularly for those who live in urban areas. Although it is not mentioned as a main motivation, there are participants who have briefly explained that the business has helped them to survive living in Kuala Lumpur.

\subsubsection{Summary}

Section 7.4 and its sub-sections have shown how participation in the virtual community has shaped the motivations of sellers and helped them achieve their goals for participating, which are profit and businesses sustainability. Table 7.2 shows a summary of the main findings for this section and the comparison between the findings with the past studies by several researchers. 


\begin{tabular}{|c|c|c|c|}
\hline \multirow[t]{2}{*}{ Topics } & \multirow[t]{2}{*}{ Findings of this study } & \multirow[t]{2}{*}{ Past studies } & Status \\
\hline & & & $\begin{array}{c}\text { Confirm/ } \\
\text { Disconfirm/Extend }\end{array}$ \\
\hline Goals & $\begin{array}{l}\text { Businesses venture into social commerce to access more } \\
\text { customers, to gain more opportunities and to sustain the } \\
\text { business, as well as to make a profit. }\end{array}$ & $\begin{array}{l}\text { Baird and Parasnis } \\
\text { (2011a); Crum (2010); } \\
\text { Curty and Zhang (2013); } \\
\text { Naylor et al. (2012); Wang } \\
\text { and Zhang (2012). }\end{array}$ & Confirm \\
\hline \multirow[t]{3}{*}{ Social support } & $\begin{array}{l}\text { Micro-businesses' sellers who are involved personally in } \\
\text { the virtual community, are likely to gain social support } \\
\text { from the members, including customers in the community. }\end{array}$ & $\begin{array}{l}\text { Brüderl and Preisendörfer } \\
\text { (1998) }\end{array}$ & Extend \\
\hline & $\begin{array}{l}\text { Social support that they gain from the customers is the } \\
\text { result of their social ties in the community. }\end{array}$ & Granovetter (1973) & Extend \\
\hline & $\begin{array}{l}\text { Sellers tend to build the relationship first before getting } \\
\text { down to business, influencing the support they obtain from } \\
\text { members. }\end{array}$ & Abdullah (1996) & Confirm \\
\hline
\end{tabular}




\begin{tabular}{|l|l|l|c|}
\hline $\begin{array}{l}\text { Perceived } \\
\text { convenience }\end{array}$ & $\begin{array}{l}\text { The ease of use and perceived usefulness of social media } \\
\text { has assisted them in their business and made it convenient } \\
\text { for the sellers to conduct online business. }\end{array}$ & $\begin{array}{l}\text { Augar and Zeleznikow } \\
(2013)\end{array}$ & Confirm \\
\hline $\begin{array}{l}\text { Other relevant } \\
\text { motivational } \\
\text { factors }\end{array}$ & $\begin{array}{l}\text { The convenience of using social media technology allows } \\
\text { more access to potential customers. }\end{array}$ & $\begin{array}{l}\text { Naylor et al. (2012); } \\
\text { Stephen and Toubia } \\
(2010)\end{array}$ & Extend \\
\cline { 2 - 5 } & $\begin{array}{l}\text { By accessing more potential customers, sellers are able to } \\
\text { create more opportunities for their businesses. }\end{array}$ & $\begin{array}{l}\text { Curty and Zhang (2013) } \\
\text { and Wang and Zhang } \\
\text { (2012) Berthon et al. } \\
\text { (2012) }\end{array}$ & Confirm \\
\hline
\end{tabular}

Table 7.2: Summary of the main findings

The next section will discuss the customers' motivation. 


\subsection{Motivational Factors for Customers in the Community}

The findings show that the customers' main goals (values) for participating in social commerce activities include self-esteem, loyalty, satisfaction and a sense of obligation. These goals show that there is a mixture of participating for their own benefit, as well as for the benefit of the community. How the customers in this community achieve these goals can be explained by factors such as trust, giving social support to bloggers and perceived convenience. These factors, which are influenced by their relationship with the bloggers, will be explained in this section.

\subsubsection{Trust Transfer}

Previously, Section 7.3.4 has explained that trust in this community is created before engagement in commerce activities begins. When the bloggers started to sell in the community, the members acknowledge that they were able to purchase items without any fear as they already trusted the members of the community. Although the actual security systems are rather loose in their implementation, the trust that they have in sellers leads them to trust sellers with information such as their address and payment details. This finding is in line with the trust transfer theory (Stewart, 2003).

According to Stewart (2003), trust transfer theory describes how trust transfer occurs when the unknown target is being perceived as related to the source of the transferred trust. Lee et al. (2007) defines it as people's trust in one field influencing their trust in other fields. It can be transferred from one individual to other individuals (Strub \& Priest, 1976; Uzzi, 1996) or from a place to an individual (Henslin, 1968), and may occur based on the communication process or the cognitive process (Stewart, 2003) where a relationship exists between sources and target. It can also be transferred in the same or different contexts (Buntain \& Golbeck, 2015; Stewart, 2003).

The trust already developed in this community has been proven to be the reason why the members trust bloggers as sellers. This study has shown that 
trust in this community is gained based on homophily, social ties, the personality of the bloggers, as well as the consistency of the blog content. The trust towards the blogger has consequently influenced their intention to continue participating in commerce activities. This finding confirms and extends the claim made by Chen and Shen (2015) who found that in social commerce communities, trust towards the sellers is influenced by trust towards members. Their findings indicate that trust towards the social commerce community has the strongest impact on social shopping and social sharing intention, whilst in this study, trust towards the bloggers in the community influences members to also trust them, the bloggers as sellers. So, although the constructs and the context of their research are different, this study does conform to past studies by Qing et al. (2008), Stewart (1999), Lee et al. (2011), Shi and Chow (2015), Ng (2013), McKnight et al. (2000), Jiang et al. (2008) and $\mathrm{Lu}$ et al. (2010) who found that trust can be transferred from one context to the other.

\subsubsection{Social Support to Sellers}

In the previous discussion on social support practices in the community (refer to Section 7.3.5), it was noted that readers had shown their willingness to provide support to other members, whether bloggers or readers. The social support offered was not restricted to the personal matters experienced by other members (i.e. any difficulty related to family, relationships, financial problems, workplace issues etc.), but was also offered for their business endeavours (i.e. purchasing, co-creating and so on) in the event that fellow community members (in this case: bloggers) ventured into business.

The support that members give to other members before they began participating in social commerce, was found to continue once bloggers began selling. This supports includes informational support, instrumental support, emotional support and appraisal support. Social support is given to sellers as a result of the relationships and strong social ties in the community, as explained in Section 7.3.5. This finding complies with the argument made by 
Antonucci (1990) and Leung and Lee (2005). Antonucci (1990) claims that companionship in the community has a positive influence on social support, whilst Leung and Lee (2005) found that the frequency of participation in new media activities (in this case via social media) shows a positive relationship with social support. These findings show that members in the blogosphere community who participate in social commerce acknowledge that giving social support is part of the practice of their community. Note that generally the Malay lifestyle blogging community is likely to have a higher sense of virtual community, therefore they expect to give support to others. This has also been explained in Section 7.3.5 where as a Muslim, they perceive that they are obligated to help others. Regardless of whether activities are noncommerce or commerce activities, customers are willing to provide support.

These findings on social support confirm the studies by Hajli (2014), Zhang et al. (2014), Wang and Hajli (2014) and Liang et al. (2011) where social support is one of the important constructs in social commerce studies. Hajli (2014) found that social support with emotional and informational dimensions is being created in social networking sites (SNS), and refers to the concept as online social support. According to Hajli (2014), this factor is a key construct in the development of e-commerce into social commerce. This phenomenon is most likely to occur when supportive interactions among consumers in SNS develop strong relationships, making them feel closer to peers. Although this is similar to what was found in the blogosphere community, nonetheless, his study only focuses on relationship building in Facebook by a community of customers. His findings are similar to Zhang et al. (2014), Wang and Hajli (2014) , Kim and Srivastava (2007) and Liang et al. (2011) where all authors suggest that social support exists in social commerce communities and this can influence their relationships as well as their participation in e-commerce. However, all the communities involved in their studies were customer-based communities which explains the contradicting findings from the blogosphere community, which will be explained next. 
Firstly, this study extends the research on social support found by previous studies (Hajli, 2014; Liang et al., 2011; Wang \& Hajli, 2014; Zhang et al., 2014) by establishing that a different type of support exists in this community in addition to emotional and informational support. The community members in this study perceived social support differently from the previous studies because they had previously engaged with the community before it ventured into social commerce.

Hajli (2014), Zhang et al. (2014), Liang et al., (2011) and Wang and Hajli (2014) focused on different types of communities, which were mainly the community of customers. Different types of communities are likely to have different types of social support within the community. This could well be why their findings on social support were limited to informational and emotional support as compared to the blogosphere community. This argument is supported by Blanchard (2004) who claimed that each community has its own unique characteristics.

Secondly, although this study found similar findings to Wang and Hajli (2014), where the social media constructs is likely to influence the social support in the community, however the context of the social media constructs are slightly different. The social commerce constructs are inclusive of (i) forums and communities, (ii) ratings and reviews, and (iii) referrals and recommendation, nonetheless, the definition of the these constructs are slightly different when applied to the Malay lifestyle blogging community context. Table 7.3 shows the comparison between the social commerce constructs defined by Wang and Hajli (2014) with the context of this study.

\begin{tabular}{|l|l|l|}
\hline $\begin{array}{l}\text { Social Commerce } \\
\text { Constructs }\end{array}$ & $\begin{array}{l}\text { Wang and Hajli } \\
\mathbf{( 2 0 1 4 )}\end{array}$ & $\begin{array}{l}\text { The findings of this } \\
\text { study }\end{array}$ \\
\hline Forums and & $\begin{array}{l}\text { Customers only } \\
\text { communities }\end{array}$ & $\begin{array}{l}\text { - Consist of sellers and } \\
\text { customers who also } \\
\end{array}$ \\
& vendors & $\begin{array}{l}\text { play different roles in } \\
\text { the same community }\end{array}$ \\
\hline
\end{tabular}




\begin{tabular}{|c|c|c|}
\hline & & $\begin{array}{l}\text { (i.e. bloggers and } \\
\text { readers). }\end{array}$ \\
\hline Ratings and reviews & $\begin{array}{l}\text { - Rating and review on } \\
\text { brand page }\end{array}$ & $\begin{array}{l}\text { - Rating and reviews on } \\
\text { members' personal } \\
\text { space such as blog, } \\
\text { Facebook and so on. }\end{array}$ \\
\hline $\begin{array}{l}\text { Referrals and } \\
\text { recommendation }\end{array}$ & $\begin{array}{l}\text { - Recommendation on } \\
\text { brand page }\end{array}$ & $\begin{array}{l}\text { - Referrals and } \\
\text { recommendation on } \\
\text { members' personal } \\
\text { space such as blog, } \\
\text { Facebook and so on. }\end{array}$ \\
\hline
\end{tabular}

Table 7.3: Comparison between the constructs' criteria

The different columns in Table 7.3 show that though the social commerce construct could represent similar terms (i.e. forums and communities) it holds different meanings based on the type of communities. Therefore the definition of these constructs as found in this research can be used to redefine the social commerce constructs by Wang and Hajli (2014) so that it can be used to represent many types of communities.

This study found some interesting findings while investigating the social support practice, where customers were helping sellers clear up some false accusation made by haters. Note that haters is the term used by this community for those who troll and negatively provoke people in the community. Haters are anonymous members who post negative and provocative comments without giving any helpful remarks (Lindgren, 2012). Haters are usually negative towards members who are considered an outgroup to the haters, by not having similar values or opinions to themselves.

In a similar way to other influential figures on the Internet, for example Youtubers (Lindgren, 2011; Nycyk, 2012; Rotman \& Preece, 2010), the lifestyle bloggers community has also experience haters attacking their page, be it personal attacks or business-related attacks. However, because of the strong ties they have, members will help to clarify the truth by sharing their 
positive experiences dealing with the sellers. When members find any hate post or pages related to businesses, they usually report it to the sellers. In other words, readers (who may or may not be customers) do the monitoring on the sellers' behalf. This situation is in contrast with what was found in Senadheera et al. (2011) who discovered that hate pages were usually created by disgruntled customers and businesses had to take their own initiative to monitor the hate pages. Although this finding is interesting as it uncovers an important aspect of social support, nonetheless it is outside the main scope of this study.

The discussion of social support shows that community members, including customers, are willing to provide social support for sellers, which is in contrast to the findings in traditional e-commerce literature where social support is usually only provided from customers to other customers in the community.

\subsubsection{Perceived Convenience}

In this study, perceived convenience refers to the perception of the customers when a product or service lowers the cognitive, emotional and physical burdens for a user. Convenience includes the time and effort saved by the consumers (Ranganathan \& Ganapathy, 2002; Swaminathan, Lepkowska-White, \& Rao, 1999). Customers acknowledge that when purchasing and giving business input in this community, they experience a lot of convenience in their transactions, as well as the convenience of using technology that they are so familiar with. Both sellers and customers claim that one of the motivations for them to continue their participation in commerce activities is the perceived convenience as claimed by previous studies in e-commerce.

Meanwhile, in a similar way to the sellers (refer to Section 7.4.2), the customers perceive the convenience of using social media as one of the motivations for them to participate in social commerce activities. The customers claim that they can easily access the sellers in the community, as 
well as the blog shops or any social media platforms used as a shop because they use social media every day. The social media pages are also easily to access using mobile applications. While browsing their Facebook or reading blogs, the customers can easily browse the shops. The customers also confirm that most of them are advanced users of social media, therefore it is easy for them to use social media for social commerce activities. This ease of use influences their continued participation in commerce activities, which complies with TAM (Gefen \& Straub, 2000; Teh \& Ahmed, 2012).

In addition, it helps customers to communicate directly with the sellers. They acknowledge the perceived usefulness of social media to access the blog shops as well as accessing sellers for interaction related to their purchase. Customers have also admitted that the flexible system created by sellers using social media makes it easy for them to customize their order and communicate directly with the sellers. This influences them to buy more from sellers in the community. This finding however contradicts with Doolin, Dillons, Thompson, and Corner (2007) who claim that there is no support for the hypothesis that convenience is associated with increased online purchasing. The different context of this study could explain the difference in the finding as Doolin et al. (2007) were focusing on electronic retailing websites.

The perceived convenience for the customers is also influenced by their relationships and social ties in the community. By knowing the sellers, customers are likely to believe that it is comfortable and easy to communicate with them. In most cases, the system created by the sellers can be flexible and adjusted to their preferences if they are close to the sellers. For example, they can ask if they can make two payments before receiving the product rather than paying in full. They found it hard to deal with traditional e-commerce sites as it is difficult to contact the sellers if anything goes wrong. Usually it takes more than 2 days and sometimes up to 14 days to get a reply to an email if they are dealing with a big merchant. They can also get a refund earlier as compared to purchasing from established e- 
commerce websites as they can contact the sellers using their personal mobile phone number via instant messaging such as WhatsApp.

On the customers' side, these findings are consistent with the ease of use and perceived usefulness in TAM by Davis (1987). It is also in line with Eastin's (2002) study which found that participation in e-commerce activities is influenced by perceived convenience. It also confirms the findings by Jih (2007) who found a positive relationship between customers' perceived convenience with shopping intention. Jih (2007) used the following convenience dimensions in her study: use dimension, time dimension, place dimension, shopping dimension and service dimension. Although the customers in this study do not fulfil all of the dimensions, this study argues that perceived convenience is similar to the use dimension (ease of use), acquisition dimension (ease of purchase) and time dimension (purchase can be made at a convenient time) outlined by Jih (2007) and Brown (1989). It also in line with the argument made by Jih (2007) that convenience is multidimensional and context dependent on perception. The findings from the customers' HVM however contradicts the argument made by Rowley (2004) who found the association between convenience and loyalty.

The next section will discuss other relevant motivational factors that were found in this research.

\subsubsection{Other Relevant Motivational Factors for Customers}

This study also found several other motivational factors that can lead to customers' goals or values such as perceived benefits, risk awareness, product quality and social norms. Firstly, customers are motivated by the benefits they obtain by participating in the blogosphere community which reflects the findings of the similar research by Siegrist (2000), Lin and Lu (2011b), Kim et al. (2011), Forsythe et al. (2006) who have also highlighted that one of the factors that influences participation is the benefit they gain from the participation. In this community, some of the benefits that customers obtain are discounts and great shopping experiences. Customers 
in this community use extrinsic attributes, which is the information they get from other members to identify product quality. This is including word of mouth from people in the community who have experience in purchasing from other members. Customers provide testimonies to be published by the sellers, which is one of the practices of the community. Testimonials published by trusted sellers are also used as indicators.

Moreover, this study also found that trust towards the seller influenced their confidence in the product quality. They believe that by purchasing from community members, they are ensured of good quality products. These findings have also been confirmed in studies by Collier and Bienstock (2006) and Urban, Sultan, and Qualls (2000) who found that customers hoped to receive the quality of the products as they expected to get when they made the purchase. For this community, the confidence of getting the expected quality relies on the level of trust towards the sellers.

Secondly, customers in the community believe they can reduce their worry about low quality products, unsafe transactions and the risk of being cheated by scammers, particularly from online shops run by unknown microbusiness sellers. Their belief in the low risk that they may encounter influences them to participate. This finding supports Wu and Wang's (2005) claim that perceived risk has a direct impact on behavioural intention. Although their research focused on mobile commerce, it is believed that the customers from blogosphere communities are aware that the risks are lower if they buy from the community.

One of the motivations influencing the customers to continue to participate in social commerce is risk awareness which also confirms previous study by Hajli (2013) and Kim and Park (2013). Customers are aware of the risks that are associated with e-commerce including the risk of monetary loss, unreliable vendors delivering unsatisfactory products or even failing to deliver products to consumers, risk of loss of privacy, credit card information stolen, incomplete or distorted information provided by retailers, as claimed by Jarvenpaa and Todd (1996), Lim (2003), Pavlou (2003) and Nyshadham 
(2000). Because they trust the sellers, they know the risk is low, as compared to traditional e-commerce business, as sellers have their reputations as bloggers to be maintained.

Thirdly, social norms also influence the customers' participation as they participate because they want to provide social support (refer to Sections 6.4.4 and 7.5.2) which is a norm in this community. It is in line with the claim made by Boyd and Richerson (2001) who argue that social norms lead to adaptive behaviour, which means that by following norms, people behave sensibly without having to understand why they do what they do. It also confirms a view by McAdams (1997) who claims that people obey norms because they are rewarded by others if they do and punished if they do not.

\subsubsection{Summary}

Based on the discussion in Section 7.5 and its subsections, it can be concluded that customers' goals or values were mainly influenced by their membership in the community that lead them to trust and provide social support to sellers. The relationships in the community make it easier for them to communicate with sellers and it motivates them to continue their participation. Table 7.4 provides a summary of the main findings of this section. 


\begin{tabular}{|c|c|c|c|}
\hline \multirow[t]{2}{*}{ Topics } & \multirow[t]{2}{*}{ Findings of this study } & \multirow[t]{2}{*}{ Past studies } & Status \\
\hline & & & $\begin{array}{c}\text { Confirm/ } \\
\text { Disconfirm/Extend }\end{array}$ \\
\hline \multirow[t]{2}{*}{ Trust } & Trust can be transferred from one context to another. & $\begin{array}{l}\text { Buntain and Golbeck } \\
\text { (2015); Stewart (2003); } \\
\text { Qing et al. (2008); Stewart } \\
\text { (1999); Lee et al. (2011); } \\
\text { Shi and Chow (2015); Ng } \\
\text { (2013); McKnight et al. } \\
\text { (2000); Jiang et al. (2008); } \\
\text { Lu et al. (2010) }\end{array}$ & Confirm \\
\hline & $\begin{array}{l}\text { The trust between customers and sellers in this community } \\
\text { was transferred from the trust they established when the } \\
\text { members participated as bloggers and readers. }\end{array}$ & Chen and Shen (2015) & Extend \\
\hline Social support & $\begin{array}{l}\text { The social support offered was not restricted to personal } \\
\text { matters experienced by other members but was also } \\
\text { offered for their business endeavours, as a result of the } \\
\text { relationships and strong social ties in the community. }\end{array}$ & $\begin{array}{l}\text { Antonucci (1990); Leung } \\
\text { and Lee (2005) }\end{array}$ & Extend \\
\hline
\end{tabular}




\begin{tabular}{|c|c|c|c|}
\hline & $\begin{array}{l}\text { The members provide four types of social support which } \\
\text { includes informational support, emotional support, } \\
\text { appraisal support and instrumental support to the sellers. }\end{array}$ & $\begin{array}{l}\text { Hajli (2014), Zhang et al. } \\
\text { (2014); Wang and Hajli } \\
\text { (2014); Liang et al. (2011) }\end{array}$ & Extend \\
\hline & $\begin{array}{l}\text { Different types of communities are likely to have different } \\
\text { types of social support within the community. }\end{array}$ & Blanchard (2004) & Confirm \\
\hline & Members perceived that they are obligated to help others. & - & Muslim's belief \\
\hline $\begin{array}{l}\text { Social } \\
\text { commerce } \\
\text { constructs }\end{array}$ & $\begin{array}{l}\text { Social commerce constructs (forums and communities, } \\
\text { ratings and reviews, referrals and recommendation) } \\
\text { definitions are different based on types of communities. }\end{array}$ & Wang and Hajli (2014) & Extend \\
\hline \multirow[t]{4}{*}{$\begin{array}{l}\text { Perceived } \\
\text { convenience }\end{array}$} & $\begin{array}{l}\text { The blogger-reader relationship in the community allows } \\
\text { customers to experience convenience in commercial } \\
\text { activities. }\end{array}$ & Doolin et al. (2007) & Extend \\
\hline & \multirow[t]{2}{*}{$\begin{array}{l}\text { Ease of use and perceived usefulness of social media for } \\
\text { communication with the sellers, influences customers to } \\
\text { purchase from the sellers. }\end{array}$} & $\begin{array}{l}\text { Gefen and Straub (2000); } \\
\text { Teh and Ahmed (2012); Jih } \\
\text { (2007); Eastin (2002) }\end{array}$ & Confirm \\
\hline & & Doolin et al. (2007) & Disconfirm \\
\hline & $\begin{array}{l}\text { There is no association between perceived convenience and } \\
\text { loyalty. }\end{array}$ & Rowley (2005) & Disconfirm \\
\hline
\end{tabular}




\begin{tabular}{|c|c|c|c|}
\hline \multirow[t]{4}{*}{$\begin{array}{l}\text { Other } \\
\text { motivational } \\
\text { factors }\end{array}$} & $\begin{array}{l}\text { Customers are motivated to purchase by the benefits they } \\
\text { obtain by participating in the blogosphere community. }\end{array}$ & $\begin{array}{l}\text { Siegrist (2000); Lin and Lu } \\
\text { (2011); Kim et al. (2011); } \\
\text { Forsythe et al. (2006) }\end{array}$ & Extend \\
\hline & $\begin{array}{l}\text { Trust towards the seller influenced their confidence in the } \\
\text { product quality. }\end{array}$ & $\begin{array}{l}\text { Collier and Bienstock } \\
(2006) \text { and Urban et al. } \\
(2000)\end{array}$ & Confirm \\
\hline & $\begin{array}{l}\text { Belief in the low risk that they may encounter influences } \\
\text { them to participate. }\end{array}$ & $\begin{array}{l}\text { Wu and Wang (2005); Hajli } \\
\text { (2013); Kim and Park } \\
\text { (2013). }\end{array}$ & Confirm \\
\hline & $\begin{array}{l}\text { Social norms of the community such as providing social } \\
\text { support, influence participation. }\end{array}$ & $\begin{array}{l}\text { Boyd and Richerson } \\
\text { (2001); McAdams (1997) }\end{array}$ & Confirm \\
\hline
\end{tabular}

Table 7.4: Summary of the main findings 


\subsection{Lessons Learned}

This section will discuss a few aspects of the lessons learned, which include the lifestyle bloggers and the community, branding, the social commerce model, and the comparison between the study and traditional e-commerce websites.

\subsubsection{Lifestyle bloggers}

Generally there are various stages in the growth of the Malay lifestyle bloggers. Beginning with diaristic style posts, the direction of their blogs develops into a lifestyle genre as they gain more attention from community members. These changes confirm the findings of Smith (2010) who claim that bloggers often begin with a personal purpose, and increased traffic to their blogs leads bloggers to expand content considerations beyond their original purposes.

The era of social media technologies has influenced the growth of this community. When social media applications such as Facebook, Twitter and Instagram became popular in Malaysia, most lifestyle bloggers chose to integrate their blogs with these social media applications allowing their followers to add them as friends or followers. Lifestyle bloggers update their blogs on a frequent basis, as well as integrating their posts across other social media platforms. These frequent updates from various platforms gives the readers more information about the sellers, so they can identify similarities and encourages a feeling of familiarity towards the sellers. This practice could be one of the reasons why the readers feel connected to the bloggers. This situation is similar to the practice of Singaporean lifestyle bloggers, where the multiple cross platform posts have influenced the relationship between Singaporean lifestyle bloggers and their readers (Abidin, 2013a). This study also found that lifestyle bloggers who successfully attracted the attention of the readers eventually became celebrities in the community, which is in line with the claims made by Trammell and Keshelashvili (2005) and Abidin (2016). 
This study found that one of the characteristics of lifestyle bloggers in Malaysia is that they usually have good writing skills and produce informal but polite postings. This is likely to be influenced by the culture in Malaysia that values courtesy, tolerance and harmony. This is similar to the study by Lövheim (2011) on Sweden's lifestyle bloggers where she found that bloggers expressed themselves through informal and personal posts, but were also polite, supportive and used emotionally expressive language.

The readers in this community enjoy reading blogs because they can learn from each other, which supports the claims of Nasr and Ariffin (2008) who found that a lot of knowledge exchange happens in the blogosphere. The interactions during the knowledge exchange leads the bloggers and readers to get to know each other better. These interactions in the blogosphere are likely to develop feelings of membership and actually form the basis of this community development. This situation supports the argument made by Ramayah, Nejati, and Shafaei (2015), who claimed that bloggers do not only produce content to post on their blogs but also build social relations with their readers and other bloggers. The possibility for readers to leave a comment in an interactive format is an important part of many blogs and this specific function can be seen as a form of social networking (Ramayah et al., 2015). It is also in line with the USA Federal Trade Commission statement which claimed that blogs can be considered as social networking sites if they includes videos, audios, photos and comments or replies (Federal Trade Commission, 2007).

The relationship between the bloggers and readers becomes more intimate when readers start to trust the bloggers more. This can be seen when the readers starts to seek advice for their personal problems. Often the readers approach the bloggers as advisor. This is consistent with the situation of Singaporean lifestyle bloggers as found by Abidin (2013a). Many Malay bloggers claim that if they do not know about the subject matter, they will publish the problem anonymously and open it up for discussion. This method is usually beneficial as there are usually readers who can give good advice 
based on their personal or professional experience of the subject matter. In addition bloggers have also provide free advertising space for individual sellers, as well as free announcement or 'shout out' promotion for non-profit events. The readers claim that they really appreciate the support given by the bloggers to address their problems or issues. The practice of giving support to the members has become a norm in the community.

As lifestyle bloggers in Malaysia get more attention from readers, businesses and advertising companies have started to use their popularity to promote their brands. This is consistent with the argument made by Kayes, Qian, Skvoretz, and Iamnitchi (2012) and Lee and Youn (2009) who claimed that influential bloggers are recognized by businesses as significant forces for product promotion or demotion as it promotes WOM. This study found that lifestyle bloggers who successfully attracted the attention of the readers eventually became celebrities in the community, which is in line with the claim made by Trammell and Keshelashvili (2005). Many of the Malaysian bloggers have subscribed to Nuffnang, which is the blog advertising company that provides opportunities for bloggers to generate income through blog ads, as well as access to events and contests. The Nuffnang model started in Singapore and then expanded its operation in Malaysia, Thailand, Australia, China, Philiphines and United Kingdom.

The advertising opportunities provided by Nuffnang and other companies are not the only way for the bloggers to earn money. Realizing the potential for making money, Malaysian lifestyle bloggers have also provided some spaces in their blogs for advertisements as well as personalized advertisement. This specific characteristics of earning income by the lifestyle bloggers in Malaysia is similar to lifestyle bloggers in Singapore. According to Abidin (2013a) and Chiew (2008) the lifestyle bloggers in Singapore earn money from selling advertisement space, writing personalised advertisements and selling clothes to their large number of followers.

The previous discussion has shown that there are a lot of similarities between the characteristics of lifestyle bloggers in Malaysia and lifestyle 
bloggers in Singapore. This could be explained by the similarity in culture and race between Malaysia and Singaporea. However in general, it can be concluded that lifestyle bloggers around the world are using a similar approach of combining personal posts and advertising. By sharing interesting facts about their personal life online, they have managed to become a platform for advertising and are thus able to make money. Some of the bloggers have also developed their own branding. This is inline with Cross (2011) who claims successful lifestyle bloggers have built up their own brands as a result of being commercialized.

There are other practices in South East Asian countries that are similar to Malaysian and Singaporean lifestyle bloggers' practices (Abidin, 2013b). This could also extend to world-wide lifestyle bloggers as this study found that there are generally several streams of income used by many bloggers outside Malaysia, which include advertising, affiliate marketing, digital products, physical products and services (Andrew, 2016). However, there is little evidence to be found in academic research. This situation is similar to what is claimed by Brake (2009), Cenite et al. (2009) and Hopkins (2011) who argue that personal bloggers, as well as lifestyle bloggers are a category which have caught little attention in academic studies. Although there are scholars such as Abidin (2013b) and Lim et al. (2013) suggest that this implementation is unique to Malaysia, Singapore and other South East Asian countries, there is no evidence to support the claim.

\subsubsection{Beyond Branding}

Generally, previous studies (Bagozzi \& Dholakia, 2006; Da Silveira, Lages, \& Simões, 2013; He, Li, \& Harris, 2012; Laroche, Habibi, Richard, \& Sankaranarayanan, 2012; Wang \& Hajli, 2014; Wang \& Hajli, 2015) have emphasized the roles of branding in social commerce or the e-commerce setting which includes brand communities. However this study shows that people actively participate in social commerce because of their relationship with community members who happen to be the sellers without the 
influence of any particular brand or brand communities. The community was built up from the concept of homophily as explained in Section 7.3.1.

Looking at the bigger picture, for the case of this study, the relationships in this community are likely to replace the function of brand names in traditional e-commerce. In traditional business or e-commerce settings, brands play a crucial role in promoting trust, loyalty, and product quality, as well as influencing group behaviour (Chaudhuri \& Holbrook, 2001; DelgadoBallester \& Luis Munuera-Alemán, 2001; Eunju, Kim, \& Zhang, 2008; Srinivasan et al., 2002). Srinivasan et al. (2002) identified brand factors that potentially affect loyalty, which include customization, contact interactivity, cultivation, care, community, choice, and character. Bagozzi and Dholakia (2006) found that commitment to a brand can be influenced through interactions with small groups of like-minded customers. However in the lifestyle bloggers community, findings show that the bloggers create a different context of branding, which is based on their reputation as a bloggers. The explanation for this phenomenon is related to the relationships and social ties between sellers and customers which have been created years before the community progressed onto social commerce. Sellers and their status as famous, reputable and influential bloggers are the brand in the community.

Most of the sellers in the community sell their own products, which were not widely known when they started their businesses. Some are resellers of local or unknown brands. This is because they are small scale businesses with limited capital. However, despite being new brand in the market, it is surprising to see the overwhelming response from community members. As suggested by the findings, it shows the relationship is most likely the reason why members purchase from the sellers.

The previous explanation reflects the discussion that customers purchase because they are happy to deal with the bloggers and to boost their own selfesteem by being among the first to buy from the famous bloggers. In addition, as explained in Sections 7.3.5 and 7.5.2, customers feel they are obligated to 
purchase in order to give support to the sellers. The relationships and trust in a virtual community play a big role as these constructs influence members to purchase new products only because they know the sellers. So the 'traditional' branding is no longer the only construct to create trust in social commerce. In the case of this community, the reputations of sellers as a bloggers has helped them to create their own brand names without having to rely on famous branding. It also explained the risk of relying too much on the community for the sellers. The explanation on trust was discussed in detail in Sections 7.3.4 and 7.5.1.

In addition, despite the advantages of having strong ties based on homophily, sellers could face risks related to the negative aspects of homophily. This is because, although strong ties in the community help sellers to survive, they may also prove restrictive, and inhibit sellers from growing beyond the boundary of the community. This can jeopardize their growth and hinder them from expanding their business to customers with different backgrounds and values, which is in line with what was found by Woodson (2015). Therefore there are limitations on the lessons large brand communities can learn from these micro-businesses. Nonetheless, these limitations can be lessened by taking the following approach:

i. Using the advantages of WOM marketing - for example sellers organized a contest that requires their customers to repost information about the business.

ii. Dropship programme ${ }^{9}-$ recruiting agents to find more customers.

\footnotetext{
${ }_{9}$ The dropship programme is a term used for assigning agents to their business. Often, sellers open up an opportunity for members or non-members who are interested in becoming their selling agent. The responsibilities of an agent include (i) promoting the products to their circle, (ii) taking orders on behalf of sellers, and (iii) transferring orders and shipment details to sellers, who then ship the goods directly to the customers. The commission given to the agents is based on the total number of sales.
} 
iii. Stockist - recruiting other sellers inside or outside the community to resell their products.

These are some of the approaches which have been taken by sellers in this community to promote their business to people outside the community.

\subsubsection{Social Commerce Implementation}

The investigation into social commerce motivation in this research has shown that there are missing chapters in social commerce research. Often social commerce research focuses on the adoption of social media in business operations and investigates a single platform community of customers. Although there are many important findings, there is a need for scholars to investigate more isolated cases as it has the potential to bring more understanding to the field.

In the mid to late 2000s, while the Malay lifestyle blogging community was developing its community practices and norms, another phenomenon called blogshop arose in the community. The blogshops phenomenon did not only happen inside this community but it also attracted the attention of others outside the community. However, the discussion will only focus on the phenomenon inside this community.

The general model of social commerce implemented by sellers in this community includes the concepts of multi-platform shop, multi-platform ordering systems, multi-platform payment channels, multi-platform communication channel, as well as multiple methods of delivery. Basically, the implementation of social commerce in this community requires a flexibility in conducting business.

\begin{tabular}{|l|l|}
\hline Characteristics & Description \\
\hline Platforms \& & $\bullet$ Blog \\
Promotions & $\bullet$ Facebook \\
& $\bullet$ Instagram \\
\hline
\end{tabular}




\begin{tabular}{|c|c|}
\hline & - Twitter \\
\hline $\begin{array}{l}\text { Communication } \\
\text { Method }\end{array}$ & $\begin{array}{l}\text { Via } \\
\text { - WhatsApp messenger } \\
\text { - Social Media: Public and private message } \\
\text { - Email } \\
\text { - SMS } \\
\text { - Telephone }\end{array}$ \\
\hline Ordering System & $\begin{array}{l}\text { Via } \\
\text { - WhatsApp messenger } \\
\text { - Social Media: Public and private message } \\
\text { - Email } \\
\text { - Shopping cart } \\
\text { - SMS }\end{array}$ \\
\hline $\begin{array}{l}\text { Notification } \\
\text { (Sellers to } \\
\text { customers) }\end{array}$ & $\begin{array}{l}\text { Purposes } \\
\text { - Confirmation of order } \\
\text { - Acceptance of proof of payment } \\
\text { - Tracking number } \\
\text { Method } \\
\text { - WhatsApp messenger } \\
\text { - Social Media: Public and private message } \\
\text { - Email } \\
\text { - SMS }\end{array}$ \\
\hline Delivery Method & $\begin{array}{l}\text { - Courier } \\
\text { - By hand }\end{array}$ \\
\hline $\begin{array}{l}\text { Payment Method } \\
\& \text { Notification of } \\
\text { payment (from } \\
\text { customers to } \\
\text { seller) }\end{array}$ & $\begin{array}{l}\text { - Online transfer (direct notification of payment } \\
\text { - } \text { via email or screenshot of successful payment) } \\
\text { (picture of transaction slip) } \\
\text { - Cash on delivery } \\
\text { - PayPal }\end{array}$ \\
\hline
\end{tabular}




\begin{tabular}{|c|c|}
\hline Coaching & $\begin{array}{l}\text { - } \text { Coaching on how to use the products (mostly } \\
\text { related to beauty products and supplements) }\end{array}$ \\
\hline After sale & - Contact customers to get feedback \\
\hline $\begin{array}{l}\text { Marketing } \\
\text { Strategy }\end{array}$ & $\begin{array}{l}\text { - Testimonials by customers } \\
\text { - Share own experience using the products on } \\
\text { social media } \\
\text { - Create blog post related to current issues that } \\
\text { can attract the attention of netizens. Google } \\
\text { search results on interesting topics will lead } \\
\text { netizens to read the blogs and encounter the } \\
\text { online shop } \\
\text { - Contest } \\
\text { - Stockist }\end{array}$ \\
\hline
\end{tabular}

Table 7.5: Descriptions of social commerce implementation in Malay lifestyle blog community

Table 7.5 shows the characteristics of how multi-platforms shops describe the use of multiple social media applications in conducting business. This is done to target more customers as customers have their own preferences in using social media platforms. Usually sellers will accept orders from multiple channels such as orders by email, order forms (on blog), as well as public and private messages on social media. Recently, some of the sellers have also included shopping cart. Instructions on how the payment can be made usually will be sent to customers as a confirmation of order. Customers will also be provided with sellers' banking details. Customers will then need to make the payment via any method listed by the sellers. Upon notification of payment proof by the readers, sellers will pack and courier the order. Sellers will contact the customers to notify the courier tracking number. Products can also be delivered by hand depending where they are located. An agreed meet up point can be set up; it could be either at the bloggers or customers' house or any convenient place. This is similar to what has been practiced in Singapore as claimed by Fletcher and Greenhill (2009). Participants of this 
research claim that the system used by the bloggers is very flexible. However, these findings conflict with Fletcher and Greenhill (2009) who claim that the "terms and conditions" on Singaporean blogshops are entirely in the sellers' favour and are designed to benefit their desire to accumulate the arbitrarily right set of goods. The reason behind these conflicting findings could be the different age group of participants (13 - 22 years old) studied by Fletcher and Greenhill (2009).

This section has shown that the implementation of social commerce varies based on individual cases. This is especially applicable in terms of community interaction and participations and the technology used for their daily operation. This study concludes by stressing that the definition of social commerce is dependent on how it is implemented and needs to be defined on a case by case basis as suggested by Huang and Benyoucef (2013).

\subsubsection{Comparison to Traditional E-Commerce Practices}

Findings from traditional e-commerce research cannot be generalized to social commerce research without considering the difference between traditional e-commerce and social commerce implementation, specifically regarding the chosen community in this research. The difference could lie in the type of business, the technology adopted for the e-commerce websites, the particular community and many more.

Table 7.6 concludes by showing the comparison between social commerce in this community and the general traditional e-commerce websites. 


\begin{tabular}{|c|c|c|c|c|}
\hline Criteria & Traditional E-commerce & References & Findings from this study & $\begin{array}{l}\text { Supporting } \\
\text { evidence }\end{array}$ \\
\hline $\begin{array}{l}\text { Purchasing } \\
\text { intention }\end{array}$ & $\begin{array}{l}\text { Purchase intention is influenced } \\
\text { by many factors such as trust, } \\
\text { perceived risk, social presence } \\
\text { and much more, but rarely } \\
\text { because of personal relationship. }\end{array}$ & $\begin{array}{l}\text { Gefen (2000); } \\
\text { Gefen et al. } \\
\text { (2003); } \\
\text { Weisberg, } \\
\text { Te'eni, and } \\
\text { Arman (2011) }\end{array}$ & $\begin{array}{l}\text { Purchase intention is likely to } \\
\text { be similar to traditional e- } \\
\text { commerce. However the } \\
\text { main factor for purchase } \\
\text { decision is the personal } \\
\text { relationship with the sellers. }\end{array}$ & $\begin{array}{l}\text { Sections 6.3.2, } \\
7.3 .2 \text {, and } \\
7.5 .1\end{array}$ \\
\hline Community & $\begin{array}{l}\text { Communities developed by the } \\
\text { business or by people who share } \\
\text { the same sentiment towards } \\
\text { brand. }\end{array}$ & $\begin{array}{l}\text { Srinivasan et al. } \\
\text { (2002); Porter } \\
\text { (2004) }\end{array}$ & $\begin{array}{l}\text { Unique characteristics of the } \\
\text { virtual community, } \\
\text { developed from lifestyle } \\
\text { blogging community. }\end{array}$ & $\begin{array}{l}\text { Sections } 7.3 \\
\text { and } 7.61\end{array}$ \\
\hline Level of intimacy & $\begin{array}{l}\text { Low level of intimacy. } \\
\text { - The relationships between } \\
\text { businesses and customers are } \\
\text { usually at the professional } \\
\text { level. } \\
\text { - Businesses only know the } \\
\text { customers based on }\end{array}$ & $\begin{array}{l}\text { Zhang et al. } \\
\text { (2011) }\end{array}$ & $\begin{array}{l}\text { High level of intimacy. } \\
\text { - Communication is mostly } \\
\text { done informally. } \\
\text { - Sellers can be contacted } \\
\text { directly via multiple } \\
\text { channels (i.e. Facebook } \\
\text { accounts; personal phone) }\end{array}$ & Section 7.4 \\
\hline
\end{tabular}




\begin{tabular}{|c|c|c|c|c|}
\hline & $\begin{array}{l}\text { customers' data in their } \\
\text { database (contact info, history } \\
\text { of purchase, history of } \\
\text { browsing etc.). }\end{array}$ & & & \\
\hline $\begin{array}{l}\text { Reputation and } \\
\text { trust }\end{array}$ & $\begin{array}{l}\text { Trust is developed based on } \\
\text { brand or vendor reputation. }\end{array}$ & $\begin{array}{l}\text { McKnight et al. } \\
(2000)\end{array}$ & $\begin{array}{l}\text { Reputation and trust earned } \\
\text { from social ties in the } \\
\text { community. } \\
\text { - Transferred from the } \\
\text { blogger-reader } \\
\text { relationship. }\end{array}$ & $\begin{array}{l}\text { Sections 6.4.3, } \\
\text { 6.3.2.1, 6.3.2.2, } \\
\text { 7.3.4 and 7.5.1 }\end{array}$ \\
\hline $\begin{array}{l}\text { Flexibility in } \\
\text { implementation }\end{array}$ & $\begin{array}{l}\text { Inflexible. } \\
\text { - Order can only be made using } \\
\text { the system provided in the e- } \\
\text { commerce websites. }\end{array}$ & - & $\begin{array}{l}\text { Relatively flexible. } \\
\text { - Multiple ordering and } \\
\text { payment channels. }\end{array}$ & $\begin{array}{l}\text { Sections } 5.8 \\
\text { and } 7.6 .3\end{array}$ \\
\hline System security & $\begin{array}{l}\text { High level of security. } \\
\text { - Support by advance } \\
\text { technology and third party } \\
\text { certification. }\end{array}$ & $\begin{array}{l}\text { Head and } \\
\text { Hassanein } \\
\text { (2002); Siau } \\
\text { and Shen } \\
\text { (2003); Turban } \\
\text { et al. (2012) }\end{array}$ & $\begin{array}{l}\text { Low level of data security. } \\
\text { - The security of the } \\
\text { customers' data relies on } \\
\text { how sellers handle and } \\
\text { keep their personal data. }\end{array}$ & Section 7.6.3 \\
\hline
\end{tabular}




\begin{tabular}{|c|c|c|c|c|}
\hline Social support & $\begin{array}{l}\text { Very low level of social support } \\
\text { from customers to sellers. }\end{array}$ & $\begin{array}{l}\text { No evidence on } \\
\text { social support } \\
\text { for the } \\
\text { businesses. }\end{array}$ & $\begin{array}{l}\text { High social support to sellers } \\
\text { from customers } \\
\text { - Social support is provided } \\
\text { from customers to } \\
\text { customers as well as from } \\
\text { customers to sellers. } \\
\text { - Type of social support: } \\
\text { informational support, } \\
\text { emotional support, } \\
\text { instrumental support, and } \\
\text { appraisal support. }\end{array}$ & $\begin{array}{l}\text { Sections } \\
6.2 .2 .1,6.3 .2 .3 \text {, } \\
7.3 .5,7.4 .1 \\
\text { and 7.5.2 }\end{array}$ \\
\hline
\end{tabular}

Table 7.6: Comparison between the findings of this study and traditional e-commerce study. 
This study shows that the community that ties the sellers and the customers provides a new insight into the motivations in commerce activities. The type of community and the multiple roles of actors in the community has proven to derive some interesting findings which contradict the traditional ecommerce literature particularly in terms of the relationship between sellers and customers in the same community.

\subsubsection{Summary}

In general, Section 7.6 has described the lesson learned in a bigger context of the findings. The following table summarised the findings for this section: 


\begin{tabular}{|c|c|c|c|}
\hline \multirow[t]{2}{*}{ Topics } & \multirow[t]{2}{*}{ Findings of this study } & \multirow[t]{2}{*}{ Past studies } & Status \\
\hline & & & $\begin{array}{c}\text { Confirm/ } \\
\text { Disconfirm Extend }\end{array}$ \\
\hline \multirow[t]{5}{*}{ Lifestyle blogger } & $\begin{array}{l}\text { Changes of direction (i.e. from personal to lifestyle) as } \\
\text { blogs gain more attention from community members. }\end{array}$ & Smith (2010) & Confirm \\
\hline & Bloggers as celebrity. & $\begin{array}{l}\text { Trammell and } \\
\text { Keshelashvili (2005) and } \\
\text { Abidin (2016). }\end{array}$ & Confirm \\
\hline & $\begin{array}{l}\text { The growth of the community was influenced by the } \\
\text { growth of social media technologies. }\end{array}$ & Abidin (2013a) & Confirm \\
\hline & $\begin{array}{l}\text { Bloggers produced informal but polite postings, } \\
\text { influenced by the culture in Malaysia that values } \\
\text { courtesy, tolerance and harmony. }\end{array}$ & Lövheim (2011) & Confirm \\
\hline & $\begin{array}{l}\text { Readers start to seek advice for their personal } \\
\text { problems. }\end{array}$ & Abidin (2013a) & Extend \\
\hline
\end{tabular}




\begin{tabular}{|c|c|c|c|}
\hline & Popular bloggers were hired for advertising. & $\begin{array}{l}\text { Kayes et al. (2012); Lee } \\
\text { and Youn (2009) }\end{array}$ & Confirm \\
\hline & $\begin{array}{l}\text { Bloggers identity is regarded as a branding in the } \\
\text { community. }\end{array}$ & Cross (2011) & Extend \\
\hline \multirow[t]{2}{*}{ Branding } & $\begin{array}{l}\text { Relationships promote trust, loyalty, and satisfaction } \\
\text { as compared to the product branding. }\end{array}$ & \multirow{2}{*}{$\begin{array}{l}\text { Chaudhuri and Holbrook } \\
\text { (2001); Delgado-Ballester } \\
\text { and Luis Munuera-Alemán } \\
\text { (2001); Eunju et al. } \\
\text { (2008); Srinivasan et al. } \\
\text { (2002) }\end{array}$} & \multirow[t]{2}{*}{$\begin{array}{l}\text { Disconfirm } \\
\text { Extend }\end{array}$} \\
\hline & Bloggers' reputations as branding. & & \\
\hline $\begin{array}{l}\text { Social commerce } \\
\text { implementation }\end{array}$ & Flexible and fluid. & $\begin{array}{l}\text { Fletcher and Greenhill } \\
\text { (2009) }\end{array}$ & Extend \\
\hline $\begin{array}{l}\text { Comparison with } \\
\text { traditional e-commerce } \\
\text { websites }\end{array}$ & $\begin{array}{l}\text { Many of the characteristics of social commerce } \\
\text { practices in this community are influenced by their } \\
\text { active participation and close relationships in the } \\
\text { community. }\end{array}$ & \multicolumn{2}{|c|}{ Refer to Table 7.6 (Section 7.6.4) } \\
\hline
\end{tabular}

Table 7.7: Summary of the lesson learned 


\subsection{Conclusion}

This chapter has discussed in detail the similarities and contradictions of findings for this research. It shows that social commerce activities participated in by members are mainly influenced by homophily, social ties, their sense of virtual community, trust, social support and perceived convenience. The strong ties among the members have shaped many practices in this community that can be benefited by the members regardless of their roles or the activities. In the next chapters, the conclusions drawn from the findings and discussions will be discussed. Implications for theory, policy and practice will be presented. 


\section{CHAPTER 8}

\section{CONCLUSION}

This final chapter revisits the research questions and reviews the main findings of the research in the light of issues raised in the literature review. Next, the theoretical and practical contributions are presented. The limitations of this thesis are also discussed. This chapter concludes with an exploration of possible future directions for this research.

\subsection{A Synthesis of the Main Findings of this Research}

The study set out to explore the motivational factors for participation in social commerce for both sellers and customers in the Malay lifestyle blogging community. This community of lifestyle bloggers and their readers first developed in the early years of blogging in Malaysia and has experienced several phases of growth. This includes the changes in terms of technologies used, ways of communicating and the norms and practices in the community. As members ventured into social commerce, the community evolved further. As members hold multiple roles, it is important to understand the relationship between these roles and how they affect the motivations for social commerce practices in the community.

This study used means-end theory to understand the core reasons for members' participation in social commerce. The scope of this study covered the roles of influential bloggers as sellers, and readers as customers. To answer the research questions, laddering, semi-structured interviews, and observations were conducted. The relationships between the motivations were also discussed from the perspectives of both sellers and customers. At the end of Chapter 6 (refer to Section 6.6), a proposed model of the main motivations for the members (both sellers and customers) was presented at a highly summarized level (refer to Figure 6.11). 
This section will synthesize the main findings to answer the research questions. In the literature review section, three features which underpin the concept of the social network theory were introduced: the presence of homophily, social ties (refer to Section 2.2.3) and social support (refer to Section 2.5). The literature review also identified previous research on the sense of virtual community (refer to Section 2.2.4), the theories of trust (refer to Section 2.3) and trust transfer theory (refer to Section 2.4). These topics, along with past studies on motivational factors for both sellers and customers' participation in social commerce (refer to Section 2.6) will now be revisited.

The findings were compared with the literature in Chapters 6 and 7. The empirical research presented in this thesis identified the motivational factors for sellers and customers in the Malay lifestyle blogging community (refer to Sections 6.2, 6.3, 7.4 and 7.4) and the relationship of those motivational factors with their past experience in the community. In this section, the conclusions are presented as responses to the two main research questions:

RQ1: What are the main factors that motivate members of the Malay lifestyle blogging community to continue their participation in social commerce activities?

Interviewees were asked about the factors that led them to participate in commerce activities. These motivational factors, described in Sections 6.3, 6.4, 7.3 and 7.4, can be divided into two groups which are the benefits and goals of participation. They are explained below:

\section{i. $\quad$ Sellers}

Sellers in this study were selected from famous lifestyle bloggers in the community. These sellers have been blogging for more than 5 years and their blogs have attracted many avid followers who are engrossed in reading their blogs. As a consequence of having many followers, they have managed to obtain advertising revenue from businesses in Malaysia. In addition, they have also been influenced to start their own online businesses via their own blogs and other social media tools such as Facebook and Instagram. 
As explained in Chapter 6, sellers are strongly motivated to sell and provide product reviews on their blogs because they want to gain profit and sustain their business. In addition, the selling activities are moderately influenced by the costeffectiveness of using social media as a business platform, as well as improving their self-esteem in the community. Based on the means-end theory, these motivational factors were considered as the main goals or values as to why the sellers participate in social commerce activities. Meanwhile, factors such as perceived convenience, getting social support from other members, access to potential customers and gaining more business opportunities are considered the consequences or benefits they obtained from their participation.

\section{ii. Customers}

Customers within the community can be readers or bloggers themselves. However as mentioned in Section 5.9, this study only focused on the customers who are readers and not the sellers themselves.

In the case of customers, the main goals or values for them to participate by purchasing, reading the product reviews and giving business input to the sellers include their self-esteem, obligation and loyalty to the members of the community. In addition, they feel more satisfied when participating (purchasing, reading reviews and giving helpful input to the businesses) in commercial activities in the community. The benefit layers or the consequences of their participation according to the means-end theory describe how customers are able to strengthen their relationships in the community, increase their trust, identify product quality, be aware of the risks, obtain various benefits, give social support, follow norms and experience the convenience of participating in commerce activities.

\section{iii. Sellers vs. Customers}

The findings show that both sellers and customers highlight the role of social support as a motivational factor. Sellers acknowledged that they have strong support from community members, including their customers. Meanwhile 
customers claim that one of their motivations for participating is to provide support to the sellers. This shows that the ties are strong in this community. The relationship between the strength of ties in the community and commercial participation, as well as the context of convenience will be explained in detail when answering the second research question.

RQ2: What is the relationship between the members' virtual community participation and their social commerce participation?

The members joined the community for various reasons. The reasons included looking for friendship, socializing, reading blogs as an alternative medium for current issue updates, seeking support, gaining knowledge/information, sharing opinions, and earning money by blogging. By following blogs, members understand more about the bloggers' lives. Subsequently, members noticed the similarities between them and the bloggers that made them feel more connected to each other.

In addition, social media and mobile technology have influenced the way they communicate and as a result, strengthened the ties and their level of SOVC. The fact that they are from the same ethnicity and religion, as well as having a similar gender, age group and educational background, made it easier for them to understand each other, creating stronger ties between them. By building these relationships within the community, the members influenced one another and became immersed in the community. Their varying levels of involvement, from active to non-active members, differentiated their experience of SOVC. Homophily, social ties and SOVC influenced the level of trust they had in the community, as well as forming a norm of providing support to each other, regardless of the role they played in the community.

Answering RQ1 revealed several factors that contributed to participation in social commerce activities. Using means-end theory, several chains that showed the linkages between motivations emerged (refer to Section 6.2). Firstly, by selling their products in the community, the sellers can enjoy the convenience of the technology and obtain social support which also allows them to access 
potential customers who are the readers of their blogs. By gaining more customers, they can sustain their businesses and make a profit. Secondly, writing product reviews in this community will also earn them more social support from community members. This is because the community members want to know about their first-hand experience of using the products, which help them to make purchasing decisions. Therefore sellers believe that by providing reviews, they satisfy their readers and consequently members will give more support to them.

Meanwhile for customers in the community (refer to Section 6.3), purchasing and giving business input to the sellers was mainly influenced by their relationships in the community. By participating in these activities, customers can strengthen their relationships with the sellers. The consequences of the relationships are (i) trust development among members, (ii) giving social support, and (iii) convenience.

The findings show that both the sellers and customers' motivations were strongly influenced by the members' relationships as bloggers and readers in the community. The relationships that were developed were based on the presence of homophily, strong ties and the SOVC which influenced the customer trust towards the members, in this case, the sellers. This shows that the trust developed in the community has been transferred to the commerce activities.

Whilst both sellers and customers agree that they are motivated by social support and perceived convenience, the contexts of their motivations are different. Firstly, although the sellers have also perceived the convenience of using social media for their business, this particular motivation was not influenced by the sellers' past participation as bloggers. The context of perceived convenience for sellers is different from that of customers, who believe that factors for conveniently participating in commerce activities are not only the ease of use and perceived usefulness, but also to a certain extent, influenced by their relationship with the sellers. Purchasing from this community was easier for customers because they feel comfortable interacting with the sellers because of their pre-existing relationships in the community. It 
makes it easier for them to customize their orders and get faster feedback from the sellers.

Secondly, in terms of social support, the sellers were motivated by the support they gained from customers (refer to Section 7.4.1) whilst the customers were motivated by the support that they can give to sellers (refer to Section 7.5.2). In addition, as the community members come from similar backgrounds, this study found that the motivational factors are also influenced by social and cultural factors. Members have similar beliefs and cultural boundaries that form their motivation to participate. For example, one of the reasons for members to provide social support is because they want to help sellers of the same race and religion in their businesses. Further, they believe that by doing good to other people, they will receive something good in return.

Community members have shown that they have strong ties and strong support networks regardless of the activities that take place in the community. The trust they developed in their blogger-reader relationship has been transferred to the seller-customer relationship, which shows that regardless of their role in the community, practices are shaped by the characteristics of the community, which are homophily, social ties and the SOVC.

The next section summarizes the key findings of this research.

\subsection{Key Findings of this Research}

The motivational factors and the goals for social commerce participation are dependent on the roles played by the members of the community. The study has shown that the main motivational factors (i.e. trust, social support, etc.), which lead to members' goals can be achieved by nurturing the relationships in the community. Figure 8.1 summarizes the key findings of this research as explained in Section 6.6 (refer to Figure 6.12). It illustrates how participation in the virtual community influences the motivational factors to participate in social commerce, as addressed by RQ2, in order to achieve members' goals. 


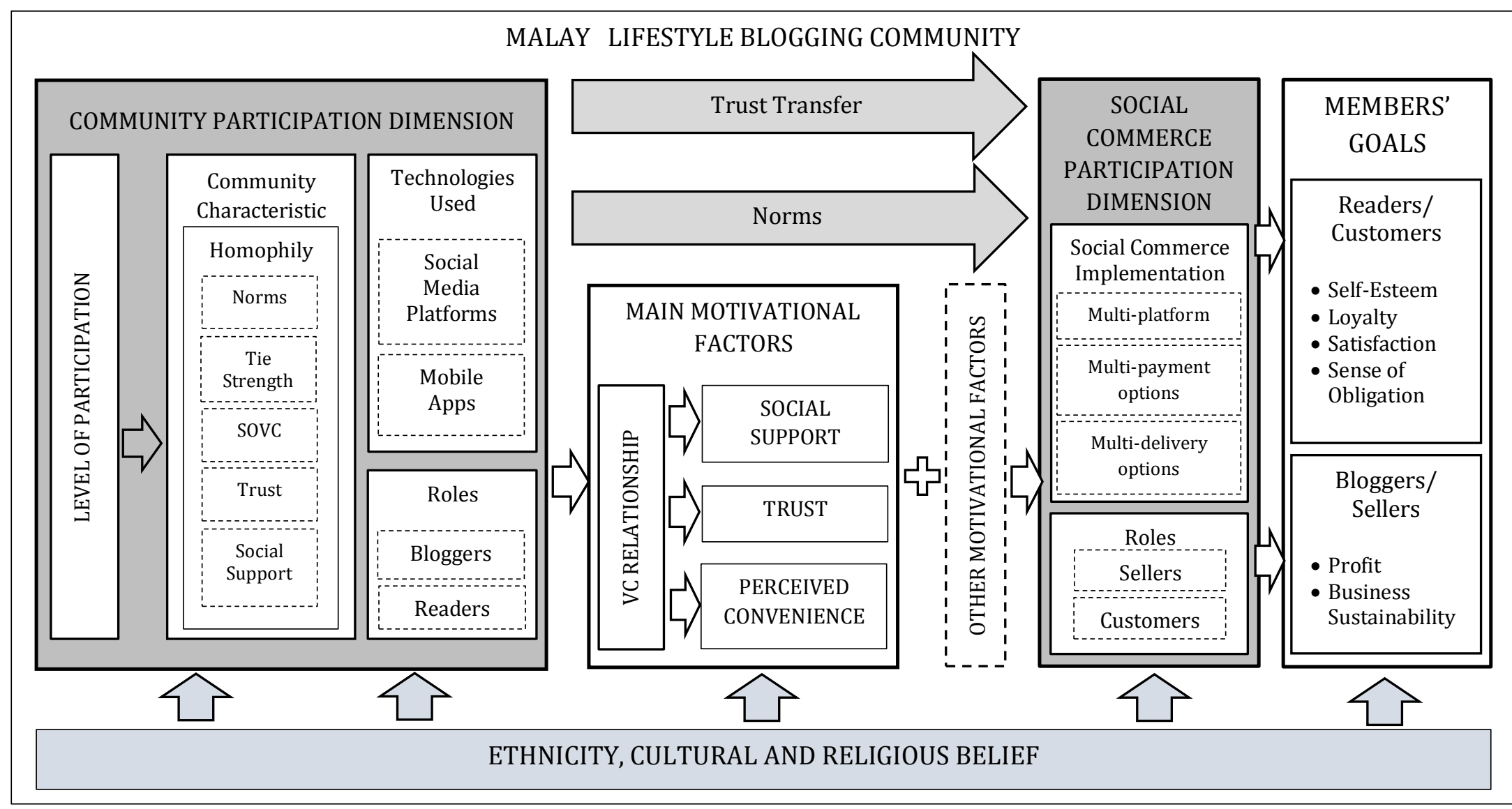

Figure 8.1: Key findings of this study 
As can be seen in the diagram, the community participation dimension consists of four elements: (i) community characteristics, (ii) technology used, (iii) members' roles, and (iv) level of participation. The community is characterized by the principle of homophily which shapes norms, social ties, the SOVC, the sense of trust between members, and the practice of social support between members. These characteristics are influenced by a member's level of participation (i.e. active; passive etc.). Generally, the more active the members are, the more connected they are to other members, which subsequently affects their level of trust and the social support practices in the community. In addition, the technology used as the communication medium (i.e. social media, mobile applications) also helps to increase the connectedness among members. The relationship at this stage is described as a blogger-reader relationship denoting the roles of the members.

The diagram also illustrates that trust in this community has been transferred from their blogger-reader relationship to their seller-customer relationship, for social commerce participation. In addition, when members of this community participate in commercial activities, they continue their usual practice which is denoted by the 'arrow of norm' from the community participation dimension to the social commerce participation dimension in Figure 8.1. This includes the practice of supporting other members. The practices in this community, including participating in commercial activities, are guided by the members' ethnicity, as well as cultural and religious beliefs, as explained in Chapter 7.

Finally, the social commerce participation dimension shows the implementation model that has also been discovered in this research. As explained in Section 7.6.3, this model is used by the sellers in this community to provide flexibility and leads customers to experience the convenience of shopping from sellers in the community. Sellers provide multiple options for customers to browse their products, as well as to choose their payment and delivery method preferences.

The diagram summarizes the understanding gained on how community participation influences members' motivation to participate in social 
commerce. The next section explains the theoretical contributions of this research.

\subsection{Theoretical Contributions}

The chosen community has unique characteristics and presents a different type of social commerce setting which has not been widely researched. The community is built around lifestyle bloggers within a unique cultural and ethnic niche. However, interestingly, it appears they did not originally set out to sell. The social commerce exchanges within the community emerged from a virtual community which originally served different purposes for its members.

This study contributes to the existing literature on virtual communities, particularly communities related to social commerce. In addition, it brings new theoretical implications to the area of social commerce and virtual and lifestyle blogging, which will be explained next.

\section{Virtual Community within Social Commerce}

This study highlights the uniqueness of the virtual community involved in social commerce. It provides new insights for scholars undertaking studies in diverse types of social commerce settings in terms of community characteristics and the role of relationships. This includes building an understanding of the characteristics of social commerce implementation in this community (e.g. multi-platform, members' multi-role, multi-communication channels and multi-channels for ordering, payment and delivery) and the factors that shape relationships in the community (e.g. homophily, social ties, SOVC, trust, and social support).

In addition, this study has also compared community practices with traditional e-commerce practices (refer to Table 7.6, Section 7.6.4). The main difference between these two practices is the role of relationships in the virtual community which highlights the sense of trust between members, the social support provided and how it motivates sellers and customers. In the case of sellers, social support from customers is influenced by their previous 
relationship as bloggers and readers. In the case of customers, they provide social support because of social ties, the sense of obligation, social norms and admiration for the bloggers. Meanwhile customers trust the sellers because they have encountered them in the community and thus trust is transferred to their new relationship of seller-customer.

\section{Social Commerce Literature}

This study has extended the literature related to social commerce. In the typical social commerce model 'ratings and reviews', which is one of the social commerce constructs, are usually done in a single space such as on a specific Facebook account of the business. This is the place where customers gather opinions about the products. However, in the Malay lifestyle blogging community, the 'ratings and reviews' of products and services are extended to the individuals' spaces such as blogs and Facebook. This is because members communicate on various platforms. Therefore the members can access the 'reviews and ratings' on other members' blogs or their social media accounts instead of going to a specific brand page. This finding shows that the social commerce constructs can be defined in different ways and are not restricted to specific platforms. The term 'ratings and reviews' varies depending on the type of community and how the community operates.

In addition, despite the promising opportunities provided by social commerce, little progress has been made in understanding the motivational factors underlying the decision of micro-business sellers and customers to participate in social commerce. By studying both the sellers' motivations and customers' motivations, this study has identified the importance of homophily, strong ties and experienced SOVC in defining their relationships within the community. Relationships based on those three elements influence the continuance behaviour in social commerce. This is because the relationships influence the customers to provide social support to the sellers, they create trust and it is more convenient. As for the sellers, support from customers enables them to gain profit and sustain their businesses. It also motivates sellers to continue selling as they receive social support from customers. These findings have 
extended the social commerce literature and could help future researchers to understand the motivational factors for participation.

\section{Social Support within Social Commerce}

This study has also contributed to the social support literature in the social commerce domain. This study has deepened and extended the understanding of the way social support helps to motivate both sellers and customers to continue their participation. The findings have emphasized four main social support types (informational support, emotional support, instrumental support and appraisal support) that are being practised in this community which contribute to our understanding of the norms in the community.

By highlighting the earlier relationship they had as bloggers and readers, it is believed that this study has provided important insights into members' distinct roles in social commerce activities. This includes the continuance of providing social support to members although their roles have shifted, from blogger to seller and from reader to customer. This extends the role of social support in the community, as social support is also given to sellers. In addition, by having known the sellers from their relationship as bloggers and readers, this contributes to the feeling of convenience for customers when purchasing from the sellers.

\section{Trust in Social Commerce}

The research extends several well-known findings related to trust in ecommerce. While most of the research on trust was developed based on brands or reputable companies, in this research trust developed from the participation of bloggers and readers in the community. The production of trust was based on homophily, social ties, the personality of the bloggers, and the consistency of blog posts. Subsequently, trust towards the bloggers has been transferred to trust towards the online business run by the bloggers. The finding shows that the trust in sellers has been developed from members' relationships as blogger 
to reader as compared to the production of trust based on a specific brand and the reputation of the businesses.

\section{Cultural Influences}

This study has also highlighted the role of ethnicity, culture and religious beliefs in social commerce which shape many practices in the community. This shows that the success of its implementation does not rely only on the business strategy and technological factors; the demographic background of the community members is also likely to influence norms in the Malay lifestyle blogging community. This includes social support practices and the strength of relationships between members in the community, which eventually influences their behaviour in the community. For example the Malay culture favours both the importance of forming relationships before proceeding with business transactions and the obligation to help other Muslims.

The next section will discuss the practical contributions of this study.

\subsection{Practical Contributions}

Lifestyle bloggers have attracted considerable attention from practitioners (Hopkins, 2010a), particularly advertisers. This is because advertisers recognise that lifestyle bloggers have significant influence on their readers via their blogs and social media accounts.

The Malay lifestyle bloggers who venture into online business within the community have shown that they have adopted various social media platforms for their business purposes. They have used the concept of 'trial and error' to find the best way to operate their businesses. In addition, they have merged the business platform with their personal space, combining business and leisure together to employ social commerce. By presenting the social commerce implementation model in this community, this study believes that this research makes several contributions to the social commerce practitioners. 
Firstly, many studies have demonstrated that gaining customers' trust is the first step in persuading them to purchase online. Typically, social commerce businesses use social media pages in order to create relationships with the customers. The findings of this study show that in this community, it takes more than a social media page to persuade customers to make a purchase, which explains the importance of past relationships. This is where the social ties and SOVC play their part for this specific group of micro-businesses in the community. Larger businesses lack this advantage and need to develop strategies to create closer relationships with potential customers that 'like' their social media pages. Businesses, regardless of their size, can use the findings to reflect on what is lacking in their social media marketing strategy.

Secondly, the model can be used for those who plan to start online businesses using social media, particularly micro-businesses. For any active participants or influential members of virtual communities, they can adapt the findings of this research to plan an online business. They can take into consideration how the community creates a bond between members and also improve their business operations such as improving the flexibility of ordering, payment and delivery systems.

Lastly, the findings show that community engagement creates social support from other community members which in turn creates more opportunity for micro-businesses to grow, and motivates members to participate in selling and product review activities. Micro-business owners who do not have the capacity to create their own community can use this case to learn how to expand their business using existing social network communities. This is crucial for the sustainability of social commerce in small non-brand communities.

\subsection{Limitations of the Study}

The research is limited by several issues which include the time period of a PhD thesis, the number of participants interviewed during the limited time frame, laddering data issues, the use of a single case design and the rapidly changing technological environment. These limitations will be explained next. 
Firstly, the current data was collected without concern for all types of members (refer to Table 5.8, Section 5.8.1) in the community. Ideally more participants should have been interviewed to get more diverse data based on the type of participation (i.e. active, non-active, lurkers) and as well as looking at nonblogger sellers in the community. Although this study interviewed 41 participants, more participants would have provided more insight in order to achieve more comprehensive findings. Nonetheless, the findings have been strengthened by carrying out further semi-structured interviews and observations to add to their accuracy.

Secondly, some scholars have highlighted issues concerning the loss of data when using the laddering technique (Saaka et al., 2004) during the transformation of the implication matrix to HVM. This study argues that the missing data in some chains shows that the factors are not shared by the majority of participants. This shows that the factors cannot be considered as the main influential factors in the chain as they are not common factors amongst customers in this community. Furthermore this study is also supported by data from observations and semi-structured interviews, therefore the loss of data is not a significant issue. The implication matrix can be referred to if needed to identify the weak constructs for future use.

Thirdly, the study was conducted using a single case study approach which is prone to generalization issues. This means that the findings cannot be generalized to the wider population of all social commerce practices. However, this research focuses on a very specific community which consists of members with multiple roles, which explains the uniqueness of this social commerce community. Hence it is argued that the single case approach best suits the nature of this study. Furthermore, the aim for this research is to provide an understanding of this specific phenomenon that can contribute to concept definition and explain relationships as suggested by Eisenhardt and Graebner (2007). Therefore, the interpretations of the findings are specific to the views and experiences of the participants that were being studied. 
Lastly, the community operates in a rapidly changing environment which influences how the community members interact as well as the way they conduct their businesses. The researcher was exposed to the risk of being the context being rendered obsolete by the changing of technologies. Nonetheless the underlying issues remain similar despite the changing technologies.

\subsection{Future Research}

There has been limited academic study focusing on the lifestyle blogging community as compared to other genres of blogging. This study has uncovered important findings focusing solely on this community. Further work would be useful to refine the findings of this study. Future research should aim to highlight other roles in the community. As mentioned in Section 8.5, this study is bound by the limited time frame for the PhD study. Therefore, only bloggers who are sellers and readers who are customers were considered in this study (refer to Section 5.9). It would be interesting to further investigate other roles in the community to compare the motivations of different roles for participating in commerce activities. For example the motivation of a reader who is also a seller in the community.

Secondly, it has been known that the community has experienced changes in the technology used for communication as well as in commercial activities. Further study should be conducted to identify the impact of technology evolution towards members' behaviour within the community. The knowledge on how the community is coping with the changes and how it influences their motivation in commerce activities could provide more understanding of this community practice.

Thirdly, the study found that members in this community were willing to share ideas on how to improve sellers' operations. This practice explains value cocreation. This study could be extended to identify who are the main actors of co-creation practices in this community. Extending this study could help scholars to understand more about voluntary participation in value co-creation activities. 
Fourthly, this study found that a few scholars suggested that the phenomenon seems to be unique to some South East Asian countries such as Malaysia and Singapore. Nonetheless the evidence for this is limited. Therefore, this study could also be extended to similar models in other countries such as Indonesia. The comparison would be a good way to understand more about social commerce practices in other countries. This will then give further insights on how a sense of virtual community could influence the continuation of social commerce participation in different environments.

\subsection{Concluding Remarks}

This study examined the intersection between lifestyle blogging, social commerce and the use of social media to support a virtual community in a specific ethnic, cultural and language niche. However, in combination, they were unique due to the nature of the community, where a member's role was interchangeable depending on the activities they engaged in. Many elements from previous research on these diverse phenomena were confirmed and extended by this study, including the presence of homophily, tie strength, SOVC, perceived convenience, trust and social support in the community, and motivational factors for members' participation.

This study has presented a wide-ranging discussion leading to conclusions grouped around the major themes of this research as summarized in Figure 8.1 (refer to Section 8.2). In many ways, the community practices, members' roles, social media technologies, as well as cultural and religious beliefs have shaped the social commerce practices in the community. Figure 8.1 shows that although the roles of members have changed based on their activities, the characteristics of the community have still influenced the same norms to be practiced in social commerce activities. This goes on to influence the trust and social support in a business context which helps members to achieve their main goals in social commerce. 


\section{REFERENCES}

Abdullah, A. (1996). Going glocal: Cultural dimensions in Malaysian management: Malaysian Institute of Management.

Abfalter, D., Zaglia, M. E., \& Mueller, J. (2012). Sense of virtual community: A follow up on its measurement. Computers in Human Behavior, 28(2), 400-404.

Abidin, C. (2013a). Cyber-BFFs*: Assessing women's 'perceived interconnectedness' in Singapore's commercial lifestyle blog industry* Best Friends Forever. Global Media Journal: Australian Edition, 7(1).

Abidin, C. (2013b). Understanding Social Currency in the Female Commercial Blog Industry in Singapore. Paper presented at the ISA eSymposium for Sociology.

Abidin, C. (2016). “Aren't These Just Young, Rich Women Doing Vain Things Online?": Influencer Selfies as Subversive Frivolity. Social Media+ Society, 2(2).

Afrasiabi, R. A., \& Benyoucef, M. (2011). A Model for Understanding Social Commerce. Journal of Information Systems Applied Research, 4(2).

Agarwal, N., Liu, H., Tang, L., \& Yu, P. S. (2008). Identifying the influential bloggers in a community. Paper presented at the 2008 International Conference on Web Search and Data Mining, New York, USA.

Aggarwal, B. A. F., Liao, M., \& Mosca, L. (2008). Physical activity as a potential mechanism through which social support may reduce cardiovascular disease risk. The Journal of Cardiovascular Nursing, 23(2), 90.

Ahmad, A. L. (2011). The social reality of the Malaysian blogosphere. International Journal of Arts \& Sciences, 4(3), 239-252. 
Amoroso, D. L. (2013). The Importance of Institution-Based Trust in Mobile Adoption with Online Shopping Applications. International Journal of Technology Diffusion (IJTD), 4(4), 1-26.

Anastas, J. W. (2002). Keynote Address: Why Epistemology Matters. Paper presented at the 16th Annual Symposium on Doctoral Research, Ohio State University, Columbus, Ohio.

Anderson, R. E., \& Srinivasan, S. S. (2003). E-satisfaction and e-loyalty: A contingency framework. Psychology \& Marketing, 20(2), 123-138.

Andrew, A. L. (2016). How to Make Money Blogging. Retrieved from https://amylynnandrews.com/how-to-make-money-blogging/

Antonucci, T. C. (1990). Social supports and social relationships. Handbook of Aging and the Social Sciences, 3, 205-226.

Arsil, P., Li, E., Bruwer, J., \& Lyons, G. (2014). Exploring consumer motivations towards buying local fresh food products: A means-end chain approach. British Food Journal, 116(10), 1533-1549.

Ashton, W. A., \& Fuehrer, A. (1993). Effects of gender and gender role identification of participant and type of social support resource on support seeking. Sex Roles, 28(7-8), 461-476.

Augar, N., \& Zeleznikow, J. (2013). I just saw this on Facebook, I need it now': exploring small business use of Facebook. Paper presented at the 24th Australasian Conference on Information Systems (ACIS), Melbourne, Australia.

Bagozzi, R. P., \& Dholakia, U. M. (2006). Antecedents and purchase consequences of customer participation in small group brand communities. International Journal of Research in Marketing, 23(1), 4561. 
Baird, C. H., \& Parasnis, G. (2011a). From social media to social CRM: What customers want-The first part of a two-part series. Executive Report, IBM Global Business Services, 1-16.

Baird, C. H., \& Parasnis, G. (2011b). From social media to Social CRM: reinventing the customer relationship. Strategy \& Leadership, 39(6), 2734.

Bansal, G., \& Chen, L. (2011). If they trust our e-commerce site, Will they trust our social commerce site too? Differentiating the trust in e-commerce and scommerce: The moderating role of privacy and security concerns. Paper presented at the 6th Midwest Association for Information Systems Conference, Omaha, Nebraska, USA.

Barnes, N. G., Lescault, A. M., \& Andonian, J. (2014). The 2014 Fortune 500 and social media: LinkedIn dominates as use of newer tools explodes. University of Massachusetts Dartmouth.

Barrera Jr, M. (1986). Distinctions between social support concepts, measures, and models. American Journal of Community Psychology, 14(4), 413-445.

Barrera, M., \& Ainlay, S. L. (1983). The structure of social support: A conceptual and empirical analysis. Journal of Community Psychology, 11(2), 133143.

Baym, N. K. (1997). Interpreting soap operas and creating community: Inside an electronic fan culture. Culture of the Internet, 103-120.

Beach, D. (2005). Social Commerce via the Shoposphere \& Pick Lists. Retrieved from http://www.ysearchblog.com/2005/11/14/social-commerce-viathe-shoposphere-pick-lists

Bech-Larsen, T., \& Nielsen, N. A. (1999). A comparison of five elicitation techniques for elicitation of attributes of low involvement products. Journal of Economic Psychology, 20(3), 315-341. 
Beisel, D. (2005). The Beginnings of Social Commerce. Retrieved from http://genuinevc.com/archives/2005/12/06/the-beginnings-of-socialcommerce.html

Benbasat, I., Goldstein, D. K., \& Mead, M. (1987). The case research strategy in studies of information systems. MIS Quarterly, 369-386.

Beniger, J. R. (1987). Personalization of mass media and the growth of pseudocommunity. Communication Research, 14(3), 352-371.

Bernama. (2010). Dewan Rakyat: 2 Million Bloggers Proof Of Media Freedom In Country. Bernama.

Berthon, P. R., Pitt, L. F., Plangger, K., \& Shapiro, D. (2012). Marketing meets Web 2.0, social media, and creative consumers: Implications for international marketing strategy. Business Horizons, 55(3), 261-271.

Blanchard, A. (2004). Blogs as virtual communities: Identifying a sense of community in the Julie/Julia project. Into the blogosphere: Rhetoric, community, and culture of weblogs. Retrieved from http://hdl.handle.net/11299/172837

Blanchard, A. (2007). Developing a sense of virtual community measure. CyberPsychology \& Behavior, 10(6), 827-830.

Blanchard, A. (2008). Testing a model of sense of virtual community. Computers in Human Behavior, 24(5), 2107-2123.

Blanchard, A., \& Markus, M. L. (2004). The experienced "sense" of a virtual community: characteristics and processes. SIGMIS Database, 35(1), 6479. doi:10.1145/968464.968470

Blanchard, A. L. (2007). Developing a sense of virtual community measure. CyberPsychology \& Behavior, 10(6), 827-830. 
Blanchard, A. L., \& Markus, M. L. (2002). Sense of virtual community-maintaining the experience of belonging. Paper presented at the 35th Annual Hawaii International Conference on System Sciences, Hawaii, USA.

Bleumers, L., Van den Broeck, W., Lievens, B., \& Pierson, J. (2012). Seeing the bigger picture: a user perspective on 360 TV. Paper presented at the 10 th European conference on Interactive TV and Video, Berlin, Germany.

Bolton, R. N., \& Drew, J. H. (1991). A Multistage Model of Customers' Assessments of Service Quality and Value. Journal of Consumer Research, $17(4), 375-384$.

Bonne, K., \& Verbeke, W. (2006). Muslim consumer's motivations towards meat consumption in Belgium: qualitative exploratory insights from meansend chain analysis. Anthropology of Food(5).

Bourne, H., \& Jenkins, M. (2005). Eliciting managers' personal values: an adaptation of the laddering interview method. Organizational Research Methods, 8(4), 410-428.

Boyd, D. (2006). A blogger \'s blog: Exploring the definition of a medium. Reconstruction, 6(4).

Boyd, D., \& Ellison, N. (2007). Social network sites: Definition, history, and scholarship. Journal of Computer-Mediated Communication, 13(1).

Boyd, R., \& Richerson, P. J. (2001). Norms and bounded rationality. Bounded Rationality: The Adaptive Toolbox, 281-296.

Braithwaite, D. O., Waldron, V. R., \& Finn, J. (1999). Communication of social support in computer-mediated groups for people with disabilities. Health Communication, 11(2), 123-151.

Brake, D. R. (2009). 'As if nobody's reading'?: The imagined audience and sociotechnical biases in personal blogging practice in the UK. (PhD), The London School of Economics and Political Science, London. 
Brandtzæg, P. B., \& Heim, J. (2009). Why people use social networking sites Online Communities and Social Computing (pp. 143-152): Springer.

Brown, J., Broderick, A. J., \& Lee, N. (2007). Word of mouth communication within online communities: Conceptualizing the online social network. Journal of Interactive Marketing, 21(3), 2-20.

Brown, J. J., \& Reingen, P. H. (1987). Social ties and word-of-mouth referral behavior. Journal of Consumer Research, 350-362.

Brown, L. G. (1989). The strategic and tactical implications of convenience in consumer product marketing. Journal of Consumer Marketing, 6(3), 1319.

Brüderl, J., \& Preisendörfer, P. (1998). Network support and the success of newly founded business. Small Business Economics, 10(3), 213-225.

Bruns, A., \& Jacobs, J. (2006). Uses of blogs. New York: Peter Lang.

Bryman, A. (2012). Social research methods: OUP Oxford.

Buntain, C., \& Golbeck, J. (2015). Trust transfer between contexts. Journal of Trust Management, 2(1), 1-16.

Burgos, D., Hummel, H., Tattersall, C., Brouns, F., Kurvers, H., \& Koper, R. (2005). Influence of face-to-face meetings on virtual community activity: the case of learning network for learning design. Paper presented at the International Conference Web Based Communities, Spain.

Campbell, D. T. (1958). Common fate, similarity, and other indices of the status of aggregates of persons as social entities. Behavioral Science, 3(1), 1425.

Celis, V., Husson, J., Abeele, V. V., Loyez, L., Van den Audenaeren, L., Ghesquière, P., ... Geurts, L. (2013). Translating preschoolers' game experiences into design guidelines via a laddering study. Paper presented at the 12 th 
International Conference on Interaction Design and Children, New York, USA.

Cenite, M., Detenber, B. H., Koh, A. W., Lim, A. L., \& Soon, N. E. (2009). Doing the right thing online: a survey of bloggers' ethical beliefs and practices. New Media \& Society, 11(4), 575-597.

Cha, M.-K., Kweon, S.-H., Choi, Y.-J., Won, Y.-A., \& Kim, H. J. (2014). A Research on Value Chain Structure of the Performing Arts Consumers' Social Media Usage-Application of Means-End Chain Theory and Involvement. Paper presented at the 6th International Conference on Intelligent Technologies for Interactive Entertainment, Chicago.

Chan, H.-C., Bhandar, M., Oh, L.-B., \& Chan, H.-C. (2004). Recognition and participation in a virtual community. Paper presented at the 37th Annual Hawaii International Conference on System Sciences, Hawaii, USA.

Chang, H. J. (2009). Online supportive interactions: Using a network approach to examine communication patterns within a psychosis social support group in Taiwan. Journal of the American Society for Information Science and Technology, 60(7), 1504-1517.

Chaudhuri, A., \& Holbrook, M. B. (2001). The chain of effects from brand trust and brand affect to brand performance: the role of brand loyalty. Journal of Marketing, 65(2), 81-93.

Chen, G.-L., Yang, S.-C., \& Tang, S.-M. (2013). Sense of virtual community and knowledge contribution in a P3 virtual community: Motivation and experience. Internet Research, 23(1), 4-26.

Chen, J., \& Shen, X.-L. (2015). Consumers' decisions in social commerce context: An empirical investigation. Decision Support Systems, 79, 55-64.

Chen, N., Rau, P.-L. P., \& Kolz, D. (2013). Comparison of Trust on Group Buying Websites between American and Chinese Young Adults. Paper presented at the International Conference on Cross-Cultural Design, Las Vegas. 
Chen, S. C., \& Dhillon, G. S. (2003). Interpreting dimensions of consumer trust in e-commerce. Information Technology and Management, 4(2-3), 303-318.

Chen, X., Huang, Q., Davison, R. M., \& Hua, Z. (2015). What drives trust transfer? The moderating roles of seller-specific and general institutional mechanisms. International Journal of Electronic Commerce, 20(2), 261289.

Chiew, K. (2008, April 28). From blogs to riches. The Straits Times, p. 80.

Chin, A., \& Chignell, M. (2007). Identifying communities in blogs: roles for social network analysis and survey instruments. International Journal of Web Based Communities, 3(3), 345-363.

Coleman, J. S., \& Coleman, J. S. (1994). Foundations of social theory: Harvard University Press.

Collier, J. E., \& Bienstock, C. C. (2006). How do customers judge quality in an etailer? MIT Sloan Management Review, 48(1), 35.

Colucci, C., \& Cho, E. (2014). Trust inducing factors of Generation Y blog-users. International Journal of Design, 8(3).

Constantinides, E., \& Fountain, S. J. (2008). Web 2.0: Conceptual foundations and marketing issues. Journal of Direct, Data and Digital Marketing Practice, 9(3), 231-244.

Cook, J., \& Wall, T. (1980). New work attitude measures of trust, organizational commitment and personal need non-fulfilment. Journal of Occupational Psychology, 53(1), 39-52.

Costa, A. d. A., Dekker, M., \& Jongen, W. (2004). An overview of means-end theory: potential application in consumer-oriented food product design. Trends in Food Science \& Technology, 15(7), 403-415. 
Coursaris, C. K., \& Liu, M. (2009). An analysis of social support exchanges in online HIV/AIDS self-help groups. Computers in Human Behavior, 25(4), 911-918.

Cranefield, J. (2009). Online communities of practice and professional change: a three-tier view of the knowledge embedding process. (PhD), Victoria University of Wellington, New Zealand.

Cranefield, J., Yoong, P., \& Huff, S. L. (2015). Rethinking Lurking: Invisible leading and following in a knowledge transfer ecosystem. Journal of the Association for Information Systems, 16(4), 213.

Creswell, J. W., \& Clark, V. L. P. (2007). Designing and conducting mixed methods research: Wiley Online Library.

Cross, M. (2011). Bloggerati, Twitterati: How Blogs and Twitter are Transforming Popular Culture: How Blogs and Twitter are Transforming Popular Culture: ABC-CLIO.

Crum, C. (2010). Facebook E-Commerce: What Online Retailers Have Been Looking For? Retrieved from http://www.webpronews.com/facebooke-commerce-what-online-retailers-have-been-looking-for-2010-03

Csikszentmihalyi, M. (1975). Beyond Boredom and Anxiety. San Francisco: Jossey Bass.

Culnan, M. J., McHugh, P. J., \& Zubillaga, J. I. (2010). How large U.S. companies can use Twitter and other social media to gain business value. MIS Quarterly Executive, 9(4), 243-259.

Cunningham, P. C., \& Wilkins, J. C. (2009). A Walk in the Cloud. Information Management, 43(1).

Currarini, S., \& Vega-Redondo, F. (2013). A simple model of homophily in social networks. University Ca'Foscari of Venice, Dept. of Economics Research Paper Series(24). 
Curty, R. G., \& Zhang, P. (2011). Social commerce: Looking back and forward. Proceedings of the American Society for Information Science and Technology, 48(1), 1-10.

Curty, R. G., \& Zhang, P. (2013). Website features that gave rise to social commerce: a historical analysis. Electronic Commerce Research and Applications, 12(4), 260-279.

Da Silveira, C., Lages, C., \& Simões, C. (2013). Reconceptualizing brand identity in a dynamic environment. Journal of Business Research, 66(1), 28-36.

Davis, F. (1987). User acceptance of information systems: the technology acceptance model (TAM). University of Michigan Business School.

Decker, S. (2007). The big idea behind Social Commerce. Retrieved from http://www.imediaconnection.com/content/15372.asp

Delerue, H., \& Hopkins, J. L. (2012). Can Facebook be an effective mechanism for generating growth and value in small businesses? Journal of Systems and Information Technology, 14(2), 131-141.

Delgado-Ballester, E., \& Luis Munuera-Alemán, J. (2001). Brand trust in the context of consumer loyalty. European Journal of Marketing, 35(11/12), 1238-1258.

Deragon, J. (2008). Will 2008 be the year of Social Commerce? Retrieved from http://www.relationship-economy.com/?p=575

Dong, X. L., Gabrilovich, E., Murphy, K., Dang, V., Horn, W., Lugaresi, C., . . Zhang, W. (2015). Knowledge-based trust: Estimating the trustworthiness of web sources. Proceedings of the VLDB Endowment, 8(9), 938-949.

Doolin, B., Dillons, S., Thompson, F., \& Corner, J. L. (2007). Perceived risk, the Internet shopping experience and online purchasing behavior: A New Zealand perspective. Electronic commerce: Concepts, methodologies, tools, and applications, 324-345. 
Du, H. S., \& Wagner, C. (2006). Weblog success: Exploring the role of technology. International Journal of Human-Computer Studies, 64(9), 789-798.

Dwyer, C., Hiltz, S., \& Passerini, K. (2007). Trust and privacy concern within social networking sites: A comparison of Facebook and MySpace. Paper presented at the 13th Americas Conference on Information Systems Keystone, Colorado, USA.

Eastin, M. S. (2002). Diffusion of e-commerce: an analysis of the adoption of four e-commerce activities. Telematics and Informatics, 19(3), 251-267.

Economic Planning Unit. (2010). Tenth Malaysia Plan 2011-2015. Putrajaya: Economic Planning Unit Retrieved from http://www.mpob.gov.my/images/stories/pdf/RMK_10.pdf

Economic Planning Unit. (2015). The Malaysian Economy in Figures 2015. Putrajaya: Prime Minister's Department Retrieved from http://www.epu.gov.my/documents/10124/a71249d3-d815-4ab6af38-ffad2560ffd8

Efimova, L., \& De Moor, A. (2005). Beyond personal webpublishing: An exploratory study of conversational blogging practices. Paper presented at the 38th Annual Hawaii International Conference on System Sciences, Hawaii, USA.

Efimova, L., \& Hendrick, S. (2005). In search for a virtual settlement: An exploration of weblog community boundaries. Paper presented at the 2005 Communities \& Technologies.

Eisenhardt, K. M., \& Graebner, M. E. (2007). Theory building from cases: Opportunities and challenges. Academy of management journal, 50(1), 25.

Ellonen, H.-K., Kosonen, M., Tarkiainen, A., \& Tonteri, L. (2013). The positive outcomes of a sense of virtual community. International Journal of Web Based Communities, 9(4), 465-482. 
Eunju, K., Kim, K. H., \& Zhang, H. (2008). A cross cultural study of antecedents of purchase intention for sports shoes in Korea and China. Journal of Global Academy of Marketing Science, 18(1), 157-177.

Fang, Y.-H., Chiu, C.-M., \& Wang, E. T. (2011). Understanding customers' satisfaction and repurchase intentions: An integration of IS success model, trust, and justice. Internet Research, 21(4), 479-503.

Farivar, S., \& Yuan, Y. (2014). The dual perspective of social commerce adoption. Paper presented at the Thirteenth Annual Workshop on HCI Research in MIS.

Farivar, S., Yuan, Y., \& Turel, O. (2016). Understanding Social Commerce Acceptance: The Role of Trust, Perceived Risk, and Benefit. Paper presented at the Twenty-second Americas Conference on Information Systems, San Diego.

Federal Trade Commission. (2007). Social networking sites: A parent's guide. Retrieved from http://www.ictliteracy.info/rf.pdf/FTC\%20Social\%20Networking\%20 Guide\%20for\%20Parents.pdf

Fernandez, D. Z., Hawley, A. H., \& Pridaza, S. (1975). The population of Malaysia. Kertas Penyelidikan(10).

Fishbein, M., \& Ajzen, I. (1975). Belief, attitudes, intention, and behavior. An Introduction to Theory and Research. Massachussets: Addison-Wesley.

Fisher, T. (2009). ROI in social media: A look at the arguments. Journal of Database Marketing \& Customer Strategy Management, 16(3), 189-195.

Fletcher, G., \& Greenhill, A. (2009). Blog/shop: it is authentic so don't worry. Journal of Information, Communication and Ethics in Society, 7(1), 39-53.

Fogel, J., \& Nehmad, E. (2009). Internet social network communities: Risk taking, trust, and privacy concerns. Computers in Human Behavior, 25(1), 153-160. 
Forster, P. M. (2004). Psychological sense of community in groups on the internet. Behaviour Change, 21(02), 141-146.

Forsythe, S., Liu, C., Shannon, D., \& Gardner, L. C. (2006). Development of a scale to measure the perceived benefits and risks of online shopping. Journal of Interactive Marketing, 20(2), 55-75.

Frauman, E., \& Cunningham, P. H. (2001). Using a Means-End Approach to Understand the Factors that Influence Greenway Use. Journal of Park \& Recreation Administration, 19(3).

Gao, Y. (2010). A conceptual framework of trust in C2C e-commerce: from multidisciplinary perspectives. Paper presented at the 2nd International Conference on Networking and Digital Society (ICNDS), Hong Kong.

Gatignon, H., \& Robertson, T. S. (1985). A propositional inventory for new diffusion research. Journal of Consumer Research, 849-867.

Gefen, D. (2000). E-commerce: the role of familiarity and trust. Omega, 28(6), 725-737.

Gefen, D., Karahanna, E., \& Straub, D. W. (2003). Trust and TAM in online shopping: an integrated model. MIS Quarterly, 27(1), 51-90.

Gefen, D., \& Straub, D. W. (2000). The relative importance of perceived ease of use in IS adoption: A study of e-commerce adoption. Journal of the Association for information systems, 1(1), 8.

Gengler, C., \& Reynolds, T. (1995). Consumer understanding and advertising strategy: analysis and strategic translation of laddering. Journal of advertising research, 35(4), 19-33.

Gibbons, B. (2008). Social Commerce for Social Media. Retrieved from http://www.practicalecommerce.com/articles/735-Social-CommerceFor-Social-Media 
Gilly, M. C., Graham, J. L., Wolfinbarger, M. F., \& Yale, L. J. (1998). A dyadic study of interpersonal information search. Journal of the Academy of Marketing Science, 26(2), 83-100.

Golafshani, N. (2003). Understanding reliability and validity in qualitative research. The Qualitative Report, 8(4), 597-607.

Goto, S. G. (1996). To trust or not to trust: Situational and dispositional determinants. Social Behavior and Personality: an International Journal, $24(2), 119-131$.

Grabner-Kräuter, S., \& Bitter, S. (2015). Trust in online social networks: A multifaceted perspective. Forum for Social Economics, 44(1), 48-68.

Granovetter, M. (1981). The strength of weak ties: A network theory revisited. Paper presented at the Conference on Contributions of Networks Analysis to Structural Sociology, State University of New York at Albany.

Granovetter, M. S. (1973). The strength of weak ties. American Journal of Sociology, $1360-1380$.

Greenbank, P. (2001). Objective setting in the micro-business. International Journal of Entrepreneurial Behavior \& Research, 7(3), 108-127.

Greer, B. G. (2000). Psychological and support functions of an e-mail mailing list for persons with cerebral palsy. CyberPsychology and Behavior, 3(2), 221-235.

Gregoriadis, L. (2007). UK Social Commerce. Retrieved from http://www.slideshare.net/LinusG/social-commerce-presentation

Grunert, K. G., Beckmann, S. C., \& Sørensen, E. (2001). Means-end chains and laddering: an inventory of problems and an agenda for research Understanding consumer decision-making: The means-end approach to marketing and advertising strategy: Lawrence Erlbaum Associates, Incorporated. 
Grunert, K. G., \& Grunert, S. C. (1995). Measuring subjective meaning structures by the laddering method: Theoretical considerations and methodological problems. International Journal of Research in Marketing, 12(3), 209-225.

Guba, E. G. (1981). Criteria for assessing the trustworthiness of naturalistic inquiries. ECTJ, 29(2), 75-91.

Guggenmoos-Holzmann, I. (1996). The meaning of kappa: probabilistic concepts of reliability and validity revisited. Journal of Clinical Epidemiology, 49(7), 775-782.

Gummerus, J., Sihlman, R., Liljander, V., \& Perret, J. (2013). Consumers' perceived benefits of participating in ethical Facebook communities, and their effect on community loyalty and commitment to ethical consumption. Paper presented at the Proceedings of the Academy of Marketing Conference 2013, 8th-11th July, Cardiff, UK. Marketing Relevance.

Guo, S., Wang, M., \& Leskovec, J. (2011). The role of social networks in online shopping: information passing, price of trust, and consumer choice. Paper presented at the 12th ACM Conference on Electronic Commerce, San Jose, CA, USA.

Gutman, J. (1982). A means-end chain model based on consumer categorization processes. The Journal of Marketing, 60-72.

Habibi, M. R., Laroche, M., \& Richard, M.-O. (2014). The roles of brand community and community engagement in building brand trust on social media. Computers in Human Behavior, 37, 152-161.

Hajli, M. (2012). Social commerce adoption model. Paper presented at the UK Academy of Information Systems Conference, New College, Oxford, UK.

Hajli, M. (2013). A research framework for social commerce adoption. Information Management \& Computer Security, 21(3), 144-154. 
Hajli, M., \& Khani, F. (2013). Establishing trust in social commerce through social word of mouth. Paper presented at the 7th International Conference on e-Commerce in Developing Countries: With Focus on e-Security, Kish Island, Iran.

Hajli, M. N. (2014). The role of social support on relationship quality and social commerce. Technological Forecasting and Social Change, 87, 17-27.

Hajli, N. (2015). Social commerce constructs and consumer's intention to buy. International Journal of Information Management, 35(2), 183-191.

Hajli, N., Lin, X., Featherman, M. S., \& Wang, Y. (2014). Social word of mouth: How trust develops in the market. International Journal of Market Research 56(5), 673-689.

Hajli, N., Shanmugam, M., Powell, P., \& Love, P. E. (2015). A study on the continuance participation in on-line communities with social commerce perspective. Technological Forecasting and Social Change, 96, 232-241.

Hampton, K., Goulet, L. S., Rainie, L., \& Purcell, K. (2011). Social networking sites and our lives: How peoples's trust, personal relationships, and civic and political involvement are connected to their use of social networking sites and other technologies. Retrieved from Washington, USA: http://pewinternet.org/Reports/2011/Technology-and-social-networ ks.aspx

Harris, L., \& Rae, A. (2009). The revenge of the gifted amateur... be afraid, be very afraid.... Journal of Small Business and Enterprise Development, 16(4), 694-709.

Hart, P., \& Saunders, C. (1997). Power and trust: Critical factors in the adoption and use of electronic data interchange. Organization Science, 8(1), 23-42.

Hartmann, M., Klink, J., \& Simons, J. (2015). Cause related marketing in the German retail sector: Exploring the role of consumers' trust. Food Policy, $52,108-114$. 
Hassan, S., Toland, J., \& Tate, M. (2016). From Blogosphere to Social Commerce: A Laddering Analysis of Sellers' Motivation. Paper presented at the 49th Hawaii International Conference on System Sciences, Hawaii, USA.

Hawley, M. (2009). Laddering: A Research Interview Technique for Uncovering Core Values. Research That Works. Retrieved from http://www.uxmatters.com/mt/archives/2009/07/laddering-aresearch-interview-technique-for-uncovering-core-values.php

Haythornthwaite, C. (2002). Strong, weak, and latent ties and the impact of new media. The Information Society, 18(5), 385-401.

He, H., Li, Y., \& Harris, L. (2012). Social identity perspective on brand loyalty. Journal of Business Research, 65(5), 648-657.

Head, M. M., \& Hassanein, K. (2002). Trust in e-commerce: Evaluating the impact of third-party seals. Quarterly Journal of Electronic Commerce, 3, 307326.

Helen Samujh, R. (2011). Micro-businesses need support: survival precedes sustainability. Corporate Governance: The International Journal of Business in Society, 11(1), 15-28.

Helgeson, V. S., \& Cohen, S. (1996). Social support and adjustment to cancer: reconciling descriptive, correlational, and intervention research. Health Psychology, 15(2), 135.

Henslin, J. M. (1968). The Cab Driver: An International Analysis of An Occupational Culture. ProQuest Information \& Learning.

Hernandez, B., \& Jimenez, J. (2011). Co-creation processes and engagement: an empirical approach. Paper presented at the 2011 Naples Forum on Service, Capri, Italy.

Herring, S. C., Kouper, I., Paolillo, J. C., Scheidt, L. A., Tyworth, M., Welsch, P., . . $\mathrm{Yu}, \mathrm{N}$. (2005). Conversations in the blogosphere: an analysis" from the 
bottom up". Paper presented at the 38th Annual Hawaii International Conference on System Sciences, Hawaii, USA.

Hinkle, D. N. (1965). The change of personal constructs from the viewpoint of a theory of construct implications. Ohio State University Columbus.

Ho, S.-H., Lin, Y.-L., \& Carlson Patrick, R. (2015). Participant Motivations in a Social Media Community Page. Global Journal of Business Research, 9(4), 67-75.

Hodkinson, P. (2007). Interactive online journals and individualization. New Media \& Society, 9(4), 625-650.

Hoffman, D. L., \& Fodor, M. (2010). Can you measure the ROI of your social media marketing? MIT Sloan Management Review, 52(1), 41.

Hopkins, J. (2010a). The Malaysian lifestyle blog: a national blogging genre. Paper presented at the Colloquium: WCU Webometrics Institute, Yeungnam University, Korea.

Hopkins, J. (2010b). How many Malaysian blogs are there? Retrieved from http://julianhopkins.net/index.php?/archives/293-How-manyMalaysian-blogs-are-there.html

Hopkins, J. (2011). Labouring Lifestyle: Assembling the lifestyle blog. The 6th Asian Graduate Forum on Southeast Asian Studies. Presentation. National Unibersity of Singapore. Singapore.

Hosmer, L. T. (1995). Trust: The connecting link between organizational theory and philosophical ethics. Academy of Management Review, 20(2), 379403.

House, J. S. (1981). Work stress and social support: Addison-Wesley Pub. Co.

Hsiao, C.-C., Ju Rebecca Yen, H., \& Li, E. Y. (2012). Exploring consumer value of multi-channel shopping: a perspective of means-end theory. Internet Research, 22(3), 318-339. 
Hsiao, K.-L., Chuan-Chuan Lin, J., Wang, X.-Y., Lu, H.-P., \& Yu, H. (2010). Antecedents and consequences of trust in online product recommendations: An empirical study in social shopping. Online Information Review, 34(6), 935-953.

Hsu, C.-J. (2008). Dominant factors for online trust. Paper presented at the 2008 International Conference on Cyberworlds, Hangzhou, China.

Huang, Z., \& Benyoucef, M. (2013). From e-commerce to social commerce: A close look at design features. Electronic Commerce Research and Applications, 12(4), 246-259.

Hwang, K. O., Ottenbacher, A. J., Lucke, J. F., Etchegaray, J. M., Graham, A. L., Thomas, E. J., \& Bernstam, E. V. (2011). Measuring social support for weight loss in an internet weight loss community. Journal of Health Communication, 16(2), 198-211.

Ibarra, H. (1992). Homophily and differential returns: Sex differences in network structure and access in an advertising firm. Administrative Science Quaterly, 422-447.

Jarvenpaa, S. L., \& Todd, P. A. (1996). Consumer reactions to electronic shopping on the World Wide Web. International Journal of Electronic Commerce, $1(2), 59-88$.

Jarvenpaa, S. L., Tractinsky, N., \& Saarinen, L. (1999). Consumer trust in an internet store: a cross-cultural validation. Journal of Computer-Mediated Communication, 5(2), 0-0.

Jarvenpaa, S. L., \& Tuunainen, V. K. (2012). Company tactics for customer socialization with social media technologies: Finnair's rethink quality and quality hunters initiatives. Paper presented at the 45th Hawaii International Conference on System Science, Hawaii, USA.

Jiang, L., Yang, Z., \& Jun, M. (2013). Measuring consumer perceptions of online shopping convenience. Journal of Service Management, 24(2), 191-214. 
Jiang, P., Jones, D. B., \& Javie, S. (2008). How third-party certification programs relate to consumer trust in online transactions: An exploratory study. Psychology \& Marketing, 25(9), 839-858.

Jih, W.-J. K. (2007). Effects of consumer-perceived convenience on shopping intention in mobile commerce: an empirical study. International Journal of E-Business Research, 3(4), 33.

Jones, Q. (1997). Virtual-Communities, Virtual Settlements \& CyberArchaeology: A Theoretical Outline. Journal of Computer-Mediated Communication, 3(3).

Jue, A. L., Marr, J. A., \& Kassotakis, M. E. (2009). Social media at work: How networking tools propel organizational performance: John Wiley \& Sons.

Kahn, R. L., \& Antonucci, T. C. (1980). Convoys over the life course: Attachment, roles, and social support. Life-span Development and Behavior, 3(253286).

Kamarudin, F. (2013). Intercultural Communication and Cross Cultural Negotiation in Business Environment: The Malaysian Context. Retrieved from https://www.inter-disciplinary.net/probing-the-boundaries/wpcontent/uploads/2013/07/kamaruddinccpaper.pdf

Kaminoff, R. (2011). Social Commerce: How and why it's a big deal! Retrieved from http://robkaminoff.com/social-commerce-how-and-why-its-abig-deal/

Kaplan, A. M., \& Haenlein, M. (2010). Users of the world, unite! The challenges and opportunities of Social Media. Business Horizons, 53(1), 59-68.

Kaplan, B., \& Maxwell, J. (2005). Qualitative research methods for evaluating computer information systems. Evaluating the Organizational Impact of Healthcare Information Systems, 30-55. 
Karpiscak, J., \& Gordon, J. (2013). The Effects of Social Media Exposure on Virtual Team Trust. International Journal of Global Management Studies Professional, 5(1).

Kayes, I., Qian, X., Skvoretz, J., \& Iamnitchi, A. (2012). How influential are you: detecting influential bloggers in a blogging community. Social Informatics (pp. 29-42): Springer.

Keller, E., \& Berry, J. (2003). The influentials: One American in ten tells the other nine how to vote, where to eat, and what to buy: Simon and Schuster.

Kelly, G. (1955). The nature of personal constructs. The Psychology of Personal Constructs, 1, 105-183.

Kemp, S. (2016). Digital in 2016. Retrieved from http://wearesocial.com/special-reports/digital-in-2016

Kiesler, S., Zubrow, D., Moses, A. M., \& Geller, V. (1985). Affect in computermediated communication: An experiment in synchronous terminal-toterminal discussion. Human-Computer Interaction, 1(1), 77-104.

Kietzmann, J. H., Hermkens, K., McCarthy, I. P., \& Silvestre, B. S. (2011). Social media? Get serious! Understanding the functional building blocks of social media. Business Horizons, 54(3), 241-251.

Kim, D. (2013). Under what conditions will social commerce business models survive? Electronic Commerce Research and Applications, 12(2), 69-77.

Kim, D. J., Ferrin, D. L., \& Rao, H. R. (2009). Trust and satisfaction, two stepping stones for successful e-commerce relationships: A longitudinal exploration. Information Systems Research, 20(2), 237-257.

Kim, H.-W., Gupta, S., \& Koh, J. (2011). Investigating the intention to purchase digital items in social networking communities: A customer value perspective. Information \& Management, 48(6), 228-234. 
Kim, S.-H., \& Park, H.-S. (2013). Social Group Factors Impacting the Customer Satisfaction, Trust and Intention to Re-purchase in Social Commerce and the Moderating Effects of Utilitarian Value. The Journal of Information Systems, 22(2), 1-24.

Kim, S., \& Park, H. (2013). Effects of various characteristics of social commerce (s-commerce) on consumers' trust and trust performance. International Journal of Information Management, 33(2), 318-332.

Kim, Y., \& Srivastava, J. (2007). Impact of social influence in e-commerce decision making. Paper presented at the 9th International Conference on Electronic Commerce, Minneapolis, MN, USA.

Klenosky, D. B., Gengler, C. E., \& Mulvey, M. S. (1999). Understanding the factors influencing ski destination choice: A means-end analytic approach. Consumer Behavior in Travel and Tourism, 25(4), 59-80.

Klinger, F. (1986). Foundations of behavioral research. New York: Holt-Rinehart and Winston.

Koh, J., \& Kim, Y.-G. (2003). Sense of virtual community: A conceptual framework and empirical validation. International Journal of Electronic Commerce, 8(2), 75-94.

Krause, J., Croft, D., \& James, R. (2007). Social network theory in the behavioural sciences: potential applications. Behavioral Ecology and Sociobiology, 62(1), 15-27.

Krishen, A. S., Trembath, L., \& Muthaly, S. (2015). From liking to loyalty: The impact of network affinity in the social media digital space. ACM SIGMIS Database, 46(2), 30-42.

Kumar, N. (1996). The power of trust in manufacturer-retailer relationships. Harvard Business Review, 74(6), 92.

Kuppusamy, B. (2006). Racism alive and well in Malaysia. Retrieved from http://www.atimes.com/atimes/Southeast_Asia/HC24Ae01.html 
Kuratko, D. F., Hornsby, J. S., \& Naffziger, D. W. (1997). An examination of owner's goals in sustaining entrepreneurship. Journal of small business management, 35(1), 24.

Langford, C. P. H., Bowsher, J., Maloney, J. P., \& Lillis, P. P. (1997). Social support: a conceptual analysis. Journal of Advanced Nursing, 25(1), 95-100.

Laroche, M., Habibi, M. R., \& Richard, M.-O. (2013). To be or not to be in social media: How brand loyalty is affected by social media? International Journal of Information Management, 33(1), 76-82.

Laroche, M., Habibi, M. R., Richard, M.-O., \& Sankaranarayanan, R. (2012). The effects of social media based brand communities on brand community markers, value creation practices, brand trust and brand loyalty. Computers in Human Behavior, 28(5), 1755-1767.

Lazarsfeld, P. F., \& Merton, R. K. (1954). Friendship as a social process: A substantive and methodological analysis. Freedom and Control in Modern Society, 18(1), 18-66.

Lee, J., Park, D.-H., \& Han, I. (2011). The different effects of online consumer reviews on consumers' purchase intentions depending on trust in online shopping malls: An advertising perspective. Internet Research, 21(2), 187-206.

Lee, K. C., Kang, I., \& McKnight, D. H. (2007). Transfer from offline trust to key online perceptions: an empirical study. Engineering Management, IEEE Transactions on, 54(4), 729-741.

Lee, M., \& Youn, S. (2009). Electronic word of mouth (eWOM) How eWOM platforms influence consumer product judgement. International Journal of Advertising, 28(3), 473-499.

Lee, S.-H., DeWester, D., \& Park, S. R. (2008). Web 2.0 and opportunities for small businesses. Service Business, 2(4), 335-345. 
Lee, Y.-K., Kim, S. Y., Chung, N., Ahn, K., Lee, J.-W., Baron, S., \& Baron, S. (2016). When social media met commerce: a model of perceived customer value in group-buying. Journal of Services Marketing, 30(4).

Lenhart, A., \& Fox, S. (2006). Bloggers. Pew Internet \& American Life Project, 2011. Retrieved from http://www.pewinternet.org/files/oldmedia/Files/Reports/2006/PIP\%20Bloggers\%20Report\%20July\%201 9\%202006.pdf.pdf

Leung, L., \& Lee, P. S. (2005). Multiple determinants of life quality: The roles of Internet activities, use of new media, social support, and leisure activities. Telematics and Informatics, 22(3), 161-180.

Lewicki, R. J., \& Bunker, B. B. (1995). Trust in relationships: A model of development and decline: Jossey-Bass.

Li, F., \& Du, T. C. (2011). Who is talking? An ontology-based opinion leader identification framework for word-of-mouth marketing in online social blogs. Decision Support Systems, 51(1), 190-197.

Liang, T. P., Ho, Y. T., Li, Y. W., \& Turban, E. (2011). What drives social commerce: The role of social support and relationship quality. International Journal of Electronic Commerce, 16(2), 69-90.

Liang, T. P., \& Turban, E. (2011). Introduction to the Special Issue Social Commerce: A Research Framework for Social Commerce. International Journal of Electronic Commerce, 16(2), 5-14.

Lim, N. (2003). Consumers' perceived risk: sources versus consequences. Electronic Commerce Research and Applications, 2(3), 216-228.

Lim, R., Diaz, J. A., \& Dash, D. (2013). Making Shops from Blogs: An Emerging Online Retailing Phenomenon in Southeast Asia. Paper presented at the 3rd Asia-Pacific Business Research Conference, Kuala Lumpur, Malaysia.

Lin, H.-F. (2007). The role of online and offline features in sustaining virtual communities: an empirical study. Internet Research, 17(2), 119-138. 
Lin, K.-Y., \& Lu, H.-P. (2011a). Intention to continue using Facebook fan pages from the perspective of social capital theory. Cyberpsychology, Behavior, and Social Networking, 14(10), 565-570.

Lin, K.-Y., \& Lu, H.-P. (2011b). Why people use social networking sites: An empirical study integrating network externalities and motivation theory. Computers in Human Behavior, 27(3), 1152-1161. doi:http://dx.doi.org/10.1016/j.chb.2010.12.009

Lin, N. (2001). Social capital. A theory of social structure and action. Cambridge: Cambridge University Press.

Lin, Y.-L., \& Tu, Y.-Z. (2012). The values of college students in business simulation game: A means-end chain approach. Computers \& Education, $58(4), 1160-1170$.

Lincoln, Y. S., \& Guba, E. G. (1985). Naturalistic inquiry (Vol. 75): SAGE Publications, Incorporated.

Lindgren, S. (2011). YouTube gunmen? Mapping participatory media discourse on school shooting videos. Media, Culture \& Society, 33(1), 123-136.

Lindgren, S. (2012). 'It took me about half an hour, but I did it!'Media circuits and affinity spaces around how-to videos on YouTube. European Journal of Communication, 27(2), 152-170.

López-Mosquera, N., \& Sánchez, M. (2011). The influence of personal values in the economic-use valuation of peri-urban green spaces: An application of the means-end chain theory. Tourism Management, 32(4), 875-889.

Lövheim, M. (2011). Personal and Popular. Nordicom Review, 32(1).

Lu, B., Fan, W., \& Zhou, M. (2016). Social presence, trust, and social commerce purchase intention: an empirical research. Computers in Human Behavior, 56, 225-237. 
Lu, B., Zeng, Q., \& Fan, W. (2016). Examining macro-sources of institution-based trust in social commerce marketplaces: An empirical study. Electronic Commerce Research and Applications, 20, 116-131.

Lu, Y., Zhao, L., \& Wang, B. (2010). From virtual community members to C2C ecommerce buyers: Trust in virtual communities and its effect on consumers' purchase intention. Electronic Commerce Research and Applications, 9(4), 346-360.

Lundkvist, A., \& Yakhlef, A. (2004). Customer involvement in new service development: a conversational approach. Managing Service Quality: An International Journal, 14(2/3), 249-257.

Malaysian Communications and Multimedia Commission. (2013). Media Matters: Networked Media Content Research Summary. Retrieved from http://www.skmm.gov.my/skmmgovmy/media/General/pdf/MediaMatters_Research-Summary.pdf

Malaysian Communications and Multimedia Commission. (2015a). Malaysia On Track To Become A Smart Nation. Retrieved from http://www.skmm.gov.my/Media/Press-Clippings/Malaysia-OnTrack-To-Become-A-Smart-Nation-MCMC.aspx

Malaysian Communications and Multimedia Commission. (2015b). Internet Users Survey 2014

Malecki, C. K., \& Demaray, M. K. (2003). What Type of Support Do They Need? Investigating Student Adjustment as Related to Emotional, Informational, Appraisal, and Instrumental Support. School Psychology Quarterly, 18(3), 231.

Mandal, D. (2015). Social media adoption by microbusinesses. (PhD), University of Waikato, New Zealand. 
Mandal, D., \& McQueen, R. J. (2012). Extending UTAUT to explain social media adoption by microbusinesses. International Journal of Managing Information Technology, 4(4), 1.

Mangold, W. G., \& Faulds, D. J. (2009). Social media: The new hybrid element of the promotion mix. Business Horizons, 52(4), 357-365. doi:http://dx.doi.org/10.1016/j.bushor.2009.03.002

Mansour, K. B., Kooli, K., \& Utama, R. (2014). Online trust antecedents and their consequences on purchase intention: An integrative approach. Journal of Customer Behaviour, 13(1), 25-42.

Marsden, P. (2009). Simple definition of Social Commerce. Retrieved from http://socialcommercetoday.com/social-commerce-definition-wordcloud-definitive-definition-list/

Marshall, C., \& Rossman, G. (1994). Doing qualitative research: Thousand Oaks, CA: Sage.

Mathwick, C., Wiertz, C., \& De Ruyter, K. (2008). Social capital production in a virtual P3 community. Journal of Consumer Research, 34(6), 832-849.

Matook, S. (2013). Conceptualizing means-end chains of user goals as networks. Information \& Management, 50(1), 24-32.

Matsumoto, F. (2009). Social Commerce: Strategies for extending online shopping beyond the e-commerce site. Retrieved from http://www.dmnews.com/social-commerce-strategies-for-extendingonline-shopping-beyond-the-e-commerce-site/article/157433/

Matzat, U. (2010). Reducing problems of sociability in online communities: Integrating online communication with offline interaction. American Behavioral Scientist.

Mayer, R. C., Davis, J. H., \& Schoorman, F. D. (1995). An integrative model of organizational trust. Academy of Management Review, 20(3), 709-734. 
McAdams, R. H. (1997). The origin, development, and regulation of norms. Michigan Law Review, 338-433.

McAllister, D. J. (1995). Affect-and cognition-based trust as foundations for interpersonal cooperation in organizations. Academy of Management Journal, 38(1), 24-59.

McHugh, M. L. (2012). Interrater reliability: the Kappa Statistic. Biochemia Medica, 22(3), 276-282.

McKenna, K. Y., \& Bargh, J. A. (1999). Causes and consequences of social interaction on the Internet: A conceptual framework. Media Psychology, 1(3), 249-269.

McKnight, D. H., Choudhury, V., \& Kacmar, C. (2000). Trust in e-commerce vendors: a two-stage model. Paper presented at the 21st International Conference on Information Systems, Pisa, Italy.

McKnight, D. H., Choudhury, V., \& Kacmar, C. (2002). Developing and validating trust measures for e-commerce: An integrative typology. Information Systems Research, 13(3), 334-359.

McMillan, D. (1976). Sense of community: An attempt at definition: George Peabody College for Teachers.

McMillan, D., \& Chavis, D. (1986). Sense of community: A definition and theory. Journal of Community Psychology, 14(1), 6-23.

McPherson, J. M., Popielarz, P. A., \& Drobnic, S. (1992). Social networks and organizational dynamics. American Sociological Review, 153-170.

McPherson, M., Smith-Lovin, L., \& Cook, J. M. (2001). Birds of a feather: Homophily in social networks. Annual Review of Sociology, 415-444.

Merelo-Guervos, J.-J., Prieto, B., Rateb, F., \& Tricas, F. (2003). Mapping weblog communities. arXiv preprint cs/0312047. 
Merriam, S. B. (1988). Case Study Research in Education. A Qualitative Approach: ERIC.

Michaelidou, N., Siamagka, N. T., \& Christodoulides, G. (2011). Usage, barriers and measurement of social media marketing: An exploratory investigation of small and medium B2B brands. Industrial Marketing Management, 40(7), 1153-1159.

Miles, M. B., \& Huberman, M. (1994). Qualitative data analysis: An expanded sourcebook: SAGE Publications, Incorporated.

Murray, J. S. (2000). A concept analysis of social support as experienced by siblings of children with cancer. Journal of Pediatric Nursing, 15(5), 313322.

Myers, M. D. (1997). Qualitative research in information systems. Management Information Systems Quarterly, 21, 241-242.

Nasr, A. A., \& Ariffin, M. M. (2008). Blogging as a means of knowledge sharing: Blog communities and informal learning in the blogosphere. Paper presented at the International Symposium on Information Technology, ITSim 2008.

Naylor, R. W., Lamberton, C. P., \& West, P. M. (2012). Beyond the "like" button: the impact of mere virtual presence on brand evaluations and purchase intentions in social media settings. Journal of Marketing, 76(6), 105-120.

$\mathrm{Ng}$, C. S.-P. (2013). Intention to purchase on social commerce websites across cultures: A cross-regional study. Information \& Management, 50(8), 609620.

Norbeck, J. S., Lindsey, A. M., \& Carrieri, V. L. (1981). The development of an instrument to measure social support. Nursing Research, 30(5), 264-269.

Nosek, J. T., \& McManus, M. (2008). Collaboration challenges: bridging the IT support gap. Information Systems Management, 25(1), 3-7. 
Nycyk, M. (2012). Tensions in Enforcing YouTube Community Guidelines: The Challenge of Regulating Users' Flaming Comments. (Master), Curtin University of Technology, Australia.

Nyshadham, E. A. (2000). Consumer perceptions of online transaction security- $A$ cognitive explanation of the origins of perception. Paper presented at the 6th American Conference on Information System, Long Beach, California, USA.

O'Leary, Z. (2009). The essential guide to doing your research project: SAGE Publications Limited.

O'Reilly, T. (2007). What is Web 2.0: Design patterns and business models for the next generation of software. Communications \& Strategies(1), 17.

Obst, P., Zinkiewicz, L., \& Smith, S. G. (2002). Sense of community in science fiction fandom, Part 1: Understanding sense of community in an international community of interest. Journal of Community Psychology, 30(1), 87-103.

Okazaki, S., \& Mendez, F. (2013). Exploring convenience in mobile commerce: Moderating effects of gender. Computers in Human Behavior, 29(3), 1234-1242.

Olson, J. C., \& Reynolds, T. J. (2001). Understanding consumer decision making: The means-end approach to marketing and advertising strategy: Psychology Press.

Orlikowski, W. J., \& Baroudi, J. J. (1991). Studying information technology in organizations: Research approaches and assumptions. Information Systems Research, 2(1), 1-28.

Osman-Gani, A. M., \& Tan, J. S. (2002). Influence of culture on negotiation styles of Asian managers: An empirical study of major cultural/ethnic groups in Singapore. Thunderbird International Business Review, 44(6), 819-839. 
Ozturk, A. B., Bilgihan, A., Nusair, K., \& Okumus, F. (2016). What keeps the mobile hotel booking users loyal? Investigating the roles of self-efficacy, compatibility, perceived ease of use, and perceived convenience. International Journal of Information Management, 36(6), 1350-1359.

Pagani, M., \& Mirabello, A. (2011). The Influence of Personal and SocialInteractive Engagement in Social TV Web Sites. International Journal of Electronic Commerce, 16(2), 41-68.

Pai, P., \& Arnott, D. C. (2013). User adoption of social networking sites: Eliciting uses and gratifications through a means-end approach. Computers in Human Behavior, 29(3), 1039-1053.

Pangil, F., \& Moi Chan, J. (2014). The mediating effect of knowledge sharing on the relationship between trust and virtual team effectiveness. Journal of Knowledge Management, 18(1), 92-106.

Parise, S., \& Guinan, P. J. (2008). Marketing using web 2.0. Paper presented the 41st Hawaii International Conference on System Sciences, Hawaii, USA.

Pavlou, P. A. (2003). Consumer acceptance of electronic commerce: Integrating trust and risk with the technology acceptance model. International Journal of Electronic Commerce, 7(3), 101-134.

Pavlou, P. A., \& Gefen, D. (2004). Building effective online marketplaces with institution-based trust. Information Systems Research, 15(1), 37-59.

Pieters, R., Baumgartner, H., \& Allen, D. (1995). A means-end chain approach to consumer goal structures. International Journal of Research in Marketing, 12(3), 227-244.

Porter, C. E. (2004). A Typology of Virtual Communities: A Multi-Disciplinary Foundation for Future Research. Journal of Computer-Mediated Communication, 10(1).

Preece, J. (1999). Empathic communities: Balancing emotional and factual communication. Interacting with Computers, 12(1), 63-77. 
Qing, Y., Huang, L. h., \& Xu, Y. (2008). Role of trust transfer in E-commerce acceptance. Tsinghua Science and Technology, 13.

Raito, L. (2007). Social Commerce Chapter. Retrieved from http://leeraito.com/social-commerce-chapter

Ramaswami, S. N., Srinivasan, S. S., \& Gorton, S. A. (1997). Information asymmetry between salesperson and supervisor: postulates from agency and social exchange theories. Journal of Personal Selling \& Sales Management, 17(3), 29-50.

Ramayah, T., Nejati, M., \& Shafaei, A. (2015). Modelling predictors of blog stickiness and retention by university students. Malaysian Journal of Library \& Information Science, 20(3), 15-27.

Ranganathan, C., \& Ganapathy, S. (2002). Key dimensions of business-toconsumer web sites. Information \& Management, 39(6), 457-465.

Ratnasingham, P. (1998). Trust in web-based electronic commerce security. Information Management \& Computer Security, 6(4), 162-166.

Reich, S. M. (2010). Adolescents' sense of community on myspace and facebook: a mixed-methods approach. Journal of Community Psychology, 38(6), 688-705.

Rempel, J. K., Holmes, J. G., \& Zanna, M. P. (1985). Trust in close relationships. Journal of personality and Social Psychology, 49(1), 95.

Reynolds, T. J., \& Gutman, J. (1988). Laddering theory, method, analysis, and interpretation. Journal of Advertising Research, 28(1), 11-31.

Reynolds, T. J., \& Gutman, J. (2001). Advertising is image management. Understanding Consumer Decision Making: The Means-end Approach to Marketing, 145-162.

Rheingold, H. (1996). A slice of my life in my virtual community: The MIT Press. 
Rheingold, H. (2000). The virtual community: Homesteading on the electronic frontier: MIT press.

Richardson, P. S., Dick, A. S., \& Jain, A. K. (1994). Extrinsic and intrinsic cue effects on perceptions of store brand quality. The Journal of Marketing, 28-36.

Ridings, C. M., \& Gefen, D. (2004). Virtual community attraction: Why people hang out online. Journal of Computer-Mediated Communication, 10(1).

Ridings, C. M., Gefen, D., \& Arinze, B. (2002). Some antecedents and effects of trust in virtual communities. The Journal of Strategic Information Systems, 11(3), 271-295.

Rochan, M. (2014). Middle-Class Spending Curbs May Hit Malaysia's GDP Growth. Retrieved from http://www.ibtimes.co.uk/middle-classspending-curbs-may-hit-malaysias-gdp-growth-1431338Middle-Class

Rogers, E. M. (1983). Diffusion of Innovations: University of Illinois.

Rosenbaum, M. S., Ostrom, A. L., \& Kuntze, R. (2005). Loyalty programs and a sense of community. Journal of Services Marketing, 19(4), 222-233.

Roth, L. M. (2004). The social psychology of tokenism: Status and homophily processes on Wall Street. Sociological Perspectives, 47(2), 189-214.

Rotman, D., \& Preece, J. (2010). The'WeTube'in YouTube-creating an online community through video sharing. International Journal of Web Based Communities, 6(3), 317-333.

Rousseau, D. M., Sitkin, S. B., Burt, R. S., \& Camerer, C. (1998). Not so different after all: A cross-discipline view of trust. Academy of Management Review, 23(3), 393-404.

Rowley, J. (2004). Just another channel? Marketing communications in ebusiness. Marketing Intelligence \& Planning, 22(1), 24-41. 
Rowse, D., \& Garrett, C. (2012). ProBlogger: Secrets for Blogging Your Way to a Six-Figure Income: John Wiley \& Sons.

Rubel, S. (2006). 2006 Trends to Watch Part II: Social Commerce. Retrieved from http://www.micropersuasion.com/2005/12/2006_trends_to_.html

Rugg, G., Eva, M., Mahmood, A., Rehman, N., Andrews, S., \& Davies, S. (2002). Eliciting information about organizational culture via laddering. Information Systems Journal, 12(3), 215-229.

Russell, C. G., Busson, A., Flight, I., Bryan, J., van Pabst, J. v. L., \& Cox, D. N. (2004). A comparison of three laddering techniques applied to an example of a complex food choice. Food Quality and Preference, 15(6), 569-583.

Saaka, A., Sidon, C., \& Blake, B. F. (2004) Laddering: A “How to do it" Manualwith a note of caution. Research Reports in Consumer Behavior: How to Series. Ohio: Cleveland State University.

Sangwan, S., Guan, C., \& Siguaw, J. A. (2009). Virtual social networks: toward a research agenda. International Journal of Virtual Communities and Social Networking (IJVCSN), 1(1), 1-13.

Sarason, B. R., Shearin, E. N., Pierce, G. R., \& Sarason, I. G. (1987). Interrelations of social support measures: Theoretical and practical implications. Journal of Personality and Social Psychology, 52(4), 813.

Sarason, I. G., Sarason, B. R., Shearin, E. N., \& Pierce, G. R. (1987). A brief measure of social support: Practical and theoretical implications. Journal of Social and Personal Relationships, 4(4), 497-510.

Saundage, D., \& Lee, C. Y. (2011). Social commerce activities-a taxonomy. Paper presented at the 22nd Australasian Conference on Information Systems, Sydney, Australia. 
Schaupp, L. C., \& Bélanger, F. (2016). Social Commerce Benefits for Small Businesses: An Organizational Level Study. Journal of Organizational and End User Computing (JOEUC), 28(3), 49-66.

Senadheera, V., Warren, M., \& Leitch, S. (2011). A study into how Australian banks use social media. Paper presented at the 15th Pacific Asia Conference on Information Systems, Brisbane, Australia.

Shafie, L. A., Nayan, S., Mansor, M., Maesin, A., Mahadi, R., \& Fadzillah, N. (2011). Trust attributes and female blogshop entrepreneurs in Malaysia. Interdisciplinary Journal of Research in Business, 1(8), 1-9.

Shapiro, D. L., Sheppard, B. H., \& Cheraskin, L. (1992). Business on a handshake. Negotiation Journal, 8(4), 365-377.

Shenton, A. K. (2004). Strategies for ensuring trustworthiness in qualitative research projects. Education for Information, 22(2), 63-76.

Sherchan, W., Nepal, S., \& Paris, C. (2013). A survey of trust in social networks. ACM Computing Surveys (CSUR), 45(4), 47.

Shi, S., \& Chow, W. S. (2015). Trust development and transfer in social commerce: prior experience as moderator. Industrial Management \& Data Systems, 115(7), 1182-1203.

Shin, D.-H. (2010). The effects of trust, security and privacy in social networking: A security-based approach to understand the pattern of adoption. Interacting with Computers, 22(5), 428-438.

Shin, D.-H. (2013). User experience in social commerce: in friends we trust. Behaviour \& Information Technology, 32(1), 52-67.

Siau, K., \& Shen, Z. (2003). Building customer trust in mobile commerce. Communications of the ACM, 46(4), 91-94.

Siegrist, M. (2000). The influence of trust and perceptions of risks and benefits on the acceptance of gene technology. Risk Analysis, 20(2), 195-204. 
Siegrist, M., Cvetkovich, G., \& Roth, C. (2000). Salient value similarity, social trust, and risk/benefit perception. Risk Analysis, 20(3), 353-362.

Silva, L., Goel, L., \& Mousavidin, E. (2008). Exploring the dynamics of blog communities: the case of MetaFilter. Information Systems Journal, 19, 5581. doi:10.1111/j.1365-2575.2008.00304.x

Singal, M., \& Wokutch, R. E. (2016). Newly industrialized country (NIC) Encyclopædia Britannica.

Singh, M., Davison, C., \& Wickramasinghe, N. (2010). Organisational Use of Web 2.0 Technologies: An Australian Perspective. Paper presented at the 16th American Conference on Information System, Lima, Peru.

Sitkin, S. B., \& Roth, N. L. (1993). Explaining the limited effectiveness of legalistic "remedies" for trust/distrust. Organization Science, 4(3), 367-392.

Smith, B. G. (2010). The evolution of the blogger: Blogger considerations of public relations-sponsored content in the blogosphere. Public Relations Review, 36(2), 175-177.

Smith, C. (2015). It's time for retailers to start paying close attention to social media. Retrieved from http://www.businessinsider.com.au/socialcommerce-2015-report-2015-6?r=US\&IR=T

Sproull, L., \& Faraj, S. (1997). Atheism, sex, and databases: The net as a social technology. Culture of the Internet, 35-51.

Srinivasan, S. S., Anderson, R., \& Ponnavolu, K. (2002). Customer loyalty in ecommerce: an exploration of its antecedents and consequences. Journal of Retailing, 78(1), 41-50.

Stephen, A. T., \& Galak, J. (2010). The complementary roles of traditional and social media publicity in driving marketing performance. Fontainebleau: INSEAD working paper collection. 
Stephen, A. T., \& Toubia, O. (2010). Deriving value from social commerce networks. Journal of Marketing Research, 47(2), 215-228.

Stewart, K. J. (1999). Transference as a means of building trust in world wide web sites. Paper presented at the 20th International Conference on Information Systems, Charlotte, North Carolina, USA.

Stewart, K. J. (2003). Trust transfer on the world wide web. Organization Science, 14(1), 5-17.

Stewart, K. J., \& Zhang, Y. (2003). Effects of hypertext links on trust transfer. Paper presented at the 5th International Conference on Electronic Commerce, Pittsburgh, Pennsylvania, USA.

Storey, D., \& Curran, J. (2000). Small Business Policy: Past Experience and Future Direction. Paper presented at the SME Seminar Series: Linking Research and Policy., London

Strub, P. J., \& Priest, T. (1976). Two patterns of establishing trust: The marijuana user. Sociological Focus, 9(4), 399-411.

Subramony, D. P. (2002). Why Users Choose Particular Web Sites Over Others: Introducing a" Means-End" Approach to Human-Computer Interaction. J. Electron. Commerce Res., 3(3), 144-161.

Sun, Y., Wei, K. K., Fan, C., Lu, Y., \& Gupta, S. (2016). Does social climate matter? On friendship groups in social commerce. Electronic Commerce Research and Applications, 18, 37-47.

Sutanto, J., Kankanhalli, A., \& Tan, B. C. Y. (2011). Eliciting a sense of virtual community among knowledge contributors. ACM Transactions on Management Information Systems (TMIS), 2(3), 14.

Swaminathan, V., Lepkowska-White, E., \& Rao, B. P. (1999). Browsers or buyers in cyberspace? An investigation of factors influencing electronic exchange. Journal of Computer-Mediated Communication, 5(2). 
Tajfel, H., \& Turner, J. C. (1979). An integrative theory of intergroup conflict. The Social Psychology of Intergroup Relations, 33(47), 74.

Tamjidyamcholo, A., Baba, M. S. B., Tamjid, H., \& Gholipour, R. (2013). Information security-Professional perceptions of knowledge-sharing intention under self-efficacy, trust, reciprocity, and shared-language. Computers \& Education, 68, 223-232.

Teas, R. K., \& Agarwal, S. (2000). The effects of extrinsic product cues on consumers' perceptions of quality, sacrifice, and value. Journal of the Academy of marketing Science, 28(2), 278-290.

Teh, P.-L., \& Ahmed, P. K. (2012). Understanding social commerce adoption: an extension of the technology acceptance model. Paper presented at the IEEE International Conference on Management of Innovation and Technology (ICMIT), Singapore.

Tey, Y. (2015). The state of social media in Malaysia. Retrieved from https://www.techinasia.com/talk/state-social-media-malaysia

The Statistic Portal. (2016). Active social network penetration in selected countries as of January 2016. Retrieved from http://www.statista.com/statistics/282846/regular-socialnetworking-usage-penetration-worldwide-by-country/

The Straits Times. (2015). Malaysian economists feels that there is a serious imbalance between income and the prices of goods, and that it will not be easy for the government to meet its high-income target by 2020 Retrieved from http://www.straitstimes.com/asia/se-asia/gettingharder-to-make-ends-meet-in-malaysia-says-housewife-who-haslived-in-4-asian

Thoits, P. A. (1982). Conceptual, methodological, and theoretical problems in studying social support as a buffer against life stress. Journal of Health and Social behavior, 145-159. 
Todri, V., \& Adamopoulos, P. (2014). Social commerce: An empirical examination of the antecedents and consequences of commerce in social network platforms. Paper presented at the 35th International Conference on Information Systems, Auckland, New Zealand

Tonteri, L., Kosonen, M., Ellonen, H.-K., \& Tarkiainen, A. (2011). Antecedents of an experienced sense of virtual community. Computers in Human Behavior, 27(6), 2215-2223.

Toral, S., Martínez-Torres, M. d. R., \& Barrero, F. (2010). Analysis of virtual communities supporting OSS projects using social network analysis. Information and Software Technology, 52(3), 296-303.

Trammell, K. D., \& Keshelashvili, A. (2005). Examining the new influencers: A self-presentation study of A-list blogs. Journalism \& Mass Communication Quarterly, 82(4), 968-982.

Tredinnick, L. (2006). Web 2.0 and Business A pointer to the intranets of the future? Business Information Review, 23(4), 228-234.

Tsai, M.-T., Cheng, N.-C., \& Chen, K.-S. (2011). Understanding online group buying intention: the roles of sense of virtual community and technology acceptance factors. Total Quality Management \& Business Excellence, 22(10), 1091-1104.

Tsai, W., \& Ghoshal, S. (1998). Social capital and value creation: The role of intrafirm networks. Academy of Management Journal, 464-476.

Tsuchihashi-Makaya, M., Kato, N., Chishaki, A., Takeshita, A., \& Tsutsui, H. (2009). Anxiety and poor social support are independently associated with adverse outcomes in patients with mild heart failure. Circulation Journal, 73(2), 280-287.

Turban, E., Lee, J. K., King, D., Liang, T. P., \& Turban, D. (2012). Electronic commerce 2012: Prentice Hall Press. 
Turban, E., Strauss, J., \& Lai, L. (2016a). Tools and Platforms for Social Commerce Social Commerce (pp. 23-45): Springer.

Turban, E., Strauss, J., \& Lai, L. (2016b). Implementing Social Commerce Systems Social Commerce (pp. 265-289): Springer.

Urban, G. L., Sultan, F., \& Qualls, W. J. (2000). Placing trust at the center of your Internet strategy. MIT Sloan Management Review, 42(1), 39.

Utusan Malaysia. (2008). Blogging in Malaysia ranks among highest in the world. Retrieved from http://www.malaysia-today.net/blogging-inmalaysia-ranks-among-highest-in-the-world/

Uzzi, B. (1996). The sources and consequences of embeddedness for the economic performance of organizations: The network effect. American Sociological Review, 674-698.

Valenzuela, S., Park, N., \& Kee, K. F. (2009). Is there social capital in a social network site?: Facebook use and college students' life satisfaction, trust, and participation. Journal of Computer-Mediated Communication, 14(4), 875-901.

Van den Hooff, B., \& Huysman, M. (2009). Managing knowledge sharing: Emergent and engineering approaches. Information \& Management, $46(1), 1-8$.

van Huylenbroek, G., Mondelaers, K., Aertsens, J., Aertsens, J., Verbeke, W., Mondelaers, K., \& Van Huylenbroeck, G. (2009). Personal determinants of organic food consumption: a review. British Food Journal, 111(10), 1140-1167.

Vanden Abeele, V., Gajadhar, B., \& De Schutter, B. (2009). Gaming naturally is more fun together: the influence of controller type on player experience.

Veludo-de-Oliveira, T. M., Ikeda, A. A., \& Campomar, M. C. (2006). Discussing laddering application by the means-end chain theory. The Qualitative Report, 11(4), 626-642. 
Walsham, G. (1993). Interpreting information systems in organizations: John Wiley \& Sons, Inc.

Wang, C. (2009). Linking shopping and social networking: Approaches to social shopping. Paper presented at the 15th Americas Conference on Information Systems, San Francisco, USA.

Wang, C., \& Zhang, P. (2012). The Evolution of Social Commerce: An Examination from the People, Business, Technology, and Information Perspectives. Communications of the Association for Information Systems, $13,105-127$.

Wang, N., Shen, X.-L., \& Sun, Y. (2013). Transition of electronic word-of-mouth services from web to mobile context: A trust transfer perspective. Decision Support Systems, 54(3), 1394-1403.

Wang, Y., \& Hajli, M. N. (2014). Co-creation in branding through social commerce: The role of social support, relationship quality and privacy concerns. Paper presented at the 20th Americas Conference on Information Systems, Savannah, USA.

Wang, Y., \& Hajli, N. (2015). Co-Creating Brand Value through Social Commerce. Handbook of Research on Integrating Social Media into Strategic Marketing, 17.

Wansink, B. (2003). Using laddering to understand and leverage a brand's equity. Qualitative Market Research: An International Journal, 6(2), 111118.

Wasko, M. M., \& Faraj, S. (2000). "It is what one does”: why people participate and help others in electronic communities of practice. The Journal of Strategic Information Systems, 9(2), 155-173.

Weaver, J. (2010). Social Commerce: Selling with social media. Retrieved from http://www.slideshare.net/shoutlet/social-commerce-selling-withsocial-media 
Wei, C. (2004). Formation of norms in a blog community. Into the Blogosphere. Retrieved from http://hdl.handle.net/11299/172809.

Weisberg, J., Te'eni, D., \& Arman, L. (2011). Past purchase and intention to purchase in e-commerce: The mediation of social presence and trust. Internet Research, 21(1), 82-96.

Welbourne, J. L., Blanchard, A. L., \& Boughton, M. D. (2009). Supportive communication, sense of virtual community and health outcomes in online infertility groups. Paper presented at the 4th International Conference on Communities and Technologies, State College, Pennsylvania, USA.

Wellman, B., \& Gulia, M. (1999). Net surfers don't ride alone: Virtual communities as communities. Networks in the Global Village, 331-366.

Whelan, C. (2016). Informal social networks within and between organisations: On the properties of interpersonal ties and trust. Policing: An International Journal of Police Strategies \& Management, 39(1), 145-158.

Willis, B. (2014). The advantages and limitations of single case study analysis. E-International Relation Students. Retrieved from http://www.eir.info/2014/07/05/the-advantages-and-limitations-of-single-casestudy-analysis/

Wills, T. A. (1985). Supportive functions of interpersonal relationships. In S. Cohen \& S. L. Syme (Eds.), Social support and health (pp. 61-82). San Diego, CA, US: Academic Press.

Wilson, D. K., Kliewer, W., Bayer, L., Jones, D., Welleford, A., Heiney, M., \& Sica, D. A. (1999). The influence of gender and emotional versus instrumental support on cardiovascular reactivity in African-American adolescents. Annals of Behavioral Medicine, 21(3), 235-243.

Wilson, S. M., \& Peterson, L. C. (2002). The anthropology of online communities. Annual Review of Anthropology, 449-467. 
Wong, C. K. (2010). An untapped e-commerce opportunity. Retrieved from http://www.zippycart.com/ecommerce-news/1186-malaysia-anuntapped-ecommerce-opportunity.html

Wong, J. (2012). The evolution of e-commerce to social commerce. The Borneo $\begin{array}{lll}\text { Post. } & \text { Retrieved }\end{array}$ http://www.theborneopost.com/2012/10/07/the-evolution-of-ecommerce-to-social-commerce/

Woodruff, R. B., \& Flint, D. J. (2006). Marketing's service-dominant logic and customer value. The Service-Dominant Logic of Marketing: Dialog, Debate, and Directions, 183-195.

Woodson, K. (2015). Race and Rapport: Homophily and Racial Disadvantage in Large Law Firms. Fordham L. Rev., 83, 2557.

Wu, J.-H., \& Wang, S.-C. (2005). What drives mobile commerce?: An empirical evaluation of the revised technology acceptance model. Information \& Management, 42(5), 719-729.

Wu, J., Xu, M., Mo, Z., \& Liao, L. (2015). The Research of Design Based on Social Commerce. International Journal of Social Science Studies, 3(4), 157-165.

Xiang, R., Neville, J., \& Rogati, M. (2010). Modeling relationship strength in online social networks. Paper presented at the 19th International Conference on World Wide Web, North Carolina, USA.

Xiao, L., Guo, Z., \& DAmbra, J. (2014). A Typology of Online Group Buyers: Using Means-end Structures for Benefit Segmentation. Paper presented at the Thirty Fifth International Conference on Information Systems, Auckland.

Yadav, M. S., De Valck, K., Hennig-Thurau, T., Hoffman, D. L., \& Spann, M. (2013). Social commerce: a contingency framework for assessing marketing potential. Journal of Interactive Marketing, 27(4), 311-323. 
Yang, S.-U., \& Lim, J. S. (2009). The effects of blog-mediated public relations (BMPR) on relational trust. Journal of Public Relations Research, 21(3), 341-359.

Yeung, G., \& Ang, K. L. (2016). Online fashion retailing and retail geography: the blogshop phenomenon in Singapore. Tijdschrift voor economische en sociale geografie, 107(1), 81-99.

Yin, R. K. (2003). Case Study Research: Design and Methods: SAGE Publications, Incorporated.

Yin, R. K. (2008). Case study research: Design and methods (Vol. 5): SAGE Publications, Incorporated.

Yin, R. K. (2013). Case study research: Design and methods: SAGE Publications, Incorporated.

Young, K. S. (1996). Psychology of computer use: XL. Addictive use of the Internet: a case that breaks the stereotype. Psychological Reports, 79(3), 899-902.

Zaman, B. (2005). Evaluating games with children. Paper presented at the Workshop on Child computer Interaction: Methodological Research.

Zhang, H., Lu, Y., Gupta, S., \& Zhao, L. (2014). What motivates customers to participate in social commerce? The impact of technological environments and virtual customer experiences. Information \& Management, 51(8), 1017-1030.

Zhang, Y., Fang, Y., Wei, K.-K., Ramsey, E., McCole, P., \& Chen, H. (2011). Repurchase intention in $\mathrm{B} 2 \mathrm{C}$ e-commerce-A relationship quality perspective. Information \& Management, 48(6), 192-200.

Zhou, L., Zhang, P., \& Zimmermann, H.-D. (2013). Social commerce research: An integrated view. Electronic Commerce Research and Applications, 12(2), 61-68. 
Zhou, Z., Jin, X.-L., Fang, Y., \& Vogel, D. (2015). Toward a theory of perceived benefits, affective commitment, and continuance intention in social virtual worlds: cultural values (indulgence and individualism) matter. European Journal of Information Systems, 24(3), 247-261.

Zucker, L. G. (1986). Production of trust: Institutional sources of economic structure. Research in Organizational Behavior, 1840-1920. 


\section{APPENDIX A : INVITATION EMAIL TO PARTICIPANTS}

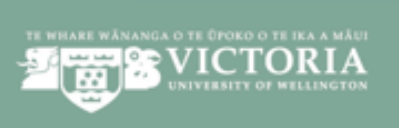

SCHOOL OF INFORMATION MANAGEMENT

TE KURA TIAKI, WHAKAWHITI KÖRERO

LEVEL. 5, RUTHERFORD HOUSE, PIPITEA GAMPUS, 23 LAMBTON QUAY, WELLINGTON

PO Box 600, Wellington 6140, New Zealand

Phone + 64-4.4635103 Fax +64-4.4635446 Email simQvww.ac.nz Website uww.vichoria.ac.nz/sim

\section{Invitation email to participants}

\section{Hi Miss XXX}

I am Syahida Hassan, $\mathrm{PhD}$ candidate in the School of Information Management, Victoria University of Wellington. I am inviting you to participate in my research aiming to understand the active participation of Malaysian Blogosphere community members and the effects of the participation to them.

In this interview I would like to know about your participation in the Malaysia Blogosphere community (bloggers and readers) and your business and/or purchasing experience within the community. Ethical approval from the University Research Committee has been granted for this interview.

Other details are attached to this email that include the:

i. Participant Information Sheet and

ii. Consent Form

Thank you.

Best regards,

Syahida Hassan

$\mathrm{PhD}$ Candidate,

School of Information Management, Victoria University of Wellington, NZ

Email: syahida.hassan@vuw.ac.nz

Phone no: +64220975172 or +60124333442 
APPENDIX B: SOCIAL COMMERCE EXPERIENCE - SELLERS

\begin{tabular}{|l|l|l|l|}
\hline Code & $\begin{array}{l}\text { Social } \\
\text { Commerce } \\
\text { Experience } \\
\mathbf{2 0 1 4 )}\end{array}$ & Main Product & Other Product \\
\hline S1 & 3 years & Toys & Kid's apparel \\
\hline S2 & 4 years & Toys & - \\
\hline S3 & 5 years & Women clothing & Health supplement \\
\hline S4 & 3 years & Health Supplement & - \\
\hline S5 & 2 years & Cake \& Bakery & - \\
\hline S6 & 1 year & Women clothing & - \\
\hline S7 & 3 years & Women clothing & - \\
\hline S8 & 5 years & Health supplement & Beauty products \\
\hline S9 & 3 years & Bags & Clothes \\
\hline S10 & 5 years & Women clothing & \\
\hline S11 & 2 years & Women clothing & \\
\hline S12 & 5 years & Handbags & \\
\hline S13 & 3 years & Women clothing & \\
\hline S14 & 2 years & Women clothing & \\
\hline S15 & 3 years & Health supplement & \\
\hline S16 & 2 years & Books & \\
\hline S17 & 6 years & Photography & \\
\hline S19 & 3 years & Women clothing & \\
\hline S20 & 1 year & Beauty product & \\
\hline S21 & 2 years & Beauty product & \\
\hline
\end{tabular}


APPENDIX C: SOCIAL COMMERCE EXPERIENCE - CUSTOMERS

\begin{tabular}{|c|l|l|}
\hline Code & $\begin{array}{l}\text { Purchasing } \\
\text { Experience } \\
\text { in Social } \\
\text { Commerce }\end{array}$ & Products \\
\hline B1 & 4 years & Clothes \\
\hline B2 & 5 years & Clothes, toys, health supplement \\
\hline B3 & 4 years & Health supplement \\
\hline B4 & 5 years & Toys, children apparels \\
\hline B5 & 1 year & Clothes, foods \\
\hline B6 & 3 years & Toys, children apparels \\
\hline B7 & 4 years & Toys \\
\hline B8 & 3 years & Clothes, books \\
\hline B9 & 5 years & Clothes, breastfeeding equipment, health supplements \\
\hline B10 & 4 years & Clothes, handbags \\
\hline B11 & 3 years & Health supplement \\
\hline B12 & 4 years & Clothes \\
\hline B13 & 1 year & Clothes, toys \\
\hline B14 & 1 year & Clothes \\
\hline B15 & 4 years & Clothes \\
\hline B16 & 5 years & Clothes \\
\hline B17 & 3 years & Clothes, foods \\
\hline B18 & 2 years & Beauty product, clothes \\
\hline B19 & 1 year & Clothes, mobile phone accessories \\
\hline B20 & 3 years & Clothes \\
\hline B21 & 2 years & Clothes, food, health supplements \\
\hline & & \\
\hline
\end{tabular}


APPENDIX D: INTERVIEW PROTOCOL

\begin{tabular}{|c|c|c|}
\hline TOPICS & ITEM & NOTES \\
\hline $\begin{array}{l}\text { Before } \\
\text { interview }\end{array}$ & Checklist for interview & $\begin{array}{l}\text { - Voice recorder } \\
\text { - Back-up recorder } \\
\text { - Consent forms } \\
\text { - Notebook }\end{array}$ \\
\hline Introduction & $\begin{array}{l}\text { 1) Introduce myself } \\
\text { 2) Explain the purpose of the interview }\end{array}$ & \multirow{2}{*}{$\begin{array}{l}\text { - Ice-breaking } \\
\text { - To ensure that the } \\
\text { participants are } \\
\text { comfortable to start the } \\
\text { interview. } \\
\text { - To make the participant } \\
\text { aware that the data is } \\
\text { going to be used only for } \\
\text { academic purposes. }\end{array}$} \\
\hline Ethics & Consent form & \\
\hline Record & $\begin{array}{l}\text { Mention at what date/time the interview } \\
\text { begins. }\end{array}$ & $\begin{array}{l}\text { - } \text { Basic housekeeping } \\
\text { - Recording descriptive } \\
\text { information about the } \\
\text { data source and data } \\
\text { collection event }\end{array}$ \\
\hline $\begin{array}{l}\text { Getting to know } \\
\text { the participant }\end{array}$ & $\begin{array}{l}\text { Ask the participant of the following (if } \\
\text { applicable) } \\
\text { - name } \\
\text { - occupation } \\
\text { - education level } \\
\text { - age } \\
\text { - race }\end{array}$ & $\begin{array}{l}\text { - } \text { Basic housekeeping } \\
\text { - To understand the } \\
\text { participant } \\
\text { - To identify other factors } \\
\text { that could influence the } \\
\text { experience }\end{array}$ \\
\hline $\begin{array}{l}\text { Generating } \\
\text { interest }\end{array}$ & $\begin{array}{l}\text { Explain to the participant that the } \\
\text { researcher is going to ask about their } \\
\text { involvement in blogosphere } \\
\text { communities. } \\
\text { - Explain terms used in the interview i.e. } \\
\text { social commerce, virtual communities, } \\
\text { members etc. }\end{array}$ & $\begin{array}{l}\text { - To make the participant } \\
\text { focus on the topic } \\
\text { - To give participant some } \\
\text { idea of what type of } \\
\text { questions will be asked. } \\
\text { - To generate interest }\end{array}$ \\
\hline
\end{tabular}




\begin{tabular}{|c|c|c|}
\hline Topics & Questions & Notes \\
\hline \multicolumn{3}{|c|}{ Community Participation } \\
\hline $\begin{array}{l}\text { Sense of virtual } \\
\text { community }\end{array}$ & $\begin{array}{l}\text { Can you please describe your participation } \\
\text { in the community? } \\
\text { Follow-up questions: } \\
\text { - How long have you been reading blogs? } \\
\text { - How often do you read blogs? } \\
\text { - How often do you read comments? } \\
\text { - How often do you post comments? } \\
\text { - Are you regularly in contact with other } \\
\text { - } \text { mombers in blogosphere community? } \\
\text { How frequently do you communicate } \\
\text { - } \text { - Are you attached to any members } \\
\text { within the community? Why? } \\
\text { - Do you feel connected to the members? } \\
\text { - Can you describe how do you feel with } \\
\text { this group? } \\
\text { - Are you planning to continue your } \\
\text { participation? Why? } \\
\text { - Did anyone in the community influence } \\
\text { other members? How? } \\
\text { - mou you know the identity of other } \\
\text { members? How? }\end{array}$ & $\begin{array}{l}\text { Blanchard (2007); } \\
\text { Blanchard and Markus } \\
\text { (2004); Koh and Kim } \\
\text { (2003); Van den Hooff and } \\
\text { Huysman (2009); Abfalter et } \\
\text { al. (2012); }\end{array}$ \\
\hline Roles & $\begin{array}{l}\text { - Can you explain your role in the } \\
\text { community? } \\
\text { - What are the other roles in this } \\
\text { community? }\end{array}$ & $\begin{array}{l}\text { - To understand more } \\
\text { about the community }\end{array}$ \\
\hline $\begin{array}{l}\text { Community } \\
\text { Participation }\end{array}$ & $\begin{array}{l}\text { - Why do you participate in this } \\
\text { community? } \\
\text { - What do you think of this community? }\end{array}$ & \\
\hline
\end{tabular}




\begin{tabular}{|c|c|c|}
\hline & $\begin{array}{l}\text { - How does your participation benefit } \\
\text { you? }\end{array}$ & \\
\hline \multirow[t]{3}{*}{ Practice } & $\begin{array}{l}\text { - Can you explain the common practice in } \\
\text { the community? }\end{array}$ & \\
\hline & $\begin{array}{l}\text { - What activities are you involved in the } \\
\text { blogosphere community } \\
\text { a) Reading blog } \\
\text { b) Comment/Interact virtually } \\
\text { c) Face-to-face meeting } \\
\text { d) Others (please state) }\end{array}$ & \\
\hline & $\begin{array}{l}\text { Have you ever shared your problem } \\
\text { with other members (including } \\
\text { seller/blogger)? }\end{array}$ & \\
\hline Trust & $\begin{array}{l}\text { Do you trust the members? } \\
\text { If yes, how do you know they can be } \\
\text { trusted? }\end{array}$ & \\
\hline Social Support & $\begin{array}{l}\text { Have you ever contributed anything to } \\
\text { other members? } \\
\text { Follow up questions: } \\
\text { - How? } \\
\text { - Why? }\end{array}$ & \\
\hline Homophily & $\begin{array}{l}\text { Do you sense any similarity between } \\
\text { you and the bloggers/other community } \\
\text { members? } \\
\text { - If yes, how does the similarity influence } \\
\text { your participation? }\end{array}$ & \\
\hline Social ties & $\begin{array}{l}\text { - Can you explain your relationship with } \\
\text { other members? }\end{array}$ & \\
\hline \multicolumn{3}{|c|}{ Social Commerce Participation } \\
\hline \multirow[t]{2}{*}{ Laddering } & $\begin{array}{l}\text { - List the commercial or business-related } \\
\text { activities that you have participates in } \\
\text { the community }\end{array}$ & $\begin{array}{l}\text { - Choose from a list of } \\
\text { attributes } \\
\text { - Free elicitation }\end{array}$ \\
\hline & $\begin{array}{l}\text { a. What are the activities that you } \\
\text { participate in the community? }\end{array}$ & $\begin{array}{l}\text { - } \text { Means-end theory } \\
\text { - 'Why' questions will be } \\
\text { based on the previous }\end{array}$ \\
\hline
\end{tabular}




\begin{tabular}{|c|c|c|}
\hline & $\begin{array}{l}\text { b. Why is it important to you? (based on } \\
\text { a) } \\
\text { c. Why is it important that you... (based } \\
\text { on b) } \\
\text { d. Why should it be...? }\end{array}$ & $\begin{array}{l}\text { answer. If the participant } \\
\text { looks exhausted, proceed } \\
\text { with other questions. } \\
\text { - Note the main point and } \\
\text { ask more questions later } \\
\text { to understand the } \\
\text { explanation behind their } \\
\text { choice. }\end{array}$ \\
\hline \multirow{2}{*}{$\begin{array}{l}\text { Discussion on } \\
\text { the experience } \\
\text { using Social } \\
\text { Commerce }\end{array}$} & $\begin{array}{l}\text { - How often do you buy product/services } \\
\text { from businesses that used social media? }\end{array}$ & $\begin{array}{l}\text { - General experience in } \\
\text { social commerce }\end{array}$ \\
\hline & $\begin{array}{l}\text { - How long have you been selling/ buying } \\
\text { via Facebook/blog/forum? }\end{array}$ & $\begin{array}{l}\text { To confirm that the } \\
\text { participant has used } \\
\text { social commerce before. } \\
\text { - To identify whether or } \\
\text { not the participant is a } \\
\text { new user. }\end{array}$ \\
\hline $\begin{array}{l}\text { Discussion on } \\
\text { general } \\
\text { practices }\end{array}$ & $\begin{array}{l}\text { Can you please describe the general } \\
\text { process of buying-selling of } \\
\text { products/services in this community? }\end{array}$ & $\begin{array}{l}\text { - To understand about } \\
\text { what is happening in the } \\
\text { community } \\
\text { - To know about the } \\
\text { general practices in that } \\
\text { particular community }\end{array}$ \\
\hline \multirow[t]{2}{*}{$\begin{array}{l}\text { Discussion on } \\
\text { buyer-seller } \\
\text { relationship }\end{array}$} & $\begin{array}{l}\text { - How did you start the conversation? } \\
\text { Explain the relationship between } \\
\text { community members, and between } \\
\text { customer and seller. }\end{array}$ & $\begin{array}{l}\text { - To investigate about the } \\
\text { actors in the virtual } \\
\text { communities } \\
\text { - To identify how } \\
\text { community members } \\
\text { interact }\end{array}$ \\
\hline & $\begin{array}{l}\text { Seller A and Seller B in your community } \\
\text { sell the same product. } \\
\text { What are the criteria that make you } \\
\text { choose one particular seller over } \\
\text { another? }\end{array}$ & $\begin{array}{l}\text { - To identify the } \\
\text { relationship of } \\
\text { purchasing and past } \\
\text { relationship }\end{array}$ \\
\hline
\end{tabular}




\begin{tabular}{|c|c|c|}
\hline $\begin{array}{l}\text { Discussion on } \\
\text { other practices } \\
\text { (non- } \\
\text { commercial } \\
\text { practices) }\end{array}$ & $\begin{array}{l}\text { Apart from buying-selling products or } \\
\text { services, do you actively interact with } \\
\text { other community members (other } \\
\text { sellers/buyers)? } \\
\text { - How often you interact with them? }\end{array}$ & $\begin{array}{l}\text { - To understand the } \\
\text { practices }\end{array}$ \\
\hline $\begin{array}{l}\text { Discussion on } \\
\text { technology }\end{array}$ & $\begin{array}{l}\text { - How do you communicate? } \\
\text { - What are the technologies used to } \\
\text { communicate with other community } \\
\text { 1) What happens if something goes wrong } \\
\text { with the technology? } \\
\text { 2) In your opinion, does the technology } \\
\text { have any impact on the activities in the } \\
\text { community? }\end{array}$ & $\begin{array}{l}\text { - To identify the type of } \\
\text { technology used } \\
\text { - How do these } \\
\text { technologies influence } \\
\text { the practices? }\end{array}$ \\
\hline \multirow[t]{2}{*}{ General } & $\begin{array}{l}\text { - Can you describe the initiatives taken } \\
\text { by seller in order to promote their } \\
\text { products in social media? } \\
\text { - Have you ever helped them in their } \\
\text { business? What? How? Why? }\end{array}$ & - Customer \\
\hline & $\begin{array}{l}\text { - How do you run/ promote your } \\
\text { business? } \\
\text { - Have you ever got any help in any form } \\
\text { from the customers (community } \\
\text { members?) What? How? Why? }\end{array}$ & - Sellers \\
\hline Conclusion & - Do you have anything else to share? & \\
\hline
\end{tabular}


APPENDIX E-1: INFORMATION SHEET

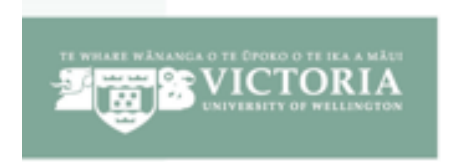

SCHOOL OF INFORMATION MANAGEMENT

TE KURA TLAKI, WHAKCWWHIT KÖRERD

LEVEL 5, RUTHERFORD HOUSE, PIPITEA CAMPUS, 23 LAMBTON QUAY, WELUNGTON

PO Box 600, Wellington 6140, New Zealand

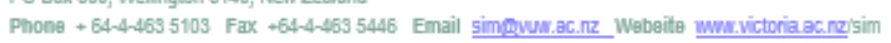

\section{INFORMATION SHEETS}

I am Syahida Hassan, a PhD student in School of Information Management at Victoria University of Wellington. As part of this degree requirement, I am working on a thesis entitled "Motivations for Virtual Community Participation in Social Commerce: Customers and Sellers in the Malay Lifestyle Blogging Community". The aim of this research is to understand the active participation of Malaysian Blogosphere community members and the effects of the participation to them. The University requires that ethics approval be obtained for research involving human participants and this approval has been granted by the School of Information Management Human Ethics Committee for this research.

I am inviting sellers and customers who are members of the Malaysian blogosphere community to participate in this study. Participants will be interviewed and the interview session may take about 60 minutes. In this interview, I would like to know about your participation in the Malaysia Blogosphere community (bloggers and readers) and your purchasing experience within the community. I will be recording the interview if you give your approval. Should you feel the need to withdraw from the project, you may do so without question at any time within 1 month after the interview date. You also have the right to refuse to answer any question asked during the interview.

Responses collected will form the basis of my research project and will be put into a written report on an anonymous basis. It will not be possible for you to be identified personally. Business names will also be masked. All material collected will be kept confidential. No other person besides me and my supervisors, Dr Janet Toland and Dr Mary Tate will have access to the materials collected. The thesis will be submitted for marking to the School of Information Management and deposited in the University Library. It is intended that one or more articles will be submitted for publication in scholarly journals. Audio recording and interview transcripts will be destroyed five years after the end of the project.

If you have any questions or would like to receive further information about the project, please contact me at Syahida.Hassan@vuw.ac.nz (+64220975172/+60124333442) or my supervisors, Dr Janet Toland (Janet.Toland@vuw.ac.nz) and/or Dr Mary Tate (Mary.Tate@vuw.ac.nz), at the School of Information Management at Victoria University of Wellington, P.O. Box 600 , Wellington, $+6444636861 / 5265$,

Thank you

Yours sincerely,

Syahida Hassan 


\section{CONSENT TO PARTICIPATION IN RESEARCH}

Title of project: Motivations for Virtual Community Participation in Social Commerce: Customers and Sellers in the Malay Lifestyle Blogging Community

I have been given and have understood an explanation of this research project. I have had an opportunity to ask questions and have them answered to my satisfaction. I understand that I may withdraw myself (or any information I have provided) from this project (within 1 month after the interview) without having to give reasons or without penalty of any sort.

I understand that any information I provide will be kept confidential to the researcher, the supervisors and the person who translate the audio recordings of our interview, the published results will not use my name, and that no opinions will be attributed to me in any way that will identify me.

I understand that the translator has signed a confidentiality agreement, agreeing not to disclose any details relating to identity or other information, to store material securely, and to destroy it after completing the translations.

I understand that the business name may be disclosed to related participants (customers) during the data collection phase. In the thesis, the business name will be masked*

I understand that the data I provide will not be used for any other purpose or released to others.

I understand that the audio recording of interviews will be destroyed five years after the end of the project

Please indicate (by ticking the boxes below) which of the following apply:

- I agree to this interview being audio recorded.

- I would like to receive a summary of the results when this research is completed.

(Please provide your email address:

Signed:

Name of participant:

Date:

*Applicable only for business owner 
APPENDIX F-1: LIST OF LADDERS - SELLERS

\begin{tabular}{|c|c|c|}
\hline Participants & S1 (Ladder 1) & S2 (Ladder 1) \\
\hline Values & $\begin{array}{l}\text { Business Sustainability } \\
\text { Profit }\end{array}$ & Profit \\
\hline Consequences & $\begin{array}{l}\text { Perceived Convenience } \\
\text { Potential Customer } \\
\text { Business Opportunity }\end{array}$ & Customer Trust \\
\hline Attributes & Selling & Selling \\
\hline Participants & S2 (Ladder 2) & S2 (Ladder 3) \\
\hline Values & Profit & Self-Esteem \\
\hline Consequences & $\begin{array}{l}\text { Business Opportunity } \\
\text { Potential Customer } \\
\text { WOM } \\
\text { Social Support }\end{array}$ & $\begin{array}{l}\text { Technical Knowledge } \\
\text { Perceived Convenience }\end{array}$ \\
\hline Attributes & Review & Selling \\
\hline Participants & S3 (Ladder 1) & S3 (Ladder 2) \\
\hline Values & $\begin{array}{l}\text { Business Sustainability } \\
\text { Profit }\end{array}$ & Profit \\
\hline Consequences & $\begin{array}{l}\text { Potential Customers } \\
\text { Customer Trust } \\
\text { Perceived Convenience }\end{array}$ & $\begin{array}{l}\text { Business Opportunity } \\
\text { Social Support }\end{array}$ \\
\hline Attributes & Selling & Selling \\
\hline Participants & S4 (Ladder 1) & S4 (Ladder 2) \\
\hline Values & Profit & Business Sustainability \\
\hline Consequences & $\begin{array}{l}\text { Potential Customer } \\
\text { WOM } \\
\text { Social Support }\end{array}$ & $\begin{array}{l}\text { Potential Customer } \\
\text { WOM } \\
\text { Social Support }\end{array}$ \\
\hline Attributes & Review & Selling \\
\hline Participants & S5 (Ladder 1) & S5 (Ladder 2) \\
\hline Values & Profit & Self-Esteem \\
\hline Consequences & $\begin{array}{l}\text { Business Sustainability } \\
\text { Customer Engagement } \\
\text { Potential Customer } \\
\text { Social Support }\end{array}$ & $\begin{array}{l}\text { Perceived Risk } \\
\text { Cost-effectiveness }\end{array}$ \\
\hline Attributes & Review & Selling \\
\hline Participants & S6 (Ladder 1) & S7 (Ladder 1) \\
\hline Values & Business Sustainability & Self-Esteem \\
\hline Consequences & Cost-effectiveness & Perceived Risk \\
\hline
\end{tabular}




\begin{tabular}{|c|c|c|}
\hline & $\begin{array}{l}\text { Technical knowledge } \\
\text { Perceived Convenience }\end{array}$ & $\begin{array}{l}\text { Perceived Convenience } \\
\text { Business Opportunity } \\
\text { Potential Buyers } \\
\text { Social Support }\end{array}$ \\
\hline Attributes & Selling & Selling \\
\hline Participants & S8 (Ladder 1) & S8 (Ladder 2) \\
\hline Values & Self-Esteem & Profit \\
\hline Consequences & $\begin{array}{l}\text { Personal Achievement } \\
\text { Financial Security } \\
\text { Business Opportunity }\end{array}$ & $\begin{array}{l}\text { Business Opportunity } \\
\text { Social Support }\end{array}$ \\
\hline Attributes & Selling & Selling \\
\hline Participants & S9 (Ladder 1) & S9 (Ladder 2) \\
\hline Values & Business Sustainability & Self-Esteem \\
\hline Consequences & Perceived Convenience & $\begin{array}{l}\text { Social Support } \\
\text { Sense of Obligation }\end{array}$ \\
\hline Attributes & Selling & Review \\
\hline Participants & S10 (Ladder 1) & S10 (Ladder 2) \\
\hline Values & Business Sustainability & Satisfaction \\
\hline Consequences & $\begin{array}{l}\text { Cost-effectiveness } \\
\text { Potential Buyer } \\
\text { Perceived Convenience }\end{array}$ & $\begin{array}{l}\text { Profit } \\
\text { Cost Effective }\end{array}$ \\
\hline Attributes & Selling & Selling \\
\hline Participants & S11 (Ladder 1) & S12 (Ladder 1) \\
\hline Values & Profit & Profit \\
\hline Consequences & $\begin{array}{l}\text { Perceived convenience } \\
\text { Potential Buyers } \\
\text { Social Norms } \\
\text { New media Attitude }\end{array}$ & $\begin{array}{l}\text { Business Opportunity } \\
\text { Social Support }\end{array}$ \\
\hline Attributes & Selling & Selling \\
\hline Participants & S13 (Ladder 1) & S13 (Ladder 2) \\
\hline Values & Profit & Business Sustainability \\
\hline Consequences & $\begin{array}{l}\text { Customer Trust } \\
\text { WOM } \\
\text { Social Support } \\
\text { Business Opportunity }\end{array}$ & $\begin{array}{l}\text { Customer Trust } \\
\text { WOM } \\
\text { Social Support } \\
\text { Business Opportunity }\end{array}$ \\
\hline Attributes & Selling & Selling \\
\hline Participants & S14 (Ladder 1) & S14 (Ladder 2) \\
\hline Values & Profit & Profit \\
\hline
\end{tabular}




\begin{tabular}{|c|c|c|}
\hline Consequences & $\begin{array}{l}\text { Customer Engagement } \\
\text { Perceived Convenience } \\
\text { New Media attitude }\end{array}$ & $\begin{array}{l}\text { Potential Buyers } \\
\text { Competitive Advantage } \\
\text { Social Support }\end{array}$ \\
\hline Attributes & Selling & Review \\
\hline Participants & S14 (Ladder 3) & S14 (Ladder 4) \\
\hline Values & Profit & Potential Buyers \\
\hline Consequences & $\begin{array}{l}\text { Potential Buyer } \\
\text { Social Support }\end{array}$ & Perceived Convenience \\
\hline Attributes & Review & Selling \\
\hline Participants & S15 (Ladder 1) & S15 (Ladder 2) \\
\hline Values & Self-Esteem & Profit \\
\hline Consequences & $\begin{array}{l}\text { Potential Buyers } \\
\text { Perceived Convenience } \\
\text { Social Support }\end{array}$ & $\begin{array}{l}\text { Business Opportunity } \\
\text { Potential Buyers } \\
\text { Customer Trust } \\
\text { Knowledge Sharing }\end{array}$ \\
\hline Attributes & Selling & Review \\
\hline Participants & S15 (Ladder 3) & S15 (Ladder 4) \\
\hline Values & Profit & Profit \\
\hline Consequences & $\begin{array}{l}\text { Business Opportunity } \\
\text { Potential Buyers } \\
\text { Social Support }\end{array}$ & $\begin{array}{l}\text { Potential Buyers } \\
\text { Perceived Convenience } \\
\text { Social Support }\end{array}$ \\
\hline Attributes & Review & Selling \\
\hline Participants & S16 (Ladder 1) & S16 (Ladder 2) \\
\hline Values & Profit & Business Sustainability \\
\hline Consequences & $\begin{array}{l}\text { Potential Buyer } \\
\text { Social Support }\end{array}$ & $\begin{array}{l}\text { Customer Engagement } \\
\text { Sense of Obligation } \\
\text { Social Support }\end{array}$ \\
\hline Attributes & Selling & Selling \\
\hline Participants & S16 (Ladder 3) & S17 (Ladder 1) \\
\hline Values & Profit & Profit \\
\hline Consequences & $\begin{array}{l}\text { Cost Effective } \\
\text { Business Opportunity } \\
\text { Social Support }\end{array}$ & $\begin{array}{l}\text { Potential Buyers } \\
\text { Business Opportunity } \\
\text { Social Support }\end{array}$ \\
\hline Attributes & Selling & Selling \\
\hline Participants & S19 (Ladder 1) & S19 (Ladder 2) \\
\hline Values & Business Sustainability & Profit \\
\hline Consequences & Business Opportunity & Business Opportunity \\
\hline
\end{tabular}




\begin{tabular}{|c|c|c|}
\hline & $\begin{array}{l}\text { Potential Buyers } \\
\text { Social Support } \\
\text { Social Norms }\end{array}$ & $\begin{array}{l}\text { Potential Buyers } \\
\text { Social Support } \\
\text { Social Norms }\end{array}$ \\
\hline Attributes & Selling & Selling \\
\hline Participants & S20 (Ladder 1) & S20 (Ladder 2) \\
\hline Values & Self-Esteem & Self-Esteem \\
\hline Consequences & $\begin{array}{l}\text { Potential Buyers } \\
\text { Social Support } \\
\text { Perceived Convenience } \\
\text { Business Opportunity }\end{array}$ & $\begin{array}{l}\text { Sense of Obligation } \\
\text { Social Support }\end{array}$ \\
\hline Attributes & Selling & Review \\
\hline Participants & S20 (Ladder 3) & S21 (Ladder 1) \\
\hline Values & Profit & Profit \\
\hline Consequences & $\begin{array}{l}\text { Perceived Risk } \\
\text { Business Opportunity } \\
\text { Social Support }\end{array}$ & $\begin{array}{l}\text { Potential Buyers } \\
\text { Business Opportunity } \\
\text { Perceived Convenience } \\
\text { Social Support }\end{array}$ \\
\hline Attributes & Selling & Selling \\
\hline Participants & S21 (Ladder 2) & \\
\hline Values & Profit & \\
\hline Consequences & $\begin{array}{l}\text { Potential Buyer } \\
\text { Profit }\end{array}$ & \\
\hline Attributes & Selling & \\
\hline
\end{tabular}


APPENDIX F-2: LIST OF LADDERS - CUSTOMERS

\begin{tabular}{|c|c|c|}
\hline Participants & B1 (Ladder 1) & B2 (Ladder 1) \\
\hline Values & Self-Esteem & Satisfaction \\
\hline Consequences & $\begin{array}{l}\text { Self-Image } \\
\text { Personal Standard }\end{array}$ & $\begin{array}{l}\text { Perceived Convenience } \\
\text { Risk Awareness } \\
\text { Trust } \\
\text { VC Relationship }\end{array}$ \\
\hline Attributes & Purchasing & Purchasing \\
\hline Participants & B2 (Ladder 2) & B2 (Ladder 3) \\
\hline Values & Satisfaction & Loyalty \\
\hline Consequences & $\begin{array}{l}\text { Social Norms } \\
\text { Social Support } \\
\text { VC Relationship }\end{array}$ & $\begin{array}{l}\text { Perceived Benefit } \\
\text { Sense Of Obligation } \\
\text { VC Relationship }\end{array}$ \\
\hline Attributes & Purchasing & Giving Business Input \\
\hline Participants & B3 (Ladder 1) & B3 (Ladder 2) \\
\hline Values & Loyalty & Self Esteem \\
\hline Consequences & $\begin{array}{l}\text { Perceived Benefit } \\
\text { Decision Quality } \\
\text { Risk Awareness } \\
\text { Trust } \\
\text { VC Relationship }\end{array}$ & $\begin{array}{l}\text { Sense Of Obligation } \\
\text { Social Support } \\
\text { Social Norms }\end{array}$ \\
\hline Attributes & Purchasing & Giving Business Input \\
\hline Participants & B4 (Ladder 1) & B4 (Ladder 2) \\
\hline Values & Self Esteem & Self Esteem \\
\hline Consequences & $\begin{array}{l}\text { Social Image } \\
\text { Decision Quality } \\
\text { Response Time } \\
\text { Perceived Convenience } \\
\text { Trust } \\
\text { VC Relationship }\end{array}$ & $\begin{array}{l}\text { Social Support } \\
\text { Sense Of Obligation } \\
\text { VC Relationship }\end{array}$ \\
\hline Attributes & Purchasing & Giving Business Input \\
\hline Participants & B5 (Ladder 1) & B5 (Ladder 2) \\
\hline Values & Loyalty & Satisfaction \\
\hline Consequences & $\begin{array}{l}\text { Perceived Benefit } \\
\text { Group Buying } \\
\text { WOM }\end{array}$ & $\begin{array}{l}\text { Perceived Convenience } \\
\text { VC Relationship }\end{array}$ \\
\hline Attributes & Giving Business Input & Purchasing \\
\hline
\end{tabular}




\begin{tabular}{|c|c|c|}
\hline Participants & B6 (Ladder 1) & B6 (Ladder 2) \\
\hline Values & Self Esteem & Satisfaction \\
\hline Consequences & $\begin{array}{l}\text { Perceived Benefit } \\
\text { Perceived Convenience } \\
\text { VC Relationship }\end{array}$ & $\begin{array}{l}\text { Sense Of Obligation } \\
\text { Social Support } \\
\text { Social Norms } \\
\text { VC Relationship }\end{array}$ \\
\hline Attributes & Purchasing & Giving Business Input \\
\hline Participants & B7 (Ladder 1) & B7 (Ladder 2) \\
\hline Values & Loyalty & Loyalty \\
\hline Consequences & $\begin{array}{l}\text { Satisfaction } \\
\text { Perceived Benefit } \\
\text { Risk Awareness } \\
\text { Decision Quality } \\
\text { Trust } \\
\text { VC Relationship }\end{array}$ & $\begin{array}{l}\text { Perceived Benefit } \\
\text { VC Relationship }\end{array}$ \\
\hline Attributes & Reading Review & Purchasing \\
\hline Participants & B7 (Ladder 3) & B8 (Ladder 1) \\
\hline Values & Loyalty & Loyalty \\
\hline Consequences & $\begin{array}{l}\text { Risk Awareness } \\
\text { Trust } \\
\text { VC Relationship }\end{array}$ & $\begin{array}{l}\text { Perceived Benefit } \\
\text { Decision Quality } \\
\text { Product Variety }\end{array}$ \\
\hline Attributes & Purchasing & Purchasing \\
\hline Participants & B8 (Ladder 2) & B9 (Ladder 1) \\
\hline Values & Loyalty & Self Esteem \\
\hline Consequences & $\begin{array}{l}\text { Product Quality } \\
\text { Trust }\end{array}$ & $\begin{array}{l}\text { Risk Awareness } \\
\text { Product Information } \\
\text { Trust }\end{array}$ \\
\hline Attributes & Purchasing & Reading Review \\
\hline Participants & B9 (Ladder 2) & B10 (Ladder 1) \\
\hline Values & Loyalty & Loyalty \\
\hline Consequences & $\begin{array}{l}\text { Product Quality } \\
\text { Trust } \\
\text { VC Relationship }\end{array}$ & $\begin{array}{l}\text { Risk Awareness } \\
\text { Perceived Convenience } \\
\text { Trust } \\
\text { VC Relationship } \\
\end{array}$ \\
\hline Attributes & Purchasing & Purchasing \\
\hline Participants & B11 (Ladder 1) & B12 (Ladder 1) \\
\hline Values & Self Esteem & Loyalty \\
\hline
\end{tabular}




\begin{tabular}{|c|c|c|}
\hline Consequences & $\begin{array}{l}\text { VC Relationship } \\
\text { Sense Of Obligation } \\
\text { Social Support } \\
\text { Social Norms } \\
\text { New Media Attitude }\end{array}$ & $\begin{array}{l}\text { Perceived Benefit } \\
\text { Product Quality } \\
\text { Product Review }\end{array}$ \\
\hline Attributes & Purchasing & Purchasing \\
\hline Participants & B12 (Ladder 2) & B12 (Ladder 3) \\
\hline Values & Self Esteem & Satisfaction \\
\hline Consequences & $\begin{array}{l}\text { Perceived Benefit } \\
\text { Risk Awareness } \\
\text { WOM }\end{array}$ & $\begin{array}{l}\text { Sense Of Obligation } \\
\text { VC Relationship }\end{array}$ \\
\hline Attributes & Purchasing & Giving Business Input \\
\hline Participants & B13 (Ladder 1) & B13 (Ladder 2) \\
\hline Values & Satisfaction & Self Esteem \\
\hline Consequences & $\begin{array}{l}\text { Social Norms } \\
\text { Perceived Benefit } \\
\text { VC Relationship }\end{array}$ & $\begin{array}{l}\text { Social Norms } \\
\text { Social Support } \\
\text { Trust }\end{array}$ \\
\hline Attributes & Purchasing & Purchasing \\
\hline Participants & B13 (Ladder 3) & B14 (Ladder 1) \\
\hline Values & Satisfaction & Satisfaction \\
\hline Consequences & $\begin{array}{l}\text { Social Norms } \\
\text { VC Relationship }\end{array}$ & $\begin{array}{l}\text { Risk Awareness } \\
\text { Status Of Purchase Order } \\
\text { Perceived Convenience } \\
\text { VC Relationship }\end{array}$ \\
\hline Attributes & Purchasing & Purchasing \\
\hline Participants & B14 (Ladder 2) & B15 (Ladder 1) \\
\hline Values & Satisfaction & Loyalty \\
\hline Consequences & $\begin{array}{l}\text { Risk Awareness } \\
\text { Product Information } \\
\text { Trust }\end{array}$ & $\begin{array}{l}\text { Risk Awareness } \\
\text { Trust } \\
\text { WOM }\end{array}$ \\
\hline Attributes & Purchasing & Purchasing \\
\hline Participants & B15 (Ladder 2) & B16 (Ladder 1) \\
\hline Values & Satisfaction & Satisfaction \\
\hline Consequences & $\begin{array}{l}\text { Risk Awareness } \\
\text { Perceived Convenience } \\
\text { WOM }\end{array}$ & $\begin{array}{l}\text { Sense Of Obligation } \\
\text { Social Norms } \\
\text { Social Support } \\
\text { VC Relationship }\end{array}$ \\
\hline Attributes & Purchasing & Purchasing \\
\hline
\end{tabular}




\begin{tabular}{|c|c|c|}
\hline Participants & B16 (Ladder 2) & B17 (Ladder 1) \\
\hline Values & Satisfaction & Self Esteem \\
\hline Consequences & $\begin{array}{l}\text { Product Quality } \\
\text { Decision Quality } \\
\text { Product Information } \\
\text { Trust }\end{array}$ & $\begin{array}{l}\text { Perceived Benefit } \\
\text { Product Quality } \\
\text { Decision Quality } \\
\text { Trust } \\
\text { VC Relationship }\end{array}$ \\
\hline Attributes & Reading Review & Purchasing \\
\hline Participants & B17 (Ladder 2) & B18 (Ladder 1) \\
\hline Values & Loyalty & Self Esteem \\
\hline Consequences & $\begin{array}{l}\text { Perceived Benefit } \\
\text { Risk Awareness } \\
\text { Perceived Convenience } \\
\text { Trust } \\
\text { VC Relationship }\end{array}$ & $\begin{array}{l}\text { Product Quality } \\
\text { Trust } \\
\text { VC Relationship }\end{array}$ \\
\hline Attributes & Purchasing & Purchasing \\
\hline Participants & B18 (Ladder 2) & B18 (Ladder 3) \\
\hline Values & Loyalty & Sense Of Obligation \\
\hline Consequences & $\begin{array}{l}\text { Self-Image } \\
\text { Perceived Benefit } \\
\text { Product Quality } \\
\text { Product Variety }\end{array}$ & $\begin{array}{l}\text { Creating Value } \\
\text { Product Quality } \\
\text { Product Variety }\end{array}$ \\
\hline Attributes & Purchasing & Purchasing \\
\hline Participants & B19 (Ladder 1) & B19 (Ladder 2) \\
\hline Values & Loyalty & Satisfaction \\
\hline Consequences & $\begin{array}{l}\text { Risk Awareness } \\
\text { Trust } \\
\text { VC Relationship }\end{array}$ & $\begin{array}{l}\text { Sense Of Obligation } \\
\text { Social Norms } \\
\text { Social Support } \\
\text { VC Relationship }\end{array}$ \\
\hline Attributes & Purchasing & Giving Business Input \\
\hline Participants & B20 (Ladder 1) & B20 (Ladder 2) \\
\hline Values & Loyalty & Loyalty \\
\hline Consequences & $\begin{array}{l}\text { Perceived Benefit } \\
\text { Perceived Convenience } \\
\text { Trust } \\
\text { VC Relationship }\end{array}$ & $\begin{array}{l}\text { Perceived Benefit } \\
\text { Product Quality } \\
\text { Product Information } \\
\text { Trust } \\
\text { VC Relationship }\end{array}$ \\
\hline Attributes & Purchasing & Reading Review \\
\hline Participants & B21 (Ladder 1) & B21 (Ladder 2) \\
\hline
\end{tabular}




\begin{tabular}{|l|l|l|}
\hline Values & Satisfaction & Self Esteem \\
\hline Consequences & $\begin{array}{l}\text { Perceived Benefit } \\
\text { Trust } \\
\text { VC Relationship }\end{array}$ & $\begin{array}{l}\text { Social Norms } \\
\text { New Media Attitude }\end{array}$ \\
\hline Attributes & Purchasing & Purchasing \\
\hline Participants & B21 (Ladder 3) & B21 (Ladder 4) \\
\hline Values & Self Esteem & Satisfaction \\
\hline Consequences & $\begin{array}{l}\text { Social Norms } \\
\text { Sense Of Obligation } \\
\text { Social Support }\end{array}$ & $\begin{array}{l}\text { Perceived Benefit } \\
\text { Technical Knowledge }\end{array}$ \\
\hline Attributes & Giving Business Input & Giving Business Input \\
\hline
\end{tabular}

